\title{
INTRA-MIGRANT ECONOMY: \\ CHINESE RESTAURANT ENTREPRENEURSHIP AND ZIMBABWEAN MIGRANT WORKERS IN SOUTH AFRICA
}

by

Ying-Ying Tiffany Liu

A thesis submitted to the Faculty of Graduate and Postdoctoral Affairs

in partial fulfillment of the requirements for the degree of

Doctor of Philosophy

in

Anthropology

Carleton University

Ottawa, Ontario

(C) 2018

Ying-Ying Tiffany Liu 


\begin{abstract}
South Africa is "home" to the two largest populations of foreign nationals on the African continent. Its Chinese population numbers at least 300,000, and its Zimbabwean population, the largest outside of Zimbabwe, numbers at least one million. Many of these migrants end up working in Chinese restaurants as this is, by and large, a low-wage, lowskill, and low-barrier-to-entry sector. Based on original ethnographic research conducted in Johannesburg for fourteen months, this dissertation explores the cultural politics of diasporic entrepreneurs and migrant labourers, what I call the "intra-migrant economy," among everyday racialized insecurities in urban South Africa. I use the term "intramigrant economy" to refer to the employment of one or more group of migrants by another group of migrants as an economic strategy outside the mainstream labour market. With little capital, Chinese restaurant owners are able to maximize profit through cheap Zimbabwean labourers, while Zimbabweans can easily obtain jobs without proper procedure or formal training. Through exploring the structure of this sector, and the complex economic realities of and working relationships between Chinese and Zimbabwean migrants, I examine how the migrant and economic flows are negotiated and localized in South Africa's market, which also provides a concrete case study of intercultural (mis)communication.

Anthropologists have paid attention to how economic practices are intertwined and embedded in historical, political, and cultural systems. This dissertation suggests that not only are these factors intertwined but they also reinforce each other. The intramigrant economy is thus more than a story about migrants' economic hardships; it is also a reflection on two migrant groups who are linguistically and culturally different, the social structures that create their exploitation, and how they construct informal labour relations and cope with wider forms of uncertainty in one of the most notably racialized states in history.
\end{abstract}




\section{ACKNOWLDEGEMENT}

First and foremost, I would like to thank my research participants for telling me their stories and sharing their restaurant life with me. I am especially grateful for those who fed me with their homemade food, invited me to their homes, gave me a ride when my car broken down, introduced me to more research participants, and shared their hopes and fears with me.

I thank Dr. Blair Rutherford for many years of supervision and mentorship. I owe much of my scholarly accomplishment to his guidance and support. I am grateful for the inspiration and encouragement provided by my committee Dr. Bernhard Leistle and Dr. Michael Mopas. I greatly appreciate having had the opportunity to work with the Department of Sociology and Anthropology, the Institute of African Studies, and the Migration and Diaspora Studies at Carleton University. I thank the administrative staff for their kindly assistance, and many $\mathrm{PhD}$ colleagues for their interdisciplinary intellectually stimulating inspiration.

I could not have completed the fieldwork without the assistance and support from Dr. David Moore at the University of Johannesburg; Dr. Philip Harrison, Dr. Yan Yang, and Dr. Khangelani Moyo at the University of the Witwatersrand; Dr. Haifang Liu, Jun Liu, and Menghan Wu at Peking University. Mrs. and Mr. Lin from Taiwan helped me in many ways while I was living in Johannesburg. I thank Tichaona Marvel Makambwa for sharing days walking around and educating me about life in Zimbabwe. I am thankful for sharing my graduate studies journey with Kim Chi Tran and Wangui Kimari. Last but not least, I am forever grateful for my parents Mr. and Mrs. Liu and my partner Graeme for their love and support. 
TABLE OF CONTENTS

ABSTRACT 1

ACKNOWLDEGEMENT 2

TABLE OF CONTENTS 3

INTRODUCTION

Tales of a Post-Apartheid City 6

Setting Out the Fieldwork 13

Notes on the Role of Ethnographer and Translation 19

My Food Journey 20

Challenges of Translation $\quad 28$

Organization of Chapters 31

CHAPTER I: EVERYDAY RACIALIZED INSECURITIES

Inside the Restaurants 41

Petty Capitalists 45

Training, Transition, and Recruitment 51

Local vs. Migrant Employees $\quad 58$

Minimum Wage $\quad 63$

On Becoming Paranoid 66

(Dis)similarity Through Food and Insecurities $\quad 80$

Identity as Process $\quad 82$

To Go Aboard is To Return $\quad 86$

CHAPTER II: EXPLORING GUANXI WITH THE CHINESE

Why Guanxi? 93

Who are the "Chinese" in South Africa? 97

Migration Agency 100

The Complex Nature of Guanxi 105

Mianzi (Face/Honour) and Renqing (Human Emotion) 111

Guanxi or Corruption? 118

Concluding Remarks 126 


\section{CHAPTER III: CONCEPTUALIZING THE INTRA-MIGRANT ECONOMY WITH THE ZIMBABWEANS}

$\begin{array}{ll}\text { The Price of R10 } & 129\end{array}$

$\begin{array}{ll}\text { Ndebele in Johannesburg } & 133\end{array}$

$\begin{array}{ll}\text { Migrant Networks } & 137\end{array}$

Everyday Racialized Insecurities: Xenophobia 144

Sitofela: Rotating Savings and Credit Association 150

Intra-migrant Economy: Racialized Labour Market 155

$\begin{array}{ll}\text { Concluding Remarks } & 161\end{array}$

CHAPTER IV: CROSS-CULTURAL (MIS)UNDERSTANDING AND (MIS)COMMUNICATION IN THE CONTEXT OF THE INTRA-MIGRANT ECONOMY

$\begin{array}{ll}\text { Conflict, Collaboration, Emotion } & 163\end{array}$

$\begin{array}{ll}\text { Language Issues } & 166\end{array}$

$\begin{array}{ll}\text { Racial Discrimination or Ignorance? } & 169\end{array}$

"Not just about English" 175

Intercultural (Mis)communication: Zimbabwean Employees 184

Passive-Aggressive Resistance: Chinese Employees 190

$\begin{array}{ll}\text { Concluding Remarks } & 196\end{array}$

\section{CHAPTER V: UNEQUAL INTERDEPENDENCY}

$\begin{array}{ll}\text { Division of Labour } & 199\end{array}$

Questions of Loyalty and Trust 203

Employee Theft 207

Absence of Contract 209

$\begin{array}{ll}\text { The Discourse on Illegality } & 213\end{array}$

$\begin{array}{ll}\text { Begging or Reciprocity? } & 216\end{array}$

Money Borrowing and Lending 221

Questions of Freedom and Exploitation 225

Equal but not Equal; Free but not Free 229

\section{CONCLUSION}

$\begin{array}{ll}\text { Rethinking Diaspora } & 235\end{array}$

$\begin{array}{ll}\text { Ending Remarks } & 240\end{array}$

$\begin{array}{ll}\text { Future Research } & 246\end{array}$ 


\section{LIST of TABLES}

Table 1: Minimum Wages for Wholesale and Retail Sector in Area A (2014-15) 64

Table 2: Minimum Wages for Domestic Workers Who Work More Than 27

Ordinary Hours per Week (2015-16)

Table 3: Large-Scale Xenophobic Attacks in South Africa since May 2008

Table 4: Distribution of Income within Chinese Restaurants

Table 5: An Example of Sitofela

Table 6: Average Annual Income of the Household Head by Racial Group

\section{LIST of ILLUSTRATIONS}

Map 1: Two Routes from the University of Johannesburg to the New Chinatown 8

Figure 1: Photo of Downtown Johannesburg 11

Figure 2: Chinese Take-Away Menus in South Africa 47

Figure 3: Advertisements for Restaurants for Sale 52

Figure 4: Recruiting Through Friends 55

Figure 5: Job Advertisement 55

Figure 6: Job Search Advertisement 56

Figure 7: Looking for Trainees 56

Figure 8: Safety Tips for the Chinese Residents in Johannesburg $\quad 70$

Figure 9: Safety Tips When Travelling in Johannesburg 72

Figure 10: Job Advertisements with Preference 110

$\begin{array}{ll}\text { Figure 11: Fahfee } & 117\end{array}$

Figure 12: Rental Advertisements on Telkom Towner Wall in Hilllbrow 140

Figure 13: Chinese Helping Zimbabweans Job Search 141

Figure 14: Warning Posts 143

Figure 15: Discourse on "Undocumented African Migration" 214 


\section{INTRODUCTION}

\section{Tales of a Post-Apartheid City}

Alice ${ }^{1}$ was late when I went to pick her up in Hillbrow, downtown Johannesburg, for our first interview. I sat inside my car exploring the surroundings while waiting for Alice. It is not a neighbourhood that I- or anyone who is not in certain segments of the migrant working class - would usually go to in South Africa. An endless stream of cars and minibus taxis ${ }^{2}$ made non-stop honking noises in the background. High-rise buildings in ruins gave the appearance of abandonment, but the busy crowd and washed clothes hanging outside of the broken windows suggested residency. Countless street hawkers were selling inexpensive goods, and food items were scattered around crowded and cluttered sidewalks. Most pedestrians did not look like they were from South Africa, but I was probably the only non-black person there.

Hillbrow, once called the New York of Africa, was a glorious symbol of the apartheid regime's prosperity and success (Smith 2015). Through interviews with Chinese chefs, I learned that two top-of-the-line Chinese restaurants used to be in this formerly whites-only area during the heyday of apartheid. Apartheid is an Afrikaans term that means separateness. It was an institutionalized legal system of racial segregation where the whole population was racially divided in every sphere of life (Yap and Leong

\footnotetext{
${ }^{1}$ All names of people and restaurants are pseudonyms. Detailed locations of the restaurants and participants' hometowns are not provided to protect their privacy; instead, I use broad markers such as "an upper-middle-class neighbourhood in Johannesburg" or "a rural town in Guangdong," with the exception of certain areas in Johannesburg such as Hillbrow and Cyrildene.

${ }^{2}$ Minibus (share) taxi is the main form of transportation for working-class people in South Africa. Commuters stand on the street, stick out their hands, and signal where they want to go. Drivers stop when they are going in the same direction. Passengers can be picked up or let off anywhere along main routes.
} 
Man 1996). The system distributed economic wealth and reinforced social privilege along racial lines (van der Berg 2011). Black people then had to carry "passbooks"3 to work in white neighbourhoods, and they had to leave before nightfall to return to the townships ${ }^{4}$ or have permission to live in a cottage ${ }^{5}$ at the edge of their white employer's garden (Johnstone 1976). After the official collapse of apartheid in 1994, blacks who had been segregated in townships and homelands ${ }^{6}$ were free to move into inner-city areas.

Hillbrow has been considered a "migrant space" because of its high percentage of African migrant residents, including Zimbabweans (Moyo 2017). Gang members have "occupied" or "hijacked" buildings and then collected income by renting out space to foreign-born African residents who cannot afford a self-contained unit (Silverman and Zack 2008). ${ }^{7}$

Black people came, and white inhabitants left. Local businesses closed down or relocated to the affluent and predominately white suburbs such as Hyde Park and Sandton

\footnotetext{
${ }^{3}$ The pass law system was implemented by the apartheid government to control the movement of nonwhite South African residents. For instance, black Africans were prohibited from being in any public place between 9 p.m. and 4 a.m. without a written pass from their white employers (Johnstone 1976).

${ }^{4}$ From the late-nineteenth-century colonial era to the apartheid era, townships were created for non-white residents. Nowadays, townships usually mean underdeveloped urban living areas in South Africa.

${ }^{5}$ Unlike the meaning of the term in North America as a holiday home, "cottages" in South Africa means small houses in gardens; many were built during the apartheid era for the purpose of housing domestic workers.
}

${ }^{6}$ During apartheid, residents were segregated based on racial classifications, and policies were enforced by the apartheid legal system, for instance, the Bantu Authorities and Group Areas Acts (Gradin 2012). Bantustans, or homelands, were established to reserve land for black populations with two purposes: to prevent them from living in urban areas and to strip them of their civil and political rights (South African History Online 2011a).

${ }^{7}$ For instance, Alice and her sister shared a room together for 900 South African Rand (ZAR) a month. The space is no bigger than 200 square feet and is divided from their neighbours' space with curtains. In contrast, renting a cottage in Johannesburg's middle-class neighbourhoods usually costs around R 2,500 to 3,500. The exchange rate from the Canadian Dollar to South African Rand is usually around 1 CAD to 10 ZAR. The currency symbol of the rand is R. 
in the north, leaving behind a high-rise landscape notorious for its high rates of drugs, theft, violent crimes, prostitution, and poverty. Murder in South Africa has steadily increased as violent crime rates remain high in the country, and Hillbrow is one of the top neighbourhoods for reports of serious crimes (Gous 2017). There have been property and commercial investments to revitalize many parts of the downtown during the past ten years (Smith 2015). But most Chinese migrants do not know about these new developments and changes because they have been warned by other Chinese to not go near "black areas" such as Hillbrow.

\section{Map 1: Two routes from the University of Johannesburg to the New Chinatown}

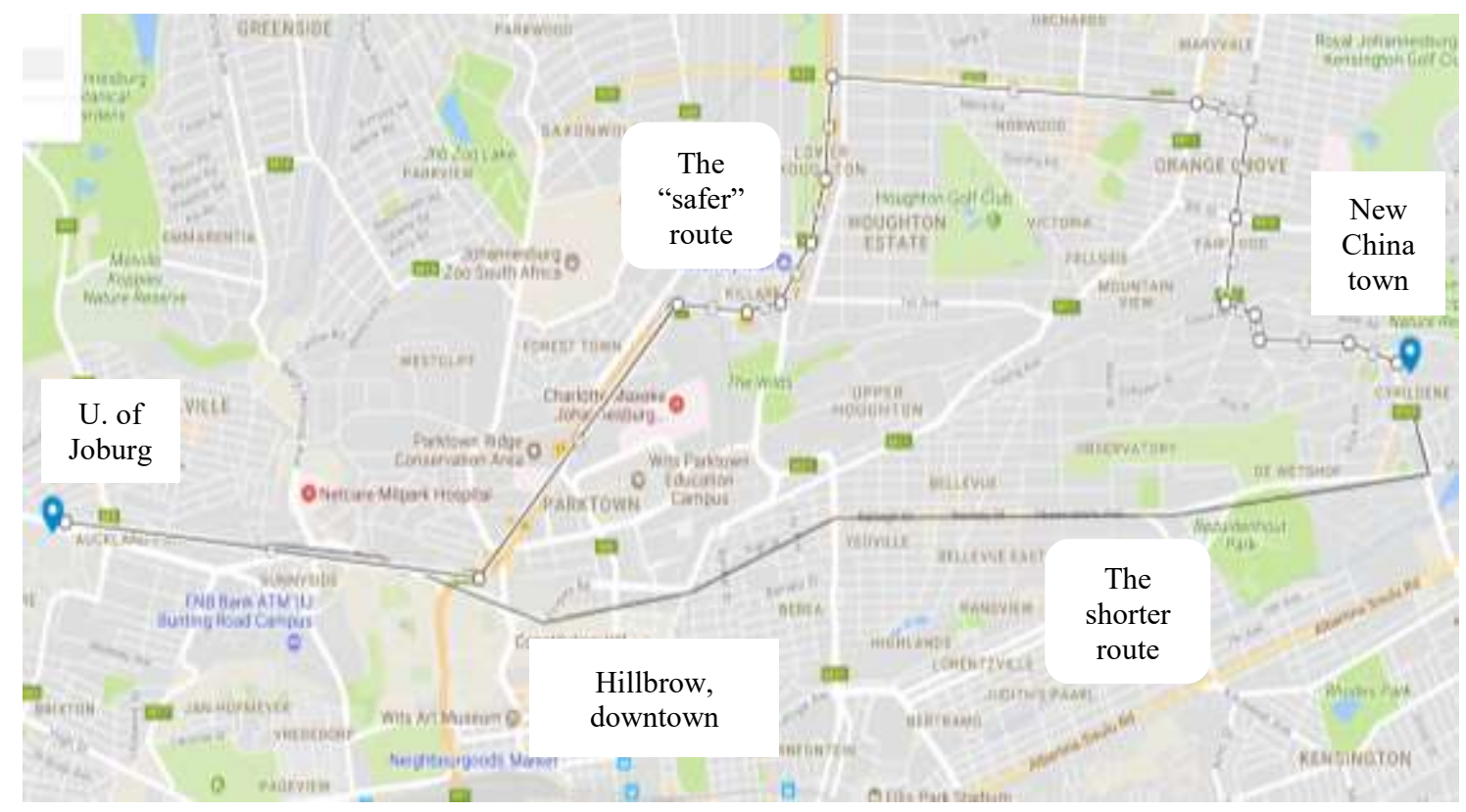

Source: Google Maps (2018)

"Which route are you taking?" This question was asked several times by different Chinese interlocutors when I told them that I was leaving New Chinatown to go home. I was renting a cottage near the University of Johannesburg, on the western side of downtown, about 25 minutes away by driving from New Chinatown, which is located in Cyrildene, a formerly Jewish suburb on the eastern side of town. 
"I go through town." I told them my usual route, as it was the shortest way.

"No, no, no way, not safe. Don't you know that criminals are targeting us [the Chinese], especially you are a woman and alone? Take M1 [freeway] even it takes longer." (See Map 1).

Warnings usually came with a story to validate their concerns. The typical storyline was that they or someone they knew had been "smashed and grabbed" in a bad area. Moreover, they taught me to not keep valuables that could be sighted through my car windows, and to always lock up as soon as I got into the car. One time I was getting a ride with a Chinese interlocutor. The first thing she said was not about the broken seat belt but about putting my purse under the passenger seat. My first visit to New Chinatown was with a black friend. We went to a Chinese grocery store. The cashier asked if I was new to South Africa and if the black man was my driver. I told her that he was a friend, and she warned me not to trust black people.

These random "friendly" warnings I received from Chinese acquaintances and strangers made me wonder if the Chinese in South Africa were being paranoid. Sure, Johannesburg is notorious for crime. Sure, the high walls and electric fences are everywhere. But was it really that bad? I was not sure until my money was stolen from where I was staying and I did not feel safe going back to the place. I asked around, looking for another accommodation. Once Chinese people heard what had happened, they started opening up to me about the details of their frightening experiences, their constant fear of crime, and how to get over it as life just goes on. I began to understand why they lived anxiously and always took extra precautions. But what is considered a "bad area" or

\footnotetext{
${ }^{8}$ People in Johannesburg, including Chinese migrants, usually refer to the downtown area as "town."
} 
"no-go zone"? I asked around. After all, street muggings, car hijackings, and break-in robberies happen everywhere in Johannesburg. Surprisingly, or not, it is not uncommon to hear Chinese people use the degree of presence of white people in an area to measure whether it is a safe neighbourhood.

"You know, when my cousin told me to come to South Africa, I didn't want to because I thought Africa was backward and black people are so poor," said a Chinese migrant from a rural village in Guangdong, who thought that coming to Africa was a socially downgrading move but still came because her cousin promised her a high-paying server job. She realized her image of South Africa was wrong when she arrived in Johannesburg five years ago. She said, "I was so surprised to see South Africa is quite advanced. Look at so many white people and high-rise buildings!" Because her idea of development was related to lighter-skinned people and tall architecture, she had a hard time believing me when I told her that Johannesburg probably had more high-rise buildings than Ottawa (see Figure 1). In her mind, Canada must be more "modernized" than South Africa. I heard similar comments as several Chinese people said to me jokingly, "What are you doing in South Africa when you could stay in Canada?"

But the Chinese were not the only ones who had such geopolitical ideas. On the one hand, to some South Africans, Hillbrow is a shameful reminder of "a First World country turned into Third World," as a white South African described to me when expressing his anger and disappointment with the post-apartheid government. On the other hand, Hillbrow represents a "land of hope" for someone like Alice, a migrant worker from a rural town in Matabeleland North province, Zimbabwe, a country with a 
high rate of unemployment. ${ }^{9}$ What is interesting is that most Chinese migrants, however, do not share the same vision as African migrants and instead view Hillbrow as a remnant of the "good old days of South Africa"- even though most of them were not in the continent during the apartheid era (1948-1994), and they are not even sure what apartheid was about.

\section{Figure 1: Downtown Johannesburg, taken from Hillbrow (Fieldwork photo)}

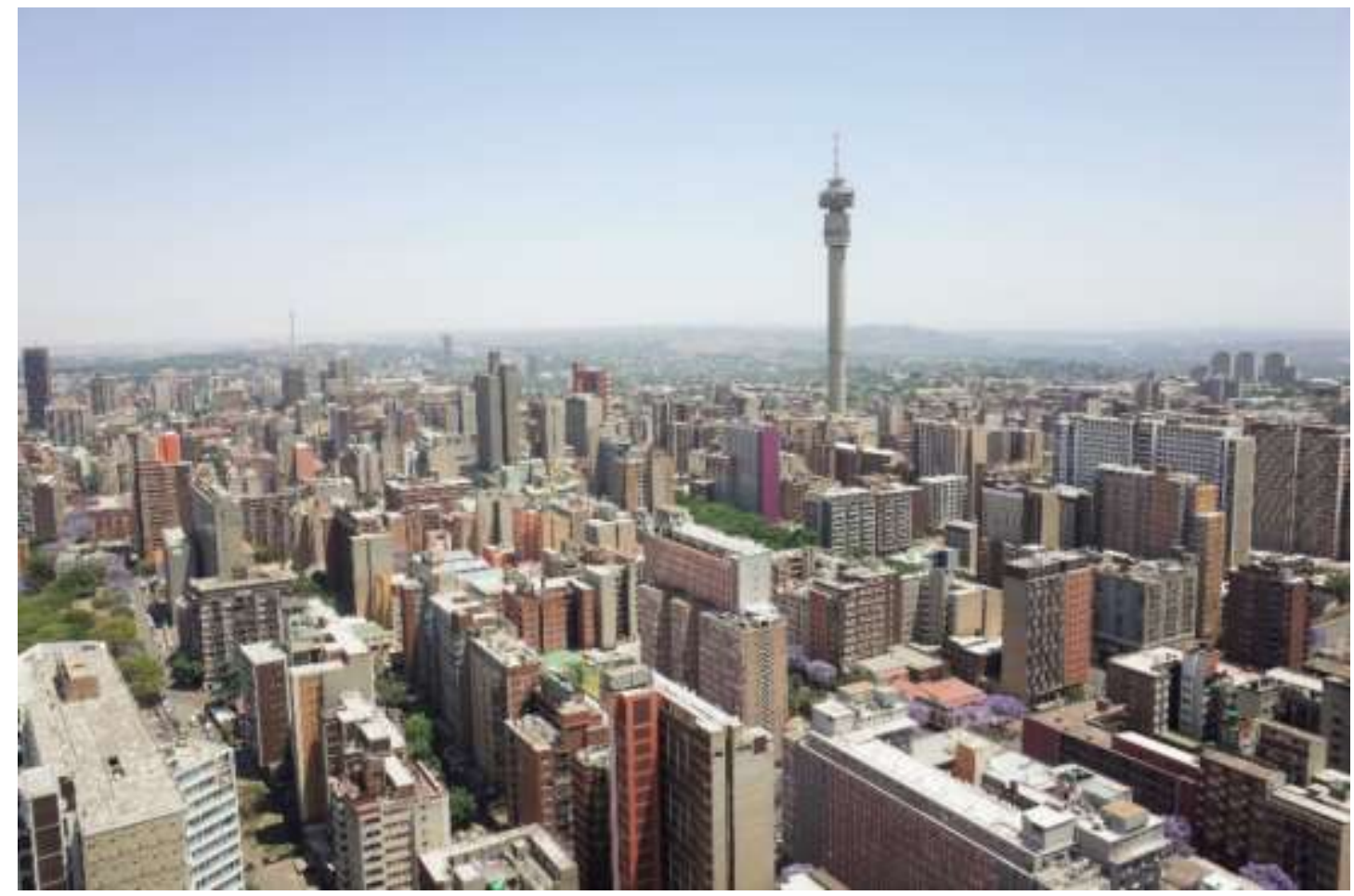

Johannesburg, often called Jo'burg or Jozi by the locals, is not an easy city to figure out. A Chinese immigrant once told me, "I'm having a love and hate relationship with Jo’burg (我对约堡是又爱又恨).” Beyond its notably high crime rate is great weather, a green environment, hospitable people, diverse cultures, beautiful houses, and

\footnotetext{
${ }^{9}$ Estimates of Zimbabwe's unemployment rate range wildly. According to ZIMSTAT, Zimbabwe's national statistics agency, the country's national unemployment rate was $11.3 \%$ in 2014 . Others argue that it is as high as $95 \%$ (BBC Reality Check team 2017).
} 
wide-ranging fine dining. Johannesburg can be a paradise for individuals from certain racial and class backgrounds, but only a limited number of residents can afford such a comfortable lifestyle. As if the wide gap between rich and poor is not humiliating enough, a poor community full of shacks without running water is usually just a few streets away from luxurious houses with swimming pools. Why is the Alexandra Township located less than a kilometre away, across the M1 highway, from Sandton, the most affluent financial centre in South Africa?

Johannesburg, as Achille Mbembe and Sarah Nuttall describe, "is a city where historical structures of racial inequity are simultaneously being sedimented and unbundled" $(2004,366)$. We have to dig into the past in order to understand why this city (and perhaps all of South Africa) was constructed this way. During apartheid, black people were physically pushed to the margins of white areas. The purpose was to keep blacks out of sight of the white communities but still have them live close enough to supply cheap labour (McCool 2016). More than two decades after the end of apartheid, the working poor (inevitably made up of blacks) still continue to live at the edge of wealth and still continue to offer their cheap labour.

Apartheid, after all, is still influencing and challenging South Africa's social, economic, and political reconstitution (Dodson 2013). Migration, including that of the Chinese, is also a product of the colonial past. Chinese settlement in other parts of Africa might still be a recent phenomenon, but in South Africa, Chinese migration has a much longer history. The discovery of the Witwatersrand gold reef in 1884 led to the rapid establishment of Johannesburg (South African History Online 2011b), and more than 
63,000 Chinese labourers were imported by the colonial state to work in gold mines from 1904 to 1910 (Yap and Leong Man 1996).

South Africa's migrant labour system was entrenched by the mining industry and extended by apartheid (Wilson 2011). By 1972, it was estimated that one out of every two black workers in the urban areas was a migrant (Wilson 2011). The lives of Chinese labourers who stayed in South Africa and many more Chinese who later entered the country have inevitably been affected by apartheid, and the process of racialization is continuously affecting their daily lives in the so-called post-apartheid city of Johannesburg. Geographer Belinda Dodson argues, "Perhaps it is time to put the term post-apartheid to rest, as it anchors understanding of South African society and geography both to the historical past and to the geographically national. Apartheid's 'malevolent geographies' are still very much in evidence” $(2013,7)$. While exploring two groups of migrants' lived experiences in Johannesburg, their stories confirmed that although apartheid ended officially in 1994, its effects still haunt not only South Africans but also migrants. Perhaps it is time to recognize the dangers of neglecting South Africa's racial inequality as a structural problem. Perhaps it is time, as Dodson suggests, to recognize that there is no "post" in post-apartheid.

\section{Setting Out the Fieldwork}

This dissertation is about Chinese and Zimbabwean im/migrants who have worked in Johannesburg's Chinese restaurants, a typical labour-intensive sector. I use the 
term "im/migrants" because of first-generation ${ }^{10}$ Chinese and Zimbabwean migrants' complicated legal statuses and emotional conditions and to reflect the fact that the concept of "home" is not easily defined. While this ethnography explores how these two groups of im/migrants work together in this sector and live in this city, it examines the intertwining of diasporic entrepreneurship, labour migration, economic dependency, and livelihood strategy.

Since the 1990s, the process of globalization and the inequality in the concentration of strategic resources and activities has sharpened; as a result, an informal and transnational economy has emerged rapidly in Johannesburg (Mbembe and Nuttall 2004, 365). Chinese restaurants, as a transnational and somewhat "informal" business, have been growing in major cities and suburbs in South Africa since 2000. When I initially explored the field site, I had not expected to see, like in North America, the Chinese take-away restaurants serving Westernized Chinese food such as chop suey and fortune cookies. Once I looked deeply into Chinese migration history in South Africa, I realized there were parallels between Canada and South Africa in terms of how these two host states have treated their Chinese populations: compare the Chinese Immigration Act of 1923 in Canada ${ }^{11}$ to the Chinese Exclusion Act passed by the Cape Parliament in 1904, the Chinese head tax in Canada to the racial classification and legislation of South Africa, and the way that the Chinese in both countries were predominantly limited to working in laundries and restaurants.

\footnotetext{
10 Throughout this dissertation, I use the term "first generation" to refer to a person who has migrated to a new country. The terms "second generation" and "third generation" refer, respectively, to the children and the grandchildren of im/migrants.

${ }^{11}$ In 1923, Canada passed the Chinese Immigration Act, which was unofficially known as the Exclusion Act. Along with the Chinese head tax that was implemented in 1885, it made Chinese immigration into Canada virtually impossible (Cho 2010).
} 
But it gets more complicated in South Africa. As soon as I began conducting fieldwork inside Johannesburg's Chinese restaurants, I realized that the Chinese were not the only group of migrants involved in this business. Historically, overseas Chinese in North America and Europe who participated in restaurants did not always do so voluntarily, but rather ended up in this alternative labour market through migrant networks. ${ }^{12}$ In South Africa, the same story is repeating. Only this time, it also includes African migrant labourers like Alice who do all the menial work.

This original ethnographic research was conducted in Johannesburg for fourteen months, from November 2014 to November 2015 and the following year from July to September. A mixed-methods research approach was deployed:

1) Participant observation: I worked part-time voluntarily ${ }^{13}$ at five Chinese restaurants in different neighbourhoods all over Johannesburg. This level of engagement allowed me to gain first-hand insight into their restaurant life. I call it "restaurant life" because of the long working hours (at least nine hours a day, six days a week, and even longer for restaurant owners) and because many Chinese employees also live with their employers. For instance, I met some Chinese women who worked as servers and spent most of their time with their employers and co-workers. They only saw their husbands, who work as fahfee (gambling) men, once a week.

\footnotetext{
${ }^{12}$ For example, see Maggi W.H. Leung's research on the Chinese restaurants in Germany (2002); Ching Lin Pang's article about the Chinese restaurants in Antwerp (2002); Yuson Jung's research in Bulgaria (2012); Lily Cho's work in Western Canada (2010); and Maria Godoy's piece about the Chinese restaurants in the United States (2016).

${ }^{13}$ Three restaurant owners cooked good meals to show their appreciation of my voluntary work, and two other owners paid me afterwards.
} 
2) Unstructured and semi-structured interviews: I interviewed 40 Chinese employers and employees (twenty-two men and eighteen women) in person during 2015. I also interviewed twenty-six Zimbabwean employees (twentyone women and five men) in person, some in 2015 during my first round of fieldwork but most in 2016 during my second round of fieldwork, and asked follow-up questions over WhatsApp after I returned to Canada.

3) Archival research: I have collected restaurant menus, photographs, advertising posts, online and hardcopy Chinese- and English-language news articles, and news from social media (e.g., WeChat) to gain access to the discursive context of relevant social practices and relations.

Selling Chinese food has enabled numerous overseas Chinese to settle down and establish businesses and trading networks in many parts of the world ( $\mathrm{Wu}$ and Cheung 2002). South Africa is no exception. But what is unique in this host country is that, as I stated earlier, Chinese restaurant entrepreneurship is somewhat informal, meaning there is no contract between employers and employees, many Chinese and Zimbabwean migrant workers hold invalid work permits, and in some cases proper business licences are also absent.

Generally speaking, there are three striking features shared by Chinese restaurants in Johannesburg. First, it is common to find one Chinese chef managing three to five black kitchen helpers, the majority of whom are not from South Africa. Second, Chinese employees' wages are at least three times higher than those of black employees, and the number of black employees usually exceeds the number of Chinese ones. Third, this form of restaurant entrepreneurship operates without legal contracts to bond employers and 
employees. Another interesting point about the people I met who are involved in this entrepreneurship is that before coming to South Africa, most of the Chinese restaurant owners had no experience operating a business, and none of the Zimbabwean employees had ever worked for Chinese people. In addition, for more than half of the Zimbabwean interviewees, working in the Chinese restaurants was their first employment. These features made Chinese restaurants in Johannesburg a very natural space in which to understand the relationship between Chinese and Zimbabweans - two groups of migrants who are linguistically and culturally different but bound to work together in order to make ends meet. How do they interact with each other? How do they construct and negotiate new working relationships in a new country?

By examining their restaurant life as a significant part of their migration experiences, this dissertation also explores Johannesburg's paradoxes: rich and poor, progressive and decaying, clean and filthy, safe and perilous, gregarious and xenophobic, law-abiding and corrupt. The contradictions in these images of Johannesburg are not only evident in the reality of South Africa itself but in the experiences of migrants as well. Chinese and Zimbabwean migrants work in the same industry and live in the same city; however, they are in very different socioeconomic positions, profoundly influenced by their nationality and racialization, which, in turn, has influenced the formation of their migrant experiences.

Of course, not every Chinese or Zimbabwean person in Johannesburg is involved in restaurant entrepreneurship, and Chinese and Zimbabwean im/migrants are by no means homogenous groups, made up as they are of regional, linguistic, class, and generational variations. But there are some trends. Scholars (e.g., Harrison et al. 2012; 
Park 2009; Yap and Leong Man 1996) agree that the Chinese im/migration timeline can be roughly categorized into three periods: 1) Cantonese- and Hakka-speaking Chinese people migrated to South Africa before the 1970s, 2) Taiwanese migrants (and some from Hong Kong) migrated between the early 1970s and the mid-1990s, and 3) Chinese newcomers of mixed regional origins migrated from the 1990s onwards.

As a result of economic crisis and social collapse, the flow of out-migration from Zimbabwe increased massively during the 1990s and has risen again sharply since 2000 (Crush and Tevera 2010). Zimbabweans, from all kinds of social and educational backgrounds, skilled professionals and unskilled workers, have left. For instance, more than half of trained medical doctors went abroad in 2000 (Chikanda and Dodson 2013). It is estimated that over two million Zimbabweans have left for various destinations (Makina 2010). As the largest city in South Africa, as well as the one with the most employment opportunities, Johannesburg has become a major destination for Zimbabwean migrants (Moyo 2017). In Johannesburg, semi-skilled and unskilled Zimbabwean migrants often end up working in the food industry, as this is, by and large, a low-wage, low-skill, and low-barrier-to-entry sector.

In this research, the focus was on recently arrived Chinese and Zimbabwean semiskilled and unskilled im/migrants, although the link between new and old diasporas is sometimes apparent. Demographically speaking, most of the Chinese participants were Cantonese-speaking migrants from rural areas in Guangdong and Guangxi provinces who came to South Africa after 1995. The majority of Zimbabwean participants were Ndebele-speaking migrants from the southwestern part of Zimbabwe who moved to South Africa after 2005. 
Migration - whether within or across borders, whether voluntary or forced - is not new to Johannesburg. The contemporary mining industry and vibrant business opportunities have long attracted internal and international migrants. Most Chinese and Zimbabwean participants I interviewed had been living in Johannesburg for years. They all came to Johannesburg to work. Some first came by themselves and then brought their family over once established. Some of them met partners and got married here. Some of their children were born and go to school here. But Johannesburg never becomes home. To them, home is in China or Zimbabwe. Johannesburg is where opportunities arewhere "things are happening," as a Zimbabwean interlocutor said.

\section{Notes on the Role of Ethnographer and Translation}

Anthropology has engaged with the subject of food from its very beginnings (Mintz 2008). As Sidney Mintz, the "father of food anthropology," argues, how we eat is related to our cultural practice and what we eat is related to political economy. Mintz's (1985) ethnographic research on the commercialization of sugar plantations in the Caribbean is a classic piece of work that demonstrates how the colonies and slavery changed European and American food consumption patterns and social productivity. He argued that we can use food as a medium to talk about people and culture. Jason Antrosio describes it best: “[Mintz] perhaps felt food was a way to eventually sell a more radical agenda. If people became interested in food, then they would inevitably learn about global interconnection; about history; and about power" (Antrosio 2016). 


\section{My Food Journey}

My study of restaurant entrepreneurship grew out of my obsession with food, which is certainly tied to my identity. Growing up in Taiwan and then in Toronto, I have had the privilege of exploring an incredible variety of cuisines. Taiwan's diverse culinary culture is a reflection of the island's complicated past. Taiwan's history of settlement began with Austronesian peoples, then Holo- and Hakka-speaking settlers from China, followed by Dutch and Japanese colonization and later the arrival of between one and two million Chinese fleeing there after the Kuomintang (Chinese Nationalist Party) was defeated by the Chinese Communist Party in 1949. Aboriginal peoples already had a well-rooted culinary tradition, rustic and hearty, based on hunting, fishing, gathering, and basic agriculture (Taiwan Today 2011). The arrival of the Japanese in 1895 brought new ingredients such as seaweed, raw fish, and miso, all of which happily blended with the cooking styles of the Holo and Hakka from southern China, who had settled in Taiwan since the 17th century (Taiwan Today 2011). The food culture in Taiwan was further enhanced by the one to two million mainland Chinese who brought their regional styles to Taiwanese tables. My mother usually bought Shanghai shengjian bao (pan-fried bun) or Shandong mantou (steamed bun) for breakfast and Japanese chhialunpia (pancake) for an afternoon snack. We often had Hunan-style dinner at the house of my parents' friend, Uncle Yang. On many weekends, my extended family gathered together at a Sichuan restaurant.

When we moved to Toronto in the 1990s, I was excited to try new food from every immigrant community, taking advantage of one of the most culturally varied cities in the world. The Chinese food in Canada, or what Canadians thought of as Chinese food 
for a long time, was predominantly influenced by one regional cuisine in ChinaCantonese. Up until 2000, the majority of Chinese immigrants to Canada were Cantonese-speaking from Guangdong and Hong Kong, which explains why the earlier Chinese cuisine was strongly influenced by the Cantonese style. It simply reflected the origins of the vast majority of Chinese immigrants to the country.

My Hong Kongese high school friends and I often hung out at a Chinese café near school. The first time I went there, I looked at the English menu written on a blackboard behind the counter and ordered chicken fried rice in Cantonese as I tried to practice this new Chinese dialect I had just learned from these friends. The restaurant owner told me it was "not for Chinese." "What? Fried rice is not Chinese food?" I was confused. "No, that fried rice is not for Chinese," the owner explained and handed a Chinese menu to me. This restaurant served Chinese food for Chinese customers, and Western food (e.g., grilled cheese sandwiches and hamburgers) and simple Chinese takeout food for nonChinese customers. It was the first time I learned there is a type of Chinese cuisine called "Canadian Chinese food," which has been adapted to Western tastes.

After we graduated from high school, this Chinese café closed down, but more and more diverse Chinese restaurants opened up all over Toronto. After decades of sizeable migration from China came to Canada, there is a sufficiently sized Chinese population to create a demand for what new immigrants view as more genuine "home" cuisines. There are plenty of Chinese restaurants in Toronto's suburbs where, if you do not have knowledge of the particular regional cuisine on offer, you will not know how to order. 
When I was conducting fieldwork in Johannesburg, most restaurant owners were initially suspicious about my intention, not because of my Taiwanese Mandarin accent or because I am from Canada. They did not understand why I was interested in something they do every day just to make ends meet. From their point of view, there is no academic value in this sweaty and insignificant sector. One owner said to me, "If I had a chance to go to university, I wouldn't have to come all the way to South Africa to run this stressful business." Another owner told me that she and her husband were trapped in the restaurant sector so their children would not have to be.

Low self-esteem is not a unique characteristic among the Chinese restaurant owners in South Africa. When interviewing Chinese restaurant owners in Belgium, Ching Lin Pang (2002) noted that they suffered from an inferiority complex, even if their business was successful and they earned more than enough to support their children and themselves financially. They constantly complained about the hardship they had to endure (e.g., lack of freedom and social respect) and wished they had a different job.

“Why is research on restaurants worth it (餐厅有甚麼好研究的)?” Restaurant owners often asked me this question when I first visited them and explained my research. Without giving a hypothetical answer that might throw them off, I was able, thanks to my relatively rich food journey, to talk about my favourite food from their region and the difference between regional variations. I told them I was looking for the meaning of Chinese food, knowing this would intrigue them. Although the people who work in restaurants might lack confidence about their occupation, Chinese food is the core of Chinese people's pride, and most see their home cuisine as the best (Chen 2017). Chinese food, after all, is incredibly diverse. As David Wu and Sidney Cheung suggest, 
“Historically speaking, there was never one 'national cuisine' but many regional Chinese cuisines, due to geographical differentiation and social stratification" $(2004,4)$. In other words, the category "Chinese food" is really just an oversimplification.

Sometimes my food stories were not enough to make a good first impression on Chinese people because they had had an awful working experience with Taiwanese people. “You Taiwanese people (你们台湾人)...” was the typical opening phrase, usually followed by an unhappy story of how their former Taiwanese employers had exploited them. Instead of taking it as a personal insult, I just sat there and listened. Eventually, most of the Chinese restaurant owners agreed to do an interview or agreed to let me conduct fieldwork inside their restaurants. Some even reached out to their contacts to recruit more participants for my research. This strategy to facilitate recruitment was extremely helpful, particularly with people from a relation-based society such as China. In Chinese, interpersonal connection is referred to as guanxi, a concept that will be introduced and discussed in Chapter II.

While there were some minor disadvantages to my Taiwanese identity, there were many more advantages. I met several Chinese migrants who had had good experiences working for or with Taiwanese people. For instance, as soon as one restaurant owner heard my Mandarin accent, he smiled and began to tell me how his former Taiwanese employer helped him to settle down in South Africa, which made the interview go smoothly. Another restaurant owner, whom I only met once, insisted on giving me a full container of spiced shrimps after our interview. It was the most expensive item on the menu. I insisted on paying. The owner said it made him feel good to help someone from Taiwan. He had lost contact with his former boss, who had retired and returned to Taiwan 
years ago. I accepted the food and told myself to visit later and pay for it then; unfortunately, I haven't had the chance. When I drove back to my rental cottage and opened the takeout container, it smelled like the food from my childhood. Once I bit into a shrimp, it felt as if my family were eating at Uncle Yang's house again, except that Uncle Yang had passed away many years ago. That was the best food I had eaten in South Africa.

On a few occasions, a small number of Chinese people brought up the political debates over China and Taiwan. It could be uncomfortable at times, but I learned to embrace my identity as a whole because for the most part, my food journey had not only enabled me to generate conversation with Chinese migrants from various backgrounds but had also helped to bring us closer even though I shared none of their life experiences in China and little of their migration experiences in South Africa. Most of them came to South Africa to make higher wages. My parents emigrated so their children could receive an education in Canada. Our families' goals might have been the same - seeking better opportunities - but our migration journeys were not.

The majority of the Chinese working in restaurants were from rural areas of China and had a limited chance to continue to higher education, as their families simply could not afford it. In order to contribute to the family expenses, some of them worked on family farms at a young age, or they left their villages and worked in a minimum wage job in a city. When the opportunity came, they hired migration agencies to get into South Africa (see Chapter II for details). Some Chinese migrants I met sent remittances back to China while still paying off loans to the migration agency. 
The life and migration journey that Zimbabwean employees experienced was even further away from my own. I do not think I could survive on R 2000 a month and still support dependents. ${ }^{14}$ I do not think I can ever truly understand what it feels like to live in constant struggle against both exploitation and discrimination every day (see Chapter III). After all, I was born in a middle-class Taiwanese family that did not immigrate to Canada out of desperation.

When I started conducting fieldwork inside the restaurants and approached Zimbabwean employees, they usually kept a distance from me. Their reaction, of course, was just a normal response to the tense working relationships between Chinese and Zimbabweans and the boundary between "us" and "them"- no matter how ambiguous it can be sometimes. In addition, some restaurant owners told me that they did not want me to interview their employees, either Chinese or Zimbabwean. It was not necessarily because they were afraid that I would find out their "dirty secrets." They worried I would disturb productivity, as most of them already complained that their employees were not efficient enough (see Chapter IV).

Due to research ethics, I did not actively recruit Zimbabwean participants while doing research inside the restaurant they worked in. Out of the twenty-six Zimbabwean interviewees, only six worked at the same restaurants as I did. The first restaurant was Silver City, where Alice and her sisters were employed (see Chapter I for their stories). When I first started working at Silver City, Alice and her sisters thought, "Here comes another Chinese woman who is going to boss us around," as they told me afterwards. We had some chats here and there at work because I was the only employee who could

\footnotetext{
${ }^{14}$ The average income of Zimbabwean and Chinese im/migrants is discussed in Chapter I and in Chapter IV.
} 
communicate with them in English. We kept in contact after I left Sliver City, and eventually I recruited them for interviews. The other three Zimbabwean interviewees were from the Golden Sun Chinese restaurant, where the environment was quite calm (see Chapter V). The working relationship between Chinese and Zimbabwean employees was not as tense, but they did not hang out either. It was easier to talk spontaneously to anyone, and I did not feel that I had to pick the Chinese or Zimbabwean side. As soon as a young Zimbabwean woman heard that I was in school, she was excited to talk to me about her plan to go to university in South Africa. Eventually I interviewed her and two other Zimbabwean employees. In a way, my English ability and my Canadian education brought me closer to my Zimbabwean interlocutors, because they were able to identify me as "not just another Chinese woman."

While conducting research in Johannesburg, I was also a visiting research associate in the Department of Anthropology and Development Studies at the University of Johannesburg, where I had opportunities to meet and discuss issues with many great colleagues who also share research interests in migration in South Africa. Almost every week, I attended a weekly seminar organized by the Sociology Department at the University of Johannesburg, and I also joined a number of conferences and seminars at the University of the Witwatersrand. Topics like migration, xenophobia, the informal sector, and social inequality were often presented and discussed during these events, which helped me to gain a better understanding of South African perspectives and challenges.

When I returned to South Africa in 2016 for three months, I revisited some Chinese participants, but I primarily spent my time on recruiting and interviewing 
Zimbabwean employees. I hired Tichaona Marvel Makambwa, who is fluent in isiNdebele, chiShona, and English, to assist me in recruiting Zimbabwean restaurant workers. Tichaona and I walked around Cyrildene's Chinatown for days. While I stood outside waiting for him, Tichaona went inside restaurants and had a quick chat to see if any employees were from Zimbabwe. If so, he explained my research to prospective participants. If they agreed to participate, he gave them my business card and WhatsApp number, and I would wait for them to contact me. We tried recruiting at two Chinese malls' food courts but without success. African workers were either reluctant to talk to Tichaona, or the restaurant owner was around and found us suspicious. But Tichaona managed to find out that there were more Shona than Ndebele working in Chinese malls.

Since I had previous experience from my fieldwork in 2015, I had a general idea of what restaurant life was like, which made it easy for me to set up the most convenient schedule and location for Zimbabwean participants to do interviews. Tichaona joined a few interviews and helped to translate them afterwards. Most of the Zimbabwean workers in Chinese restaurants were women due to the gendered division of labour. I interviewed (or re-interviewed) more than half of the Zimbabwean women participants alone in order to pay closer attention to gender dynamics. I conducted all of the interviews with Chinese participants in Mandarin or Cantonese and translated them myself. The transcribed interview data with both Chinese and Zimbabwean participants have been edited for the purpose of confidentiality. 


\section{Challenges of Translation}

Translation is not easy, especially between two languages that have very distinctive grammatical and sentence structures. To translate Chinese idioms and expressions that are not always familiar to me is even more challenging. Among the newly arrived Chinese migrants in South Africa, about one-third (around 100,000) are from Fujian province, and migrants from Guangdong are the second-most numerous (Chen 2013). Traditionally, Fujian and Guangdong, both coastal provinces, have been the main sources of emigration from China to other parts of the world. South Africa is no exception.

The Cantonese-speaking Chinese migrants I met were from either Guangdong or Guangxi. There are at least five different Cantonese dialect groups living in Johannesburg. They learned their own dialects at home; they learned baakwaa (白话) or "Standard Cantonese" mainly by watching television, and they learned Mandarin in school. Mandarin is the official language in China and Taiwan. When communicating with other Cantonese from different dialect backgrounds, they use Standard Cantonese, which is the one that I can understand. Standard Cantonese is commonly used in Guangzhou (the capital city of Guangdong province), Hong Kong, Macau, and many Cantonese-speaking Chinese communities in Canada.

There is no standard Fujianese. People from Fujian who speak different Fujianese dialects use Mandarin when communicating with each other as well as with other Chinese. My native language, Taiwanese Hokkien or Minnan hua (闽南语, Southern Min), is a type of southern Fujianese dialect and is not mutually intelligible with the dialects of Fujianese-speaking migrants in South Africa because the majority of them are 
from eastern Fujian. Consequently, we use Mandarin when communicating with each other.

Despite the variety of Chinese dialects, many of which are not mutually intelligible, there are only two written forms: simplified and traditional. Although I learned the traditional Chinese characters, as that was the system used in the schools of Taiwan and Hong Kong, the Chinese characters that appear in this dissertation are the simplified version, because this dissertation is about migrants from China who used the simplified characters.

By and large, people who have learned Mandarin in Taiwan and China can understand and communicate with each other. But there are some differences in words and usages between Chinese and Taiwanese Mandarin. When I encountered an unfamiliar term, I either searched the internet or checked with a Taiwanese friend who had studied and lived in China for years and is familiar with both forms of Mandarin. I have not received any professional translation training, so I have left the original Chinese data where I was not fully sure of my interpretation. Moreover, since there is a major difference between Chinese and English grammar - for example, there is no plural in Chinese, and no past, present, or future tenses - I have left terms like guanxi the way they are even when they are sometimes plural. Instead of attempting to be grammatically perfect, I have minimized the editing of interview data to better reflect interviewees' original language and emotion.

Another difficulty is in translating slang related to race or ethnicity such as the word "black" (黑 hei). Chinese people like to add "black" in front of terms that are associated with black people_for instance, black worker (黑工 heigong), black woman 
(黑婆 heipo), black area (黑人区 heirenqu), and black bus (黑巴 heiba) ${ }^{15}$ During the early stage of my fieldwork, I found these terms offensive because these descriptions were generally associated with negative connotations in the South African context, such as unsafe areas or dirty and crowded buses. Later, when I began to interview Chinese participants individually, I realized they did not know any other term to describe black African workers, and they were not aware of the negative implications of their words. When I used more neutral terms (e.g., "Zimbabwean migrant workers" or "kitchen helpers") in my questions, many Chinese interviewees had no idea who I was referring to. Even when they were describing Zimbabwean people positively, they still used "black woman" or "black worker." When I asked the Chinese interviewees where these terms came from, they simply replied, “I don't know. I just follow what other Chinese people call them.”

After having been called "Oriental" by South Africans of European descent (who meant it in a positive way) several times, I began to reflect on my experiences in North America, where the word "black" is often substituted with "African American" and, similarly, the term "Asian" is used instead of "Oriental." These replacements are considered to be less offensive and more politically correct. People in other parts of the world might not necessarily understand the discriminatory meanings behind what we in North America perceive as inappropriate racial terms. As such, when my Chinese interviewees used the word "black," I translated it literally without giving it negative connotations.

${ }^{15}$ A term for a minibus taxi, which is the most popular and affordable form of transportation for workingclass people in South Africa. 


\section{Organization of Chapters}

How did Zimbabwean im/migrants get involved in a sector dominated by Chinese migrants? How do the Chinese and Zimbabweans feel about working with each other? Moreover, what influenced their choice of coming to South Africa? What kind of strategies and social networks support restaurant operations? In each chapter, I explore one by one, step by step, the following aspects of Chinese and Zimbabwean im/migrants' lives: their support networks, job opportunities, real-life challenges in South Africa, and way of building informal working relationship with each other (rather than formal contracts).

In the beginning of Chapter I, we return to Alice's story to see how she ended up working in a Chinese restaurant and what is it like working there, in order to see the structure of restaurant life. Then, we follow some Chinese restaurant owners' stories to understand how they started their businesses. Their steps to becoming entrepreneurs suggest there is a high level of flexibility and mobility between Chinese employers and Chinese employees in Johannesburg, especially in contrast to the Zimbabwean employees. Only a small number of them were promoted to chef or manager, and none of them had become a restaurant owner.

This chapter aims to answer a question: Why do small- and medium-sized Chinese restaurants prefer to hire Zimbabwean im/migrants? The most obvious reason is that they can pay these employees lower wages for working longer hours. But Chinese entrepreneurs expressed that they still would not hire local workers if the wages were the same. Several restaurant owners reported that they were robbed by former South African employees, some had troubles with South African unions, and a few of them were 
mugged by South African police. Due to these experiences, they would rather not hire local people.

My observations, along with those of others (Chen 2013; Harrison et al. 2012; Park 2009), also suggest that Chinese im/migrants constantly worry about crime at home, at work, and just about everywhere. For instance, every restaurant owner installed cameras for both security and surveillance purposes. This fear has constrained Chinese im/migrants' physical mobility, as most of them avoided going to certain areas. The high level of distrust also discouraged them from socializing with people outside of Chinese communities. Because of this, I use the term "everyday racialized insecurities" to describe Chinese migrants' anxiety when encountering "racial strangers," which is compounded by the general uncertainty about life they are also dealing with in Johannesburg — namely, illegality, petty corruption, and threats to safety.

As a result of limited interactions outside of Chinese communities, on top of linguistic and cultural barriers, Chinese im/migrants tend to live in a relatively close-knit community. Stuart Hall (1990) argues that diasporic identity is always in a process of "becoming" rather than "originating" and that "identity" is a process not a product. This understanding of identity helps to explain the diversity among Chinese communities, though at the same time certain Chinese groups share more commonalities than othersfor instance, coming from the same hometown and speaking the same dialect. The diversity among Chinese communities is also evident when contrasting between new Chinese im/migrants who arrived after 1990 and the older generations who were born in South Africa during apartheid. 
Moreover, while the Chinese South Africans had a national and racial "identity crisis" (Park 2008a, 2008b, 2009, 2010), such sentiment is not evident among firstgeneration Chinese im/migrants who arrived after 1990. Their concern about identity has less to do with a sense of self-identity and more to do with the popular perception in South African society that "Chinese are rich" or "Chinese carry around loads of cash," which makes them a target for crime. For the majority of Chinese im/migrants, safety and economic issues are their top concern. For instance, how much does this job pay? How much can they save a month? How will the exchange rate affect the remittances they send to China? Which "bad areas" should they avoid going to? What precautions should be taken to protect their property and lives? Hence, instead of putting the emphasis on "who they were," my ethnographic research paid attention to Chinese participants' current restaurant life in and of itself. This raises two questions: What makes their high crossborder mobility possible? How did the Chinese newcomers get their jobs?

Based on my ethnographic data, which was gathered mainly from recently arrived Cantonese-speaking im/migrants, Chapter II examines the role of guanxi - a combination of migrant networks and social relations - in shaping their economic activities and opportunities in Johannesburg. Guanxi has been misinterpreted and reduced to solely a "social network" by many, but in fact it can be conceptualized in many ways: as a type of power, a cultural norm, an everyday practice of extending and maintaining social relationships, or a connection that is used with an instrumental purpose (Chen and Chen 2004; King 1991; Smart and Hsu 2007; So and Walker 2006; Yan 1996; Yang 1994, 2002; Zhai 1993). Even though scholars have different views on how to define, analyze, 
and theorize guanxi, most would agree that it is a common cultural norm that is practiced by Chinese people in and outside of China.

Through Cantonese im/migrants' narratives and stories, this chapter reveals that the practice of guanxi often strengthens personal and employment relationships. As such, Cantonese im/migrants tend to be employed in the restaurant and fahfee sectors, which are partially inherited from the early generations of Chinese South Africans. Before the 1970s, most Chinese businesses in Johannesburg, including restaurants and fahfee, were operated by Cantonese immigrants. Fahfee (fafi, also known as mo-china in South Africa) is a popular illegal lottery game that has been played mainly by black South Africans in urban townships, suburbs, industrial centres, and rural towns for nearly a century (Krige 2011). Chinese people brought this betting game to South Africa, but they no longer play it themselves; instead, it has become an important business for the economic survival of Chinese im/migrants (Ho 2011).

Moreover, I examine how Western interpretations of corruption as something universally constituted lead to an ambiguous boundary between guanxi and corruption. The aim is not to risk reducing guanxi to a social network or business strategy. Guanxi is a combination of these concepts and more. The literature review on guanxi in this chapter shows the differences between Western and Chinese perceptions of guanxi. A discussion of these cultural differences provides a further understanding of how and why guanxi is distinguished from other types of social-networking concepts, and shows there is a distinction between guanxi and corruption, even though these two practices can be easily conflated (Yang 2002). 
It is important to note that this chapter is by no means a complete discussion of guanxi, nor does it try to use "cultural norms" to justify corruption. Rather, it aims to probe the following question: How are the boundaries between pulling guanxi and engaging in corruption challenged when Chinese migrants operate in new contexts? By investigating Chinese im/migrants' experiences of corruption in South Africa from their own perspectives on the basis of rich ethnographic data, I aim to deepen our understanding of Cantonese im/migrants' realities in Johannesburg.

Chapter III shifts back to Zimbabwean im/migrants, as they are the largest foreign migrant group (in terms of nationality but perhaps not race/ethnicity) in South Africa. Although linguistically they are not as diverse as the Chinese im/migrants, as black Zimbabweans speak either chiShona or isiNdebele, demographic variety is found in their socioeconomic backgrounds. This chapter examines some of the challenges they face in and outside of restaurant life, particularly with respect to low income, safety issues, extortion, and xenophobia. The purpose is to show that, after all, Zimbabwean $\mathrm{im} /$ migrants also live with everyday racialized insecurities given that lighter-skinned migrants in South Africa, including the Chinese, are generally not the targets of xenophobic attacks.

Social networks, as Khangelani Moyo's (2017) and my data suggest, also play an important role in shaping Zimbabwean migrants' access to accommodation and employment opportunities. A comparison between Chinese guanxi and Zimbabwean migrant networks shows that even though there is a relatively stronger financial aid system (through guanxi and underground banking) for the Chinese im/migrants, the Zimbabwean im/migrants use other network sources, such as the rotating savings and 
credit association (ROSCA; sitofela in isiNdebele), to borrow and save together among a group of trustworthy friends.

In the latter part of Chapter III, I examine Chinese and Zimbabwean restaurant employees' incomes in the South African context. Using the lens of the "intra-migrant economy" enables us to look beyond a migrant's story of economic hardship, and offers ways to understand how certain groups of migrants have been positioned in a host country: What are their national, racial, or ethnic relationships with the host society? What economic and political structures in the host country shaped the underlying conditions that created economic differentiation, in this case between Chinese and Zimbabwean im/migrants who make significantly less even though their local language skills are better than those of their Chinese co-workers?

This is where we see differences in the racial and economic positions of Chinese and Zimbabweans become apparent, embedded as they are in a framework of racial inequality stemming from apartheid. As Mbembe and Nuttall argue, Johannesburg is "where the relations of capital, technology, labor, and the unequal distribution of wealth engendered the greatest conflict. Here, race became the critical nexus between the body politic, the creation and distribution of wealth, and systematized human degradation" $(2004,353)$. In this case, Chinese im/migrants, due to linguistic and cultural barriers and business and job opportunities that are largely structured around guanxi relations, can avoid integration into South African society, but this does not prevent them from getting an average monthly income that is higher than that of black South Africans and much higher than that of Zimbabwean migrant workers. Thus, I suggest, Chinese im/migrants are socially marginalized but not economically underprivileged, which stands in contrast 
to the Zimbabwean im/migrants, who can look or sound like South Africans (Moyo 2017) but remain economically underprivileged.

Based on ethnographic data on both Chinese and Zimbabwean workplace behaviours and interactions, Chapter IV examines how the Chinese and Zimbabwean im/migrants negotiate labour relations in South Africa. While exploring their collaborations and tensions in a cross-cultural context, it becomes obvious there are certain factors that aggravate miscommunication and mistrust between Chinese employers and Zimbabwean employees_-for instance, language barriers, different ways of showing affection, and long hours working together. Many Chinese employers were unable to explain themselves fully in English, and Zimbabwean employees often mistook this as dismissiveness. As more issues arising from cross-cultural misunderstandings are explored in this chapter, we see that besides communication problems, there are also differences of attitudes and expectations.

The concept of guanxi is discussed again to examine "proper" workplace etiquette, since this cultural norm often indicates how one should act and negotiate according to one's position in a given relationship. In other words, while Chinese people tend to have many rules and customs aimed at demonstrating respect to superiors, Africans expect to be taken care of by their superiors (Wu 2014). Since there are often different interpretations of what a "good employer" and "good employee" should be, it is not surprising that tensions and conflicts often occurred at workplaces. Even though conflict is in the nature of any employer-employee relationship, these confrontations complicate Chinese and Zimbabweans' everyday perceptions of and interactions with each other. 
While Chapter IV analyzes from intercultural perspectives how the intra-migrant economy has been experienced by actors involved in it, Chapter V seeks to answer why these actors participated in it despite the high tension, conflict, and many complaints. It aims to go beyond their conflicts to examine their working relations. Here I use the term “interdependency" to describe a mutual dependence between Chinese employers and Zimbabwean employees, where Chinese can avoid hiring South Africans and maximize profit from cheap Zimbabwean labourers, while Zimbabweans can easily obtain jobs without proper procedure or skills. As much as the Zimbabweans need the Chinese for jobs, the Chinese need the Zimbabweans for labour.

The concept of interdependency builds on James Ferguson's “declarations of dependence" $(2013,2015)$, where he explores the social reality in Southern Africa and points out that a massive number of poor Africans are excluded from the wage economy and hence can only survive "through a combination of petty trade, hustling, casual labor, smuggling, prostitution, begging, theft, seeking help from relatives or lovers, and so on" $(2015,91)$. In this sense, dependence is not a passive and weak behaviour but an active survival strategy. This ideological shift helps us to better understand those who are in precarious jobs. Their main concern is to maintain their relations of dependence for dayto-day survival, even if that means maintaining a working relationship with exploitative employers.

The Chinese and Zimbabwean migrant workers (including the Chinese employers to some extent) featured in this research chose to knowingly work under such unfair conditions not due to threat of physical force but due to lack of options because they are already in an alternative "intra-migrant" labour market. Besides the economic factor of 
interdependence, I advocate for the need to better understand African and Chinese concepts of personhood—namely, guanxi and ubuntu. Ubuntu is a social philosophy that is prevalent in sub-Saharan Africa (Thuku 2007) and there is a commonality between the two concepts of guanxi and ubuntu, as both emphasize social role obligations and a recognition of interdependence. This is perhaps the key point in bridging the gap between Chinese and African people and their intercultural interactions.

Even though I suggest that there is a sense of commonality and collaboration in the intra-migrant economy and there have been positive outcomes, I do not see this as an equal or free interdependency. A lack of work opportunities back home is why Chinese and Zimbabwean migrants came to South Africa. Moreover, inequality and insecurity were the reason the intra-migrant economy existed in the first place. After all, what creates job opportunities, and what makes it so that "things are happening" as the Zimbabwean interlocutor said, is the vibrant informal economy and income inequality, which is also what makes Chinese and Zimbabwean im/migrants often feel insecure and uncertain in Johannesburg. As Mbembe and Nuttall describe, In Johannesburg, the underneath of the metropolis is akin to the world of extractionthe underground city of gold mining, with its own syntax, its arteries, its depth, its darkness, and the crucial figure of the migrant worker. Living in places and circumstances not of his or her choosing, the migrant worker is constrained to experience the metropolis as a site of radical uncertainty, unpredictability, and insecurity. (2004, 364, emphasis in original)

This dissertation aims to examine what constitutes Johannesburg "as a site of radical uncertainty, unpredictability, and insecurity" and how this condition shapes access to resources and the livelihood choices Chinese and Zimbabwean migrants make, which in 
turn shape how their present is lived continually through political and economic structures from the past. 


\section{CHAPTER I}

\section{EVERYDAY RACIALIZED INSECURITIES}

\section{Inside the Restaurants}

Alice knocked on the window. I almost did not recognize her because she was in a different style of outfit. She was thrilled that I had noticed her new jeans and said, "I bought this pair three months ago. Finally, a chance to wear them out!" Alice spent eleven hours a day, six days a week, at her workplace and one and a half hours per day commuting between work and home. She rarely had time to go out.

"We should go somewhere else, you know, like where the Silver City is, or the place near the Indian family's house," Alice suggested. Before being employed at Silver City, the Chinese restaurant where I met her, she was a domestic worker for an Indian family in an upper-middle-class suburb of Johannesburg. It was her first job after moving to South Africa in 2013. The Indian family paid Alice R 25 a day for working five hours and provided one meal, but she had to spend R 23 a day on transportation. "It was a joke," Alice said with a dry laugh. "I earned nothing, but that was the only thing I could get. Two months later Silver City needed more people so my sister took me to see Madam."16

Alice was in her mid-twenties and had not found any job after graduating from her GCE Ordinary Level in secondary school in Zimbabwe (roughly equivalent to grade 11 in Canada). She left her two-year-old son to be raised by her sister at home, and joined her two half-sisters, Betty and Sandra, who had left Zimbabwe for the same reason, in

\footnotetext{
${ }^{16}$ Alice and other Zimbabwean staff addressed the female owner of the Silver City restaurant as "Madam," and the male owner as "Boss." Other Zimbabwean staff usually called female owners "Lady Boss" or just their names.
} 
Johannesburg. Another sister of Betty's was the first one in the family who had come to Johannesburg, and she worked at Silver City. That sister helped Betty to get work there. Knowing that her employers, Mr. and Mrs. Hong, preferred to hire migrants, Betty introduced Sandra to them, as Sandra introduced Alice later on. Ever since, Alice had worked at Silver City from 10:30 a.m. to 9:30 p.m., with a two-hour lunch break, six days a week. Her starting salary was R 85 a day and paid in cash once a month. No tips. No benefits. No contract. No insurance.

On Alice's recommendation, I drove us to a coffee shop in a predominately white neighbourhood, where a coffee and cookie plus tip would cost more than half of her daily wage (raised to R 90 after one year of work, then R 100 after four years). Alice ordered a piece of cake and a cup of rooibos tea and asked for lots of milk. The server who was taking our order turned her head and looked at me. I soon realized what she was concerned about. I said to the server, "Do you mind bringing more milk for my friend?" to indicate that I would pay for the bill. Alice did not seem to care or even notice what had happened. She could not wait to complain about her employers.

Alice began with communication problems, as Mr. and Mrs. Hong had bad tempers and lacked proficiency in English: "Boss and Madam always say that we [Zimbabweans] don't listen to them or we don't understand English. But they are the ones with bad English. Not us!" I asked Alice if there had been any training when she first started. She replied, "What training? They just shouted at me. Nobody can understand them, especially when they never stop shouting. Betty and Sandra taught me everything." Alice continued to talk about employment issues:

Boss and Madam are too cheap. When it gets too busy, Madam tells us to help the Chinese to deliver food to customers, clean tables, and bring dishes into the kitchen. 
Madam also warns us not to talk to customers because she thinks that we will ask for tips. She always says she will share tips with us at the end of the month, but never once has! Boss and Madam don't allow us to eat restaurant food, even customers' leftovers. I'm at work all day long. When I get home it's almost 10:30 every night. I'm too tired to cook.

In fact, two former Chinese employees from Silver City also told me that Mrs. Hong cheated them out of tips. Many times, when I went to the back of Silver City's kitchen, where piles of dirty dishes and boxes of raw meats and vegetables lay waiting for kitchen helpers to clean, Alice and her sisters were eating rice from the rice cooker or other foods.

It is important to note that Mrs. Hong was probably the least generous Chinese employer — to both Chinese and African staff_-I met throughout my fieldwork in Johannesburg. At the five Chinese restaurants I did research in, two provided meals for African staff, two did not (including Silver City), and in the fifth one, the African employees usually cooked their own meals and were also free to use some food products from the restaurant.

Most owners of small- and medium-sized restaurants prefer to hire black African migrant workers. I met kitchen staff, shelf stockers, shopkeepers (who worked at Chinese-owned shops or restaurants) from Lesotho, Malawi, and Mozambique, but Zimbabweans constituted the greatest number of workers from an African country. This is not surprising considering that Zimbabwean migrants make up the largest foreign national group in South Africa (Moyo 2017). Following Alice's story to this point, we get a sense of how Alice and her sisters ended up working at Silver City. But we have not seen why there are many more Zimbabweans following this path. Their stories are 
explored in Chapter III, and Chapter IV discusses what the everyday working situation between Chinese and Zimbabwean migrants is like. This chapter focuses on ownership, job description, recruitment, and how businesses and skills are transferred within the Chinese community. ${ }^{17}$

The purpose of providing these details on the structure and transformation of restaurants is to enable readers to better understand the common challenges and situations that Chinese entrepreneurs with small- and medium-sized businesses face while operating a business in South Africa. Limited access to finance and low levels of capital are the most common conditions encountered by this type of business, which has been conceptualized as "petty capitalist" (Smart and Smart 2005). By analyzing local employment advertisements and news articles that reflect the local situation, I argue that in addition to the economic factors (i.e., the desire to lower costs), the fear of local crime contributes to why most restaurant owners favour hiring migrant workers. I describe Chinese migrants' anxiety when encountering "racial strangers" in terms of everyday racialized insecurities. This anxiety is fueled even more since most of them are also dealing with wider forms of uncertainty in Johannesburg — worrying about safety and wanting to protect their property, as seen in this chapter, and there are also constant issues of illegality and petty corruption to deal with, as shown in the next chapter.

The last section of this chapter looks at the linkage between Chinese food and diasporic identity to see how it maintains and solidifies social membership. Diverse Chinese culinary traditions demonstrate that Chinese communities in South Africa are by no means homogenous. This section focuses on recently arrived Chinese im/migrants and

\footnotetext{
${ }^{17}$ See Chapter IV for the recruitment and training of Zimbabwean employees.
} 
South African-born Chinese. Examining their "sojourning" tendency and connections, whether real or imagined, to China (Chen 2013; Park 2008a, 2008b, 2009) shows the complexity behind the migration of Chinese people to South Africa during different periods.

\section{Petty Capitalists}

Most actors involved in entrepreneurship in small- and medium-sized Chinese restaurants in the South African context fit the description of petty capitalists. Anthropologists Alan Smart and Josephine Smart define petty capitalists as "individuals or households who employ a small number of workers but are themselves actively involved in the labor process" $(2005,3)$. They argue there is a need to make a distinction between "entrepreneur" and "petty capitalist," and there is a difference between multinational corporation entrepreneurship and small-scale entrepreneurship with little capital like the restaurant owners in this project.

Smart and Smart point out that there are positive perspectives that stem from this type of employment relationship; for instance, "reduced separation between labor and management creates opportunities for gradual improvement of production processes through mobilization of tacit knowledge available to workers, and for flexible resolution of conflicting demands characteristic of a business environment" $(2005,4)$. I come back to the discussion on the blurred line between employer and employee and opportunity creation later in Chapter V, as this kind of employment relationship needs further examination along with the issues of interpersonal relations and loyalty. In this chapter, I focus on the flexibility and mobility that Smart and Smart describe here, which is evident 
in the Chinese restaurant business in South Africa as it is largely not contract based, and every restaurant owner I interviewed started as a worker in this industry. Moreover, Chinese employees, including culinary chefs, sushi chefs, servers, and "front counter" staff, ${ }^{18}$ were mostly trained as apprentices, and Chinese employers also paid for their daily meals, accommodation, and transportation. However, I did not see any such apprenticeship between Chinese employers and Zimbabwean employees. There were a handful of trained African cooks and sushi chefs, and even fewer Africans who became chefs that could cook Chinese food on their own. But I did not hear of any African chef who lived with Chinese employers as Chinese apprentices did.

My rough estimate is that there are around 150 Chinese restaurants in Johannesburg and surrounding suburbs. It is difficult to pin down the number because more than half are take-away restaurants that are dispersed throughout almost every suburb, and some closed down or relocated while I was there. Chinese take-away restaurants in Johannesburg, besides those in the two Chinatowns, all serve Westernized versions of Chinese food and sushi (and sometimes Thai-style cuisine)—for instance, chop suey, deep-fried batter chicken in sweet and sour sauce, and California rolls. As such, they usually offered two sets of menus: one for warm Chinese food and one for freshly made sushi. Figure 2 shows the types of food that customers could order from three take-away restaurants.

\footnotetext{
${ }^{18}$ I use the term "front counter" to describe the staff standing behind the counter taking walk-in and phone orders, calling out orders, charging customers, and sometimes serving customers, as most take-away restaurants have a few tables inside the shop. This job title in Chinese is 吧台, which literally translates to "bar counter," but "front counter" makes more sense to English readers.
} 
Figure 2: Chinese Take-Away Menus in South Africa

\begin{tabular}{|c|c|c|c|}
\hline \multicolumn{4}{|c|}{ CHINESE TAKE-AWAY MENU } \\
\hline $\begin{array}{l}\text { Souph } \\
\text { veretami sour }\end{array}$ & & $\begin{array}{l}\text { pace pisties } \\
\text { Defe fred penwy }\end{array}$ & \\
\hline chocienswert cony sour & K12.to & 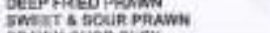 & B4250 \\
\hline 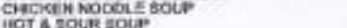 & $\sum_{010}^{k 100}$ & PQWW EHOP ELEY & A A2.20 \\
\hline Win ruk goup & $\begin{array}{l}N 1200 \\
83300\end{array}$ & 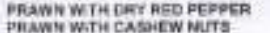 & $\begin{array}{l}\text { Rat:co } \\
\text { Rascon }\end{array}$ \\
\hline SEAPOCD Sot? & & paine roo rows & 84.60 \\
\hline 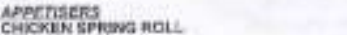 & & PFAWN WTIR LEMCN SAUCE & \\
\hline 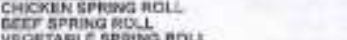 & 90.00 & $\begin{array}{l}\text { nSH chop SUEY } \\
\text { Figh S ELACK OEAN SAUCE }\end{array}$ & $\begin{array}{lll}20250 \\
202000\end{array}$ \\
\hline 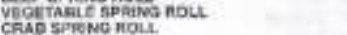 & & & B.2.200 \\
\hline 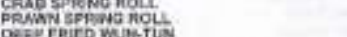 & pisois & CALANRer shert S soum & 94000 \\
\hline 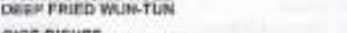 & & CALAMVHI CHOP GUEY & Ma000 \\
\hline ace orsugs & & 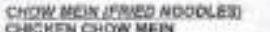 & \\
\hline gliguen Giop surer & notso & BEE CNOW MANA & 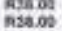 \\
\hline CiAckry Curser & N301900 & DONX CHOW WEN & NQSOE: \\
\hline 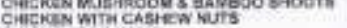 & 1038.00 & ABsohted GHOW HEW & Rez Oa \\
\hline CHicks foo roks & $\operatorname{los} 90$ & CALANANG COOW NEEN & 940.90 \\
\hline 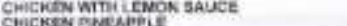 & 200.00 & $\begin{array}{l}\text { MAWW CROW NEIN } \\
\text { WXXP }\end{array}$ & A2200 \\
\hline 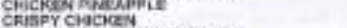 & 230.00 & 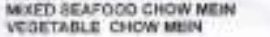 & 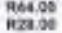 \\
\hline 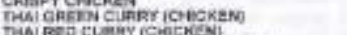 & pap. 00 & VESTABLE CHOW Baid & \\
\hline 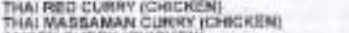 & 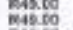 & 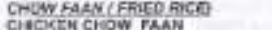 & \\
\hline 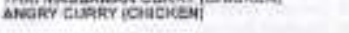 & Rete to & aeer choN taen & Ras. 00 \\
\hline popk gewst s soun & Kang & $\begin{array}{l}\text { PORK CHOW FKAN } \\
\text { ASSONTTD CIKCW TMAN }\end{array}$ & $\begin{array}{l}\text { Eas.00 } \\
\text { RA2.60 }\end{array}$ \\
\hline $\begin{array}{l}\text { pokk cive suter } \\
\text { poak cuitur }\end{array}$ & patog & 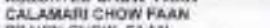 & Rat.60 \\
\hline Poak witiparr reo rementh & xaen & PHANE CHOW FAAN & Ra230 \\
\hline & & 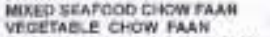 & 208000 \\
\hline $\begin{array}{l}\text { netr ciop suty } \\
\text { Wer WTN gater peppen }\end{array}$ & paga & 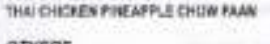 & 80000 \\
\hline 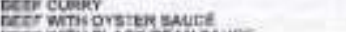 & म39.08 & Onters & \\
\hline 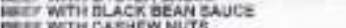 & Kage & 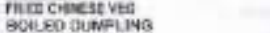 & 22zon \\
\hline 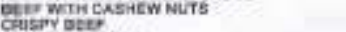 & $\begin{array}{l}\text { A } \$ 3.90 \\
\text { P\$ }\end{array}$ & 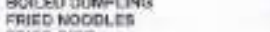 & 90,00 \\
\hline GWWGHUETEAK & R०390 & reied nuce & H. 3.05 \\
\hline 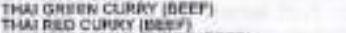 & $\begin{array}{l}\text { Ruz.90 } \\
\text { Rat.90 }\end{array}$ & SHALA CAPS & M12.06 \\
\hline 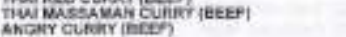 & Ras.po & sweeta & \\
\hline 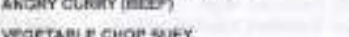 & & gowre & A. 6.90 \\
\hline 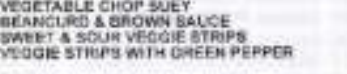 & 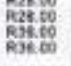 & 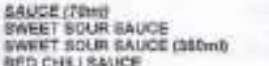 & 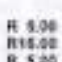 \\
\hline 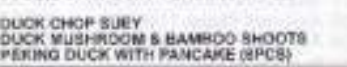 & 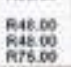 & $\begin{array}{l}\text { RED CHLI SAUCE } \\
\text { SOYGAUCE }\end{array}$ & $\begin{array}{l}R .20 \\
\text { R } 5,00\end{array}$ \\
\hline
\end{tabular}

\section{0) SUSHMEN CO}

Makiuspesy

101 Avocaso

102 Cusint

109 Promin

tod Gaver

ich Crab

107 sonded samon

tor Sprey Tina

$16 \mathrm{se}$

Caltona Rol (BPCS)

201 Grab

202 Prawn

204 Tuna

205 smoked samen

209 Vegetatice

207 Spicy Sáman

200 Splay Tund

210 Eal

211 Horay Chicken
212 Rempura Prawn

Farhion Sndwictes IPPCS:

301 Cras

SC2 Firan

2.2. Tura

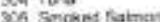

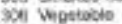

Nigai [aecs)

401 Prawn

402 Saman

404 Smokest Satmon

$406 \mathrm{Crob}$

400 Inar

$407 \mathrm{Eer}$
$406 \mathrm{Cavier}$
Sarhimi (3PCes)

81800
$R 1800$
$R 2500$
12500
22500
12200
82500
82500
12505
13500

501 Prawn

sol Smowed Sainoen

Ra2 00

R30.00

$\mathrm{kas}<0$

Hand Roll IPC)

sat wootisis

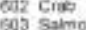

ton Tina

exts Prim

606 Smokes Salmon

607 Oosp Fred pram

ose secocy Tira

Qibers

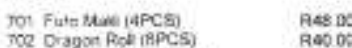

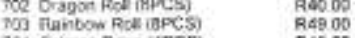

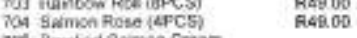

Tod Bmoked Bamos Crear

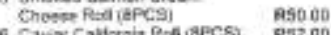

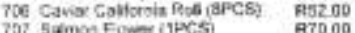

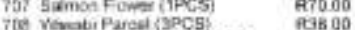

709 Honey Chidem Mas (ePCS) H4000

710 Tenpin Plawn (PPCS) Ra5co

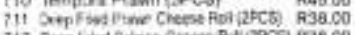

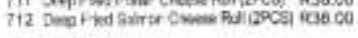

spencial

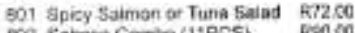

502 Salnot Combo (11POS) RSO X0

Do3 Assatied Nogn (7FCS) $\quad$ R7 .00

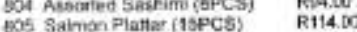

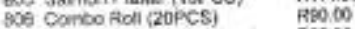

E07 Vegolabe Combe (11PCS) Re68.00

BOS Assorted Ptalla (18RCS) R13400

B09 Assorted Combe (2CFCS) R154,0

810 Kung-ba Plather (24PCS) R196.00 


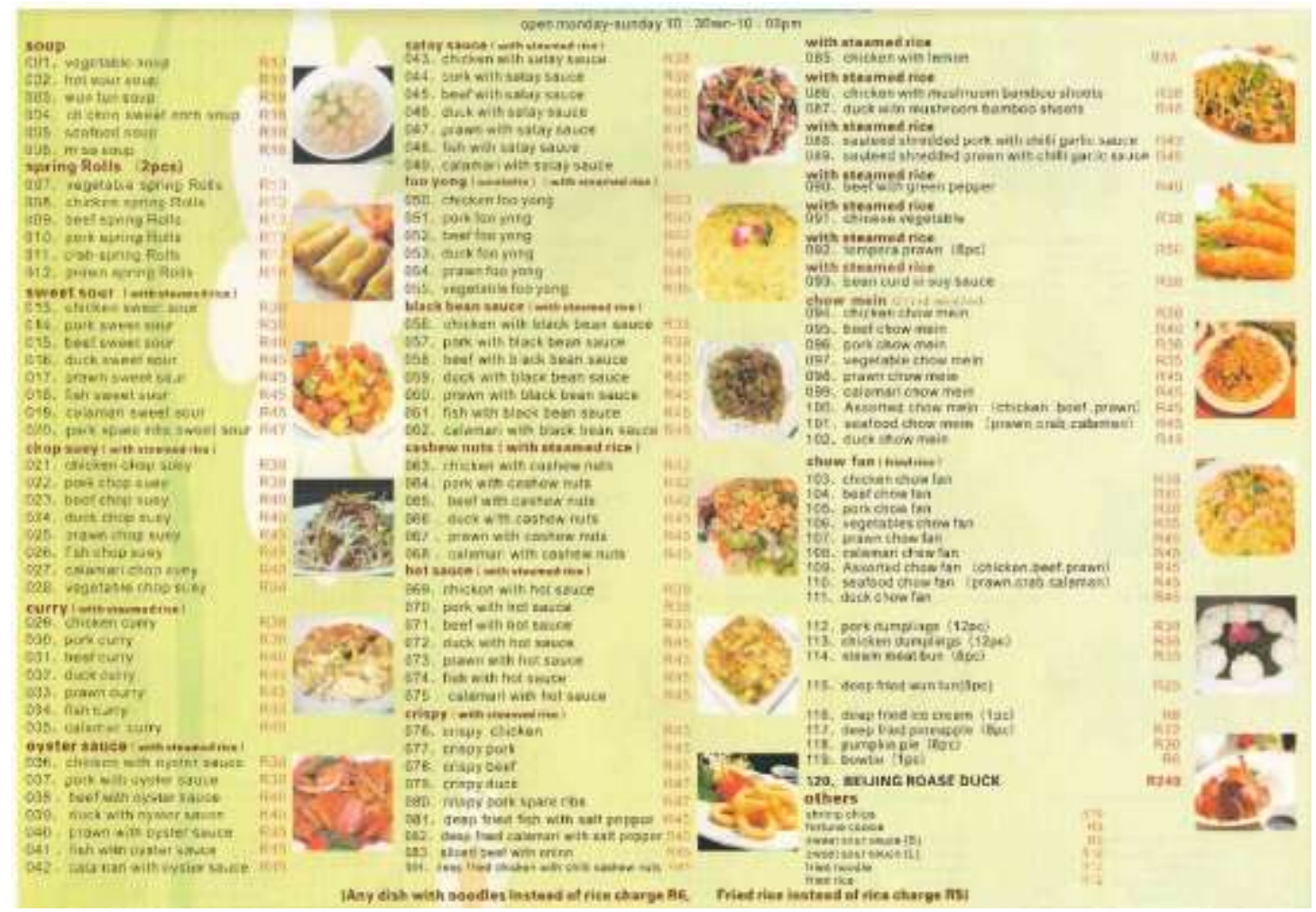

Sunday - Tuesday sushi special buy 2 get 1 freelno sashimi and plattet) Lunch time R145 eat as much as you likeino sashimi,no platter, no share, no take away, no waste)
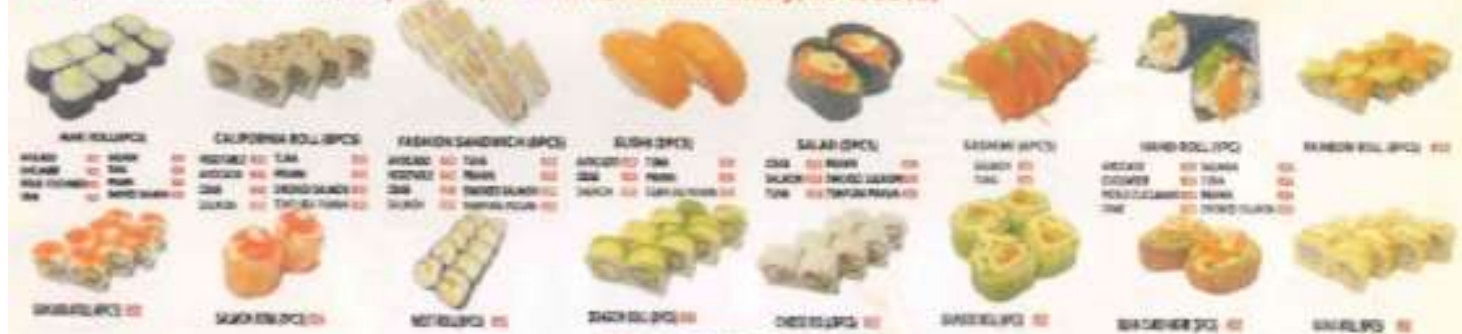

Assonte comato

somen $=$

vicasu e

asem $\mathrm{s}$
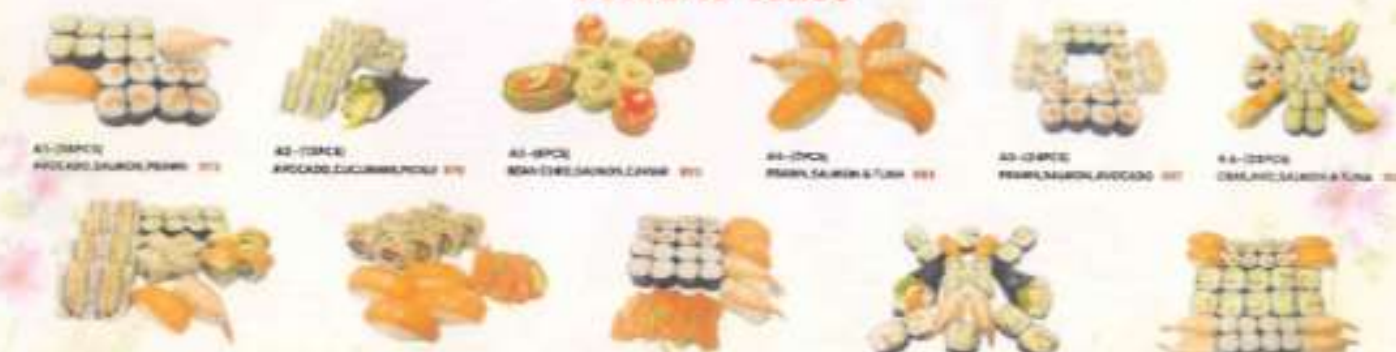

a-rase

$\sin$

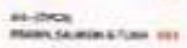

a awe
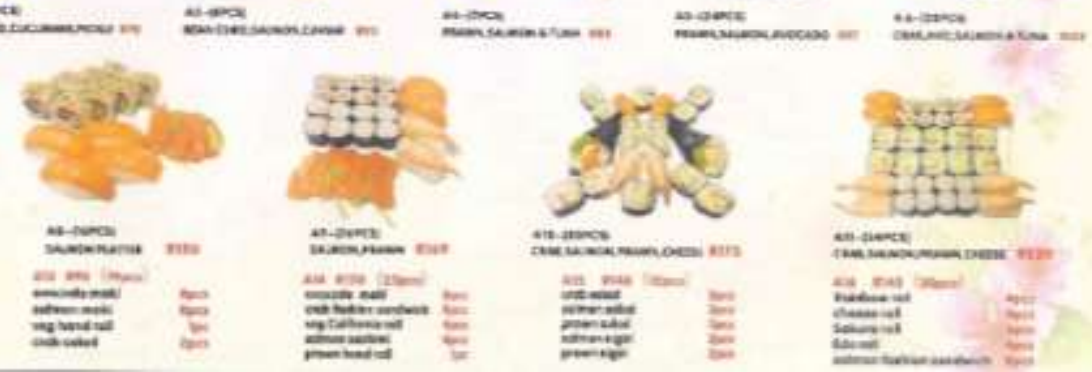


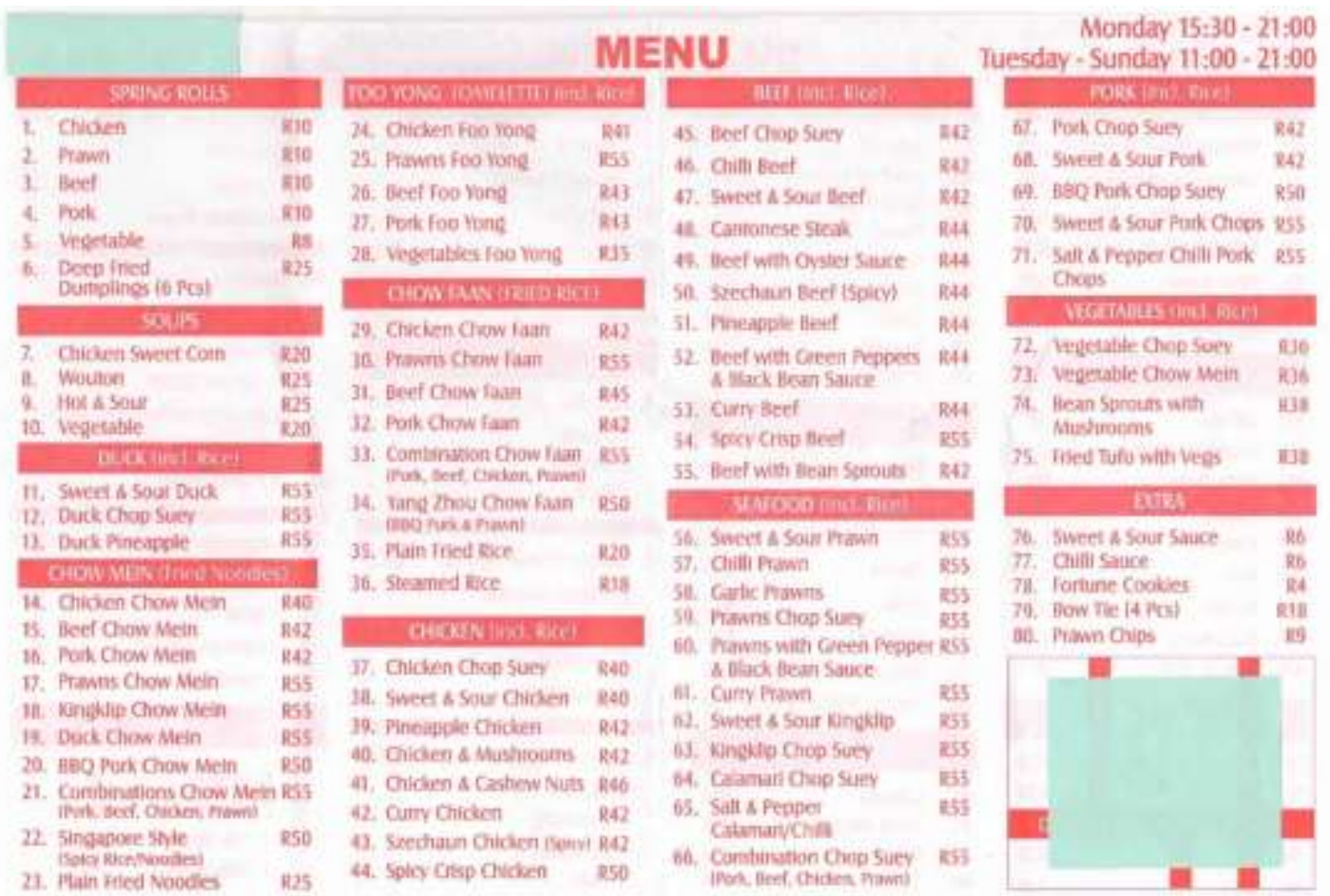

\begin{tabular}{|c|c|c|c|c|c|c|c|c|c|}
\hline & & & SU & & MENU & & \multirow{2}{*}{\multicolumn{3}{|c|}{$\begin{array}{r}\text { Monday 15:30 - 21:00 } \\
\text { Tuesday - Sunday 11:00 - 21:00 } \\
\text { entas }\end{array}$}} \\
\hline \multicolumn{3}{|c|}{ Mentans: } & \multicolumn{2}{|c|}{ 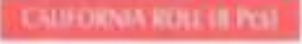 } & \multicolumn{2}{|l|}{ 116xolotili Ra! } & & & \\
\hline At. & Salteon bases if $\mathrm{kal}$ & eus & A. Satmon & us & Mil. Sarroes & exs & & \multicolumn{2}{|c|}{ 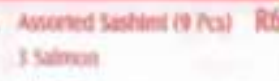 } \\
\hline N. & Salmop Sechimi (4 ha) & ris & C. Snnked Saimon & 20 & 16. Snviled Sabten & 21 & & \multicolumn{2}{|c|}{ I hasn } \\
\hline A. & funa sesham it $\mathrm{hal}$ & as & $\begin{array}{l}\text { C. Sicyliona } \\
\text { ca. phan }\end{array}$ & as & 10. Spicr Tuna & es & & \multicolumn{2}{|l|}{ ISelnon hases } \\
\hline M. & haw Sulen it Red & 20 & c8. Oab & 38 & He. haven & 25 & & & \\
\hline N5. & Muse Youp & Ee & c. Eanbow & 245 & ML. coub & m & \multirow{2}{*}{\multicolumn{3}{|c|}{ 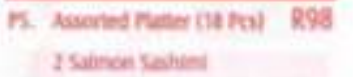 }} \\
\hline A. & $\begin{array}{l}\text { Salmon Eanbos } \\
\text { Bind it fav }\end{array}$ & 213 & C. nes & 602 & 16. Vevesable & 20 & & & \\
\hline \multicolumn{3}{|c|}{ 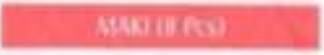 } & $\begin{array}{l}\text { a. Draven } \\
\text { c. vejetatie }\end{array}$ & $\begin{array}{l}\text { us } \\
\mathrm{an}\end{array}$ & \multicolumn{2}{|l|}{ whits } & \multicolumn{3}{|c|}{$\begin{array}{l}2 \text { Rawn Noit } \\
2 \text { Sulthon kaen }\end{array}$} \\
\hline ait & Salmen & as & \multicolumn{2}{|l|}{ 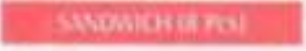 } & \multirow{4}{*}{ 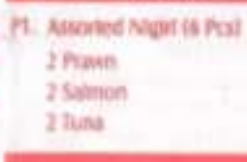 } & \multirow[t]{2}{*}{ R66 } & \multicolumn{3}{|c|}{ 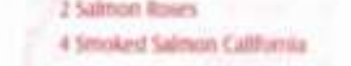 } \\
\hline M2. & Semsed Salman & sMl & 51. Submon & nu & & & & \multirow{2}{*}{\multicolumn{2}{|c|}{$\begin{array}{l}4 \text { Vederable Caltima } \\
4 \text { hawn Mal }\end{array}$}} \\
\hline M4. & Sum bina & $\begin{array}{l}2 a \\
\text { ear }\end{array}$ & 5. Sencked Sumnn & nis & & & & & \\
\hline Mi. & $\begin{array}{l}\text { hawn } \\
\text { Cable }\end{array}$ & as & 4. Selcy tane & 24 & & & \multirow{2}{*}{ nis. } & & \\
\hline MS & Con & aes & St hawn & 844 & n. Combe Fumer (W Fo) & $\mathrm{R} 78$ & & \multicolumn{2}{|c|}{ Wegcable Combe (1) Rosi R6S } \\
\hline Mu & hos & 20 & 55. Cabs & na & \multicolumn{2}{|c|}{ 2 Sulmon Senchim } & \multicolumn{3}{|c|}{ Isandwich } \\
\hline M2. & $\begin{array}{l}\text { Rolits } \\
\text { Cucurnber }\end{array}$ & 20 & 8. Lenbow & kal & \multicolumn{2}{|c|}{ 4Sedved Sibmon Calfonu Roll } & \multicolumn{3}{|c|}{4 Way } \\
\hline Mt. & $\begin{array}{l}\text { Cocumber } \\
\text { has it pul }\end{array}$ & nes & 5. Whosule & ese & \multicolumn{2}{|c|}{ zCub butilenho } & \multirow{2}{*}{\multicolumn{3}{|c|}{ 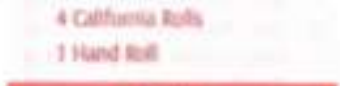 }} \\
\hline \multirow{2}{*}{\multicolumn{3}{|c|}{ 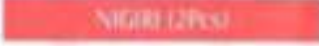 }} & Sa Wesaby Faces is fes & rese & \multirow{2}{*}{\multicolumn{2}{|c|}{ If Fann Mali }} & & & \\
\hline & & & \multirow{2}{*}{\multicolumn{2}{|c|}{ axilisy }} & & & \multicolumn{3}{|c|}{ Ming: } \\
\hline Ni. & Silnon & as & & & n. Selinos Raner (18 Rot & R98 & \multirow{4}{*}{\multicolumn{2}{|c|}{ 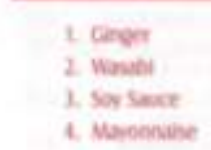 }} & \\
\hline $\mathrm{Ne} 2$ & Senced Salmin & $2 a$ & 01. Sulinon & 63 & ISsherm & & & & is \\
\hline NJ & Dina & os & 12. Solor lare & as & 2 antestie & & & & is \\
\hline Ni. & $\begin{array}{l}\text { Fann } \\
\text { cos }\end{array}$ & 206 & $\begin{array}{l}\text { 11. Nawn } \\
\text { be. Cab }\end{array}$ & 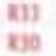 & $\begin{array}{l}\text { I Calforitas } \\
\text { I way }\end{array}$ & & & & is \\
\hline
\end{tabular}


Generally speaking, white South Africans are the main clientele for take-away and upscale Chinese restaurants. Most of the expensive Chinese restaurants are located in affluent northern suburbs. A server I interviewed who worked at one of these restaurants estimated that at least $80 \%$ of customers were white and another $5 \%$ to $10 \%$ were Indian.

The term "New Chinatown" indicates that there is an old one. Johannesburg's original Chinatown is located in Newtown, along Commissioner Street in the downtown area. Most restaurants and shops in First Chinatown closed down or relocated to New Chinatown to escape crime and decay. New Chinatown is located in Cyrildene, a formerly Jewish suburb on the eastern side of downtown Johannesburg. ${ }^{19}$ There are about fifty to sixty restaurants located in both Chinatowns. Most Chinese South Africans tend to support the long-established restaurants in First Chinatown in downtown Johannesburg. These restaurants mainly serve old-style Cantonese cuisine that tastes closer to what Chinese South Africans are used to. Recent Chinese migrants prefer to dine in the restaurants in Cyrildene's New Chinatown or restaurants in areas with large Chinese populations, such as Edenvale and Sandton. You can find almost every regional cuisine in these restaurants, as they reflect the diverse backgrounds of Chinese newcomers. Each restaurant is characterized by multiple factors such as geographic location, facilities, types of cuisine offered, and main clientele.

Regardless of the size of the restaurant, the total number of black employees usually exceeds the number of Chinese ones. Lower skill jobs_-including but not limited

\footnotetext{
${ }^{19}$ As most of the Chinese state-owned enterprises in South Africa are located in Sandton, and most of their Chinese employees settle in nearby areas, I heard people refer to Rivonia - an upper-middle-class suburb in the Sandton area - as the third Chinatown of Johannesburg. One of the largest Chinese supermarkets is located in Rivonia's Oriental City shopping centre, and there are about ten to fifteen Chinese restaurants around as well.
} 
to washing dishes, chopping vegetables, cutting meats, cleaning pots and floors, preparing ingredients (e.g., wrapping dumplings), and making simple items (e.g., sauces)—are all performed by black employees. The service and cashier jobs are performed by Chinese female family members and/or employees. The medium- to largesized restaurants that cater to South African clientele usually have a combination of Chinese and black African servers. ${ }^{20}$ The jobs that require more specialized skills, like cooking Chinese cuisine and making sushi, are mostly performed by Chinese male family members and/or employees.

\section{Training, Transition, and Recruitment}

A typical Chinese take-away restaurant in South Africa needs at least six people to make it fully operational: one front counter staff for taking orders, answering the phone, and charging customers; two chefs (one for sushi and one for hot items) for making food products; and three kitchen helpers for everything else from cleaning to packing. The take-away restaurants I visited all employed at least four African kitchen workers but no more than one cooking or sushi chef because it would be too costly to hire another. The chef's salary usually took up a large percentage of operating costs, which is why owners themselves are usually the chefs of their own restaurants. More and more Chinese owners/chefs have been training, or starting to train, African employees to cook simple items (e.g., spring rolls) in order to reduce their own working time. It is also a result of the weakening South African currency, which has affected the recruitment of

\footnotetext{
${ }^{20}$ I met quite a few Zimbabwean servers working at non-Chinese-run restaurants in Johannesburg. In fact, several Zimbabwean participants in this project used to work in Chinatown and later switched to nonChinese restaurants when they had the chance. The reason did not necessarily concern the Chinese employers; customers tend to tip more at non-Chinese restaurants, one interviewee told me.
} 
Chinese employees in South Africa and from China. By the end of my fieldwork (September 2016), as the value of the rand continued to fall, fewer Chinese migrants were coming to South Africa, and more and more Chinese immigrants were talking about leaving South Africa (also see Kuo 2017).

Most take-away restaurant owners I interviewed had worked at other take-away restaurants for a few years until they had saved up some capital to open their own restaurants. The most common way of owning a restaurant is buying an existing business since the equipment, name, and menu are already there. On a popular WeChat group for information exchange between Chinese in South Africa that my informants told me to join, I often saw restaurants advertised for sale. Two examples follow that were posted on the WeChat group by the owners (see Figure 3).

Figure 3: Advertisements for Restaurants for Sale

\begin{tabular}{|c|c|}
\hline 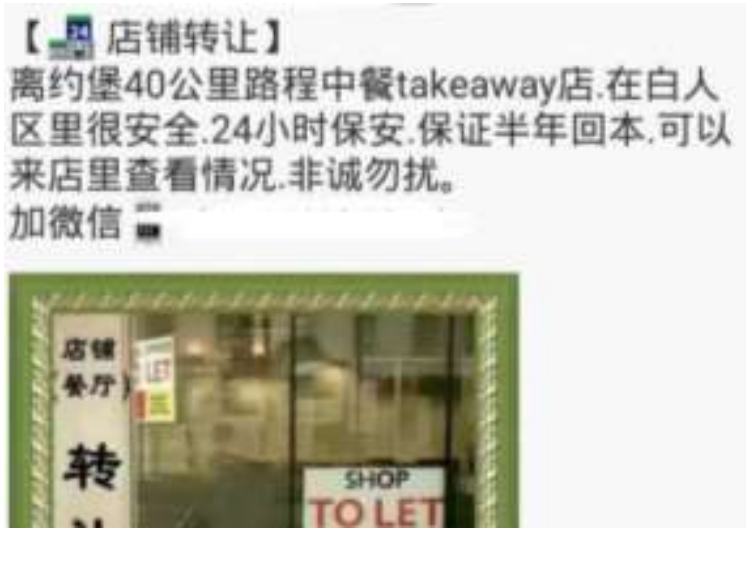 & $\begin{array}{l}\text { [Store Transfer] } \\
\text { A take-away restaurant around } 40 \mathrm{~km} \\
\text { from Johannesburg, in a white } \\
\text { neighbourhood, very safe, } 24 \text { hours } \\
\text { security. Guaranteed return in half } \\
\text { year. Feel free to come to see the } \\
\text { store. Sincere inquiries only. } \\
\text { Add my WeChat: } x x x-x x x-x x x\end{array}$ \\
\hline
\end{tabular}




\begin{tabular}{|c|c|}
\hline 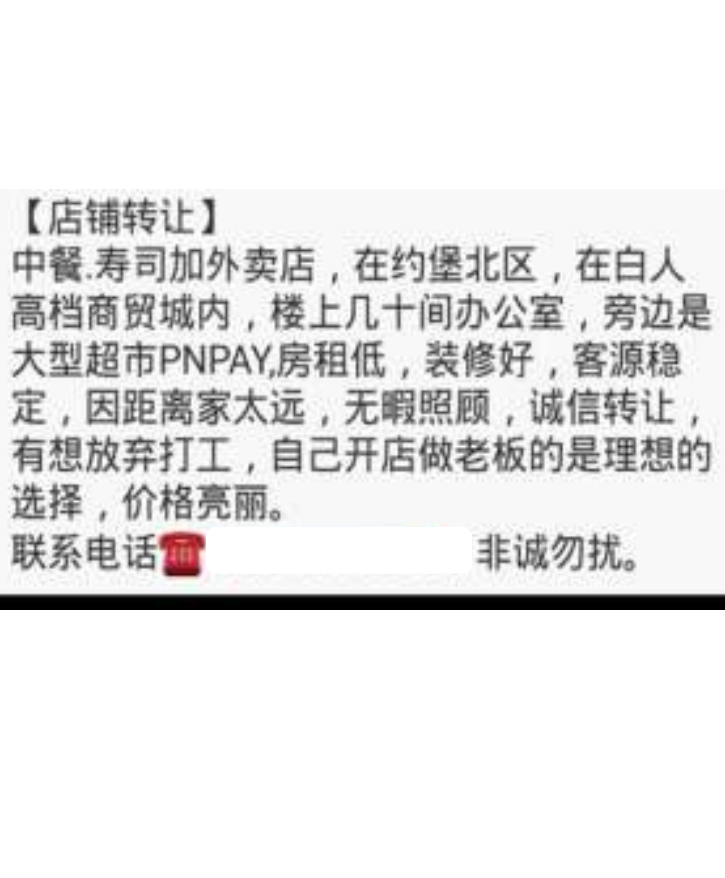 & $\begin{array}{l}\text { [Store Transfer] } \\
\text { Chinese restaurant. Sushi bar plus } \\
\text { take-away in northern area of Joburg, } \\
\text { inside a high-end commercial } \\
\text { building with white people, there are } \\
\text { dozens of offices upstairs, next to a } \\
\text { large PNPAY supermarket, the rent is } \\
\text { low, the decoration is good, the } \\
\text { source of customers is stable. } \\
\text { Because it is too far from home, I } \\
\text { have no time to take care of it, } \\
\text { integrity transfer, for those who want } \\
\text { to give up working for others, } \\
\text { owning this one is the ideal choice, } \\
\text { the price is good. } \\
\text { Contact number: XXXXXXXX, } \\
\text { sincere inquiries only. }\end{array}$ \\
\hline
\end{tabular}

I will come back to why it was important for the restaurant owners to mention safety in these advertisements. Most buyers, at least those I interviewed, started as employees at a restaurant in Johannesburg. For instance, Mr. Li, a trained chef, was recruited to work at a Chinese restaurant in Johannesburg in the late 1990s. When his former employer retired, he bought the restaurant. The previous owner passed supply contacts to $\mathrm{Mr}$. Li; trained him to negotiate with the suppliers, manage inventory and employees, and read basic accounting; and made sure that regular customers would not be affected by the change of ownership. The previous owner basically taught Mr. Li everything he needed to know to continue to run the business successfully.

In Mr. Li's case, because he was already a chef, he did not have to learn how to cook. In other cases of restaurant transitions, recipes, skills, knowledge, and sometimes even employees were bought and sold as part of the business. The previous owners 
usually spent weeks, even months depending on their agreement, teaching new owners everything from how to cook every single item on the menu to how to write orders. When taking an order, there is usually no time or space to write out the full name of each dish. New front counter staff have to be trained in writing abbreviations, while new chefs have to learn to read them. The following is a list of examples:

$\begin{array}{ll}\text { CCF } & \text { Chicken Chow Faan (fried rice) } \\ \text { PCM } & \text { Prawn Chow Mein (friend noodles) } \\ \text { Cu M } & \text { Cucumber Maki } \\ \text { S/Sa CR } & \text { Smoked Salmon California Roll } \\ \text { Veg HR } & \text { Vegetable Handroll }\end{array}$

Several restaurant owners suggested that it was more practical and economic for them to train in Chinese cooking and not as a sushi chef. There are a couple of reasons for this. First, making sushi is a relatively easy skill to learn (though not by Japanese standards) compared to cooking Chinese food, which leads to the second reason: the salary of a Chinese sushi chef is less than that of a Chinese cooking chef.

There are several ways to recruit Chinese employees. ${ }^{21}$ One of the most common methods is through agencies, which is explored in the next chapter. Another one is simply asking around. The following message is an example of a WeChat post shared by a Chinese server with her friends (see Figure 4).

${ }^{21}$ The recruitment of Zimbabwean employees is explained in Chapter III. 
Figure 4: Recruiting Through Friends

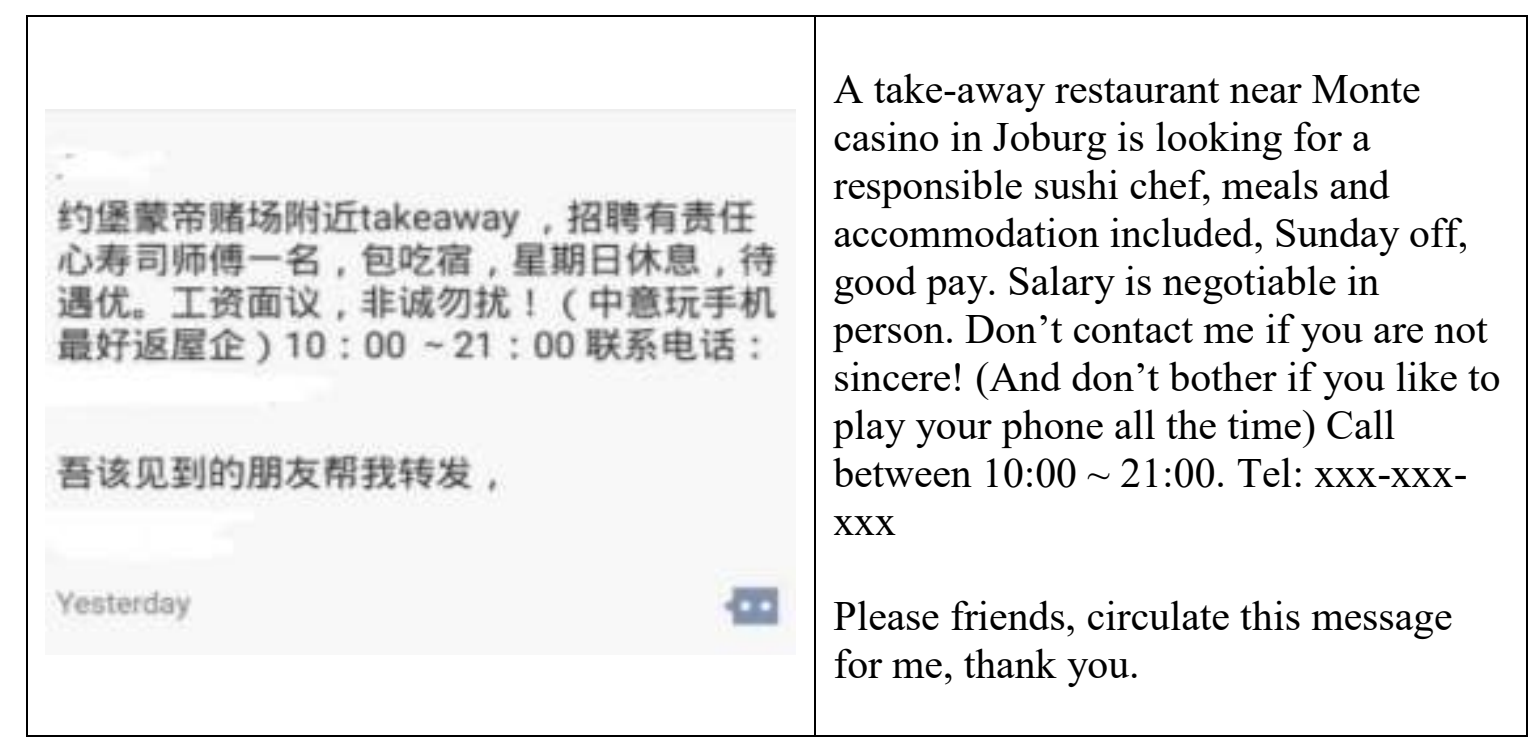

Posting employment advertisements on WeChat groups is also a common method.

Each week, I saw at least one job offer or job search advertisement. The following example is a typical employment advertisement post (see Figure 5).

Figure 5: Job Advertisement

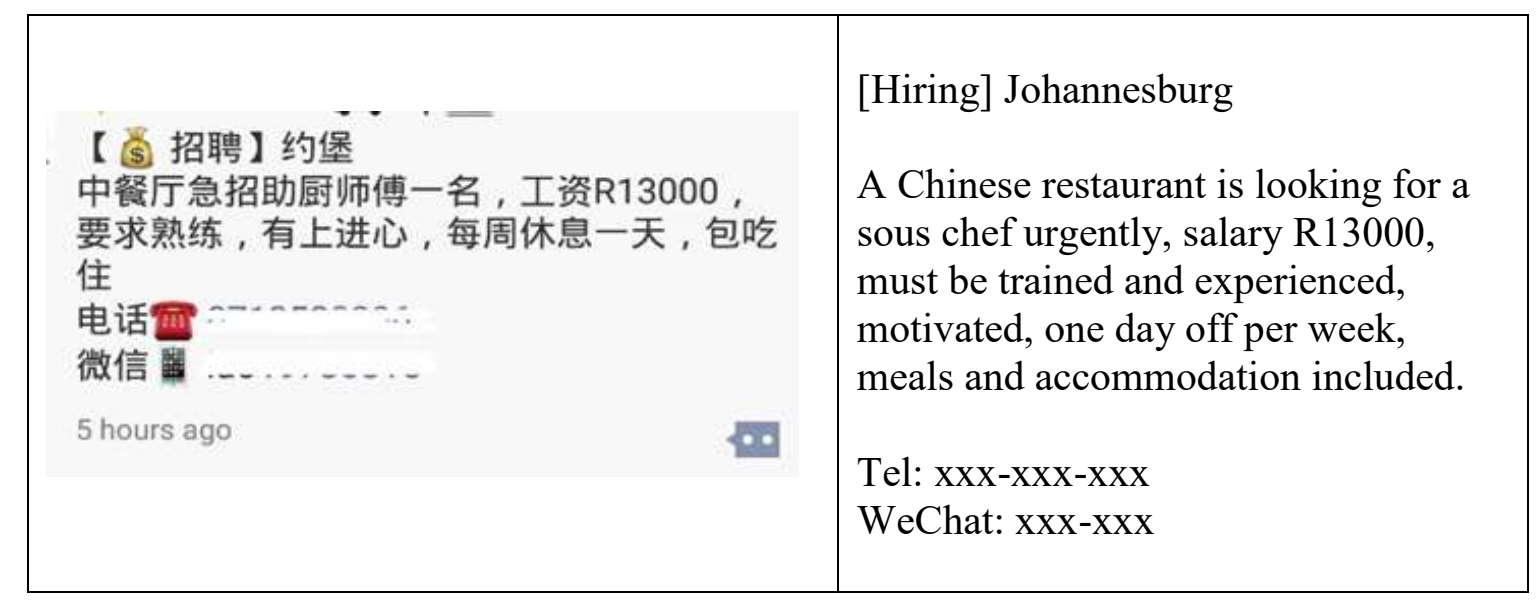

It is also common to see people look for employment through these WeChat groups, as the following post shows (see Figure 6). 
Figure 6: Job Search Advertisement

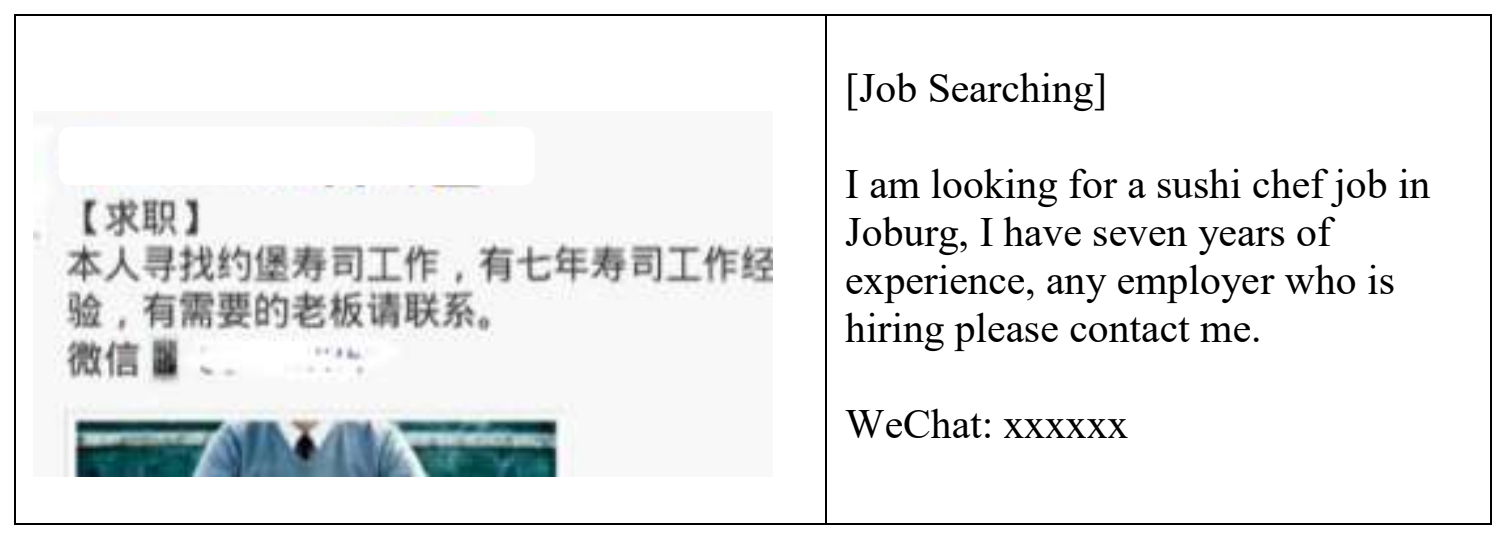

Some restaurant owners indicated that they were willing to train new staff.

Unexperienced staff usually start the job with a lower salary during the training period.

Depending on negotiations, a raise is typically expected after training (see Figure 7).

Figure 7: Looking for Trainees

\begin{tabular}{|c|c|}
\hline 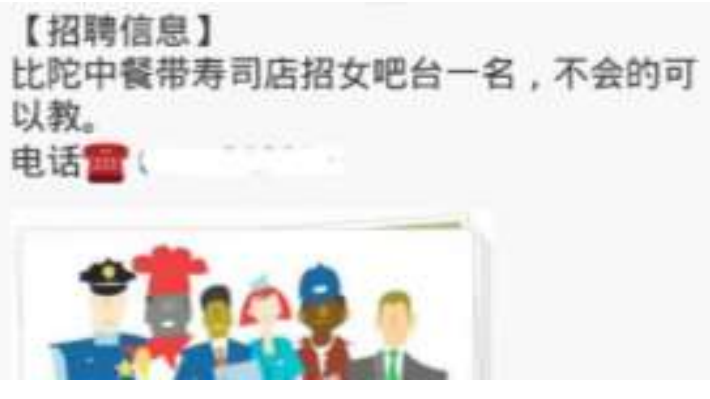 & $\begin{array}{l}\text { [Job Offer] } \\
\text { A Chinese take-away restaurant with } \\
\text { sushi bar in Pretoria is looking for a } \\
\text { female front counter staff. We can } \\
\text { provide training. } \\
\text { Phone number: xxxxxxxxx }\end{array}$ \\
\hline $\begin{array}{l}\text { 【2. 招聘信息】 } \\
\text { 约保地区mall里招聘寿司师傅，和吧台 } \\
\text { 各1名,或者收寿司学徒，男女无限，无查 } \\
\text { 身份治安安全。 } \\
\text { 联系电话面 }\end{array}$ & $\begin{array}{l}\text { [Job Offer] } \\
\text { A restaurant in a mall located in the } \\
\text { Joburg area is looking for one sushi } \\
\text { chef and one front counter staff, or } \\
\text { sushi apprentice, male and female are } \\
\text { welcome, no checking ID, secure and } \\
\text { safe. } \\
\text { Contact phone number: xxx-xxx-xxx }\end{array}$ \\
\hline
\end{tabular}


The issue of Chinese migrant workers without proper documentation is discussed in the next chapter along with the Chinese networking system (i.e., guanxi). What is worth noting for now is that there are eleven official languages in South Africa, and Johannesburg is also a city full of internal and international migrants from various regions and nations. English is the most commonly used language in major South African cities like Cape Town and Johannesburg. Nonetheless, there is no "standard" South African English accent, which instead varies depending on speakers' mother tongues. One of the most challenging tasks when I started working at the Chinese restaurants was taking phone orders. I had troubles understanding customers over the phone, and it took me a while to fully get used to a wide range of English accents even after having lived for more than two decades in two of Canada's most diverse cities, Toronto and Ottawa, which have immigrants from all over the world. It is, inevitably, even more challenging for Chinese newcomers who have never communicated in English before. The first training every front counter staff and server receives is in memorizing and learning how to pronounce every item on the English menu. Most servers I interviewed said it usually took them two to three weeks to understand customers' orders in person. A front counter staff told me it took her two to three months to be able to fully handle phone orders.

Although English is not part of the training for the cooks and sushi chefs, as their interaction with customers is limited, they still need training in how to make the takeaway food items and sushi-none of which originated in China. As two sushi chefs told me, they had not heard of chop suey or sushi before coming to South Africa. The following section describes a restaurant transition that involved conflict with the employees. 


\section{Local vs. Migrant Employees}

Mr. Hong, a trained chef from Guangdong, was recruited by a Chinese South African restaurant owner in the early 1990s. Some years later, in the late 1990s, Mrs. Hong and their children relocated to South Africa to join him. After Mr. and Mrs. Hong had worked at Chinese restaurants (mainly for Chinese clientele) for a few years, they had some savings. Combined with money borrowed from family, they finally had enough capital to open their own restaurant. They took over a take-away restaurant from another Chinese couple.

Although both Mr. and Mrs. Hong had already worked in restaurants, the clientele and recipes at the new restaurant were different. The previous male owner taught Mr. Hong how to make sushi and popular dishes that were suitable for the customers from the neighbourhood. The female owner taught Mrs. Hong basic accounting skills and how to fill out the bill slips. Within a short period of time, Mr. and Mrs. Hong were confident that the skill and knowledge transfer was successful and they could run the business smoothly. Mrs. Hong said, "We were so excited and thought we were finally getting rewarded after working so hard all these years, but turned out it was the beginning of a nightmare!"

When Mr. and Mrs. Hong took over the restaurant, the three South African employees there continued to work for them. One day, Mrs. Hong found out that one of these employees was stealing food products. She gave a warning. The employee reported this conflict to the union. Later, Mrs. Hong caught the other two employees stealing kitchen equipment. She phoned the police. The police came to the restaurant, asked them for information, wrote a report, and arrested the two employees. When Mr. and Mrs. 
Hong went home the next night, they found these two employees and the same police officer inside their house. They were assaulted and had their cash taken. "These people were organized criminals! Probably why the last couple wanted to sell this restaurant for cheap. And we thought we were lucky. We were so stupid!” Mrs. Hong was still very angry about what happened almost fifteen years ago. She continued to tell her story about her first time becoming an employer in South Africa:

Not only were we mugged, we also lost two employees. That's when I realized Chinese cannot trust black South Africans, especially those dirty cops! I was an optimistic person. I still said to my husband, “That's okay, we can always make more money as long as we're safe. No problem. We can endure this hardship.” ... Just when I thought things couldn't get any worse, the labour union threatened to shut our business down if we didn't accept the demand from the employee who stole food. Everything was so absurd! We paid a lot of money for the employee to go away.... Even still, the restaurant was busy, but here came another problem - there were not enough helpers in the kitchen. We couldn't afford a Chinese employee because we were still in debt, and we were too traumatized to hire South Africans. I had no choice but to have my kids help in the restaurant. Of course I would rather my children stayed in school. I want them to have a better future; that's why we moved to South Africa! A restaurant is an unpleasant business. When it's not busy you worry about no money coming in. When it's too busy you also worry about lack of food suppliers and human resources. But it was a situation where either everyone had to sacrifice or the whole family would go hungry together.

Subsequent to this terrifying experience, Mr. and Mrs. Hong did not hire South Africans in order to avoid union disputes. Thus, Mrs. Hong hired Alice's sister and continued to 
hire people from her family. I asked Mrs. Hong about the risk of hiring migrant workers whom might not have proper documentation. She laughed and said, "You just haven’t been in South Africa long enough to understand how corrupt this country is. Cops only come after the Chinese if they want bribes, not because they are serious about crimes. Every Chinese person in this county has to learn how to protect themselves. The police will rob you if the opportunity comes." Not only did she feel that it was safer to have foreign workers around, she also thought it was easier to manage them. "Migrant workers are more innocent and obedient," Mrs. Hong explained. "And they are willing to work harder for less money. But they also steal. All blacks steal. It's only a matter of different degrees of values. At least migrants appreciate that I provide them stable jobs."

I interviewed Mrs. Hong several times when the restaurant was not busy. One indepth interview was conducted on a quiet Tuesday dinner night for two hours without too many interruptions. It was nearly the end of my field research with this restaurant. Mrs. Hong sat at her usual spot, sipping her tea, when she put down the cup, shook her head, and said to me,

Those Zimbabweans [working at Silver City, including Alice and her sisters] think that I don't know they steal food. Of course I do. I'm just not saying anything because I would rather have people stealing food a little bit here and there than having to train new people and not know what they are going to steal. South Africa wasn't like this when we first came here. Things were better under the white government. There was law and order. There were serious consequences for people if they broke any law. Now black people are the law and they run this country like a joke! 
She then gave me a look and said, "Running a business in this country is not as easy as it sounds when other Chinese people say, 'South Africa is a land of opportunities.' Maybe fifteen to twenty years ago. But now, if you don't know how to deal with corruption, theft, and lies, don't bother to do business here."

One time, Mrs. Hong asked me to get something under the counter because she was too busy talking to customers. That was the first time I went behind the counter, as Mrs. Hong always handled the bills by herself. I realized that there were security cameras all over the restaurant: front entrance, back entrance, cash register, the dining area, and the kitchen. In other words, Mrs. Hong had seen Alice and other kitchen staff eating food all along.

The issue of employee theft is analyzed in depth in Chapter V. What is important to note for now is that there are often contradictions and misconceptions like "all blacks steal." For instance, there have been cases of theft committed by Chinese employees, but those were less likely to be publicly discussed because of the complicated interpersonal relationships (guanxi) within the Chinese community, which are explained in Chapter II.

Mrs. Hong was not alone in being concerned about the legal consequences of hiring migrant workers without proper procedure. In fact, all Chinese employers I met thought the legal risk of hiring South Africans was higher because they are protected by South Africa's labour laws. Furthermore, employers can also avoid taxes when paying their employees under the table_-it's an all-cash economy. There are several reasons why most Chinese people do not use official banks: language barriers, questionable immigration status, or a desire to avoid state financial regulation. Because it is a wellknown fact that Chinese people are doing business in cash, carrying cash around, and 
storing large amounts of money at home, they are targeted for violent crime (see also Chen 2013). For instance, a Chinese man used to work for a wholesale trader business. His job was going around Chinese shops and collecting account money owed. The company hired armed private security to protect him. The first time he was mugged, he was shot in his hand but did not panic. The second time, after he got shot in the back and a co-worker's legs became paralyzed by a bullet, he quit the job. He said he thought that police were involved in the second robbery. He told me, "In the eyes of South Africans," as several other Chinese people also warned me, "we [Chinese] are like a walking ATM."

As noted, when Mr. Li took over a restaurant when the previous owner retired, the South African employees also retired. Mr. Li hired new ones, but the new South African employees were not happy with their jobs. They filed a complaint against Mr. Li with the labour union. Meanwhile, there was a burglary at the restaurant. Mr. Li reported the incident to the nearby police station. A cop found out his income and his address, broke into his house, and began beating him until he opened his combination safe. He was scared the cop would come back. He relocated the restaurant to another area and lived near the restaurant.

When Mr. Li told me this story, he warned me that if anything happened and I had to report to the police, to make sure not to tell them my real income or any personal details, which might lead to ending up like him—becoming an easy target for robbers. Though the incident happened years ago, Mr. Li was still very agitated.

Due to his negative experience with a South African union and the police, Mr. Li thereafter only hired African migrants to work at his restaurant and at home. However, he did not share the same point of view about his black employees as others. Unlike Mrs. 
Hong, Mr. Li appreciated his African employees more (three Malawians and five Zimbabweans) and paid them relatively higher wages with meals and transportation included. He said, "I would pay them even more, but the problem is other Chinese restaurant owners are not happy with me because I ruined the labour market value.” People who belong to a "Chinese community" tend to share and exchange business information. I come back to the concept of community, as well as information exchange, in Chapter II.

I asked Mr. Li the difference between running a restaurant business in China and running one in South Africa. Although he had never operated a restaurant in China, based on his previous employee experience, he responded, "I think the challenges are similar, like keeping good employees, finding stable suppliers, knowing your clientele, staying up to date with market trends, etc. But the competition is much greater in China, and there is a large supply of cheap labour in South Africa." Mr. Li was one of the few Chinese entrepreneurs who explained to me that running a restaurant in South Africa while making good profits is largely due to being able to pay migrant workers below minimum wage. To him, hiring migrant labour to lower costs was certainly an important business strategy, especially for a petty entrepreneur with little capital. However, it also meant he could avoid dealing with South African unions and authorities.

\section{Minimum Wage}

The South African government is in the process of implementing a national minimum wage of R 20 an hour (Ndenze 2018). In other words, there is currently no minimum wage standard, and wage prescriptions differ according to industry, occupation, 
and region. As an example, Table 1 shows the different minimum wages for five occupations under the Wholesale and Retail Sector in Area A and the minimum that employees should get paid per hour, week, and month. Table 2 shows the different minimum wages for domestic workers in Area A and Area B. Most urban cities, including City of Cape Town, City of Johannesburg Metropolitan Municipality, and City of Tshwane (Pretoria) Metropolitan Municipality, are under Area A.

Table 1: Minimum Wages for Wholesale and Retail Sector in Area A (2014-15)

\begin{tabular}{|c|c|c|c|c|}
\hline Job Type & $\begin{array}{l}\text { Min. wage } \\
\text { /hour }\end{array}$ & $\begin{array}{l}\text { Min. wage } \\
\text { /week }\end{array}$ & $\begin{array}{l}\text { Min. wage } \\
\text { /month }\end{array}$ & $\begin{array}{c}\text { Min. wage/ } \\
\text { hour for those } \\
\text { who work for } \\
\text { more than } 27 \\
\text { hours }\end{array}$ \\
\hline Cashiers & R 16.73 & R 752.67 & R 3261.33 & R 17.32 \\
\hline $\begin{array}{c}\text { General } \\
\text { Assistant/ } \\
\text { Trolley } \\
\text { Collectors }\end{array}$ & R 13.43 & R 604.17 & R 2617.87 & R 13.90 \\
\hline $\begin{array}{c}\text { Sales } \\
\text { Assistant }\end{array}$ & R 19.83 & R 892.27 & R 3866.20 & R 20.54 \\
\hline $\begin{array}{c}\text { Shop } \\
\text { Assistant }\end{array}$ & R 15.71 & R 706.93 & R 3063.13 & R 16.28 \\
\hline Merchandiser & R 15.71 & R 706.93 & R 3063.13 & R 16.28 \\
\hline
\end{tabular}

Source: South Africa Department of Labour Online: "Wholesale \& Retail Sector: Minimum Wages for the Period 01/02/2014 to 31/01/2015." 
Table 2: Minimum Wages for Domestic Workers Who Work More Than 27 Ordinary Hours per Week (2015-16)

\begin{tabular}{cccc}
\hline Region & $\begin{array}{c}\text { Minimum } \\
\text { wage/hour }\end{array}$ & $\begin{array}{c}\text { Minimum } \\
\text { wage/week }\end{array}$ & $\begin{array}{c}\text { Minimum } \\
\text { wage/month }\end{array}$ \\
\hline $\begin{array}{c}\text { Area A (including } \\
\text { Johannesburg) }\end{array}$ & R 11.44 & R 514.82 & R 2 230.70 \\
Area B & R 10.23 & R 460.15 & R 1993.82 \\
\hline
\end{tabular}

Source: South Africa Department of Labour Online: "Domestic Worker Minimum Wage Increases from 1 December 2015."

As we can see in Table 1, if an employee works more than twenty-seven hours per week, then that employee is entitled to a slightly higher salary. Since I could not find any job title under "restaurant" on the Department of Labour's official site, I picked five entry-level jobs for Table 1 in order to get a sense of the pay for a job that requires little skill or knowledge and may require physical strength, like working in the kitchen. Table 2 shows the minimum wage for domestic workers (one of the lowest paying jobs in South Africa) who work more than twenty-seven hours per week. In these two tables, I show data from 2014 to 2016 because that was the period in which I conducted fieldwork in South Africa.

The purpose of these two tables is to show that most Zimbabwean kitchen workers make far below any South African minimum wage. For instance, Alice from the Silver City Chinese restaurant, as noted, works eleven hours a day with two hours of break, six days a week. She started at R 85 a day. After working at the same restaurant for four years and only taking two weeks of vacation off each year, her current daily salary is 
R 100. In other words, Alice makes R 9 per hour, or R 11 if the two hours of break are not included in the working hours. In other words, Alice might earn around the same salary as South African domestic workers in Johannesburg; however, most full-time domestic workers are provided with accommodation and live in their employees' cottages. Alice has to pay for her own rent and transportation. Because she cannot afford to live near her workplace, which is in an upper-middle-class suburb, she and her sister share a rental room in Hillbrow, and she spends one and a half hours per day on average commuting six days a week.

In fact, Alice was the highest paid kitchen helper I interviewed. The monthly income of the Zimbabwean workers I interviewed was in the range of R 1700 to R 2200 , and some of the Zimbabwean newcomers had accepted even lower starting salaries such as $\mathrm{R} 1$ 400. This was not the case for Chinese migrant workers. Both Chinese and African employees work nine to eleven hours a day, six days a week, but Chinese employees' wages are at least three times higher than those of black employees. The details of Chinese employees' salaries are discussed in Chapter IV with a comparison to South African monthly incomes. What is worth noting for now is that not only are Chinese employees' wages at least three times higher than those of their African co-workers, but their meals, accommodation, and transportation are also included.

\section{On Becoming Paranoid}

When I asked Mrs. Wong, a take-away restaurant owner who was interested in opening a second branch, which location she was looking for, she responded, "Of course a safe neighbourhood. I even feel my current location is becoming less safe because too 
many black people are moving into this neighbourhood." A few days prior, a person had walked in, grabbed a customer's cell phone, then ran away. Mrs. Wong closed the gate and offered the customer use of the restaurant's phone to call the police or family. Mrs. Wong seemed calm; this was not her first time seeing theft. In fact, she had expected something like this was going to happen. She could, however, be very anxious at work at times.

Before Mr. and Mrs. Wong opened their own restaurant, they worked for around five years at other restaurants. Mrs. Wong's first job was at a take-away restaurant as front counter staff, where she had her first experience of armed robbery:

It was a very busy night. A lot of customers were lined up waiting for their food. There were at least ten orders. We were too busy to pay attention to the door, and also because my boss told us if there are many white people around, black people won't rob us, so we didn't close the gate.... All of a sudden the room was quiet. I raised my head, then saw two armed black men come in shouting at everyone not to move. I also saw another black man standing outside, not letting anyone in or out. That was the first time I experienced robbery. I had just arrived in South Africa three months previously. I didn’t know what to do. Luckily, I remembered my boss had told me if this were to happen to just open the cash machine, which was exactly what I did. The black robbers took the money, then took off.

"Were you scared?" I asked Mrs. Wong. "Not at first," she replied. "It happened so quickly, maybe less than five minutes. My brain was blank, as if I were watching a movie. After the robbers left, some customers called the police, some customers called friends and family. I was thinking, 'I can't call my mom [in China] at work to tell her 
what happened,' and then I started crying, couldn't stop for days. I asked myself, 'Oh my, what kind of terrible country am I living in?",

Perhaps because of this experience, Mrs. Wong always closed the gate as soon as the sun went down. If she found out that her husband or an employee forgot to do so, she screamed at them regardless of whether there was a customer in the store. Generally, Mrs. Wong was friendly and pleasant to people, but when it came to "crimes" and suspicious looking "black people," which in her view were often associated with each other, she lost control over herself. When I first began to know Mrs. Wong, her constant shouting and suspicious mind made her difficult to talk to. But after hearing more stories of her terrifying experiences, and how her husband was mugged twice and her sister-in-law was beaten up by robbers, it was not hard to understand where her paranoia came from.

One time, a new shop in the same plaza as Mrs. Wong's restaurant was broken into and robbed at night. The next morning, I went to work and Mrs. Wong told me what had happened. She suggested we find out more information from the neighbours, so we joined others who were in front of the shop chatting. One store owner said, "I already told them [the new shop owners] they need to install metal bars. Just an iron gate is not enough." Another owner added, "I knew this was going to happen. I told them to at least get an alarm or camera."

In fact, the plaza had an entrance gate and was closed off every night. There was an on-site security guard twenty-four hour per day and a patrol car from the security company every night. But I stood there and found myself nodding and agreeing with their point of view. That was when I realized perhaps I, too, had adopted this "extra cautious" mentality. 
If this incident happened in Canada, I assume most people would not blame the new shop owners for not having installed metal bars or surveillance equipment, and would instead condemn the robbers. In South Africa, this sort of victim-blaming discourse is common. It is not that people do not blame criminals. They do, and they know crime is a problem. But it is too frequent, and people start to feel they need to look after their own. All of these shop owners even contributed fees to hire the security company, and yet they still felt responsible for protecting their own assets. It is a similar in logic to the common advice people give, as noted in the introductory chapter, about keeping the windows rolled up when driving in Johannesburg and keeping valuables out of sight through the car windows. The mentality is that if you do not, you are sending an "invitation" to thieves to "smash and grab." In other words, it is kind of the driver's responsibility to not provide any opportunity for potential theft.

The Chinese Consulate-General in Johannesburg had held several high-level meetings with the provincial minister of safety and security and various Chinese communities to address these problems (Park 2009b). They issued regular warnings to remind Chinese residents how to prevent crime and stay safe in Johannesburg. ${ }^{22}$ Figure 8 shows one of the notifications that was published in 2016 with seven safety tips for the Chinese people in South Africa (Consulate-General of the People's Republic of China in Johannesburg 2016).

\footnotetext{
${ }^{22}$ See, for example, the notifications posted on the official website of the Consulate-General of the People's Republic of China in Johannesburg during recent years: “提醒在约翰内斯堡中国公民注意安全 Remind Chinese citizens to pay attention to safety in Johannesburg” (2013); “驻约堡总领馆提醒领区侨胞关注自 身安全 The Consulate General in Joburg reminds overseas Chinese to pay attention to their safety” (2014); and “提高安全意识、避免遭遇抢劫切记六个“不”一中国驻约翰内斯堡总领事馆领事提醒 Raise Safety Awareness and Avoid Robbery, A reminder of Six 'Don't'-from Consulate General of Consulate General of China in Johannesburg" (2015).
} 
Figure 8: Safety Tips for the Chinese Residents in Johannesburg

\section{近期抢劫案件频发, 驻约堡总 领馆提醒侨胞注意安全}

2016/09/06

近日, 约堡地区侨胞生活、工

作聚集的商城区、唐人街、

Rivonia 地区以及部分高速路出

口、红绿灯处发生多起涉我侨

胞拦路抢劫、入室盗窃案件,

部分侨胞受到人身伤害和财产

损失。结合近期我们掌握了解

的侨胞被抢、被盗案件情况，

驻约翰内斯堡总领馆再次提醒

领区内广大侨胞务必注意安

全, 尤其留意以下事项:

一、安全是侨胞在南生活、

工作的第一要素, 要时刻紧绷

这根 “弦” , 任何情况下都不

放松警惕。切勿因近期针对侨

胞的恶性伤亡案件减少, 误以

为治安状况有所好转而掉以轻

心。

二、开车时, 尤其在红绿灯

路口、高速路下道口, 要留意 是否有其他车辆跟踪。遇有跟 踪, 尽快前往附近人群集中的 地区, 并采取措施寻求救助。

三、切勿将手提包、行李箱 等易引起关注的物品, 随意放 置在副驾驶座位或车辆中其他 明显位置。

四、女士或防卫能力较弱 者, 尽量避免独自驾车外出, 减少在街道、社区等道路上步 行。

\section{A number of cases of robbery have occurred recently, the Consulate-General in Joburg reminds overseas Chinese to pay attention September 6, 2016}

Recently, there have been many cases involving robbery and burglary close to where Chinese nationals usually live and work, Chinese malls, Chinatown, and the Rivonia area, as well as hijackings and break-ins near freeway exits and intersections. Some overseas Chinese have suffered personal injury and property damage. Based on what we understand in light of the recent cases, the Consulate General in Johannesburg once again reminds Chinese nationals to pay attention to safety and pay particular attention to the following issues:

First, safety is the first priority for overseas Chinese living and working in South Africa. Always stress your "guard," and do not relax under any circumstances. Do not drop your guard and mistakenly believe that the state of public security has improved because of the recent decline in the number of cases of assaults against overseas Chinese.

Second, when driving, especially in intersections with traffic lights and freeway exits, it is necessary to check if you have been followed. If this is the case, go to a nearby area where there are more people and take measures to seek help as soon as possible.

Third, do not put handbags, luggage and other valuable items on the passenger seat or other visible places in the vehicle.

Fourth, women or those with weak defence capabilities should try to avoid driving by themselves and reduce walking outside in streets or communities. 
五、经商过程中确需运送大 笔现金、大量货物的情况，尽 量雇佣专业保安公司和人员协 助运送。

六、留意家庭、公司中所雇 佣人员，尽可能多的了解、掌 握雇工身份信息、家庭状况、 结交朋友，防止内外勾结，联 合作案。

七、如遇抢劫、盗窃案件, 务必保持冷静, 一切以确保人 身安全为前提, 避免与抢罒发 生正面冲突。
Fifth, for businesses that need to transport large sums of cash and large quantities of goods, if it is possible, hire professional security companies and personnel to assist.

Sixth, pay attention to employees who work in your company and home and understand as much as possible about their family and friends, in order to prevent internal and external collusion.

Seventh, in the event of robbery or theft, it is important to keep calm and prioritize your personal safety. Avoid direct confrontation with robbers.

Source: Consulate-General of the People's Republic of China in Johannesburg (2016)

Similar warnings were also provided by Chinese officials to Chinese tourists, as there have been a number of cases where Chinese tourists were followed and mugged at gunpoint. For instance, in 2015, after a group of Chinese tourists left the airport, five armed robbers with three cars blocked their van and robbed them of everything they had, leaving some of the travellers with minor injuries (Xinhua Net 2015). In 2017, several Chinese tourists were seriously injured after being robbed at gunpoint, and the Chinese Consulate-General in Johannesburg put out safety tips for Chinese tourists visiting Johannesburg. See Figure 9 for the Chinese news article about this incident and the advice provided, which was published in China News Service, one of the largest stateowned news media outlets in China (Song 2017). 
Figure 9: Safety Tips When Travelling in Johannesburg

中新网约翰内斯堡 2 月 5 日电 （记者 宋方灿）

最近一周内, 南非约翰内斯堡 (约堡) 地区连续发生两起劫匪尾 随中国旅行团至酒店持枪抢劫案 件，造成数名人员受伤和巨额财 物损失。

当地时间 2 月 4 日晚, 中国 国内一个旅行团结束在南非的参 观游览, 抵达约翰内斯堡机场附 近一酒店办理入住, 遭 4 名多徒 尾随后冲进酒店抢劫。店内游客 四散逃跑, 3 名来自广西柳州的 一家三口不幸被歹徒拦住抢劫。 在反抗过程中, 歹徒开枪, 导致 三名中国游客全部受伤。

上周四, 约翰内斯堡地区还 发生另外一起针对中国旅行团的 武装抢劫案, 游客行李箱和护照 等财物被抢, 所幸无人员伤亡。 目前，被抢人员已经回国。

2 月 5 日, 中国驻约翰内斯堡 总领馆提醒来南非旅游或在约翰 内斯堡转机的中国公民, 提高防 范意识, 加强安全防护, 掌握紧 急情况正确应对措施。特别注意 以下几点:

一、千万不要在机场兄换当 地货币。机场来往人员众多, 可 能有劫匪眼线混杂其中, 兄换大 额货币易被跟踪抢劫。

二、随身携带和使用大量现

金。南非金融体系发达，国内银 行发行的银联卡或威士、万事达 等多种银行卡在南非住宿、餐 饮、购物、租车、娱乐均可使
China News Service, Johannesburg, February 5 (Reporter Song Fangcan)

In the past week, there were two cases of Chinese tourists in the Johannesburg (Joburg) region of South Africa being followed to their hotels and robbed at gunpoint, which resulted in several injuries and huge losses of assets.

On the evening of February 4, local time, it was a tourist group's last day in South Africa. They arrived at a hotel near Johannesburg Airport to check in. Four bandits ran into the hotel. The tourists fled and scattered. Unfortunately, three tourists from Liuzhou, Guangxi, were stopped by the robbers. During the incident, the criminals opened fire and caused injury to all three Chinese tourists.

Last Thursday, another armed robbery against another Chinese tourist group took place in the Johannesburg area. The travellers' suitcases and passports were looted. Fortunately, no casualties were reported. At present, these tourists have returned to China.

On February 5, the Chinese Consulate General in Johannesburg reminded Chinese citizens when travelling to South Africa or transiting through Johannesburg to increase their awareness to prevent and protect themselves. In order to take proper precautions, pay special attention to the following points:

First, do not exchange local currency at the airport. There are many people in and outside of the airport, and there may be robbers watching and following if you exchange large amounts of money.

Second, do not carry and use a lot of cash. The financial system in South Africa is well developed. UnionPay cards issued by domestic banks or various bank cards such as Visa and MasterCard 


\begin{tabular}{|c|c|}
\hline $\begin{array}{l}\text { 用, 除小费外一般无需现金支 } \\
\text { 付。 }\end{array}$ & $\begin{array}{l}\text { can be used in South Africa for accommodation, } \\
\text { catering, shopping, car rental, and entertainment. } \\
\text { Generally, no cash payment is required except for } \\
\text { tips. }\end{array}$ \\
\hline $\begin{array}{l}\text { 三、不露财、不炫富, 行事 } \\
\text { 要低调。不要佩带昂贵的珠宝首 } \\
\text { 饰、手表、携带奢华手包等。如 } \\
\text { 有需要, 请务必在当地安全、正 } \\
\text { 规的商店采购钻石、珠宝等贵重 } \\
\text { 商品, 并尽快离境。 }\end{array}$ & $\begin{array}{l}\text { Third, do not show off wealth, and act in a low-key } \\
\text { manner. Do not wear expensive jewelry, watches, } \\
\text { luxury handbags, etc. If necessary, be sure to } \\
\text { purchase precious goods such as diamonds and } \\
\text { jewellery from legal local shops. Once purchased, } \\
\text { leave the country as soon as possible. }\end{array}$ \\
\hline $\begin{array}{l}\text { 四、尽量不乘坐夜间抵达的 } \\
\text { 航班。夜间警力薄弱, 机场周边 } \\
\text { 及机场高速路出入口抢劫案件多 } \\
\text { 发。 }\end{array}$ & $\begin{array}{l}\text { Fourth, try not to take flights arriving at night. The } \\
\text { police force at night is weak, and there have been } \\
\text { many cases of robbery at the airport entrance and } \\
\text { exit of the airport highway. }\end{array}$ \\
\hline $\begin{array}{l}\text { 五、不要将护照等证件与现 } \\
\text { 金一起存放。以免被盗、被抢, } \\
\text { 影响回国或下一步的行程。 }\end{array}$ & $\begin{array}{l}\text { Fifth, do not put passports and other ID documents } \\
\text { with your cash. If you are robbed, this will prevent } \\
\text { it from affecting your return trip or your schedule. }\end{array}$ \\
\hline $\begin{array}{l}\text { 六、不要激怒劫匪或与劫匪 } \\
\text { 对抗。如不幸遭遇抢劫, 务必要 } \\
\text { 保持冷静, 一切以确保生命安全 }\end{array}$ & $\begin{array}{l}\text { Sixth, do not provoke or confront robbers. If you } \\
\text { are unfortunately facing a robbery, be sure to stay } \\
\text { calm and prioritize your safety. }\end{array}$ \\
\hline
\end{tabular}

Before these incidents with the Chinese tour groups were reported and aired on the news, many people in China had already heard about Johannesburg being an unsafe place. Most Chinese interviewees mentioned that before coming to South Africa, they had heard stories about immigration and customs officers looking for bribes, and police colluding with criminals to rob Chinese people. Once they arrived in Johannesburg, they either heard terrifying stories from other Chinese people or witnessed or experienced their own. During my fieldwork, I heard similar stories regularly. For instance, after I told a Chinese interlocutor I went to a Chinese grocery store, she told me that the grocery owner had been almost tortured to death by robbers. Another time an interlocutor at a different Chinese store told me it was under new ownership because the previous owner was shot to death right in front of the shop. 
Not only did I hear these stories regularly, but Chinese people also liked to give me warnings as a way to show concern. For instance, when I told a Chinese interlocutor that I was visiting Soweto, the largest township in South Africa, he said, "Are you out of your mind?" He told me when he first arrived in Johannesburg, a relative and some friends warned him not to go out by himself or to go out at night. Although he had heard about Johannesburg, he did not believe them: "Look, the environment is so good and people are smiling. How dangerous can it be?" He thought his relative and other Chinese people were exaggerating and being overprotective. But after having lived in Johannesburg for eight years, he advised me, "There is a reason why we say 'If you haven’t been mugged, you haven't lived in South Africa long enough (没被抢劫过就不 算住过南非).' You just don't know when it will happen. The only thing we can do is to prevent crime and to protect ourselves. Better listen to us [senior Chinese immigrants]." This interlocutor was robbed twice, and one of his close friends was murdered. But he was one of the few Chinese migrants I met who was certain about staying in South Africa.

Most Chinese migrants feel uncertain about Johannesburg. It has lovely weather, beautiful and diverse landscapes, a high level of food safety, clean air, and a green environment. At the same time, its high crime and corruption rates present challenges that Chinese migrants face frequently. Every Chinese migrant I met in Johannesburg had personally, or known someone who had, experienced at least one robbery, burglary, car hijacking, break-in, shoplifting incident, and so on. ${ }^{23}$ In addition, the majority of Chinese

${ }^{23}$ See Harrison et al. (2012) and Chan (2013), as their interviews with Chinese migrants in South Africa also revealed crime to be a main issue of concern. 
migrants I spoke to, regardless of their regional origins, educational background, or occupation, all claimed that they had been asked for bribes. My ethnographic data is consistent with sociologist Yoon Jung Park’s. As she writes,

The biggest challenge regarding life in South Arica, however, is crime. Anecdotal evidence suggests that most Chinese immigrants have fallen victims at least once or twice to break-ins and armed robberies. During the course of recent interviews with new Chinese immigrants, every single person mentioned at least once such incident. The fact that all of these new immigrants were engaged in some sort of small retail business and dealt in some quantities of cash makes them soft targets for South Africa's criminal element. (Park 2009, 160)

I come back to the issue of corruption in the next chapter. It is important to note that all of these "criminality" discourses are linked to "blackness" and have shaped mindsets about "black people"; once Chinese im/migrants live in South Africa, the local high crime rates also seem to confirm their perceptions of "black people." As sociologist Guangzhi Huang (2018) argues, generally Chinese people are familiar with the negative perceptions against "blacks" or "Africans." 24

Huang (2018) conducted field research in Guangzhou, the capital city of the Guangdong province, where the largest African community is located in China, to examine Guangzhou's Public Security Bureau role in constructing the perception of "Africans" and how the system makes Africans the main targets of police. Huang argues that "Africans" have often been constructed as sanfei (三非 triple illegal) by the media and the Chinese public. Sanfei refers to "those who enter, stay and work in China

${ }^{24}$ More discussion on race and racism, along with examples drawing from the interaction between Chinese employers and Zimbabwean employees, is provided in Chapter IV. 
illegally" $(2018,5)$. As Huang explains, "Although the term does not single out any racial group, news media in China have constantly linked it to Africans so much so that in many online forums, Chinese simply label Africans 'sanfei blacks"” (ibid). Consequently, terms like "Africa" or "blacks" often have negative connotations such as "chaos, crime, drugs, backwardness, disease and poverty, all of which are seen as the antitheses of modernity" (22). Huang argues that this construction of "Africans" and "blacks" is used to justify Chinese police officers targeting African communities in China.

On top of the prevalent negative perceptions of and biases against black Africans in China, I observed in South Africa that one of the factors that contributes to this problematic stereotype of "blackness" is the legacy of apartheid, as much racial inequality, such as racial discrimination and black poverty, has its roots in apartheid (Gradin 2012; van de Berg 2011; Wilson 2011). But without understanding this influential history, most Chinese migrants jump to the conclusion that blacks are overrepresented in poverty and crime because of their poor ethics. However, I do not wish to imply that it is the fault of the Chinese for not learning South Africa's history. A large number of new Chinese migrants are from rural areas with limited educational access, and they do not speak or read much English or any local language. Issues of language and cultural misunderstandings faced by recent Chinese migrants are elaborated on in Chapter IV.

The issue of safety, though, is not a concern for Chinese migrants only in South Africa. Based on sixteen months of ethnographic fieldwork in Zambia, Di Wu (2014) observed that the main issue of concern for Chinese migrants was crime as well. Like Mrs. Wong, who got anxious when the gate to her restaurant was not closed, Chinese 
people in Zambia also keep the gate closed and build walls "since they both exclude strangers from the property, and protect the family from the danger outside. They are considered an 'efficient' device of self-protection" (Wu 2014, 58). For instance, the family that Wu was staying with paid $\$ 30000$ USD to build walls around their onehectare farm, which cost more than one-third of the total budget to build the farm.

Like me, $\mathrm{Wu}$ also noticed that terrible robbery and murder stories were told again and again, and passed on from one Chinese person to another, in order to warn each other. $\mathrm{Wu}$ argues that whether these rumours were real or not, all had tremendous effects on Chinese migrants' feelings of anxiety. As he writes, "Among the Chinese migrants, anxiety is like a virus. It is contagious and gets amplified as it passed from mouth to mouth" (Wu 2014, 62). Since these rumours all carry a negative image of "the outside" and "the outsiders," as though Zambia is a fearful place and Zambians are dangerous people, Wu argues, Chinese migrants experience daily mundane life and activities anxiously. As he explains:

They are anxious that they will be cheated when doing business with the local Zambians; they are anxious that they might be mugged or stabbed when walking on the street; they are anxious that their house would be broken in to at any time and they are anxious that all the things they have saved up after days and nights of hard work would disappear overnight. Anxiety is their everyday mode of existence in Zambia. (74)

Wu further argues this shared anxious attitude among the Chinese in Zambia is one of the reasons that they are less likely to socialize with their Zambian hosts.

The degree of anxiety that Wu described, I suggest, is felt, if not equally then perhaps even more, among the Chinese in South Africa, especially in a city like 
Johannesburg, where crime remains an ever-present threat to everyone who lives there, not just the Chinese. For instance, according to a survey published by South African Cities Network, more than $60 \%$ of interviewees who lived in Hillbrow said they were scared of letting their children play outside because of their fear of crime, almost $60 \%$ were scared of running a business from home, and nearly $50 \%$ were scared of going to open spaces or parks (Nicolson 2017). Due to warnings and experiences, many Chinese believe they are targets for crime; as Wu describes it, "anxiety is like a virus" $(2014,62)$. Accordingly, as mentioned previously I use the term "everyday racialized insecurities" to describe Chinese migrants' anxiety.

Whether it is anxiety that causes the Chinese to believe they are being targeted for crime, or vice versa, there is a shared fear of crime. These feelings of anxiety and insecurity, I argue, contribute to one of the reasons that Chinese owners of small- to medium-scale businesses in South Africa prefer to hire African migrant workers. According to local Chinese media, inside Chinese malls, foreign migrants account for 70 to $90 \%$ of workers, and at some malls this even reaches $100 \%$ (Song 2015a). So what percentage of the Chinese restaurant workforce is made up of African migrant workers? My impression is that there were migrant workers in every restaurant I visited, including those where I conducted fieldwork. ${ }^{25}$

Fenglan Chen (2013) makes a similar suggestion. Chen conducted fieldwork in Johannesburg for her doctoral dissertation at Xiamen University, Fujian province, China. She visited grocery stores, restaurants, retail shops, and malls owned by newly arrived

\footnotetext{
${ }^{25}$ On top of the five restaurants that composed my field sites, I interviewed Chinese owners, Chinese employees, and Zimbabwean employees from at least ten more restaurants. Some Zimbabwean interviewees were no longer working at Chinese restaurants and they did not remember the restaurants' names.
} 
Chinese migrants. She notes that regardless of the size of the business, almost every business employed at least one African migrant worker. As such, she writes, "The new Chinese migrants' economic activities in South Africa cannot possibly be completely detached from this group of illegal immigrant workers (中国新移民在南非的经济活动 已经完全无法摆脱非法移民劳工这个群体了)”(Chen 2013, 143).

During interviews, I asked several restaurant owners whether they would hire local South Africans if the salary were the same. There were several answers ("South Africans are lazy;" "I don't want to deal with unions;" "migrants work harder"), but all restaurant owners indicated that they preferred non-South African employees. When Chen $(2013,143)$ asked Chinese shop owners a similar question, she also got similar responses about the trouble with hiring South African workers: too much trouble with unions, laziness, constant strikes, and difficult labour laws.

Let's go back to the point Mrs. Hong raised earlier. When I asked about the benefits of employing migrant workers, the first thing she explained, before she talked about wages, was, "migrant workers are more innocent and obedient.” Even though Mrs. Hong did not really trust any black person, she had to employ some African workers in order to make the business profitable. In her view, South Africans were more difficult to deal with since they had more resources (e.g., labour unions) and stronger local contacts (e.g., police). As a result, she preferred to hire migrants as she could have more control over them, because she knew the reality was that her Zimbabwean employees needed the work desperately.

The preference of hiring migrants over local workers should not be taken to mean that no Chinese employers hired locals in South Africa. There is no denying that the fact 
that African migrant workers are more likely to accept lower pay and longer working hours is an attractive factor to Chinese businesspeople, particularly for petty entrepreneurs who struggle with little capital and limited resources. Lowering costs is certainly an important business strategy, but it is not the sole determining factor in the case of South Africa. To many Chinese employers, hiring migrant workers is also a way to cope with South Africa's corruption and crime.

It is important to note that employing migrant workers is a common business strategy being practiced by many entrepreneurs in South Africa, including South Africans and non-Chinese migrants. For instance, six Zimbabweans I interviewed had worked for black South Africans, Indians, or Ethiopians prior to their jobs at Chinese restaurants. A Zimbabwean woman told me the reason she came to work in Johannesburg was that her husband, a farm worker in Limpopo, had not been paid and was deported from South Africa. The white South African employer had reported her husband as an illegal immigrant to the authorities. ${ }^{26}$ Although various local Chinese business associations and Chinese officials note that it is more dangerous to hire migrant workers (see Chapter V), many Chinese employers still see at least three benefits to doing so: 1) lowering their costs, 2) avoiding labour regulations, and 3) protecting themselves from serious crimes.

\section{(Dis)similarity Through Food and Insecurities}

In South Africa, although it is common to find Chinese and Zimbabwean (or other African) migrants working together at the same restaurants, it is rare to see them having

\footnotetext{
${ }^{26}$ Without further data collection and investigation, I am unable to extend this analysis of non-Chinese business owners who hire Zimbabweans. See, for example, Blair Rutherford's (2008) work about Zimbabwean migrant farm workers in Limpopo, the border between South Africa and Zimbabwe.
} 
meals together. At every restaurant where I conducted fieldwork, Chinese employers and employees sat at the same table and ate lunch and dinner together (usually 2:30 p.m. for lunch and 8:30 p.m. for dinner). The Zimbabwean staff usually found a place in the kitchen to eat their meals in smaller groups.

As noted, some restaurants provide meals for African staff or allow them to cook their own meals - they usually have $\operatorname{pap}^{27}$ with meat and vegetable stew for lunch and eat in the kitchen. Other restaurants do not. Every afternoon in Chinatown, it is common to see African co-workers sit under a tree, in smaller groups, and together eat the lunch they have brought to work. They eat mostly bread. Inside the restaurant, the Chinese servers set up the table while waiting for the owner/chef to make the lunch. It is usually two dishes of vegetables, one meat dish, and a bowl of rice. What the Chinese owner/chef cooks for the staff meals is not necessarily on the menu. On ordinary days, the owner/chef just cooks with whatever ingredients are left from that day, but they also provide more exclusive meals for special occasions.

Anthropologist Mary Douglas argues that how people make and eat their food can define a group's boundary, writing, "By endowing food choice, preparation, and eating with such a symbolic load, cultures invest heavily in themselves whenever they engage in eating" (1984 as cited in Davis 2002, 73). The "father of food anthropology," Sidney Mintz, has also pointed out that we can examine people's interactions and relations to each other, both physically and symbolically, through food: “[People’s] food preferences are close to the center of their self-definition: people who eat strikingly different foods or similar foods in different ways are thought to be strikingly different, sometimes even less

${ }^{27}$ Thickened maize porridge. It is called lsitshwala in the IsiNdebele language in Zimbabwe. 
human" $(1986,3)$. Indeed, just by looking at what and where Chinese and Zimbabwean staff eat, it is clear where the boundary between "us" and "them" is drawn.

But the division between "us" and "them" is not always about race or nationality. During staff meals, if there were Chinese from different regions, sometimes the conversation turned into a debate of the "proper" way to prepare certain dishes. Chinese food, after all, is incredibly diverse. As Yudan Chen from the Fudan University in Shanghai argues: "Variety is our country's culinary hallmark, but it doesn't help us pin down exactly what it means to be Chinese.... The difficulty in defining Chinese cuisine cannot be simply attributed to the fact that China is large and complex" (2017).

When I asked a Chinese chef how he felt about the food he cooked for South African customers, he said to me, “This is, and is not, Chinese. We just don't eat it.” I found what he said can not only describe the modification of Chinese food; it may also explain the reproduction of Chinese diasporic identity. Food can be easily circulated, imitated, and modified to adapt to South African customers' tastes, but how about migrants' identity? Can it be easily modified to become less Chinese and more South African just like the food they cook? Do they even want to be South Africans? In the following section, I first define what I mean by "identity," then discuss it in the context of the Chinese in South Africa.

\section{Identity as Process}

In his important essay, "Cultural Identity and Diaspora", Stuart Hall (1990) points out there are at least two ways of thinking about identity. First, it is defined "in terms of one, shared culture, a sort of collective 'one true self,' hiding inside the many other, more 
superficial or artificially imposed 'selves,' which people with a shared history and ancestry hold in common" (Hall 1990, 223). Hall argues that even though such a conception of identity played a critical role in all postcolonial struggles, it is grounded in "the act of imaginative rediscovery" (224) to believe that there is an "identity" waiting to be found. Identity in this sense is understood as a collective, shared history among individuals that is considered to be stable.

Hall then offers a second way of thinking about identity to challenge the meaning and representation of "one people" being a fixed essence from the past. As he states, "Cultural identity, in this second sense, is a matter of 'becoming' as well as of 'being.' It belongs to the future as much as to the past. It is not something which already exists, transcending place, time, history, and culture" (Hall 1990, 225). To explain the process of identity formation, Hall argues that rather than thinking of "identity as an already accomplished fact, which the new cultural practices then represent, we should think, instead, of identity as a 'production' which is never complete, always in process, and always constituted within, not outside, representation" (222). In this regard, identity is understood as an unstable process that can never be consistent; it always depends on sociopolitical situations.

Identity is constructed, and diasporic identity is always in a process of "becoming" rather than "originating," yet most newly arrived Chinese im/migrants in South Africa I met were not so interested in the identity process, as they had no doubt about their "Chinese" identity. Generally speaking, discussions of Chinese im/migrants' identity in South Africa and in Africa have been less about "identity" itself and more about the representation of "China" on this continent (e.g., see Chen 2013 on South 
Africa; Sheridan 2018 on Tanzania; Wu 2014 on Zambia), with one exception. Park (2008a, 2008b, 2009, 2010) has argued that many Chinese South Africans experience an "identity crisis."

Currently there are fewer than ten businesses operating in Johannesburg's First Chinatown, with some Chinese residents, mostly laoqiao (older-generation Chinese in South Africa). The two Chinatowns in Johannesburg are not just two different spaces; they also represent regional and generational differences between old and new Chinese diasporas. As noted, Chinese South Africans tend to support the restaurants in First Chinatown, which all serve old-style Cantonese cuisine. Recent migrants prefer to dine in New Chinatown, where they can find almost every regional cuisine available.

One time I had lunch with Chinese South African friends at a northern-style Chinese restaurant in New Chinatown. They requested that I come to this restaurant because they were curious about the food. English was their native language, and they spoke a little bit of a Cantonese dialect with their parents at home. They found it difficult to communicate with most Chinese newcomers because they did not understand Mandarin and the newcomers spoke little to no English. They asked me to order for them. When a Chinese South African friend bit into a northern-style Chinese noodle, she said, "This food tastes so foreign to me."

According to Park, during apartheid, because Chinese South Africans felt "rejected by and excluded from South Africa, China became a refuge and a place of belonging in their imagining" (2008a, 87). Regardless of whether they had a real or imagined connection to China, Chinese South Africans needed the idea of a "great China" to remain alive, something that lasted for several generations, in order to cope 
with social exclusion. As Park argues, "The construction of their Chinese South African identity, and in particular the unique, 'superior' Chinese aspects of their identity, were both a form of protest and a means of survival" (87). As such, Park describes a state of mind where the idea of "China" is an important way for Chinese South Africans to regain lost pride.

Nonetheless, Park argues (2009) that the new Chinese im/migrants, those who have been coming to South Africa since 1990, are challenging the Chinese South Africans' idea of "great China." Many Chinese South Africans do not get along with the Chinese newcomers. They complain about new Chinese immigrants' inability to speak English (or Afrikaans) and their illicit activities, such as the involvement of Chinese triads in abalone and rhino-horn smuggling (Park 2009). The resentment is growing gradually, as an interviewee told Park:

I don't agree with many actions of the new immigrants. I hate when I see a lot of the behaviour is bringing down the reputation of the Chinese in Pretoria. Before, in Pretoria, I guess elsewhere as well, the credibility of the Chinese, the credit worthiness, as well, was very high. Today, it's not so. We are being questioned because of all the - call it fraudulent - dealings that have happened, and all this has come about because of the new immigrants... They ruined the good reputation of the local Chinese who were here... the fact that they are Chinese makes me even more unhappy that Chinese could behave in that way... so the unlawful elements...they have pulled down the general reputation of the Chinese in South Africa. $(2009,159)$ Park argues that this generational conflict between the old and new diaspora is a consequence of apartheid. The Chinese South Africans had to be extremely "well behaved" in order to survive and be tolerated by the white South Africans. They felt their 
hard-earned and honoured "labels" like "law-abiding, apolitical, quiet, honest, industrious, low-key, and conservative" should be passed on and maintained within the Chinese community as a whole (Park 2009, 158). The new im/migrants, on the other hand, see the Chinese South Africans as "quaint and out-dated," and they question how "Chinese" these Chinese South Africans are, as many of them do not speak Chinese (ibid).

\section{To Go Abroad is To Return}

While Park sees the tensions between old and new diaspora as ongoing construction and contestation processes around Chineseness, Chen (2013), on the other hand, argues that new Chinese migrants tend to focus only on economic activities, and the extent of newcomers' willingness to integrate is generally low. She points out that the new im/migrants from China share several characteristics that make it difficult for them to integrate into South Africa. First, most new im/migrants came to South Africa because of kin-based networks. Since they usually get help and support from the network they belong to, they do not need much interaction with the local people. Second, many new $\mathrm{im} /$ migrants are less likely to learn local languages or adapt to local culture because they do not intend to live in South Africa permanently.

My interviews with most Chinese im/migrants resemble Chen's analysis. As the majority of them arrived from China less than ten years, they might not all agree with what constitutes "Chineseness" or what is the best Chinese food, but rarely I did hear them questioning their national and ethnic identity as Chinese or expressing a desire to be South African. Most of them rejected the term "immigrant," and some disagreed with 
"overseas Chinese" when I used these terms to describe their diasporic status. They suggested that they were “Chinese living in South Africa (住在南非的中国人)," as they saw themselves less as immigrants and more as "sojourners" who intended to make and save money for several years and then return to China. When I asked Chinese interviewees how likely they were to continue to live in South Africa in the future, the most common response I got was, "Let's see how things go." I rarely heard a Chinese newcomer plan to settle down in South Africa permanently. This phenomenon is not only clearly evident with the Chinese restaurant employees, but also in the context of Chinese employers, as some of them mentioned they would sell their businesses to return to China if necessary - for instance, if South Africa's economy became worse or they had to provide care for their elderly parents back home.

This "sojourning" tendency can be explained by anthropologist Biao Xiang's (2017) argument about the "Chinese dream." Xiang has conducted long-term ethnographic research on the emigration from China of unskilled and semi-skilled labourers who work abroad temporarily for a few years. In an interview, he suggests that these Chinese migrants go abroad not to stay overseas but to earn and save up money so they can come back home and live more comfortably. As he states (English translation as follows):

東北農村的這些人出國, 他要想的是什麼呢? 不是一個法國夢或者說日本夢, 他做的還是一個「中國夢」。但問題是, 他要在中國做中國夢的話, 永遠也完 成不了。你看房價天天在往上漲, 以他在中國打工、務農, 就不要再想了... 那你為了實現這個中國夢要怎麼辦呢?... 出國就是一個辦法。其實出國的工 資並不一定比國內的工資高好多一以前是高出五六倍, 現在也就是兩三倍... 
那你為什麼還要去? 在國外, 正因為你完全沒有社會生活, 沒有娛樂, 天天工 作, 而且工資基本能夠保証支付, 所以你能夠月月看到很高額的積蓄。你其實 是把自己作為一個社會人的交友、消費需求壓到最低, 然后把自己積蓄的能量 強迫性地放到最大。出國就是把自己扁平化為一個純粹的勞動者和積蓄者, 從 而能夠達到躍進式的積累。所以出國是為了躍進式地追求中國夢, 完全不是在 追求生活意義上的日本夢、法國夢或者美國夢。28

When someone from the northeastern countryside leave China, what does he think about? ${ }^{29}$ Not a French dream or a Japanese dream, he wants a "Chinese dream.” But the problem is that if he wants to make a Chinese dream in China, he will never finish it. You see that housing prices rise every day; if you are a wage labour or a farmer in China, don't even bother to think about it. So what do you do to grip this Chinese dream? ... Going abroad is one way. In fact, the wages you earn from going abroad are not necessarily much higher than you can earn domestically - they were five or six times higher than before, but now just two or three times... Then why do you go? In foreign countries, you have no social life at all, no entertainment, you just work every day, and only spend on basic needs, so you can see a high amount of savings every month. You actually minimize all of your consuming demands and social needs, and then maximize all of your energy into saving compulsively. Going abroad is to reduce yourself into a pure labourer and a money saver, so that you can achieve fast accumulation. Therefore, going abroad is a quick and realistic way to pursue the

\footnotetext{
${ }^{28}$ Here I have reproduced the original article, which was published in traditional Chinese characters, as the interview was conducted by a Hong Kong-based media outlet.

${ }^{29}$ In Chinese, there is no differentiation in the spoken language between "he" or "she," but in writing "he" is used when the gender of a group of people is unclear, as a somewhat gender-neutral pronoun.
} 
Chinese dream. It is not a Japanese dream, a French dream, or an American dream in the pursuit of the meaning of life.

To conceptualizing Chinese migrants as "sojourning" is not new, certainly not in North America. The "sojourner" concept was originally developed by Paul C.P. Siu (1952, 1987) based on long-term ethnographic research conducted among Chinese laundry workers in Chicago from the 1940s to 1960s. Siu argues that due to the strong anti-Chinese sentiment in the United States (e.g., Chinese Exclusion Act), American customers in general only interacted with Chinese laundry workers on an impersonal level, as a "laundry machine" or a "thing." As a result of racial discrimination and segregation, Chinese immigrants usually lived close to each other in the same community (i.e., Chinatown), and longed to return to China. In Siu's explanation, sojourners are not characterized by the length of their residence but by their orientation towards their homeland and their low levels of willingness to integrate into a host country. A sojourner might have spent the majority of his lifetime in the United States for economic betterment, but he still "clings to the culture of his own group" (Siu 1952, 34) and "is unwilling to organize himself as a permanent resident in the country of his sojourn" (ibid). In other words, it was not only because Chinese laundry workers were unable to integrate that they were marginalized and isolated by mainstream American society and hence unable to establish social relationships outside of the Chinese community.

Canada shares a similar Chinese migration history. Lily Cho (2010) points out that in 1931, Chinese people made up less than $1 \%$ of the Canadian population, yet one out of every five restaurants was owned by Chinese, and one out of every three male cooks was Chinese. In most small Canadian towns, the first restaurant ever established was the so-called "Chinese café," which served both Chinese and Western food. Cho 
argues that even though Chinese immigrants played an important role in shaping the Canadian restaurant industry, they have been largely neglected in Canadian history. Siu used the term "immigrant economy" to define an ethnic-specific labour market. The relationship between ethnicity and entrepreneurship, what I call the intramigrant economy, is discussed in the South African context in Chapter III. What is important to note for now is that based on the historical data and arguments by Siu and Cho, it may be accurate to suggest that the Chinese immigrants who participated in restaurants and laundries were not always making a voluntary choice, but rather had to use migrant networks to join an alternative labour market that did not demand high language and cultural skills based on the host country. In addition, Maggi W.H. Leung's (2002) study in Germany and Ching Lin Pang's (2002) research in Belgium also exposed a similar situation.

After the 1960 s, as economies began to prosper in many parts of Asia, there was a shift in the pattern of Chinese immigrants' economic and educational backgrounds from manual labourers to mostly well-educated professionals and entrepreneurs. Due to Chinese immigrants' social and class mobility in North America being much more fluid, and many North American Chinese having settled for generations, scholars began to move away from the "sojourner" concept in the 1990s. For instance, anthropologist Aihwa Ong's (1999) well-known concept "flexible citizenship," which is one of the most cited in the study of transnationalism, is one example of how wealthy Chinese immigrants in the United States can cross national boundaries to create economic opportunities. 
However, this theoretical shift is not evident in South Africa, according to Park's analysis of Chinese South Africans, Chen's analysis of new Chinese migrants, and my own data. Even though to Chinese South Africans, as Park argues (2008a, 2008b), the homeland may be a myth and not a reality, it is a reality in the case of im/migrants, rather than a constructive ideology. Historian Peter Li points out that Chinese immigrants' "sojourning" characteristics actually have facilitated the strengthening of their enterprise: Because of their passion towards their homeland and their desire to return to their family roots, [Chinese immigrants] are motivated to succeed through diligence and frugality in easily liquidated business ventures in a host society. Hence, the nature of business investment among Chinese immigrants reflects an apparent ephemerality that is characterized by low capital intensity, immediate profit and liquidity. Although the entry into more transient businesses can be seen as a situational response, it is the primordial orientation of the sojourner towards the homeland that provides the motivation and the choice in business ventures. (1993, 220)

$\mathrm{Li}$ argues that certain elements embedded in Chinese culture (e.g., flexibility, hard work, familism and value on education and land) may be the reason for the success of Chinese entrepreneurship, whether in North America or many parts of Asia. Li further points out that immigrants often benefit from ethnic entrepreneurship; for instance, "immigrants remain attached to certain traditional values of their home country, and their imported cultural endowment facilitates their success in entrepreneurial ventures in a host society" $(1992,220)$. 
While Li makes a good point that Chinese immigrants with "sojourning" characteristics usually receive tremendous in-group support, I argue they are also constrained by it. The next chapter explores Chinese migrants' backgrounds and examine their networking. 


\section{CHAPTER II}

\section{EXPLORING GUANXI WITH THE CHINESE}

\section{Why Guanxi?}

Ms. Tsang and I walked into a Chinese restaurant during a lunch break on a Sunday afternoon as she was helping me get to know the restaurant owners. She greeted one owner and explained my background and research purpose to him. The owner asked a few questions and then agreed, on the spot, to let me do fieldwork there. It all happened in less than ten minutes. Weeks later, I found that many of the restaurant staff, including the owner, were not so fond of Ms. Tsang. Still, they trusted people that she referred to them because of their guanxi, a Chinese concept that can be loosely translated as "interpersonal connection." If I had walked into the restaurant alone, even if the owner had believed my every word and verified my documents, I would still not have been able to gain his trust easily. This is the power of guanxi, which I realized was too important to be overlooked in any research on the economic activities of Chinese newcomers in Johannesburg.

Guanxi is arguably one of the most important factors of everyday social relationships in Chinese culture, and a key sociocultural concept in understanding Chinese social structure (King 1991). This is particularly evident in the context of migrant-owned businesses, as they usually rely on kin-based resources and the transnational connections of overseas Chinese people (Smart and Hsu 2007). By exploring stories of guanxi among recently arrived Cantonese-speaking Chinese migrants in this chapter, I address how guanxi plays a significant role in the process of migration and in shaping job opportunities for newcomers but also how Western interpretations of 
corruption as something universally constituted lead to ambiguous boundaries between the two practices and can therefore result in the victimization of newcomers.

As noted, Chinese communities in South Africa are by no means homogenous. The first section of this chapter provides a brief history and background of the Chinese in South Africa in order to understand how they are composed of different regional, linguistic, class, and generational groups. There are some common concerns that usually arise from the discussion of guanxi: To what extent does guanxi determine every opportunity? And is the use of personal ties in business a uniquely Chinese or Asian phenomenon? While the latter question is relatively simple, the first one is more complicated. Before analyzing how guanxi works, I provide an introduction to the concept to understand its complex nature and how and why it is distinguished from other types of social-networking theory (Zhai 1993). Then I trace the guanxi phenomenon in the experiences of Cantonese-speaking restaurant and fahfee migrant workers and elaborate on two related concepts_mianzi (face) and renqing (sentiment) — which are important elements in maintaining guanxi.

Before the 1970s, most Chinese businesses in Johannesburg were operated by Cantonese migrants, including restaurants and fahfee. Fahfee (fafi, also known as mochina in South Africa) is a popular but illegal lottery game that has mainly been played by black South Africans in urban townships, suburbs, industrial centres, and rural towns for nearly a century (Krige 2011). Chinese people brought this betting game to South Africa, but they no longer play it themselves; instead, it has become an important business for the economic survival of Chinese im/migrants (Ho 2011). The demographic and regional backgrounds of new-generation Chinese immigrants are much more diverse 
than those of previous generations, and the number of Chinese migrants has grown significantly since the late 1990s. Still, the most common guanxi that Cantonese newcomers have established in Johannesburg is based on shared birthplace and common dialect. Because of the overlap with an older generation of Chinese South Africans, with whom the newcomers can easily establish guanxi, the restaurant and fahfee sectors continue to employ many Cantonese speakers.

This is not to say that most Chinese restaurant owners are Cantonese. As the number of Chinese migrants rises and their regional backgrounds become more diverse, many non-Cantonese people are also opening restaurants in today's Johannesburg. For instance, the participants of this research include owners from Jiangsu, Fujian, Sichuan, and Hunan provinces. However, almost every restaurant has Cantonese-speaking employees. The fahfee industry, on the other hand, is still dominated by the Cantonese. Rumour has it that some South Africans and Fujianese are taking over the industry in several territories (Krige 2011); nevertheless, my understanding is that this industry is still mainly controlled by the Cantonese.

The last part of this chapter explores common forms of corruption that Chinese migrants face in their everyday lives and how closely these can be related to practices of guanxi, leading some to confuse the two practices depending on their perceptions. By drawing on anthropological analyses by Mayfair Yang (1994, 2002), Alan Smart and Carolyn Hsu (2007), and Daniel Smith (2007), I first illustrate how Chinese migrants have become victims of as well as participants in corruption. I then examine my ethnographic data alongside a South African survey on corruption (Struwig et al. 2014) to point out that guanxi tactics may be used in what is commonly seen as corruption, 
because both practices share an ambiguous nature and have overlapping activities (Smart and Hsu 2007; Yang 2002). The perception of what constitutes corruption, as Smith argues, varies widely depending on specific sociocultural scenarios and individual experiences. However, some forms of corruption are more clearly defined globally; for instance, when politicians steal public funds for private gains, most people consider this corruption. Other forms, such as nepotism, patronage, and gift giving, tend to be defined differently according to local and cultural norms. Moreover, different conditions or outcomes affect how one may experience and interpret corruption. Smith therefore calls into question the notion of a universal definition of corruption, which is often oriented towards Western ideologies.

It is important to note that I do not wish to suggest that guanxi takes precedence over everything, because that would underestimate the complexity of Chinese culture and social practice, as well as Chinese migrants' subjectivities and agency. Guanxi does not determine every opportunity; however, it does encompass a complex body of informal practices (Smart and Hsu 2007). People who share more similar backgrounds (e.g., birthplace and language) tend to bond more through guanxi, but it does not mean that Cantonese people do not have guanxi with non-Cantonese Chinese, as relationship building is highly encouraged in guanxi practices and Chinese people often share the same interests. Just as there is a risk of reducing everything to guanxi, there is also a risk of overlooking guanxi and reducing it to another concept such as social network or business strategy. We should, therefore, examine guanxi by itself in order to reflect closely on the reality of the Chinese diaspora, which is the purpose of this chapter. 


\section{Who are the "Chinese" in South Africa?}

According to Chinese South African writers Melanie Yap and Dianne Leong Man (1996), the authors of Colour, Confusion and Concessions: The History of The Chinese in South Africa, Chinese people may have settled in Africa long before the arrival of European settlers. Evidence shows that the first known map of southern Africa was drawn by a Chinese cartographer in 1320. During the late 1600s, a small number of Chinese were brought by the Dutch as cheap labourers to work on farms. From 1660 to the late 18th century, the number of Chinese people in the Cape Colony remained less than a hundred, but throughout the 19th century, a small but steadily growing number of Chinese migrants arrived in South Africa. For instance, a 1904 census recorded 806 Chinese (797 males and nine females) living in the Eastern Cape area.

From 1904 to 1910, a total of 63,695 Chinese mine workers came to South Africa; these contract Chinese laborers were hired by the Transvaal Colony (Gauteng, Limpopo, Northwest, and Mpumalanga provinces in South Africa today) to work in the Witwatersrand gold mines. When their contracts ended, most miners returned to China (Yap and Leong Man 1996, 120). Around 2,000 stayed in South Africa and about half of them settled in Johannesburg. In the late 1940s, records show, there were 4,340 Chinese people, a minority in a population of more than 11,000,000 (Yap and Leong Man 1996, 103-04).

Early Chinese immigrants in South Africa were predominantly Cantonese and Hakka from Guangdong who related mostly through ties of common dialect or place of origin. While most Hakka settled down in coastal towns like Port Elizabeth, East London, 
Cape Town, and Durban, most Cantonese stayed in Pretoria and the metropolis of Johannesburg (Yap and Leong Man 1996).

Although racial segregation had long been practiced in South Africa, the state took the practice to new levels of organization in 1948 by implementing a legal system of racial segregation, known as apartheid, for the next forty-six years (Yap and Leong Man 1996). South African populations were officially divided into four groups: 1) "White" distinguished those said to be European descendants, 2) "Native" referred to black South Africans, 3) "Coloured" referred to people of mixed racial or ethnic origins, and 4) "Asiatic" or "Asian" referred to immigrants from India and China.

As noted, new Chinese migrants might not have any idea what apartheid was about, but the old diaspora lived through it. As Yap and Leong Man explain, under apartheid "Whites dominated politically, socially and economically as the only group with the franchise and free access to land. Laws were promulgated to classify people by colour and regulate virtually every sphere of life and activity by race" (1996, 315-16). In 1971, the Republic of China (Taiwan) lost its seat in the United Nations to the People's Republic of China (China). Meanwhile, South Africa faced international condemnation of its apartheid policy; for instance, the United Nations called for economic sanctions against the South African government. Since both the South African and Taiwanese governments found themselves isolated from the international community, they re-established fuller diplomatic ties, which helped pave the way for the Taiwanese to become the largest group of foreign investors in South Africa (Pickles and Woods 1989). 
From the 1970 s to mid-1990s, approximately 30,000 Taiwanese migrated to South Africa. By that time, East Asian immigrants (including Taiwanese, Japanese, and South Korean) who invested in factories or had access to capital were classified as “Honorary White" and exempted from apartheid regulations (Erasmun and Park 2008). Meanwhile, Chinese South Africans were subjected to numerous restrictions in residential, educational, and business opportunities. Since the definition of "race" is so highly contested, there have been some exceptional cases. For example, in 1962 a Chinese man applied to be reclassified as "White" and this was granted. During the same year, a bus driver refused to drive a Japanese man in Pretoria because he was confused about Chinese versus Japanese. Later, both the driver and the city transport department apologized to the Japanese Consul-General. After that, all bus drivers were instructed to pick up the staff of both the Japanese and Chinese consulates (Yap and Leong Man 1996). In 1998, the South Africa government switched its recognition from the Republic of China (Taiwan) to the People's Republic of China (China) and ended diplomatic relations with Taiwan. As a result, many Taiwanese immigrants left, and their number continues to drop; meanwhile, the population of immigrants from China began to rise in the late 1990 s.

Due to the historically different situations of Chinese im/migrants and the complexity of their backgrounds, as noted in the Introduction and the previous chapter, scholars (e.g., Harrison et al. 2012; Park 2009; Yap and Leong Man 1996) suggest that the timeline of Chinese migration to South Africa should be categorized into three periods: 1) the migrations of Cantonese- and Hakka-speaking Chinese people to South Africa before the 1970s; 2) the migrations of Taiwanese migrants (and some from Hong 
Kong) from the early 1970s to the mid-1990s; and 3) the migrations, since the 1990s, of Chinese newcomers of mixed regional origins including (but not limited to) the municipalities of Beijing, Tianjin, Shanghai, and Fujian and the provinces of Guangdong, Guangxi, Jiangsu, Zhejiang, Shandong, Sichuan, Liaoning, Henan, Shaanxi, Heilongjiang, Jilin, and Yunnan (Chen 2013; Harrison et al. 2012).

Currently in South Africa, there are approximately 6,000 immigrants from Taiwan, about 8,000 to 10,000 Chinese South Africans who have been there for several generations (usually referred to as laoqiao by the new generations), and 300,000 to 400,000 new Chinese migrants (Chen 2013; Ho 2015; Park 2009). The exact number of Chinese in South Africa is impossible to verify for a number of reasons: the Chinese community in South Africa has been historically underrepresented in censuses (Harris 2007), there is a large number of non-registered Chinese migrants, and South Africa's Home Affairs officials keep poor records (Harrison et al. 2012; Park and Chen 2009).

\section{Migration Agency}

Of the newly arrived Chinese migrants, about one-third (around 100,000) are from Fujian province, and migrants from Guangdong are the second-most numerous. The number of Cantonese in South Africa might be close to that of the Fujianese if the numbers of Cantonese newcomers and the older generations of Cantonese immigrants are combined (Chen 2013). Most of these new migrants are from rural areas in Fujian and Guangdong, where there is very limited social and economic mobility. For those from rural areas in China, the best option for economic improvement is to go abroad, and the 
best chance to find an overseas job is through their overseas network (Xiang 2017; Chu 2010).

Anthropologist Julie Chu (2010) conducted extensive ethnographic research in a rural village in the Fuzhou region of Fujian province, as Fuzhou is the main source of migrants smuggled into the United States. Fuqing is part of the Fuzhou region, and is also the hometown of the largest number of Chinese migrants in South Africa. In her ethnography, Cosmologies of Credit: Transnational Mobility and the Politics of Destination in China, Chu argues that the Chinese nongmin (peasants) are "at a most awkward intersection" $(2010,4)$ since China's economic reform in the 1980s. As she states, "As state-classified peasants for four decades, they have long lingered in the stagnant, rural backwaters of a socialist vision of modernity. But as coastal subjects, they also now find themselves at the dynamic front of global exchange and capitalist circulation in the newly revised imaginary of post-Mao modernization” (ibid). Chu explains that due to the inflexibility of hukou (户口, household registration system), which determines residents' access to public systems and social welfare services, Chinese nongmin have little chance of social and economic mobility within China. In other words, there is greater possibility of socioeconomic mobility abroad. As such, Chinese nongmin risk their lives and go into debt to pay "smugglers" or "migration brokers" to arrange work overseas. It is important to distinguish between "migrant smuggling" and "human trafficking" networks. The main distinction is that "smuggling" requires consent between clients and the "migration agency," while human traffickers use coercion and abduction. Many Chinese people do not necessarily view migrant smuggling networks as harmful or unethical, especially in the case of migrants from rural areas. 
The topics of smuggling and illegality were in the air among the new Chinese communities in Johannesburg but not something that was openly discussed in public. Many Chinese newcomers were not $100 \%$ sure if they held a legitimate work visa, and anyone could have been a victim of forged documents. The majority of Chinese newcomers I spoke to during my research already had at least one relative or close friend living in South Africa prior to their arrival; their lack of knowledge of a foreign language or an understanding of the visa application process would have prevented them from applying for South African work permits on their own. Consequently, most Chinese newcomers utilized services provided by Chinese migration agencies whether coming into South Africa through legal or illegal channels. Some Chinese migrants did not know that they had paid for invalid work permits until they passed through airport immigration checkpoints and were arrested. In other cases, South Africa's Home Affairs officials had sold fake documents to the migration agencies, which affected Zimbabweans as well (IOL News 2015; Kalipa 2015). While I was in South Africa, many Chinese workingclass migrants, especially those who obtained their permits though agencies, raised concerns about the validity of their documents. One interviewee showed me her South African work permit and asked how to recognize fraudulent documents. Another asked if I could show her my South African research visa to see if hers looked like mine.

Because migrants' legal status can be a sensitive issue that is not always open for discussion, I did not seek to clarify the legal status of participants, both Chinese and Zimbabweans. I did not ask questions related to legal status, such as how they arrived in South Africa or what kind of visa they had that permitted them to stay or to work. Some interviewees happened to talk about their legal status during our conversations. My 
understanding is that some Chinese migrants arrived in South Africa by way of smuggling through neighbouring countries, or they overstayed on a visiting visa. On the one hand, whether people knew if they were legal or not, they worried about being arrested when going through the airport or being extorted when police asked for their ID at route checkpoints; on the other, however, it was not a priority concern on a daily basis. As noted in the previous chapter, the goal of many Chinese migrants going abroad is clear and simple — to work and save up money for a few years (Xiang 2017). In other words, the status of legal or illegal is not necessarily their main concern as long as they are earning an income.

As noted in the last chapter, Chen (2013) argues that newly arrived Chinese migrants come for economic activities, orient themselves with kin-based networks, and face language barriers; as a result, they are less interested in integrating into South African society. While I agree with her observation, I want to bring this point forward by suggesting that it is also their relatively high cross-border mobility that provides them more options than just staying in South Africa or returning to China. As several Chinese im/migrants mentioned to me, if South Africa's economy were to keep declining, they would go to another African country or to another continent for a better opportunity.

What makes their high cross-border mobility possible? Due to the scope of this dissertation and data limitations, I am unable to provide an in-depth discussion and analysis on migration brokers in the South African context (see Chu 2010 for the case of United States). But my data suggest that in South Africa, migration brokers play an important role in facilitating and maintaining migratory flows, and in many cases, the migration broker and client knew each other prior to the migration. 
Fred Krissman (2005) argues that the concept of "migrant network" has failed to explain the origins of migration flows and labour demand factors because of a focus on labour-sending hometowns and supply-side factors and neglect of the actors and actions that help migration networks develop in host countries. I agree with his point that the concept does not elucidate the social relationships that brokers and clients form before the migration journey begins, and it does not help to understand how their social relationships change and evolve after arrival.

Moreover, Adams Bodomo (2012, 2018), an acclaimed scholar of Africa-China relations, argues that in an era of globalization, where people, goods, and services are constantly moving, diasporic communities should not be seen as passive or homogenous and constrained by migrant-host relations. Instead, they actively serve as "bridges," strengthening Africa-China linguistic, cultural, and trade relations. As Bodomo explains $(2018,65)$, Africans who were visiting China often got their initial insights about the Chinese society through the eyes of Africans already living in China, including insights about the good relations as well as the tensions between Africans and Chinese. At the same time, Chinese people also experienced African cultural mannerisms to certain extent from Africans living among them even before they know very much about Africa. While Bodomo argues that "Networks cannot exist without socio-political, socioeconomic, and social-cultural bridge building among community members and between their host and source communities" $(2018,65)$, he also emphasizes the importance of migrant communities' participation in host countries.

In line with this argument, I suggest there is a need to understand guanxi, particularly in the case of Chinese migration, before we examine how the restaurant 
businesses and social relations were built and developed, and how they participate in South African society.

\section{The Complex Nature of Guanxi}

There are several English translations of guanxi, including particularistic ties (Jacobs 1982 in Chen and Chen 2004), personal relationships (King 1991), interpersonal connections (Xin and Pearce 1996), and personal ties (So and Walker 2006). However, since none of these translations can fully reflect the rich complexities of guanxi, most scholars prefer to use the original Chinese term rather than the translations (So and Walker 2006; Yan 1996). It is challenging to clarify guanxi and reduce it to a simple definition, as it is conditional, dynamic, and ambiguous. Most Chinese people practice guanxi, but few can explain systematically what it is; it is not something practitioners would admit to practicing, nor a subject that people would discuss in public (Yang 2002).

For Chinese people, to say someone has "good guanxi" usually conveys a positive image of an individual who is well connected to economic or social resources, like government officials or successful businesspeople. Having good guanxi might help to open doors; however, it cannot necessarily unlock the exact door you want to open whenever you wish. There is always a gap between the ideal expectation and the practical reality of guanxi. In some cases, it is difficult to determine whether someone's accomplishment is due to guanxi or personal efforts. After all, guanxi is not a fixed phenomenon, and not all guanxi is practical, functional, or reciprocal (Yang 1994, 2002).

Scholars have deployed diverse research approaches in understanding and explaining the concept of guanxi. Xiao-Ping Chen and Chao C. Chen (2004, 308-309) 
have identified different scholarly approaches in understanding and analyzing the concept and its practices: some scholars explain guanxi as a particular type of personal relationship, while others tend to examine guanxi as an instrumental social function. Either way, scholars differ in their value judgement of guanxi as having positive or negative implications.

Scholars who tend to view guanxi as a standard Chinese cultural norm often emphasize its inevitable influences on Chinese people's characters and behaviours. For example, Ambrose Yeo-chi King $(1991,63)$ argues that guanxi is key to understanding the foundation of Chinese cultural structure; King traces the notion of guanxi back to Confucian social theory, an ideology that is "concerned with the question of how to establish a harmonious secular order in the man-centered world" (65). King further compares the Chinese social system with Western ones: "Chinese society is neither kohen pen-sei (individual based) nor she-hui pen-sei (society based), but kuan-hsi [guanxi] pen-sei (relation based)" (ibid). In King's explanation, every human being is integrated into a guanxi-oriented (relationship-oriented) society according to the Confucian system; therefore, emphasis is placed on the importance of associating oneself with others and how these associations must be formed to maintain social order. Fundamental relationships are aligned in a hierarchical manner: ruler-subject, father-son, husbandwife, elder brother-younger brother, and senior friend-junior friend. While the roles listed first in these pairings have more authority than those listed subsequently, they are also obligated to provide help and care to those with less authority. Each role has its own sets of responsibilities and performativity. Every person should act accordingly, and reciprocity between people in relationships is also expected. 
Scholars who tend to look at guanxi as a social practice pay more attention to the conditions and contexts that lead to the existence of guanxi. Mayfair Yang $(1994,2002)$ is known for her ethnographic research on guanxi among Chinese people and bureaucratic systems in China during the 1980s and 1990s. Given the complex nature of guanxi, Yang advocates for understanding it as an art (or guanxixue, the art of guanxi): Guanxixue involves the exchange of gifts, favors, and banquets; the cultivation of personal relationships and networks of mutual dependence; and the manufacturing of obligation and indebtedness. What informs these practices and their native descriptions is the conception of the primacy and binding power of personal relationships and their importance in meeting the needs and desires of everyday life. $(1994,6)$

Yang illustrates how guanxi was developed in the midst of the Cultural Revolution (1966-1976) and then spread rapidly in the 1980s when China re-entered the global money economy, pushing for market reform and wealth redistribution. In her analysis, because of the lack of adequate formal social and financial institutions in China, guanxi served a positive function in helping people build trust and gain support through expanding networks. As Yang argues, I suggested that the rise of guanxixue in the midst and aftermath of the Cultural Revolution was a way of reversing the governmentalization of everyday life, by redistributing what the state apparatus had distributed according to very different principles of personal relations rather than political evaluations. Thus guanxi did not only have economic significance, but was a way to subvert state power as exercised through the state redistributive economy. $(2002,469)$ 
Drawing on anthropologist Marcel Mauss's renowned concept of the "gift economy," Yang shows how the gift economy operated when China had just begun to reconnect with the rest of the world and was emerging as a global economic entity. However, although guanxi is also based on the principles of gift and favour exchange, the practice of guanxi places great emphasis on mutual trust and obligation. In other words, building relationships between practitioners comes first, before any gifts are exchanged (Smart and Hsu 2007).

Contrary to Chinese understandings of guanxi as a powerful aid or a network of extended mutual trust that determines important outcomes, the practice of guanxi has negative connotations in the West, and is often linked to manipulation, unfairness, and indeed corruption. One explanation of these opposing views lies in different Chinese and Western perceptions of private life and the public sphere. For instance, Chen and Chen (2004) point out that most Westerners prefer to separate their personal lives from their work. In China, the overlapping of work and personal life is a common phenomenon. As Chen and Chen write, "Building guanxi in China requires greater willingness and effort to be involved in the personal and social lives of other organizational members as well as allowing others to be involved in one's own non-work lives" (2004, 321). Another explanation of the differences stems from the different ways of forming social relationships. Alan Smart and Carolyn Hsu state, "In Western Judeo-Christian tradition, the ideal friend is one who lays down his life for his friends, the antithesis of the false friend who 'uses' friends for personal gain. In contrast, in Confucian ideology, 'using' friends for personal gain is lauded as the path to true friendships" $(2007,170)$. In other words, guanxi puts an emphasis on emotional attachment, which leads to long-term bonds 
between parties. The combination of sentimental and instrumental characteristics is what distinguishes guanxi from other concepts of social capital. ${ }^{30}$

Guanxi is not just limited to groups of kin-based relatives but is often extended to others who are bound to each other in different networks of mutual trust, such as sharing a common birthplace, graduating from the same school, or working in the same place (currently or even in the past). Most overseas Chinese associations are established on the basis of shared provenance (Chen and Chen 2004), including in the case of the Chinese in South Africa.

Funglan Chen's (2013) multi-sited fieldwork in a rural town in Fujian and in three South African cities suggests that more than half the residents in some small villages have moved to South Africa through their kin-based networks. The newcomers often work for extended family members who are already settled in South Africa, until they have some savings and are able to open their own small shop. Yoon Jung Park and Anna Ying Chen (2009) conducted field research on Chinese migrants in small towns in Free State, South Africa. Their findings showed that there was at least one "China shop" or Chinese-owned grocery shop in every small town, and the majority of these business owners and employees were from the same area of Fujian province. This facilitation of employment and economic opportunity between established migrants and newcomers from the same province exemplifies how guanxi works in South Africa.

While a large number of the Fujianese newcomers in South Africa are involved in the retail and wholesale trades, Cantonese-speaking people tend to dominate the restaurant and fahfee sectors. Most of my participants were Cantonese-speaking migrants

\footnotetext{
${ }^{30}$ See Xuewei Zhai (1993) for an in-depth discussion and comparison of Western and Chinese perceptions and practices of interpersonal relations.
} 
from rural areas in Guangdong and Guangxi provinces. I met some Cantonese families whose extended family members also moved to South Africa; in fact, it appears that many of the Cantonese migrants share a regional birthplace. The migration process of Cantonese migrants demonstrates a similar pattern to that of Fujianese migrants in South Africa - migrants from a particular place follow others from that place to a particular city. However, by and large, the Cantonese extended family networks are not as strong as the Fujianese ones described by Chen (2013) and by Park and Chen (2009), and the pattern of expansion strategies for restaurants is not as closely oriented around kinship ties as in the case of the Fujianese trading networks. In Johannesburg, many Cantonese migrants work for or with Fujianese-owned businesses, including restaurants, and the Cantonese often depend on the Fujianese for transportation or food supplies because of the Fujianese migrants' stronger global trading networks. It is not rare, however, to see people prefer to work with others who are from the same region. See, for example, the two advertisements posted on a WeChat group, shown in Figure 10.

\section{$\underline{\text { Figure 10: Job Advertisements with Preference }}$}

\begin{tabular}{|c|c|}
\hline 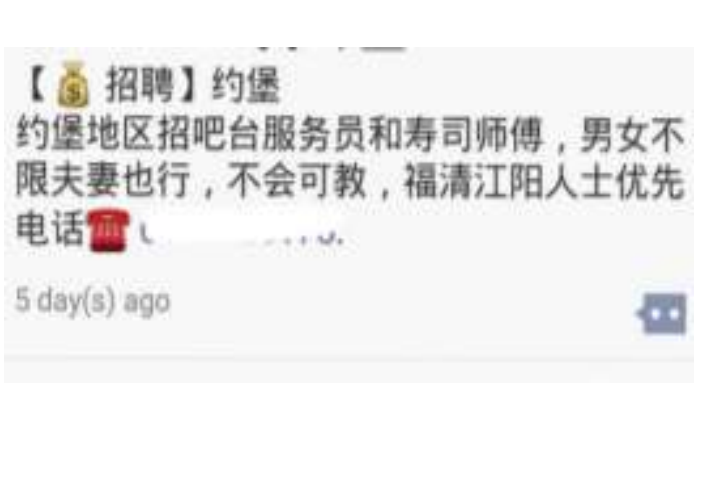 & $\begin{array}{l}\text { [Hiring] Johannesburg } \\
\text { A Chinese restaurant in the } \\
\text { Johannesburg area is looking for a sushi } \\
\text { chef and a front desk worker, single or a } \\
\text { married couple, I can teach if you are } \\
\text { inexperienced, Fujianese from Fuqing, } \\
\text { Jiangyin would be considered first. } \\
\text { Tel: } x x x-x x x-x x x\end{array}$ \\
\hline
\end{tabular}




\begin{tabular}{|c|c|}
\hline $\begin{array}{l}\text { [2 招聘信息] } \\
\text { 请寿司学徒, 包領住，最好广东人。 } \\
\text { 联系号码孟 }\end{array}$ & $\begin{array}{l}\text { [Job Offer] } \\
\text { Looking for a sushi trainee, meals and } \\
\text { accommodation included. Prefer } \\
\text { someone from Guangdong. }\end{array}$ \\
\hline
\end{tabular}

It is estimated that there are nearly 100,000 ethnic Chinese in the Johannesburg area, and between 30,000 and 50,000 live in Cyrildene (New Chinatown) and surrounding neighbourhoods (Chen 2013). Most of the time, Chinese migrants from different regional or linguistic backgrounds interact and live in the same neighbourhood without too many obvious conflicts. Marriage, business partnership, friendship, favouritism, and reciprocity are everyday forms of collaboration that build guanxi between and within different Chinese migrant groups. The following story elucidates the role guanxi plays in migration flows and how it may transcend differences of regional background.

\section{Mianzi (Face/Honour) and Renqing (Human Emotion)}

Lam Yi, originally from a rural area of Guangdong, holds down two jobs. He works at a restaurant and as a migration broker, providing assistance to Chinese newcomers to Johannesburg. He works closely with a Fujianese human transportation network. As noted, in many parts of the world, Fujianese people operate and control "human migration organizations" (Chu 2010). South Africa is no exception; Lam Yi provides newcomers with food and shelter and assists them in finding jobs. He maintains 
good guanxi with several restaurant owners and managers, as he has established a good reputation for introducing diligent Chinese migrants to work at the owners' restaurants. As a result of his strong track record, these businesspeople are likely to phone Lam Yi when they need to fill positions in their restaurants. Lam Yi is in a good position to build his guanxi by working with Chinese restaurants, as most of his clients often end up working in the restaurant industry. Guanxi from Lam's two jobs mutually strengthen and benefit each other. Guanxi then develops into a networked series of exchanges or transactions between the various relationship groupings.

Chow Fa, a Cantonese chef I interviewed, happened to be one of Lam Yi's former clients. Chow Fa came to South Africa three years ago with his help. When I asked Chow Fa how he met the Fujianese people who helped him get to South Africa, he explained, It is no secret that Lam Yi is working with Fujianese people and makes commission by bringing us to South Africa. Of course, he has to make some profit. Why would he do it for free? Lam Yi has a good reputation, and I know he wouldn't mess around with people from the same village unless he doesn't want his mianzi (face) anymore. If it wasn't for Lam, I wouldn't trust these Fujianese people at all. As Chow Fa's interview demonstrates, he was worried about the Fujianese migration agency given that there have been cases of human smugglers using force or forms of deception or fraud for the purposes of exploitation. But his guanxi with Lam Yi helped to build his trust with Fujianese organization, even in the absence of legal contracts to protect his interest.

The literal translation of mianzi is "face," and this concept is understood as "a combination of a sense of moral imperatives, social honor, and self-respect" (Yang 1994, 
141). Mayfair Yang points out that mianzi "is not only a matter of prestige, but an emblem for personal identity" $(1994,196)$. As she explains:

the Chinese relational construction of personhood represented by the importance of face provides the mechanism for the art of guanxi to constrain the actions of a gift recipient. Threats to one's face constitute threats to one's identity, which is constructed relationally by internalizing the judgment of others in oneself. And reduced or fragmented face poses a disadvantage in a person's position and leverage in social interaction. (ibid)

In other words, gaining mianzi builds one's credibility and can be understood as part of achieving social personhood in a Chinese relation-based society. People who come from the same village in China and want to find jobs in South Africa go to Lam Yi because of his good reputation. If Chow Fa was dissatisfied with Lam Yi, he would tell people and Lam would lose his mianzi, thus ruining his reputation because his relationship to his clients as a broker is largely dependent on guanxi. However, Chow Fa fully trusted Lam's arrangement with a Fujianese organization despite holding a negative impression of Fujianese people and having never met them before. Chow Fa believed that Lam Yi would take care of his interests — or, at the very least, not harm him—as long as Lam Yi wanted to preserve and maintain his mianzi, especially considering that Lam's parents and family still live in the village.

Guanxi and the related concept of mianzi, as these examples illustrate, is integral to the migration conditions of Cantonese-speaking newcomers to South Africa. But these informal networks can also constrain the decisions of newcomers. The next story is an example of how guanxi determines one's employment opportunities and decisions, and thereby can constrain them. 
Working in a kitchen can be intense and stressful when the restaurant is busy. Sometimes it can be tedious waiting for orders or repeating the same tasks over and over. Most Chinese chefs I met were rather chatty and not shy about making (often dirty) jokes to make a slow working day pass more quickly. Zhang Bao was a quiet man, especially compared to other chefs. We did not talk much to each other while I was working at the same restaurant. One afternoon, I bumped into Zhang Bao after I left the restaurant. Perhaps he felt more relaxed outside of work, because we ended up talking for hours. He complained about his low wage, problems with the work environment, and his strong dislike of his co-workers. Having heard that other restaurant owners wanted to hire him on a higher salary, I was curious about why he stayed. Zhang Bao told me that he used to work at a few higher paying restaurants, where things went well until he became addicted to gambling. He was a regular at casinos, and he used to go every day after work. He was fired when he was too drunk to show up at work. Then, when he was unable to pay his rent and owed people money, his wife and child left him. When he was at his lowest point, Mr. Ng, his current employer, called him. Mr. Ng and Zhang Bao had been trained by the same chef and had, for a few years, worked together at the same restaurant, which Mr. Ng had taken over when the master chef retired. Zhang Bao explained, Mr. Ng told me to just come back to work for him, as he was giving our master chef a mianzi (honour). I could not jeopardize our master chef's mianzi (reputation). The first day I started working for Mr. Ng, he paid off my debts. Even though I paid back every penny a while ago (by monthly payroll deduction), I still owe him a big renqing (favour).

Renqing, like mianzi, is closely associated with guanxi. Renqing can be translated as "favour" or "human feelings," as it refers to "the bond of reciprocity and mutual aid 
between two people, based on emotional attachment or the sense of obligation and indebtedness" (Yang 1994, 68). Zhang Bao’s case exemplifies the relationship among renqing, mianzi, and guanxi. For a period, Zhang Bao was jobless because of his reputation as an irresponsible worker and a gambler. Based on their pre-existing guanxi and as a way of honouring their master chef, Mr. Ng offered Zhang Bao a job and gave him a second chance. According to the rules of guanxi, Zhang received a favour from Mr. $\mathrm{Ng}$, as well as a symbolic one from their master chef. Zhang Bao is expected to return the favour. If he now performs poorly in his job or leaves his current position, he risks affecting Mr. Ng's and their master chef's mianzi and his own guanxi with them, as well as their extended guanxi with others. Zhang Bao feels obligated, because of these social values and practices, to work there as long as he can despite having higher salary potential elsewhere.

This story explains how the practice of guanxi, including renqing and mianzi, can determine - and constrain — one's employment opportunities and decisions. At the same time, it also demonstrates the characteristics of a close-knit community among newly arrived Cantonese-speaking migrants, which is integral to their lives due to language and cultural barriers and, most importantly, their economic dependency. In Johannesburg, I did not meet any new Cantonese migrants who did not work for or with other Chinese people. Most Chinese restaurant employees not only work with their employers but also live with them. It is common to find that Chinese employees, especially those new to South Africa, live with their employers or at a rental flat provided by them, and ride to work in the same car as them. 
There is competition between Chinese businesses as well. For instance, someone might open a cheaper restaurant next to an existing one. However, if these owners had guanxi with each other, the new arrival would find another location. Relationship is perhaps the most important foundation of guanxi, and guanxi evolves over time as relationships change. How it evolves is highly contextual, and I do not wish to overlook the complexity of people's relationships. But generally speaking, the more renqing (favours and indebtedness) people engage in with each other, the deeper their guanxi. Guanxi in this sense transcends the differences of regional background among Chinese migrants.

Two of the most common employment opportunities for Cantonese newcomers in South Africa are in the restaurant and fahfee sectors. Each fahfee man is assigned several stations within a territory. Players choose one or more numbers from one to thirty-six, put the betting money in a bag, and give it to a runner (a local resident) who waits for the fahfee man to show up at their station in his car (usually twice a day). Fahfee men provide betting slips and purses for players. Most fahfee men work alone, but some hire a driver or a helper. When a fahfee man's car arrives at a station, the runner approaches the side window. The fahfee man announces or pulls out a number on a small piece of paper while the runner passes the bag of purses to the fahfee man, who then makes a signal to let the players know the winning number. At the same time, the fahfee man opens the bag of purses, pulls out each player's betting money and slips, takes all the losing money and puts the winning money back into the purse. After returning the bag to the runner, the fahfee man heads off to the next station (see Figure 11). 


\section{Figure 11: Fahfee (Fieldwork photos)}
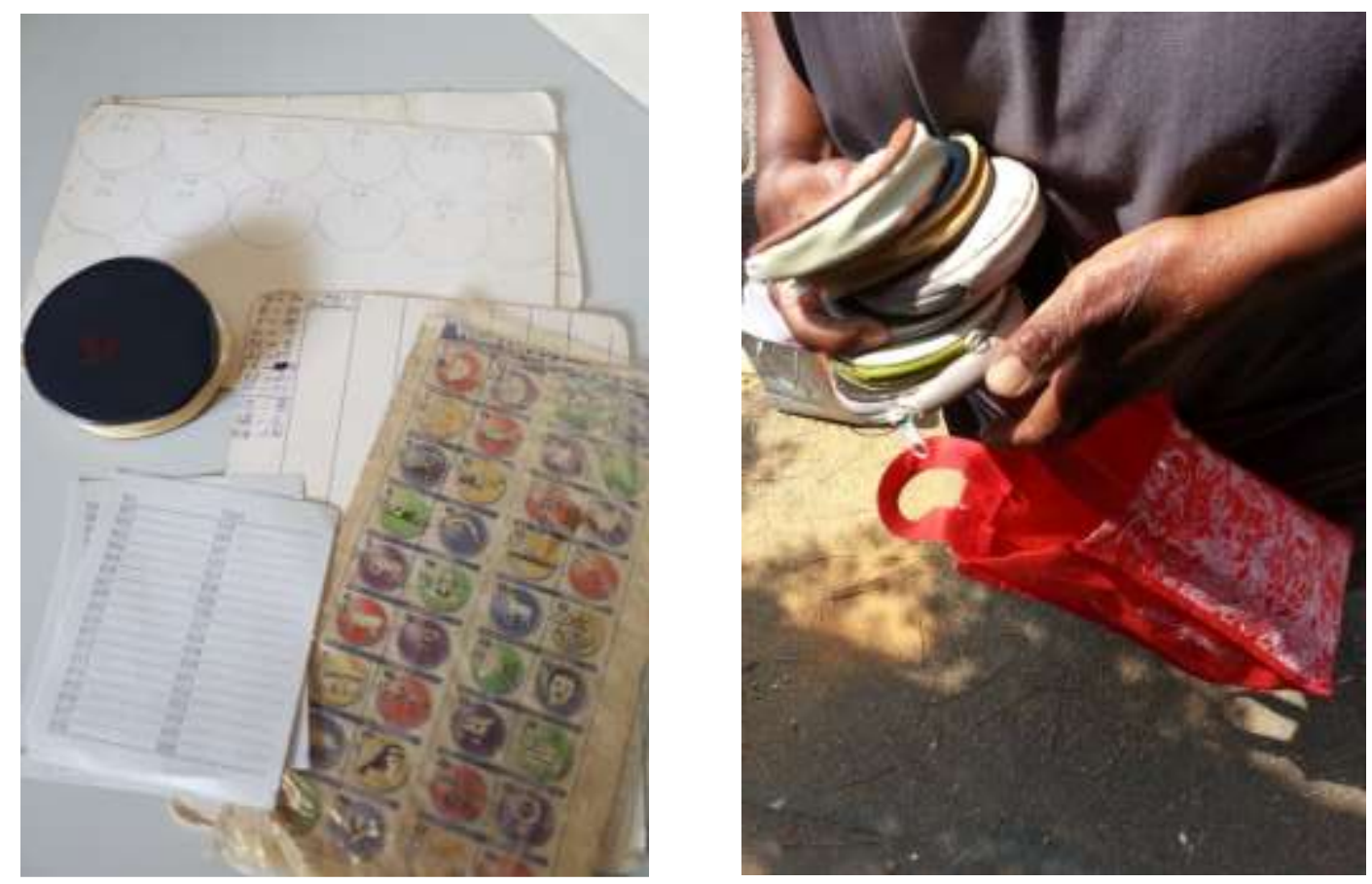

Left: Fahfee number guides, betting slips, and a purse Right: A runner collecting purses from players

Until the 1980s, the fahfee business in Johannesburg was operated solely by

Chinese South Africans. The laoqiao (older-generation overseas Chinese) of South Africa in the Johannesburg and Pretoria areas are predominately Cantonese speakers from the Sam Yup (Sanyi) area (Yap and Leong Man 1996). The first-generation laoqiao usually speak their home dialects and standard Cantonese, while English is usually the native language of South African-born laoqiao. They also have a good understanding of their home dialect or standard Cantonese, or both, and they learn Afrikaans in school. Most laoqiao do not speak or understand Mandarin. Unlike other non-Cantonese-speaking Chinese migrants, Cantonese newcomers can easily join Chinese organizations established early on by laoqiao when they need help. At the same time, when the fahfee organizations are expanding or the older fahfee men are retiring, they can easily recruit 
Cantonese newcomers through these types of networks. This Cantonese intergenerational connection is not limited to the fahfee industry; it is easy to see that laoqiao-owned restaurants employ a large number of Cantonese newcomers. It is also common to hear that, when they retire, laoqiao sell their restaurants to Cantonese newcomers as well as train them.

\section{Guanxi or Corruption?}

As noted, most Chinese migrants feel uncertain about South Africa. It has lovely weather, beautiful landscapes, a high level of food safety, and clean air. At the same time, its high crime and corruption rates present challenges that Chinese migrants face frequently. The majority of Chinese migrants I spoke to, regardless of their regional origins, educational background, or occupation, all claimed that they had been asked for bribes. The most common scenarios where they encountered this form of corruption included driving through police checkpoints, going through customs or immigration at border crossings and airports, and dealing with government officials. These are some typical stories:

Interviewee A (woman, 32): "I passed the driving test but they wouldn't give me my licence until I paid a bride. I need the licence so my husband doesn't have to drive me to work every day. What can I do? I told my coach to arrange it."

Interviewee B (man, 35): "Last month when I came back from China, an immigration officer took me to the room to check my luggage and claimed that a handbag I had bought for my wife was illegal. At first, she said it was a fake, then she said I had to pay custom fees or something. I didn't really understand until she asked me to give her the handbag if I wanted to leave. Then I realized it had nothing to do 
with whether the bag was real or not. My wife and children were waiting outside, and I didn't want to be kept there any longer, so I paid her some rand. Then she let me go."

Interviewee C (man, 47): "When I applied to renew my work permit, the Home Affairs officer asked me to pay a bribe to secure my spot. I refused. He said to me, 'No money, no paper.' I told him I understand South African law and it is my right to report his unlawful behaviour to his manager. He stamped my paper. Turned out, that bastard didn't sign my paper! I ended up spending more money and wasting more time to get a valid one."

Interviewee D (woman, 55): "We were leaving a shopping mall and driving on the N3, then we were stopped by the police. The police searched our car and found our money. They had planned on taking all our money until I started screaming. Then they decided to take half and left."

As we can see, Interviewees A and B were forced to participate in corruption in order to receive a service and to avoid further harassment. Interviewee $\mathrm{C}$ was punished for challenging the immigration officer and refusing to pay a bribe. As a result, Interviewee C said that he would consider paying a bribe next time he applies for a permit renewal. In these four cases, none of the interviewees reported their incidents to the police. Only one victim (Interviewee D) phoned the South African Chinese Community and Police Cooperation Centre, which is located in Cyrildene's Chinatown and helps Chinese people communicate with the local police. However, Interviewee D further told me that she did not expect to get the money back, as they did not record the names of the policemen who robbed them or the licence plate of the police vehicle. The other three interviewees did not report to any authority because they felt it would be a waste of time 
or a hassle, due to their lack of confidence in the police force. They believed that the police would not do anything about their cases, or, in the worst case, would ask for a bribe to look into their cases.

Among most South Africans, the police have a reputation for corruption. According to a survey conducted in 2013 (see Struwig et al. 2014), the South African Police Service and traffic police are considered some of the most corrupt government units. Because most Chinese migrants hold spousal or work permits that require regular renewal, and because many of them return to China regularly, they are more likely to experience corruption with the traffic police and the South African Police Service, as well as with the Department of Home Affairs (immigration and customs officers). The following story reveals a common distrust of law enforcement authorities among new Chinese migrants, as well as corruption within law enforcement.

During our interview, a chef complained that life in South Africa was sometimes hard because of loneliness. He worked ten to fourteen hours a day, six days a week, and he rarely had time to meet people outside the restaurant circle. He and his co-workers visited casinos regularly after work as that was the only entertainment available at that time in Johannesburg. One night, he and his friends were leaving the casino and heading back to their residence. The car owner was too drunk to drive, and even though the chef had also had a few drinks, he was in better condition than his friend. The chef took the keys and started the engine, knowing that he did not have a local driver's licence. Not too far away from the casino, police stopped their car. The chef had a few thousand rand in his pocket, and he worried that the police would steal it if they searched him. So instead, 
he rolled down the window and offered to "buy drinks" for the officers (a common code for bribery payments in South Africa). The police gladly accepted and told him to leave.

This chef paid a bribe to avoid the possibility that the police might find his large amount of cash. However, paying bribes does not always guarantee the expected resultas in the practice of guanxi, there is always a gap between the prospect and the practicality of this type of interaction. As a restaurant owner said to me, "I don't mind paying people to speed up their services if I can get things done quickly. My problem with South Africa's corruption is that these people take my money and don't accomplish what they promise to fulfill." In other words, forms of guanxi as well as forms of corruption, while sometimes seemingly practical, do not always have the desired result.

According to the above-mentioned survey conducted in 2013 (Struwig et al. 2014), 5.2\% of respondents (114 people) answered that "paying a small amount of money to a traffic officer to make a 'small' offence 'go away'" was acceptable, while the majority $(94.8 \%$, or 2,566 people) said it was not. To the question of whether they would "pay a small amount of money to speed up a government service," $5.3 \%$ of respondents (142 people) said yes and $94.7 \%$ (2,540 people) said no. As we can see, while the majority do not agree that people should pay bribes for better or faster service, a small number of South Africans still think it is reasonable to do so. The survey indicates that some forms of corruption are acceptable to some South Africans. For instance, when asked about "a government employee giving a job to a family member or friend that is qualified to do the job," $32.4 \%$ of respondents found this action acceptable, while $67.6 \%$ found it unacceptable. When asked about "government hosting large parties or other 
entertainment to improve relationships," $16.6 \%$ of respondents said it was acceptable and $83.4 \%$ that it was not. ${ }^{31}$

As noted, Daniel Smith's (2007) ethnographic study in Nigeria shows that people's perceptions of corruption are often vague, and their experiences are often contradictory. Smith points out that corruption is understood differently in different places and is culturally specific. Similarly, the Struwig et al. (2014) survey can be interpreted as showing that the majority of South Africans do not support bribery, but my interview data suggest that bribery and other forms of corruption are still common experiences in specific contexts. Mayfair Yang (1994) also argues that guanxi is not a representation of Chinese culture but "a social fact in and of itself... whose history, conditions of formation, and specific contours provide information not only on its referent, guanxi practices, but also on the larger social forces that produced the discourse and gave it prominence" (1994, 6-7). My ethnographic data on Cantonese newcomers in Johannesburg reflects this description of the fluid, multilayered, and sometimes ambiguous nature of guanxi. Guanxi is often confused with corruption due to Western ideas of a universal concept of corruption, but this concept does not take into account cultural and context-based specificity.

One evening I was sitting in a restaurant waiting for the owner to give an interview. I noticed that many customers were smoking inside the restaurant. Even though it is illegal to smoke indoors in South Africa, some restaurants in Cyrildene do not follow the rule. However, it was unusual to see smoking at this particular restaurant because it was not located in Chinatown. Later during the interview, I asked the owner if

${ }^{31}$ The data are based on 2,696 participants: 1,596 Black, 494 Coloured, 317 Indian/Asian, and 289 White (Struwig et al. 2014, 31). 
he worried about police officers finding out about it. He explained, "If I do not allow customers to smoke inside the restaurant, I lose my business. I offer police free food and drink to maintain a good guanxi so that I don't get fined." I heard a similar idea from Lau Wen, a fahfee man, as we were heading towards a township outside of Johannesburg in a bulletproof bakkie. ${ }^{32}$ Lau Wan saw a police vehicle in his mirror, so he told me he would change the route in order to avoid police. As soon as we arrived in his territory, he started driving around visiting his stations. When we passed another police car, I worried that we would get caught. Lau Wan laughed at my reaction and said, "No worries about police in this area. I have good guanxi with them. They are good cops." He then pulled over next to the police car, turned down the window, greeted the police, and handed over some cash. The police joked about Lau Wan having a new girlfriend and waved at me. After they shook hands, we left the scene to go to the next station. Before we get into an analysis of these two examples, it is important to understand the reason for the often blurred boundary between guanxi and corruption.

In their article "Corruption or Social Capital? Tact and the Performance of Guanxi in Market Socialist China," Smart and Hsu argue that precisely because of the instrumental role of guanxi in China, the boundary between reasonable guanxi and corrupt practices has become questionable:

Although guanxi and corruption are associated with two separate discursive narratives, in practice they involve overlapping activities. Despite the rhetorical distinction between "warm human sentiments" and exploitation, the behaviors they describe are often identical: the exchange of gifts and favors for instrumental

\footnotetext{
32 "Bakkie" is the South African term for pick-up truck.
} 
purposes. Indeed, a flourishing culture of guanxi transactions creates conditions that facilitate bribery and corruption. $(2007,172)$

Yang also points out that many guanxi tactics can be employed for the purposes of corruption where business interests and opportunities involve government officials who control resources. As she states, "corruption and bribery may be one outcome of the encounter between guanxi culture, official culture and a money economy" (Yang 2002, 461).

Lau Wan had been in South Africa for eight years. Like most newcomers, his English was basic, though good enough to communicate with his runners and even to joke with policemen. The policemen recognized that I was not his wife because they had met her many times when she joined Lau Wan during her days off from waitressing. Lau Wan shared cigarettes with the police, the policemen sometimes took Lau Wan for lunch, and they often joked together. Engaging in such activities did not mean that Lau Wan was not aware of the difference between bribery and guanxi. When he told me about how he once got caught by other policemen, he used the term "bribery" to describe how he offered the policemen some fees to let him leave. He used the term "guanxi" when describing his interaction with the policemen from his territory because, from his point of view, he was building a long-term relationship with them instead of engaging in a onetime transaction.

Lau Wen and the restaurant owner were aware of the questionable nature of their activities. They understood that a certain price had to be paid if they did not want to get into trouble with law enforcement, and in many cases they viewed it as guanxi building with the South African authorities rather than an act of corruption. Although guanxi is easily conflated with corruption and bribery, Yang reminds us that there is a distinction: 
"Guanxi places much more emphasis on renqing and the long-term obligations and bond of the relationship than the material interest exchanged, whereas in bribery and corruption, the social relationship is a means, not an end, of the exchange" $(2002,465)$. This distinction is clear to Lau Wen and the restaurant owner.

Yang also argues that although the line between guanxi and corruption is often a fine one, "the art of guanxi cannot be reduced to a modern western notion of corruption because the personalistic qualities of obligation, indebtedness, and reciprocity are just as important as transactions in material benefit" $(1994,108)$. Indeed, this distinction between guanxi and corruption is important to highlight here in order to understand why Lau Wan and the restaurant owner regarded their behaviours as guanxi rather than as acts of corruption. Both interviewees stated that they had maintained this social relationship with the same policemen for years. Both givers and receivers knew each other's names, talked about their work and business in daily conversations, and saw themselves as mutually benefitting from their relationship. Although we can understand the motivations from the point of view of the Chinese givers, we do not know how the South African police involved in these exchanges perceived them. Did they also see their interactions as a guanxi-based relationship or as just another act of bribery?

Without further research on the policemen, it is impossible to provide any answer. But one argument worth exploring here is that the definition of corruption is not clear-cut, and interpretations of corruption vary depending on one's social position, particular behaviour, and motivation (Smith 2007). The ethnographic data from my research suggest that some Chinese migrants tend to employ guanxi practices when dealing with South African officials as an informal and efficient way to go around formal regulations. 
Corruption, like guanxi, is ambiguous in nature, as the survey by Struwig et al. (2014) illustrates that there is no broad agreement on what forms of corruption are tolerated and acceptable. Although this dissertation is limited to the restaurant and fahfee sectors operated by Cantonese-speaking Chinese in Johannesburg, drawing on anthropological analyses (Smart and Hsu 2007; Smith 2007; Yang 2002) offers insight into Chinese migrants' experiences of guanxi as well as of corruption, illustrating that their participation in the former is culturally expected but their participation in the latter is often done with reluctance.

\section{Concluding Remarks}

Since guanxi can be understood as network ties and the tightening of bonds between parties, most scholars of Chinese migration studies agree that networks are one of the most important resources for Chinese newcomers to any host country. In other words, guanxi is being practiced everywhere, including South Africa. Given that Cantonese migrants are provided with working opportunities in the fahfee and restaurant industries, which are partially inherited from Cantonese-speaking South Africans, it is not surprising to see that many Cantonese newcomers find their first job either in a restaurant or in the fahfee sector.

Accordingly, when I conducted research in restaurants, I met several Cantonese waitresses whose husbands were fahfee men, and some male cooks and sushi chefs switched jobs between restaurants and fahfee depending on the conditions. Usually, a restaurant job is considered more stable and safer; however, the average income is lower than the earnings of a fahfee man. With businesses and job opportunities that are largely 
structured around guanxi relations, the new generation of Chinese migrants can avoid full engagement with the host society.

Operating in this parallel marketplace and society, Cantonese newcomers can function - at least to some degree and for some period of time - without having to learn a local language or adapt to the local culture. In other words, there is a strong tendency for newly arrived Cantonese-speaking migrants to join a close-knit Chinese community on which they are economically dependent in South Africa. I return to the discussion on "dependency" in Chapter V. What is important to note is that the implications and practices of guanxi may differ from situation to situation, its meanings may change over time, and it is not a fixed phenomenon. While the practice of guanxi itself remains highly fluid, scholars like Yang (1994, 2002), Xin and Pearce (1996), and Smart and Hsu (2007) have demonstrated that it tends to emerge more frequently when financial institutions and legal systems are unable to provide reliable services. In the case of Cantonese rural migrants who are, for whatever reason, unable to emigrate through formal institutions, guanxi ties enable them to depend on an informal migration agency to relocate and even to find a job in South Africa. This explains why, though most Cantonese newcomers lack proficiency in any of the official languages of South Africa, they are not excluded from the job market. This informality or "alternative economy" also explains why, as the next two chapters show, Chinese restaurant entrepreneurship in South Africa involves Zimbabwean migrants.

There is a similar emphasis on personal ties or networking in other cultures, including Zimbabwean migrants, and they, too, face the challenges of corruption in South Africa, especially when crossing the border between South Africa and Zimbabwe. The 
next chapter is about their stories and explores common forms of corruption and discrimination they face in their everyday lives. 


\section{CHAPTER III}

\section{CONCEPTUALIZING THE INTRA-MIGRANT ECONOMY WITH THE ZIMBABWEANS}

\section{The Price of R 10}

Just after lunchtime, on a sunny day with a beautiful blue sky and an easy breeze in Johannesburg, I parked my rental car on a quiet street near Chinatown, waiting for Zimbabwean participants to contact me whenever they took their breaks. I was constantly checking my phone, looking at my surroundings, and expecting participants to show up. It was not my ideal way of interviewing people, but every Zimbabwean participant worked at least ten hours a day, six days a week. They did not have extra time to meet me outside of work.

A WhatsApp message came from Kelly, whom I had met briefly through her coworker, one of the interviewees that my assistant Tichaona helped to recruit. Kelly asked if she could bring her co-worker, Grace, along for the interview. I gladly extended the invitation. Grace and Kelly came and told me they only had forty minutes for lunch break that day. I told them I could interview both of them together with their permission. Kelly and Grace said they were good friends and did not keep secretes from each other. I invited them to come in. They both sat in the back of the car.

I quickly noticed Grace was the quiet one, only responding when I asked her direct questions. Kelly had been in South Africa longer and had more experience working for the Chinese; she was dominating the conversation. When I asked how much they spent on transportation between work and their rental places in Johannesburg, Grace sat forward a bit. She stuttered through trembling lips and repeated, "Ten rand. Ten rand." 
Then she sat back quietly. She was shivering slightly. It seemed like she was in tears. The awkward silence in the air was so deep it was as if I could hear her teeth moving. I did not know why it was such a difficult question. I looked at Kelly. She gazed at Grace, also in silence. I was wondering if I should ask them what had gone wrong, but then I saw that thirty-five minutes had passed. I thanked them for the interview and asked their permission to contact them for follow-up questions. They walked out of the car and went back to work.

A few days later, I interviewed another participant, Prudy, at the same location. I asked Prudy about the cost of transportation. She told me she walked to work in the morning and took taxis after work. She said it was dangerous to walk around the area, especially at night. Some of her friends had been robbed while walking alone even during the daytime. Prudy pulled out a phone from her bra to show me how to hide valuable items. She shook her head and said, “I don't want to pay ten rand every night when I can walk, but it's just not safe. Like last month, someone who lives in my neighbourhood was raped by two men when she walked home after work."

After the interview, Prudy said she had the afternoon off. I offered her a ride home. We drove by a park. Prudy showed me where the Zimbabwean woman was raped.

"Did she get any help?” I asked.

"I heard she went to a hospital," Prudy responded.

"Did she call the police?"

"I don't know. But what's the point? No one will get arrested, and she might be deported."

“Does she work in Chinatown?” I asked.

"Yes, [name] restaurant." 
I soon realized the rape victim might have been Grace, as there were only three Zimbabwean women working at that restaurant, and I had interviewed all of them. I asked Prudy a few more questions about the victim's background. Her answers confirmed my assumption. I then understood why the question had been difficult for Grace, especially since the tragedy had happened just two weeks before our interview.

Based on the data collected from twenty-six recently arrived Zimbabwean migrants who were, or had been, working at Chinese restaurants, this chapter explores aspects of their living conditions in Johannesburg. The opening story was intended to provide readers with a sense of the insecurities and the constant battle between saving and spending (what for us in North America seems like a small amount of) money that many low-wage Zimbabwean migrants face in their daily lives. Grace's son depends on her, and she told me during the interview that she needed to get $\$ 60 \mathrm{USD}^{33}$ to pay his school fees for the term. Every day after work she faces a dilemma: Do I take a taxi knowing that it is much safer? Or risk my safety so I can save R 10 (less than \$1 CAD) today? Obviously, at one point at least, Grace chose her son's education over her own safety.

The first section of this chapter provides a brief overview on Zimbabwean migration to South Africa, particularly the Ndebele in Johannesburg as they made up the majority (twenty-three out of twenty-six) of Zimbabwean participants in my research. By comparing and contrasting my data with Khangelani Moyo's (2017) data on 150 Zimbabweans in Johannesburg, I also demonstrate some similarities between Chinese and Zimbabwean migrant groups as well as their differences, such as features of their migrant

\footnotetext{
${ }^{33}$ In 2009, after its economy collapsed, Zimbabwe dropped its currency and adopted multiple currencies, particularly the US Dollar and South African Rand.
} 
networks. By integrating secondary sources from news and Moyo's data, the next section discusses the effect of xenophobic attacks on Zimbabwean migrants in Johannesburg. One of the diasporic experiences they tend to share with Chinese im/migrants is constantly living in fear-what I called "everyday racialized insecurities" in Chapter I. For Zimbabwean migrant workers, their insecurities are driven not only by crime and xenophobic sentiments, which often run high in Johannesburg, but also the problem of corruption when crossing the South Africa-Zimbabwe border to visit home.

The chapter also discusses Zimbabwean migrants' economic livelihoods. Zimbabwean employees in Chinese restaurants, to some degree, fit within the definition of the informal sector, which is largely characterized by easy entry; low-skill, low-salary, hourly wage work; high turnover; and small-scale businesses. However, this is their only stable source of income - at least for the Zimbabwean participants in this project. Zimbabweans who earn less than the minimum wage and have others who depend on them are more likely to be involved in other sources of income-generating activities. This chapter introduces one of the methods: an informal loan club, or sitofela in the Ndebele language. In the scholarly literature, it is known as a rotating savings and credit association (ROSCA). It is usually used by a group of trustworthy friends - in this case, Zimbabwean women migrants - to borrow and save together.

Lastly, this chapter presents the idea of the "intra-migrant economy," a term I use to refer to the employment of one or more group of migrants by another group of migrants as an economic strategy outside the mainstream labour market. The terms "immigrant economy" (Siu 1987) and "ethnic entrepreneurs" (Smart 2003) refer to a minority ethnic group in a host country that tends to occupy certain types of sectors. 
Building on these concepts, which have been developed in order to understand the relationship between diaspora and entrepreneurship, I introduce the concept of the intramigrant economy to explore deeper questions beyond transnational movements and look at how the economic flow is localized and how it impacts migrants. By examining how Chinese and Zimbabwean migrants have been positioned in South Africa's racialized market, this section explains the persistence of the current racial wage gap despite some progress since the end of apartheid over two decades ago. The legacy of this colonial structure is still far from being addressed, and black bodies continue to be used as cheap labour in Southern Africa (Ferguson 2015).

\section{Ndebele in Johannesburg}

The flow of out-migration from Zimbabwe increased massively during the 1990s and has risen again sharply since 2000 due to economic crisis and social collapse (Chikanda and Dodson 2013; Crush and Tevera 2010). Similar to Chinese migration to South Africa, the demographic backgrounds of new-generation Zimbabwean immigrants are much more diverse than those who arrived earlier (Crush et al. 2015). Interestingly, while Chinese migration to South Africa has shifted to more temporary residency compared to those who arrived before the 1970s, Jonathan Crush, Abel Chikanda, and Godfrey Tawodzera (2015) observe that the pattern of Zimbabwean migration has shifted from temporary to permanent and semi-permanent migration.

Furthermore, Crush et al. $(2015,365)$ suggest that migration from Zimbabwe to South Africa should be identified in three waves: The first phase occurred from the late 1980s to the mid-1990s as South Africa opened its borders after the collapse of apartheid, 
the second wave is considered to have occurred from the mid-1990s to 2005, and Zimbabweans who came to South Africa from 2005 onwards are the third wave of migrants. There are certain characteristics shared by the third-wave migrants, such as an increase of unmarried and working-age (twenty-five to forty-four years old) women (Crush el al. 2015, 371). Most of the Zimbabwean participants in this research belong to the third wave of migrants and also share these characteristics.

As with the Chinese in South Africa as discussed in the previous chapter, it is impossible to verify the number of Zimbabweans in South Africa. Estimating the size of the Zimbabwean population is difficult for a number of similar reasons: historically, the emigration and immigration of black Africans were not officially recorded by the government of Rhodesia ${ }^{34}$ before 1980 respectively (Moyo 2017); there is a large number of poor and low-skilled Zimbabweans working in informal settlements who are not represented in current South African statistics; and it is a sensitive and controversial issue due to the xenophobic tendency in South Africa (Makina 2010). There has been much debate about the number of Zimbabwean migrants in South Africa, and estimates have ranged from 1.5 to 4 million (Crush and Tevera 2010; Sisulu el al. 2007). The South African media usually claims there are 3 million; however, Jonathan Crush and Daniel Tevera (2010, 3-4) argue this estimate is greatly exaggerated based on unreliable sources. Others argue that the number does not exceed 1.5 million; nevertheless, it is generally agreed that Zimbabwean migrants constitute the largest foreign national group in South Africa (Moyo 2017).

\footnotetext{
${ }^{34}$ Rhodesia was the name of Zimbabwe until 1980.
} 
For decades, Zimbabwean migrants worked, whether permanently or seasonally, on farms located in the borderlands of Limpopo, northern South Africa (Rutherford 2010). As Blair Rutherford (2010) points out, due to a number of changes in institutional arrangements, the size and structure of the Zimbabwean farm labour force shifted in the post-2000 period. According to the 2001 South African Census, 52\% of recorded Zimbabweans were in the province of Gauteng, 13\% in KwaZulu-Natal, $12 \%$ in Limpopo, and 9\% in the Western Cape (Crush and Tevera 2010, 7). As the largest city in Gauteng and in South Africa, and the one with most employment opportunities, Johannesburg, and particularly its inner-city areas, has thus become a major destination for Zimbabwean migrants (Makina 2010; Moyo 2017).

Since the end of apartheid, Johannesburg's downtown has been considered a “migrant space." Areas such as Hillbrow and Yeoville are home to a high percentage of African migrants, including Zimbabweans (Moyo 2017). Moyo's data indicates that the majority of Zimbabwean migrants prefer to live in the inner city because of relatively low rental costs and the high number of foreign residents, which provides a sense of belonging and security, despite the high levels of crime in these areas.

The majority of Zimbabweans (twenty-three out of twenty-six) I interviewed were Ndebele from the southwestern part of Zimbabwe. IsiNdebele is the second-largest linguistic group next to the majority Shona-speaking peoples in Zimbabwe. Ndebele ethnicity, like all identities, is fluid, and its formation has not been a coherent process. Gugulethu Siziba $(2014,263-64)$ argues that "Ndebele" is a theoretical construct and there have been debates about who is Ndebele. Moyo $(2017,118)$ also points out that Ndebele ethnicity does not only include Ndebele but also commonly represents the 
Khalanga, Tonga, Venda, Shangani, Nambya, Sotho, and other minority groups. Similarly, the Shona, as an ethnic group, represents different sub-groups, including Zezuru, Korekore, Karanga, Manyika, and Ndau. IsiNdebele is the common language spoken by the Ndebele, Kalanga, Tonga, Venda, and Sotho, and those who speak isiNdebele usually identify themselves as Ndebele (Siziba 2014). Generally speaking, Zimbabweans in South Africa refer to themselves as either Shona or Ndebele, and they usually communicate in English with each other, particularly in Johannesburg (Moyo 2017).

Moyo $(2017,82)$ notes that historically, ethnic Ndebele and Kalanga Zimbabweans moved to South Africa due to the lack of economic opportunities in the southwestern parts of Zimbabwe. Furthermore, Elinor Sisulu, Bhekinkosi Moyo, and Nkosinathi Tshuma (2007) point out that prior to 2000, most Zimbabwean migrants in South Africa were Ndebele escaping from the Gukurahundi conflicts, which occurred in the Matabeleland and Midlands provinces from 1983 to 1987. Nowadays, they notice that there has been an increasing number of Shona-speaking Zimbabweans in Johannesburg.

In Moyo's research, among 150 Zimbabwean participants, there were more Ndebele (55.3\%) than Shona (44.7\%). Nevertheless, Moyo writes, "the distribution does not however reflect the actual numbers of the Ndebele and Shona as such ethnic enumeration is not currently available in South Africa" $(2017,118)$. To my knowledge, there are more Ndebele working in Chinese restaurants and Chinatown, and more Shona working at Chinese malls. Although I did not interview those who work at malls, I suspect social networking plays a key role, as with the Zimbabweans working at Chinese restaurants, in shaping employment opportunities. 


\section{Migrant Networks}

As argued in Chapter II, the concept of guanxi is a unique combination of social network, business strategy, and cultural practice that may strengthen (or constrain) personal relationships and employment opportunities in the case of Cantonese-speaking migrants in Johannesburg. Likewise, social networks play an important role in shaping Zimbabwean migrants' access to accommodation and employment opportunities, especially upon their arrival in South Africa. As Moyo (2017) argues, Zimbabwean migrants' social networks not only play the main role in shaping where these migrants move and settle but also help to create spaces that maintain Zimbabwean identity.

Out of the twenty-six Zimbabwean interviewees for my research, twenty had received help from family members or friends when they first moved to Johannesburg. My data also shows that fifteen of them got their jobs in Chinese restaurants through a family member or friend who had worked there. The remainder followed others' advice in seeking employment opportunities with the Chinese. One interviewee who did not really know anyone when she first arrived in Johannesburg stayed on the streets of Braamfontein near the Park station for the first few days. She was desperate for a job. Any job. She asked all Zimbabweans she could find on the street how to get work. Describing how she found her first job, she said, "People told me to just go to Chinatown or any Chinese restaurant and ask every Chinese person if they are hiring. If they need people, they hire you right away." Most importantly, she noted, "Chinese don't check ID."

This job-search strategy was confirmed by the Chinese participants in this research. When I asked Chinese employers how they recruited Zimbabwean (or African) 
employees, they revealed that their current employees introduced family members or friends, or people just showed up and asked for a job. An interviewee who had been working in Chinatown for more than five years had helped several family members and friends to get jobs in Chinatown. She told me that her Chinese employers' friends always asked her to recruit Zimbabweans when they were looking for help. "Chinese don't like South Africans," she said. "To work in restaurants you can't be lazy.... Chinese like Zimbabweans because they know we are hardworking people."

My own experience seems to confirm that a large number of Zimbabweans in Johannesburg are employed in restaurants, including non-Chinese ones. In fact, I met two Zimbabwean participants at non-Chinese restaurants. One participant was serving my table; the other participant was making bread and we started a conversation while I was waiting for my take-away order. They both mentioned that they used to work at Chinese restaurants, so I recruited them for my research.

The server I met was Shona, and she had worked with three Ndebele individuals in a Chinese restaurant's kitchen when she first arrived in Johannesburg. She found that job by following a friend's suggestion, which was to walk into a Chinese restaurant and approach the Chinese employers. She was hired on the spot. Nevertheless, she did not get along with her Ndebele co-workers. After several weeks, the Chinese employer had to step in because their conflicts caused serious tensions in the kitchen, and orders were delayed. She was sent home early that night. "The Chinese lady phoned me the next day," the Shona participant explained. "The Chinese lady likes me, said I work fast, didn't want me to go, but the Ndebele worked there longer and she can't lose them. I told her I understand, I will just come to fetch my money and leave." She later found her current 
serving job at a restaurant owned by white South Africans, where she gets along with her Shona co-workers.

This is not to suggest, however, that there is serious tension between Shona and Ndebele migrants in Johannesburg. For instance, the other two Shona participants in my research did not report any conflict with their Ndebele co-workers. In fact, I met one of the Shona participants through her good friend, who is Ndebele and works in Chinatown. As Moyo's (2017) data indicates, there is a high level of interaction between Zimbabweans from different ethnic backgrounds, such as through marriage, business partnership, and friendship. On the other hand, Gugulethu Ziziba's (2014) data shows that many Shona found living in Hillbrow difficult because they felt this space was dominated by Ndebele. At the same time, some Ndebele participants from Moyo's $(2017,131)$ research voiced that the Shona were relatively better resourced than the Ndebele and dominated in the suburban areas of Johannesburg.

Indeed, Ndebele-Shona relations can be tricky at times. Both Moyo and Ziziba point out that sometimes Zimbabweans prefer to live with those who share the same ethnicity or language. For instance, Moyo $(2017,144)$ has pointed to the example of accommodation advertisements as a subtle and effective way to select tenants. When Ndebele look for tenants or roommates, they put their first names, surnames, and contact information on the advertisements because, most likely, only potential Ndebele renters will call (see Figure 12). 
Figure 12: Rental Advertisements on Telkom Towner Wall in Hilllbrow (Fieldwork photo)

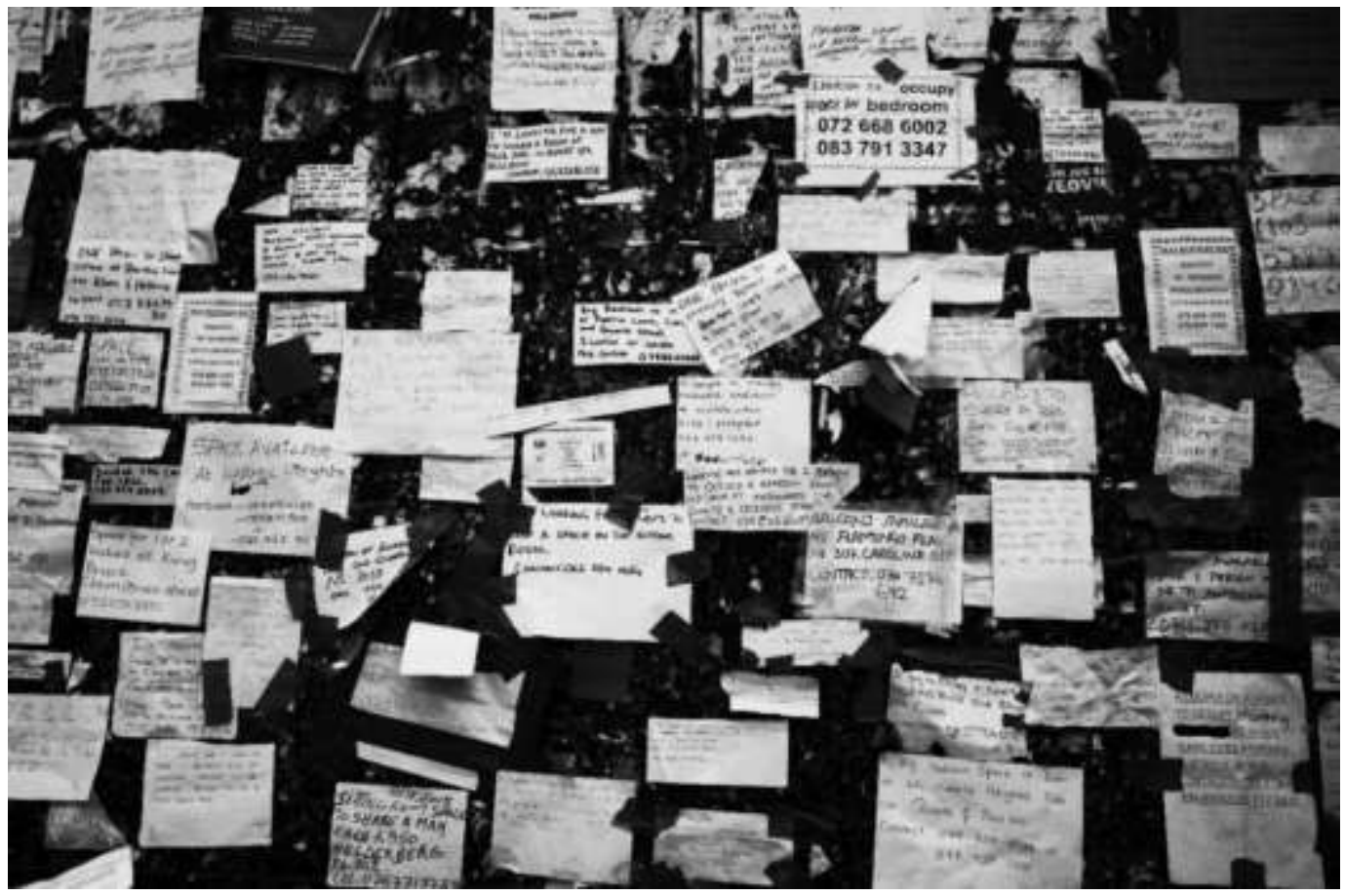

In terms of the migrant populations, as noted in Chapter II, although the exact

number of newly arrived Chinese is impossible to verify, it is generally understood that one-third are from Fujian province, and migrants from Guangdong are the second-most numerous. One reason it is easier to trace Chinese migrants' regional backgrounds in South Africa, I suggest, is the relatively strong overseas Chinese associations established on the basis of shared province of origin and a strong guanxi network.

Both new Chinese and Zimbabwean migrants usually rely on their family and friends when they first arrive in Johannesburg. As I demonstrated in the last chapter, examples of cooperation between Cantonese and Fujianese show that guanxi can transcend different regional backgrounds; interestingly, I have heard and seen a few cases where Chinese tried to help Zimbabweans to get jobs within the Chinese community. For 
example, the following two advertisements were posted in a Chinese WeChat group (see

Figure 13).

Figure 13: Chinese Helping Zimbabweans Job Search

\begin{tabular}{|c|c|}
\hline 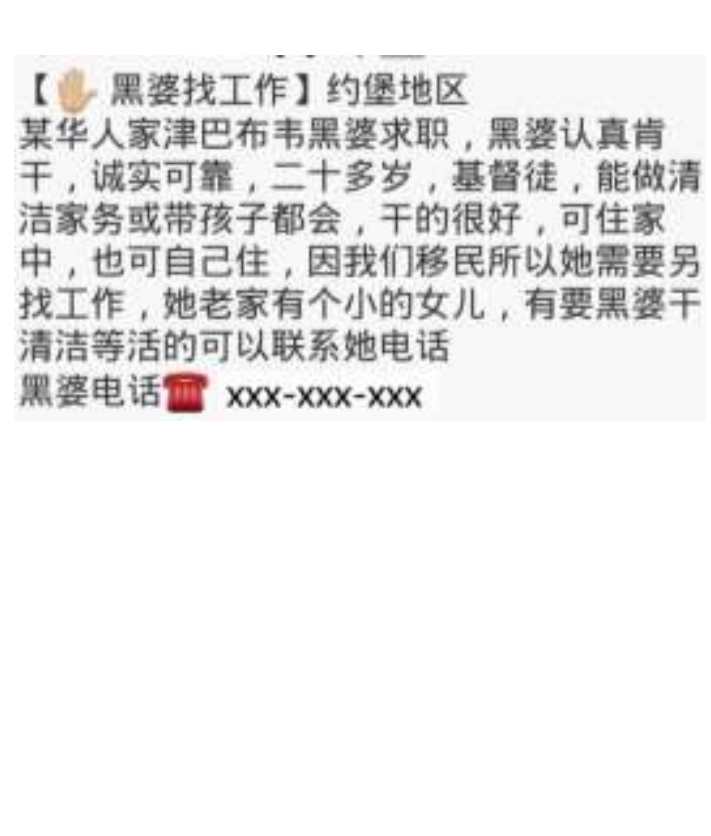 & $\begin{array}{l}\text { [Black woman looking for job] Joburg } \\
\text { area } \\
\text { A Zimbabwean black woman, who has } \\
\text { been working with a Chinese family, is } \\
\text { looking for a new job. She is } \\
\text { hardworking, honest, and reliable. Twenty } \\
\text { something years old, Christian. She can } \\
\text { clean or take care of children, all } \\
\text { performed well. She can live at home, or } \\
\text { on her own. Because we are migrating, } \\
\text { she needs another job. She has a small } \\
\text { daughter back home. If you need a black } \\
\text { woman doing cleaning or else, contact her } \\
\text { directly } \\
\text { Black woman's number: xxx-xxx-xxx }\end{array}$ \\
\hline
\end{tabular}

\begin{tabular}{|c|c|}
\hline $\begin{array}{l}\text { 【黑婆求职】 } \\
\text { 津巴布韦黑婆，会干清洁工，为人老实，能 } \\
\text { 吃苦，因原工作的中国公司关闭，所以重新 } \\
\text { 找工作，如有需要，请联系黑婆 } \\
\text { 电话而 ᄂ } \\
\text { 7hour(s) ago }\end{array}$ & $\begin{array}{l}\text { [Black woman looking for job] } \\
\text { A Zimbabwean black woman, who can } \\
\text { clean well, is honest and hardworking. } \\
\text { Her current Chinese employer is closing } \\
\text { down the business, so she needs a new } \\
\text { job. For inquiries, please contact the } \\
\text { black woman directly } \\
\text { Phone number: } x x x-x x x-x x x\end{array}$ \\
\hline
\end{tabular}

Even though Zimbabweans' social networks also play an important role in shaping their access to accommodation and employment opportunities, it is not quite the same as guanxi. I identified two main differences between Chinese and Zimbabweans when I compared and contrasted my data. First, most Zimbabweans I interviewed did not 
know other Zimbabweans outside of their own circle of family members, friends, or coworkers in Johannesburg. On the other hand, a large number of Chinese migrants involved in the restaurant business (and to some extent small retail business) might not know each other, but they can often identify who owns which restaurant or who has worked or is currently working at which restaurant and sometimes can gossip about strangers' personal lives.

Second, the Chinese share business and employment information with other Chinese more than with others. For instance, salaries are not a secret, including those of Zimbabweans or other African workers. One Zimbabwean participant found the sharing of information between Chinese people irritating. As she said during our interview, "It's impossible to ask for more salary even if I switch to work for another Chinese. Chinese all know about our salary, but it is not right. Every job is different, we have different qualifications. This is not fair!”

As noted in the last chapter, Chinese restaurant owners often talked about where to get better or cheaper suppliers and how to manage staff within their own circle. They were also willing to inform other Chinese outside of their circle about certain things; for instance, they would warn others not to hire someone (usually a non-Chinese person) if they encountered theft or fraud. Sometimes this kind of information can be found on Chinese WeChat groups (see Figure 14). 
Figure 14: Warning Posts

\begin{tabular}{|c|c|}
\hline 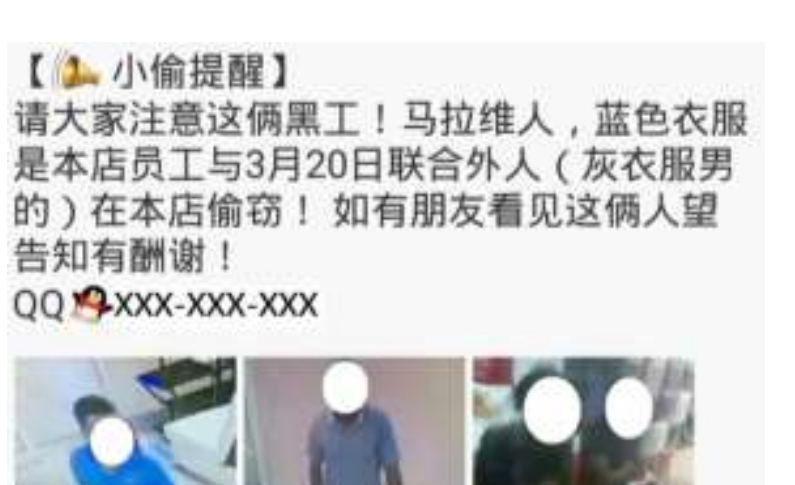 & $\begin{array}{l}\text { [Thief Warning] } \\
\text { Everyone please pay attention to } \\
\text { these two black workers! } \\
\text { Malawians. The man in blue shirt } \\
\text { was my staff. On March 20, he and } \\
\text { an outsider (the man in grey shirt) } \\
\text { stole my stuff. If any friends see } \\
\text { these two men please let me know. I } \\
\text { will thank you with a reward. }\end{array}$ \\
\hline 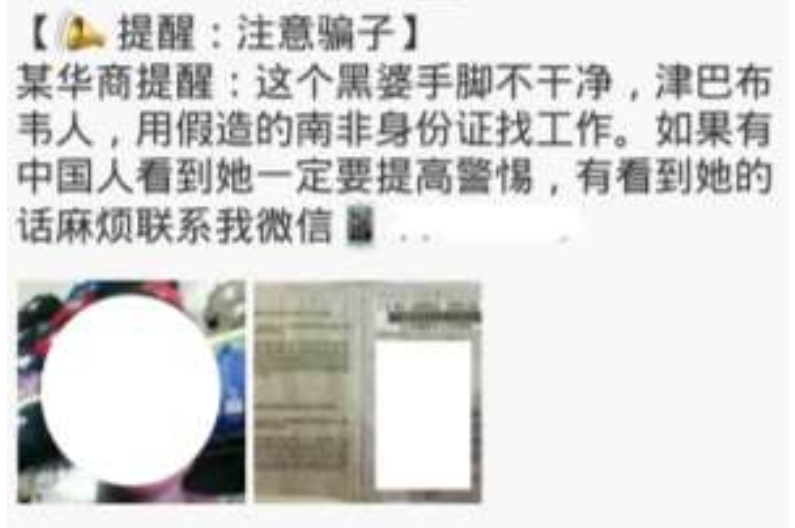 & $\begin{array}{l}\text { [Warning: Pay attention to this lair] } \\
\text { A Chinese businessperson reminds: } \\
\text { This black woman's hand and feet } \\
\text { are not clean (have sticky fingers), } \\
\text { Zimbabwean, has been job } \\
\text { searching with a fake South African } \\
\text { identity. If any Chinese people sees } \\
\text { her, must be vigilant. Anyone who } \\
\text { sees her please contact my WeChat: } \\
\text { xxxxxx }\end{array}$ \\
\hline
\end{tabular}

Chinese employers do not necessarily share information about a "bad employee" if the subject is Chinese because of guanxi and the likelihood that the "bad employee" will find out about it in such a close-knit community (see Chapter V for details). As a result, people usually take more caution when sharing any negative information about other Chinese in public. Zimbabwean migrants, on the other hand, do not necessarily warn others about "bad Chinese employers" unless they are family or close friends. For instance, one Zimbabwean interviewee mentioned that every time she saw new 
Zimbabwean migrants walking into her previous workplace looking for work, she wanted to warn them that her former employers were "bad Chinese people." I asked why she did not. "New [Zimbabwean] people are desperate for work, I know. I was like that so I took whatever first job I could get. Once they start working there they know what's wrong. If I try to stop them, maybe some will even think I am trying to prevent them from getting a job or I am jealous or something. I better mind my own business," she explained.

\section{Everyday Racialized Insecurities: Xenophobia}

“Wednesday Zulu pp are coming to town starting from market they mission is to kill every foreigner on da road pls pass ths 2 all ur contacts in case they cam pp should b on allert!"

This was an SMS message that I and many people received in April 2015 during the period of a series of xenophobic attacks in Johannesburg (see also Raborife 2015). When the Zulu king Goodwill Zwelithini called for the deportation of foreigners in March, several attacks started in Durban, then spread to parts of Johannesburg (Ndou 2015). News clips repeatedly showed a crowd of angry South Africans armed with sticks, knives, and axes chanting and burning tires. Police were sent to monitor protests and patrol in the areas with a high percentage of foreign residents like Hillbrow and Johannesburg Central Business District. Tensions were running high. Foreign-owned shops were forced to close down. At least seven people died in the attacks. Hundreds of foreigners fled their homes and sought refuge at local police stations (Patel 2016). People 
talked about what had happened in 2008. ${ }^{35}$ But people also talked about how this would not be the last time in South Africa.

The Zimbabwean kitchen helpers I worked with during that period took days off to stay home when the streets were too chaotic. While Zimbabweans were taking extra precautions for their safety, the Chinese migrants, generally speaking, were not concerned about xenophobic attacks; rather, losing business during clashes was their main worry. However, interestingly, Chinese migrants tend to be more visible, whether physically or linguistically, and Chinese communities are easily identified. The First Chinatown along Commissioner Street in the inner city, the New Chinatown in Cyrildene, and neighbouring areas such as Bruma, Edenvale, Bedfordview, and Kensington are widely known to have a large number of Chinese residences (Harrison el al. 2012).

Moyo (2017) argues that Zimbabwean migrants, on the other hand, do not fit into the ethnic enclave narrative, as there are no known "Zimbabwean spaces" besides the Central Methodist Church in the Johannesburg Central Business District. Initially, the Central Methodist Church provided help to any homeless people and refugees, but later it became a significant space for Zimbabwean migrants because of the xenophobic attacks in 2008 (Moyo 2017, 42-44). The effect of xenophobia in South Africa on Zimbabwean migrants, Moyo argues, is the determining factor for Zimbabweans deciding where to live. For instance, according to Moyo’s data (2017, 109-110) 62\% of Zimbabwean participants reside in the inner-city area of Johannesburg versus $11.3 \%$ in townships,

\footnotetext{
${ }^{35}$ In 2008, sixty-two people (among them twelve Zimbabweans) were killed due to xenophobic attacks in South Africa, and tens of thousands of people were displaced and forced to seek refuge in churches, mosques, and even police stations (News 24 Online 2008a and 2008b).
} 
where the majority of residents are low-income and poor black South Africans.

Zimbabwean migrants try to avoid townships such as Soweto, Alexandra, and Ivory Park due to the fear of xenophobia. Moyo's data also show that Zimbabwean residents who live in townships have the lowest level of attachment to their homes in South Africa.

Table 3: Large-Scale Xenophobic Attacks in South Africa since May 2008

\begin{tabular}{c|cc}
\multicolumn{1}{c}{ Time } & Location & Primary Victims \\
\hline May 2008 & $\begin{array}{c}\text { Durban, Cape Town } \\
\text { Parts of Gauteng, Western } \\
\text { Cape, Mpumalanga, North } \\
\text { West and Free State Provinces }\end{array}$ & $\begin{array}{c}\text { Mozambican, Malawian, } \\
\text { Zimbabwean }\end{array}$ \\
June 2013 & $\begin{array}{c}\text { Port Elizabeth, northern } \\
\text { Limpopo }\end{array}$ & Somali \\
April 2015 & Durban, Johannesburg & $\begin{array}{c}\text { Bangladeshi, Ethiopian, } \\
\text { Mozambican, Zimbabwean }\end{array}$ \\
October 2015 & Eastern Cape & Bangladeshi, Pakistani \\
& Pretoria & \\
June 2016 & & Somali, Pakistani \\
& Pretoria, Johannesburg & Nigerian, Zimbabwean, \\
& & Somali, Malawian \\
\hline
\end{tabular}

Sources: BBC News 2013; Ferreira 2015; GroundUp 2016; The Guardian 2017; Madia 2017; McGreal 2008; News 24 Online 2008a, 2008b; Pampalone 2010a, 2010b; Swails 2015; van Rensburg et al. 2015.

Generally speaking, xenophobic sentiment has affected many non-white migrants in South Africa, but it has much bigger impacts on Zimbabweans than Chinese. A few Chinese shops were looted during the riots but, by and large, the Chinese were not the 
target of xenophobic discrimination. Zimbabweans, along with other black Africans and a few migrants from some parts of South Asia, have been the main victims during waves of violent attacks throughout the years (see Table 3). In other words, perhaps these attacks on foreigners are more afrophobic than xenophobic (Mbembe 2015).

As argued in Chapter I, Chinese migrants constantly live in fear of crime, experiencing everyday racialized insecurities. In order to protect themselves, they have a few common practices such as avoiding contact with local black South Africans, installing security cameras at work and surveillance systems at home, and hiring security guards. Zimbabweans, too, often have to deal with job insecurity and safety issues in South Africa, but they cannot afford to hire private security or to live in gated communities. The easiest and lowest cost tactic for them, as Moyo (2017) points out, is to hide their Zimbabwean identity.

Moyo's survey shows that when asked whether they identified as Zimbabwean, most of his participants did not give a simple answer of yes or not, "but [went] on to provide explanations for their choices, which further indicates the weight attached to one's choice of identity in a given situation" $(2017,207)$. I shared a similar experience. In Johannesburg's Chinese restaurants, a few African staff members first told me that they were South Africans or claimed Zulu as their native language. Some of them later revealed to me that they actually came from Zimbabwe when I expressed my research interest in Zimbabweans.

Moyo argues that the biggest influence on the choice to hide one's Zimbabwean identity is fear of xenophobia and crime:

The fear of xenophobic discrimination is an important structural component that informs specific decisions by migrants. In this sense, South African citizens may not 
need to directly interact with foreign migrants to exert fear of xenophobic violence but the association of xenophobic sentiment with South African citizens is enough strategic power to influence tactical circumnavigation by Zimbabwean migrants. (2017, 179)

One technique for hiding their Zimbabwean identity is to not speak their native languages in public. For instance, Moyo points out that most Shona-speaking participants replaced chiShona with English as their first language after moving to South Africa. As Moyo explains it,

If you speak in English, you may not be readily identifiable as a Zimbabwean and one has to go further beyond the English speaking subject to uncover the real identity. It is better to speak in English; "you cannot go about speaking in Shona, using words like sadza (thick porridge), muriwo or maveggie (vegetables)”... Such language, which immediately distinguishes one as a foreign national exacerbates the risks of xenophobic violence. As such, there are changes in the mindset, in the habitus of a Shona Zimbabwean due to the requirements of the new social field. For the Shona Zimbabweans, for example, English becomes a dominant language in primary interactions with South Africans and other migrants, including the Ndebele speaking Zimbabweans. (2017, 185-86)

It is worth noting that it is much easier for Ndebele to blend in with the South African public compared to Shona-speaking Zimbabweans. The Ndebele language is one of the Nguni dialects and shares similarities with isiZulu, which is one of the most commonly spoken local languages in South Africa (Siziba 2014). IsiNdebele is also one of the eleven official languages of South Africa. When my assistant Tichaona and I walked around Chinatown and Chinese malls for days trying to recruit potential participants, he 
sometimes had difficulty figuring out who was Ndebele and who was Zulu even after exchanging words with them, because some Ndebele have adapted the Southern Ndebele (Zulu) accent.

Besides xenophobic sentiments and high crime rates in South Africa, many Zimbabwean migrants find crossing the border between South Africa and Zimbabwe even more frustrating than living in Johannesburg for a number of reasons. First, there is a high risk of being robbed, beaten, raped, or murdered, as smugglers and gangsters control the borderlands (Rutherford 2008). Second, corruption is very high at the Zimbabwe-South Africa border on both sides (Evans 2015). The Zimbabwean migrant workers I interviewed who did not have valid travel documents said they had to pay border transport operators R 600 to R 1000 on each side of the border. The operators would bribe the immigration officials at the border to let the migrants pass through without proper documents or to not receive a stamp in their passports. Two interviewees mentioned that they had to pay multiple parties last time they came into South Africa, as the bus driver did not make the "right" arrangements.

More than half of the Zimbabwean women I interviewed were the primary financial providers for their children, but less than one-third of them had their children with them in Johannesburg. The ones who left their children in Zimbabwe came to South Africa to work, sent money back to relatives who were taking care of their children, and periodically made trips home. They mentioned that they would like to visit home more often, but crossing the border was getting too difficult, as the required bribes were increasing. Instead of visiting, they sent remittances home through bus drivers or omalayisha (border transport operators). Sometimes instead of sending cash, 
Zimbabwean migrants buy goods in South Africa and pay omalayisha to bring the goods home. Their family members either use them or sell them to earn cash. Vusilizwe Thebe's $(2015,194-95)$ essay on the transnational movement of remittances pointed out that the omalayisha industry has grown rapidly, especially between Johannesburg and rural southwestern Matabeleland, and even begun to become the main rural bus service within Zimbabwe.

\section{Sitofela: Rotating Savings and Credit Association}

In Chinese restaurants, service and cashier jobs are mostly performed by Chinese women. Many medium-sized restaurants that cater to South African clientele have a combination of Chinese waiters (usually in manager positions), Chinese waitresses, and black African waiters and waitresses. African servers usually serve non-Chinese customers, while Chinese servers are for Chinese customers.

The jobs that require more specialized skills, like cooking Chinese cuisine and making sushi, are performed by Chinese men. I met two African chefs at different Chinese take-away restaurants. South Africa's recent economic decline and weakening currency had affected all aspects of migrant businesses and the labour market, for both Chinese and Zimbabweans. Fewer Chinese had been coming to South Africa, and some of the Chinese migrants had already left. More and more Chinese owners had trained or started to train African employees to cook Chinese food in order to reduce their own working hours and avoid having to hire an additional Chinese cook.

Although the pay may vary depending on various factors, generally speaking, Zimbabwean kitchen helpers earn from R 1500 to R 2700 per month, without 
accommodation and transportation provided. African chefs earn from R 3000 to 5000 .

Chinese cooks make R 12000 to 20000 per month, and Chinese servers make R 9000 to 11000 , with both accommodation and transportation provided or subsidized (see Table 4). A Chinese sushi chef's salary is less than a Chinese chef's (a starting salary is R 9000 to 10000 per month), because making sushi is a relatively easy skill to learn (though not by Japanese standards) compared to cooking Chinese cuisine.

Table 4: Distribution of Income within Chinese Restaurants

\begin{tabular}{|c|c|c|c|c|c|}
\hline Monthly & $\begin{array}{c}\text { Chinese } \\
\text { chef }\end{array}$ & $\begin{array}{c}\text { African } \\
\text { chef }\end{array}$ & $\begin{array}{l}\text { Chinese } \\
\text { sushi chef }\end{array}$ & $\begin{array}{c}\text { Chinese } \\
\text { server }\end{array}$ & $\begin{array}{c}\text { African } \\
\text { staff }\end{array}$ \\
\hline Salary & $\begin{array}{c}\text { R } 12000- \\
20000\end{array}$ & $\begin{array}{c}\text { R } 3000- \\
5000\end{array}$ & $\begin{array}{c}\text { R } 10000- \\
12000\end{array}$ & $\begin{array}{c}\text { R } 6000- \\
\quad 7000\end{array}$ & $\begin{array}{c}\text { R } 1700- \\
2200\end{array}$ \\
\hline Tip & sometimes & none & none & $\begin{array}{c}\text { R } 3000- \\
5000\end{array}$ & sometimes \\
\hline Meal & provided & varies & provided & provided & varies \\
\hline $\begin{array}{l}\text { Accommo- } \\
\text { dation }\end{array}$ & $\begin{array}{l}\text { provided or } \\
\text { subsidized }\end{array}$ & none & $\begin{array}{c}\text { provided or } \\
\text { subsidized }\end{array}$ & provided & none \\
\hline $\begin{array}{l}\text { Transport- } \\
\text { ation }\end{array}$ & $\begin{array}{l}\text { provided or } \\
\text { subsidized }\end{array}$ & $\begin{array}{l}\text { sometimes } \\
\text { subsidized }\end{array}$ & $\begin{array}{l}\text { provided or } \\
\text { subsidized }\end{array}$ & provided & $\begin{array}{l}\text { sometimes } \\
\text { subsidized }\end{array}$ \\
\hline
\end{tabular}

Source: Fieldwork data, 2015-2016.

Sushi is very popular in urban areas of South Africa and can be found in many local chain restaurants (e.g., Ocean Basket), in pre-packaged sushi boxes at supermarkets, and at sushi bars inside supermarket chains (e.g., Woolworths). Nevertheless, the 
cheapest place to get freshly made sushi is at Chinese restaurants, as some of them offer an "all you can eat" sushi buffet (around R 150 per person). The Chinese sushi chefs working at non-Chinese-owned sushi bars earn R 10000 to 12000 month without any additional benefits. There are African sushi chefs, mostly working at non-Chinese-owned restaurants and supermarket sushi bars, but I have no information about their wages.

Chinese servers make from R 9000 to 12000 (including tips), with accommodation and transportation provided. Chinese employees usually live with their employers or at a rental flat provided by their employers, and get a ride to work from their employers. There are some exceptions, such as those who prefer to live with their own family or have access to their own vehicles; they get their accommodation costs reimbursed.

In other words, while Chinese and African employees work nine to eleven hours a day, six days a week, Chinese employees' wages are at least three times higher than those of black employees. Furthermore, there has been increasing competition with other black Africans who are willing to accept lower wages because of the lower cost of living in their countries. For instance, some Zimbabwean workers have reported that their family members or friends are losing jobs in Chinese restaurants in Johannesburg to Malawians. As one interviewee stated, "Some of my friends lost their jobs because of Malawians. Malawians can work for less salary because they only need to send a small amount of money home, which is still a lot in Malawi. But not in Zim. And they don't go home often because their home is far-so they don't need to spend money on trips."

When the South African Rand shed 25\% against the US dollar over 2015 and 2016 (Bhoola 2016), it made it even more difficult for Zimbabweans, especially those 
financially supporting family back home in a dollar economy. Due to low wages and fewer employment opportunities, many Zimbabweans seek to survive financial hardship by having side jobs, and several women participants reported during interviews that they had formed or joined an informal loan club to help each other out.

Ndebele call this type of informal loan club sitofela, and it is also referred to as a ROSCA. It allows people without access to formal financial institutions to improve their welfare and can be found worldwide (Besley et al. 1993). Economists such as Besley et al. have provided explanations of how a ROSCA works:

Members commit to putting a fixed sum of money into a "pot" for each period of the life of the Rosca. Lots are drawn, and the pot is randomly allocated to one of the members. In the next period, the process repeats itself, except that the previous winner is excluded from the draw for the pot. The process continues, with every past winner excluded, until each member of the Rosca has received the pot once. At this point, the Rosca is either disbanded or begins over again. Roscas may also allocate the pot using a bidding procedure. We shall refer to this institution as a bidding Rosca. One individual receives the pot in an earlier period than another by bidding more, in the form of a pledge of higher contributions to the Rosca, or one-time side payments to the other Rosca members. Under a bidding Rosca, individuals may still receive the pot only once - the bidding process merely establishes priority. (1993, 792-93)

One Zimbabwean interviewee explained to me that usually a ROSCA is formed by a group of trustworthy friends, who agree to meet and make regular cyclical contributions to a common fund so they can save and borrow together. Everyone contributes a certain amount of money on a monthly basis, and the sum goes to the member of the circle who 
offers the highest bid to get the money. The person who wins cannot bid again and has to keep paying the monthly payment until the end of the lending circle. The informant drew a chart (see Table 5) in order to help me to understand how this works.

Table 5: An Example of Sitofela

\begin{tabular}{lllllllll}
\hline & A & B & C & D & E & F & G & H \\
\hline JAN & REC & PAY & PAY & PAY & PAY & PAY & PAY & PAY \\
& 700 & 100 & 100 & 100 & 100 & 100 & 100 & 100 \\
FEB & PAY & REC & PAY & PAY & PAY & PAY & PAY & PAY \\
& 100 & 700 & 100 & 100 & 100 & 100 & 100 & 100 \\
MAR & PAY & PAY & REC & PAY & PAY & PAY & PAY & PAY \\
& 100 & 110 & 710 & 100 & 100 & 100 & 100 & 100 \\
APR & PAY & PAY & PAY & REC & PAY & PAY & PAY & PAY \\
& 100 & 110 & 110 & 720 & 100 & 100 & 100 & 100 \\
MAY & PAY & PAY & PAY & PAY & REC & PAY & PAY & PAY \\
& 100 & 110 & 110 & 110 & 730 & 100 & 100 & 100 \\
JUN & PAY & PAY & PAY & PAY & PAY & REC & PAY & PAY \\
& 100 & 110 & 110 & 110 & 110 & 740 & 100 & 100 \\
JUL & PAY & PAY & PAY & PAY & PAY & PAY & REC & PAY \\
& 100 & 110 & 110 & 110 & 110 & 110 & 750 & 100 \\
AUG & PAY & PAY & PAY & PAY & PAY & PAY & PAY & REC \\
& 100 & 110 & 110 & 110 & 110 & 110 & 110 & 760 \\
\hline
\end{tabular}

Source: Drawn by an informant (with minor modifications) on September 6, 2016.

Assume that eight people joined this club and contributed R 100 monthly for eight months. Member A was the head, most likely the person who started the club. By the end of the club, she received R 700 without paying or earning any interest. Member B won the bid on the second month, so B received a $\mathrm{R} 700$ loan by paying $\mathrm{R} 60$ interest.

Member $\mathrm{H}$ was the last person to win the bid. In total, $\mathrm{H}$ contributed $\mathrm{R} 700$ and received R 760. H earned R 60, but the risk was much higher for him because anyone could have taken the entire fund and disappeared. 


\section{Intra-migrant Economy: Racialized Labour Market}

As noted in the last chapter, newly arrived Cantonese can be seen as a close-knit community due to language and cultural barriers and, most importantly, their economic dependency. In Johannesburg, I did not meet any new Cantonese migrant who did not work for or with other Chinese people. Many Zimbabwean migrants, on the other hand, have relatively higher interactions with people from outside of their own racial, ethnic, or national group (Moyo 2017). However, as noted in the last section, for those who work at Chinese restaurants or malls, average incomes are much lower than those of Chinese migrants.

Chinese entrepreneurship in North America, historically, was limited to certain industries such as retailing, clothing manufacturing, and food services (Li 1993). Paul Siu's (1987) studies on Chinese laundry workers in Chicago during the 1940s exemplify this economic phenomenon in North America. Siu used the term "immigrant economy" to describe the tendency of certain ethnic groups to occupy certain types of sectors:

The Greek ice-cream parlor, the Italian fruit stand, the Jewish clothing store, and the Chinese laundry, for example, are some of the characteristic specimens-interesting because of the fact that these were not the usual occupations of the owners in their homelands, but are new social inventions by these different ethnic groups in America as ways and means to struggle for existence in the symbiotic level of the community life. Other features, such as small capital investment, long working hours, relative or kinsman partnership, may be considered as similarities among them, and these features may serve as a basis for treating them as a type which may be called the “immigrant economy.” $(1987,1)$ 
This type of petty entrepreneurship, such as Chinese restaurants and laundries, was not always a voluntary choice. It was an alternative labour market that did not demand high language and cultural skills based on the host country. Furthermore, there were strong anti-Chinese sentiments in the United States (e.g., Chinese Exclusion Act). Siu's studies show that Chinese laundry workers were socially isolated and unable to establish social relationships outside of the Chinese community, whether in terms of upward mobility or residential segregation. They usually lived close to each other in the same community (i.e., Chinatown) and longed to return to China as a result of racial discrimination and segregation.

A similar historical migration pattern can be found in South Africa. Yoon Jung Park's $(2008,2012)$ studies on Chinese who migrated to South Africa before 1970 illustrate how during the apartheid era, the Chinese were prevented from participating in the mainstream labour market even when they had the qualifications. For example, they were denied jobs with government institutions or white companies, or unable to obtain mining licenses. Many of them ran grocery stores, restaurants, or fahfee instead. Nowadays, Chinese immigrants' social mobility in South Africa is much more fluid, especially since China has become Africa's leading financial lender and investor, as well as its largest trade partner, since 2000. Many well-educated Chinese have relocated to South Africa to work for state-owned companies, along with a few wealthy entrepreneurs who have invested in properties or run factories; yet the majority of Chinese in South Africa are from rural areas of Southern China with little or no capital. By using Cantonese newcomers as a case study, the previous chapter showed how Chinese newcomers depend on guanxi ties to relocate, find a job, and even open a small business 
in South Africa. This explains why, I argue, although most newcomers lack proficiency in any of the official languages of South Africa, this potential barrier does not exclude them from the wage economy.

As noted at the end of Chapter I, Peter Li (1993) suggests that Chinese migrants' "sojourning" characteristics actually have facilitated the strengthening of their enterprises. Li argues that certain elements that are embedded in Chinese culture (e.g., flexibility, hard work, familism, and the valuing of education and land) may be the reason for the success of Chinese entrepreneurship, whether in North America or many parts of Asia. Li further points out that immigrants often benefit from ethnic entrepreneurship; for instance, "immigrants remain attached to certain traditional values of their home country, and their imported cultural endowment facilitates their success in entrepreneurial ventures in a host society" $(1993,220)$. However, in the case of Chinese restaurants in South Africa, I suggest that with businesses and job opportunities that are largely structured around guanxi relations, the new generation of Chinese migrants can avoid full engagement with the host society. In other words, operating in a parallel marketplace and society, Cantonese newcomers can function — at least to some degree and for some period of time-without having to learn a local language or adapt to local culture.

When newcomers accumulate enough capital, usually by saving from working long hours plus borrowing from family, they tend to choose to become entrepreneurs if the situation seems right — at least this was the case for every Chinese restaurant owner I interviewed. Although almost every restaurant owner in this research seemed to share a "restaurant inferiority complex" (Pang 2002), as they constantly complained about long working hours, lack of freedom, and being cursed with laokumin (劳苦命, the fate to toil 
for life), by and large, they all reported that their financial condition had improved compared to when they were wage labourers.

The working-class Chinese migrants in this case study, whose starting salary as Chinese chefs was around R 12000 and as servers was R 6000 plus tips, were not considered rich, and they had to work more than nine hours a day almost every day of the week. But in contrast to South Africa's 79.2\% black South African population, whose average annual household income is around R 7700 a month (see Table 6 for data from Statistics South Africa 2017a), working-class Chinese migrants are definitely not poor. In South Africa, they might even be considered middle class, although they continue to be outside the social mainstream. In other words, they are marginalized but not underprivileged, because they are not positioned at the bottom of a racialized market.

Table 6 is based on data collected from 23,380 households across South Africa over a period of twelve months (2014 to 2015). The data show that white South Africans earn the highest average income at R 444446 per year, which is over one and a half times greater than Indians/Asians at R 271 621, and almost five times more than black South Africans, at R 92893 per year. This large wage inequality, along with high racial inequality, is deeply rooted in South Africa's colonial and apartheid history (Gradin 2012; van der Berg 2011). As Carlos Gradin argues, "South Africa stands out as a country with one of the largest racial divisions in the world due to European colonisation and the apartheid regime that followed independence, which officially ended in $1994 \ldots$. This racial divide has remarkable implications in terms of poverty and deprivation by population group" $(2012,187)$. 
Table 6: Average Annual Income of the Household Head by Racial Group

Census Group (percentage of national population) ${ }^{36}$ White Indian/Asian Coloured Black

\begin{tabular}{|c|c|c|c|c|}
\hline Source of income & $\begin{array}{l}\text { White } \\
8.9 \%\end{array}$ & $\begin{array}{c}\text { Indian/Asian } \\
2.5 \%\end{array}$ & $\begin{array}{c}\text { Coloured } \\
8.9 \%\end{array}$ & $\begin{array}{l}\text { Black } \\
79.2 \%\end{array}$ \\
\hline Income from work & 300498 & 215784 & 131699 & 69094 \\
\hline $\begin{array}{l}\text { Income from } \\
\text { capital }\end{array}$ & 16184 & 2173 & 1364 & 842 \\
\hline $\begin{array}{l}\text { Pensions, social } \\
\text { insurance, family } \\
\text { allowances }\end{array}$ & 30739 & 10028 & 12260 & 8921 \\
\hline $\begin{array}{l}\text { Income from } \\
\text { individuals }\end{array}$ & 5232 & 3309 & 2430 & 2194 \\
\hline Other income & 6520 & 2323 & 2265 & 1261 \\
\hline $\begin{array}{l}\text { Imputed rent on } \\
\text { owned dwelling }\end{array}$ & 85271 & 38005 & 22747 & 10671 \\
\hline Total & R 444446 & R 271621 & R 172765 & R 92983 \\
\hline Monthly & R 37037 & R 22635 & R 14397 & R 7749 \\
\hline
\end{tabular}

Source: Statistics South Africa (2017a, 14).

${ }^{36}$ The most recent available census records released by Statistics South Africa $(2012,21)$ were based on 2011 data. 
Since apartheid ended over two decades ago, the black upper and middle classes have grown; "the black share of the richest quintile of the population rose substantially, from 22 per cent in 1993 to 42 per cent in 2008 (though this remains far below their population share)" (van der Berg 2011, 128). But as shown in Table 6, the average white South African still earns at least five times more than the average black South African, and the majority of blacks are still economically disadvantaged and relatively insecure because they have fewer assets. Despite the progress made after apartheid, black people face higher poverty and deprivation rates than any other population groups. In addition, as Gradin (2012) points out, South Africa's high unemployment rates and high racial segregation across occupations also challenge South Africa's wage economy. The most recent available census (Statistics South Africa 2012, 58) record was published in 2012, and it shows that whites had the lower unemployment rate in 2012 (5\% for men and $6.9 \%$ for women), while the black population had the highest (58.7\% for men and $49 \%$ for women). With all of these economic problems falling along racial lines, where do Zimbabwean migrants fit in?

Derek Yu (2017), economics professor at the University of the Western Cape, argues that currently South Africa is facing a youth unemployment crisis. He points out that South Africa's unemployment rate has been rising steadily since 2008, and in 2017 the unemployment rate (27.7\%) was higher than that of other African countries-for instance, Botswana at $18.4 \%$ and Namibia at $25.5 \%$. Moreover, the unemployment rate for youth (ages 15 to 29 ) is at $60.3 \%$, and $39 \%$ of South Africans have never had a job. Yu suggests there are many obstacles to boosting youth employment in South Africa, but the main challenge is that 
the country's labour market is hobbled by inefficient hiring and firing practices, little cooperation between employers and employees as well as a poor relationship between pay and productivity. This tempts employers to replace labour (particularly the less skilled and experienced ones) with capital and discourages them from hiring new workers. In both cases, the youth are the most vulnerable." (2017)

In other words, $\mathrm{Yu}$ is suggesting that local employers and local employees often experienced tense working relationships, which discouraged local employers from hiring new workers. It is perhaps why many employers, including and especially Chinese petty entrepreneurs who have less language skills and knowledge to deal with local labour issues, prefer to hire non-South African workers and are not concerned with the legal status of employees. As several Chinese employers mentioned in interviews, "I cannot afford to hire only Chinese employees," reflecting the fact that Zimbabweans and other African migrants, who often work for lower wages due to their desperate economic conditions, end up filling low-skilled jobs such as kitchen helper. Consequently, it is not surprising to see that many semi-skilled and unskilled Zimbabwean migrants often end up working in Chinese restaurants.

\section{Concluding Remarks}

Chinese restaurants provide employment opportunities not only for the Chinese but also for Zimbabwean migrants, who are excluded from most jobs in South Africa's mainstream economy. Seen from this perspective, Chinese restaurants have become an economic survival strategy for many Chinese and Zimbabweans in Johannesburg. I use the term "intra-migrant economy" to refer to the employment of one group of migrants by another group of migrants as an economic strategy outside the mainstream labour market. 
In this case, Chinese petty entrepreneurs with little capital are able to maximize profits through the cheap labour of Zimbabweans, while Zimbabweans can easily obtain jobs without going through formal training or having proper documentation. Both groups of migrants have established interdependent relations outside of the mainstream market. Chinese and Zimbabweans are racially, linguistically, and even culturally distinct from each other, but these two groups of people are bound together by their common diasporic status and migrant networks in Johannesburg's Chinese restaurants.

The next chapter discusses the working relationship between Chinese employers and Zimbabwean employees in terms of collaboration, as well as conflict and misunderstanding and what might cause these tensions. 


\section{CHAPTER IV}

\section{CROSS-CULTURAL (MIS)UNDERSTANDING AND (MIS)COMMUNICATION IN THE CONTEXT OF THE INTRA-MIGRANT ECONOMY}

\section{Conflict, Collaboration, Emotion}

After a long day of work, I went home, physically and mentally exhausted. I took out my notebook to write down what had happened, including the fight between the Chinese restaurant owner and a Zimbabwean chef. It began in the dining area, with the owner yelling at the chef for not supervising the kitchen staff. The chef, who was supposed to be the kitchen manager, remained quiet. After a few moments, the chef shouted, “I just want to cook!” The owner's face turned red. He had opened his hand; he was about to lose his temper. The chef picked up a broom, threw it to the ground, then walked into the kitchen. The owner yelled after him in English, "You no come back tomorrow!" and then turned his head towards our table, where all the Chinese employees had supper together. Swearing in Chinese, he said, "Who does he think he is? How dare he talk to his boss with this kind of attitude! (甚麼东西敢用这样的态度跟老闆说话!)”

When I first started conducting fieldwork in restaurants, it was difficult to cope with the arguments and conflicts that I witnessed, and I had to keep reminding myself of my role as an ethnographer. But by the point that I witnessed this fight, I had already gotten used to it, and even expected to see it every time I went to work. During that fight, I just reacted like everyone else in that room without even thinking. The rest of us Chinese and Zimbabwean employees watched the fight quietly and continued doing whatever we were doing. 
"The only reason this lucky black man has not been fired is because he learns fast and can cook well," the owner later told me during an interview. He said that he had been pleased to train this chef, but it had turned into a disappointment. "He is smart, willing to learn, and hardworking. I recognized his ability. I taught him how to cook, trained him to manage the kitchen, and paid him well." But then the owner explained what went wrong between them:

Lately he has been giving me bad attitude, refusing me when I tell him to manage the kitchen. I promised him I would raise his salary once he could fully handle the kitchen. He said he just wants to cook. What kind of logic is that? Why doesn't he want to improve his life? What a waste of my time and effort!

I did not interview the Zimbabwean chef. My assumption is that he probably found managing his fellow Zimbabwean co-workers difficult, especially as he was newer and relatively younger than the other Zimbabwean kitchen helpers. The promotion to kitchen manager placed him in a difficult position. Perhaps he would rather have maintained a better relationship with his co-workers and have less responsibility as a chef.

The next day, the owner and the chef worked together, but ignored each other. It was not their first fight, nor would it be the last. The same episode could reoccur until the Chinese owner found another person to train, or the Zimbabwean chef found another job.

This chapter explores the everyday working conditions of Chinese employers and Zimbabwean employees. It examines their collaborations, (mis)understandings, (mis)communications, and tensions in a cross-cultural context. The first section begins with language issues. The majority of my Chinese participants did not know any English before coming to South Africa. After they relocated, most had limited exposure to those 
outside Chinese communities due to feelings of insecurity (see Chapter I), long working hours, and the job market for Chinese (see Chapter II). As a result, learning English (or any South African language) did not seem necessary and was certainly not higher on their priority list than income and safety.

While low salary, lack of benefits, rude attitudes, poor communication, and unhygienic habits were the common criticisms made of Chinese employers by Zimbabweans, Chinese employers often complained that Zimbabwean employees were unproductive, irresponsible, unreliable, and dishonest. These conflicts often arose from miscommunication but were deeper than a simple language issue; they came from cultural misunderstandings and partly from the fact that China has never been a multiracial country, so Chinese migrants to South Africa are often ignorant about and insensitive to racial issues ( $\mathrm{Li} 2016)$.

While most Zimbabwean employees find the Chinese unfriendly and lacking the ability to show affection, Chinese employers find Zimbabweans' directness (e.g., demanding a higher salary or disobeying an order they don't agree with) to be abrupt and rude. I found my ethnographic data often shared similarities or overlapped with other case studies conducted in Africa (Men 2014; Sheridan 2018; Sun 2017; Wu 2014; Zi 2017). In particular, I draw on Di Wu's (2014) research, where he examines misunderstandings between Chinese employers and Zambian employees and argues that the Chinese style of indirect speech leads to miscommunication and tensions between them.

In the latter chapter, I emphasized conflicts between Chinese employers and employees to highlight the fact that there will always be conflicts in any employer- 
employee relationship, regardless of race, ethnicity, or culture. The question is, how do they deal with and resolve such conflicts? I showed how Chinese employees negotiate with their employer in an indirect way, which gives space and time for them to find a solution that satisfies everyone. This structure of negotiation is based on guanxi, where people who are in a network of social relationships speak and act according to their position in a given relationship. At work, Chinese employers expect their employees to follow their instructions and show respect as part of proper social and workplace etiquette. This is where the Chinese employees have an advantage over the Zimbabwean employees, as they are able to get along better with Chinese employers.

\section{Language Issues}

As noted, a large number of recently arrived Chinese migrants in South Africa came from rural areas, where they had limited chances to continue to higher education, as their families simply could not afford the school fees or needed them to generate income to contribute towards the family expenses. They came to South Africa seeking higher wages or better opportunities. Despite primary schools in China offering English lessons, there is limited access to practising English and very little use of any foreign language in the rural areas. This is particularly the case for the Cantonese speakers. As discussed, most of them already had to learn three dialects (i.e., a local dialect, standard Cantonese, and Mandarin) in their daily lives.

English is one of the official languages in Zimbabwe, and Zimbabwean migrants use English as their main language of communication with Africans of different linguistic backgrounds (Moyo 2017). Most Chinese migrants only have exposure to English at 
work. Some also have exposure through their children's homework. Chinese servers learn English for work and just need to know enough to get by. Usually, the first step in training Chinese servers is to have them start with memorizing the English menus and table setting. The next step is to teach them how to explain ingredients for each dish in English. Some restaurants require their servers to pass an English test in order to have a greater share of tips or to be able to keep their jobs. There is no language training for Chinese cooks or sushi chefs, because they do not need to talk to customers. Several Chinese participants, especially those who had a child or children attending school in South Africa, expressed interest in improving their English skills. But they could rarely find affordable English lessons or time to attend class.

Almost every Zimbabwean employee I interviewed found it difficult to understand their Chinese employers or managers when they first started the job. None of them had any experience working for Chinese people or at Chinese restaurants before coming to South Africa, and they were not familiar with Chinese cooking equipment or ingredients. These language barriers between the Chinese and Zimbabwean migrants did not help their relationship. Among the twenty-six Zimbabwean interviewees, nearly $70 \%$ of them stated that they did not receive any training from their Chinese employers or managers. New employees did not quite understand what the employers or managers asked them to do. They had to interpret the tasks they were asked to do or communicate with the Chinese employers and managers through body language.

New Zimbabwean employees often said they learned how to perform their duties from other African employees (mostly Zimbabweans, and sometimes Malawians, South Africans, or Basotho) who already worked at the restaurant. One Zimbabwean woman 
told me she had been showing a new employee how to make wraps. Her employers had recently hired a young Zimbabwean man to handle packing and delivery. When he was not busy, the employer asked him to help in the kitchen. The young man had never cooked before and had no idea what the Chinese chef was telling him to do. He asked the Zimbabwean woman for help. She felt reluctant, because this was not part of her job and she did not want to do her Chinese employers a favour. But she still helped the Zimbabwean man. "The chef yells at him all the time. I feel sorry for him, and I don't want him to lose this job," she said.

Several Zimbabwean employees mentioned that their Chinese employers often asked them to do duties that were not part of the job description. In fact, many Chinese employees also had the same experience, but they perceived and interpreted it differently. I elaborate on this point later along with a discussion on cultural differences.

All Zimbabwean employees who had worked at Chinese restaurants for more than a year showed some knowledge of Chinese language during our interviews. Not all of them could say a whole sentence, but they all knew certain terms such as names of dishes and vegetables. Some mentioned that they did not mind learning Chinese; some felt they were forced to do so to make their job easier. One Zimbabwean woman said, "Boss lady told me to wash and cut vegetables. I asked her what kind. She came to point at them. Next time I asked her, she said I don't listen. I didn't know which one, so I washed and cut all vegetables. She was angry. Eish, what can I do? Chinese don't learn English, so I have to learn Chinese to understand them."

Based on my interviews and field research in restaurants, the proportion of Zimbabwean employees who could speak varying degrees of Chinese was much greater 
than that of Chinese employers who could speak English beyond a basic level, and I did not know any Chinese person who could understand or speak an African language. This phenomenon is reflected in the interview data with Zimbabwean employees, as most of them felt that they had to compromise more when it came to language communication with their Chinese employers.

Most female Zimbabwean interviewees also recognized the term heipo (black woman) as referring to them. Some of them did not know what it literally meant; they asked me during our interviews. Moreover, several Zimbabweans asked me the meaning of certain Chinese words, such as “sluggard” (懶惰) and “nut case” (神经病) because their Chinese employers or managers had been yelling these terms at them. They suspected there were negative connotations associated with these terms. One interviewee stated, "The Chinese thought because I don't understand Chinese I wouldn't know they were talking about me. I can read their facial expression, and their eyes look away when they talk about me. I don't understand Chinese, but I am not stupid.”

\section{Racial Discrimination or Ignorance?}

As noted in the introductory section, I struggle with the translation for terms that include the word "black" (黑 hei). During the early stage of my fieldwork, I found them offensive. Later, when I began to interview Chinese participants individually, I realized they did not think of the term "black" as we do in North America.

Undeniably, there has been racial discrimination against black people by Chinese communities in Johannesburg to varying degrees, and some Chinese people are undoubtedly racist. A number of factors contribute to Chinese prejudice against darker- 
skinned people. First, in China and in Asia generally, there has been a long-held association between one's economic status and one's skin colour (Pe 2016). As opposed to the Western perception of tanned skin as a sign of health and success, in Asia, peasants were darkened by the sun as they worked on the farm while upper-class people were able to stay indoors. Therefore, one's pale skin was an indicator of wealth. Moreover, as Joanne Rondilla $(2012,12-18)$ argues, the standard of beauty in Asia is in line with white standards and the white imagination. Most Chinese people also find pale skin more attractive than dark skin.

Second, most Chinese people have different perceptions of privacy and how to show affection (this will be explored in more detail). Unlike in the West, where talking about a person's physical appearance is seen as extremely rude behaviour and can even be considered a form of discrimination, Chinese people often make explicit comments about someone's looks - be it height, weight, skin tone, shapes of eyes or noses, hairstyle, or outfit. I have heard countless remarks from Chinese family, relatives, friends, acquaintances, and strangers about my physical features (both positive and negative, from their point of view) whether in Taiwan, Canada, or South Africa. Most of the time, it just reflects the fact that many Chinese people have narrow beauty standards and lack sensitivity. Sometimes, especially if the comment is from family or friends, it may be a way of showing concern. For instance, if a friend has lost weight, might there be something bothering that person?

In addition, Chinese people are more likely to talk about their bodily symptoms and health issues with others. Common subjects of conversation with my Chinese participants at work were linked to our bodies, such as diets, health, and skin condition. 
Interestingly, while many Chinese people often keep their true feelings and opinions to themselves, they do not mind discussing bodies, salary, or family income with others. In other words, what Chinese people consider private topics or subjects that are inappropriate for discussion in public may be different from what we are familiar with in North America.

Third, from a historical perspective, China was isolated and, as such, was never a multi-racial nation (Li 2016). Historian Li Anshan (2016) published an online editorial piece, "Chinese Ignorance of Race should not be Confused with Racism," in response to a controversial advertisement in China. ${ }^{37} \mathrm{He}$ argues that Chinese ignorance is driven by ethnocentrism, which happens everywhere. He writes, "The Chinese have looked down upon outsiders and used condescending labels for the people who lived in surrounding lands. China's name in Mandarin is zhongguo, meaning 'Middle Kingdom,' implying it is at the center, and those who lived outside of it were dismissed as 'barbarians"' (Li 2016). According to Li, the difference between the West and China is that Chinese ignorance is not based on colonialism or racial discrimination against black people:

Ethnocentrism is understandable in a situation where people lack contact and an understanding of others. It is another thing when ethnocentrism is converted into racism, which was harnessed by modern colonialism to justify the military, political and economic domination of foreign people.

\footnotetext{
${ }^{37}$ The Chinese laundry detergent commercial begins with a Chinese woman doing her laundry. A black man walks into the room with some paint stains on his face. She puts a tab of detergent into his mouth, then shoves him into the washing machine. When she opens the washing machine, a Chinese man emerges and she seems satisfied with the result. This advertisement caused outrage, anger, and criticism. The company removed the commercial and issued an apology. The story can be found online at https:/qz.com/695240/the-full-apology-from-the-chinese-company-behind-the-racist-laundry-detergent-ad/ (Accessed July 26, 2018).
} 
The overwhelming majority of Chinese people are ignorant of Africa, and there are quite a few misunderstandings. But we have to be cautious about labelling "the Chinese" as racist, since there are different cases of ignorance, misunderstanding, prejudice and racism. Ignorance alone is not equivalent to racism. (2016)

I think there is a need to consider ignorance further, as sometimes it leads to racial discrimination. For instance, in his study of African travellers' experience when passing through Chinese borders, Adams Bodomo (2015) argues that whether due to conscious or unconscious racial stereotypes, Chinese customs officials often racially profile African travellers. This causes friction, and sometimes African travellers refuse to cooperate. In other words, ignorance and stereotypes do lead to racial discrimination.

Research that focuses on racial relations between Chinese and black Africans has mostly been conducted among African communities in China-for instance, as already discussed, the work by Guangzhi Huang (2018) and Adams Bodomo (2012, 2015, 2018). Shanshan Lan (2015) has pointed out the racialization of "blackness" has played a role in constructing African “illegality” in Guangdong, and Roberto Castillo (2016) has suggested that the discrimination that Africans face in China is not necessarily about race and is more complex, involving factors such as business competition.

Why are such issues not as widely discussed in regard to cases of Chinese migration to Africa? There are at least three reasons. First, the number of Chinese in Africa is greater than the number of Africans in China. It is estimated that there are one million Chinese in Africa (Park 2016) and around 500,000 Africans in China as of 2012 (Bodomo 2012, 2018). But since 2014 the number of Africans in China has significantly declined (Marsh 2016). Second, although the African population is extremely diverse and 
almost every country in Africa is represented in China (Lan 2015), ${ }^{38}$ Africans tend to be more concentrated in certain cities, whereas in Africa the Chinese are scattered throughout. Third, the motivations of Chinese migrants who go to Africa are more diverse, and these migrants include individual entrepreneurs, family business operators, students, teachers, cooks, restaurant workers, shopkeepers, traders, journalists, and so on, as well as contract workers and managers from private and state-owned companies, as Chinese government and companies have invested enormously in Africa (see, e.g., Brautigam 2009, 2015; French 2015; Michel and Beuret 2010).

In contrast, the majority of Africans in China have been entrepreneurs (Bodomo 2012). Based on 312 questionnaires that were distributed and collected over a period of six years (2005-2011) in Guangzhou, Yiwu, Hong Kong, Macau, Beijing, and Shanghai, Bodomo's (2012) data showed that $78 \%$ of Africans identified themselves as businesspeople and $6 \%$ as traders. Another $7 \%$ answered they were in China for study. Starting in 2000, China has been increasing financial and political support for African education at home and aboard, including providing scholarship to aid African students coming to China (Breeze and Moore 2017). In 2015, China was the top destination for anglophone African students, replacing the United States and the United Kingdom as the most popular (Breeze and Moore 2017).

In my research experience, racial relations between Chinese and blacks in South Africa are much more complicated, because South Africa has the largest Chinese population on the continent and it has a long history. However, if we focus only on newly arrived Chinese migrants, then I agree with Li that Chinese people in general have a lack

\footnotetext{
${ }^{38}$ According to Bodomo (2012), the top ten countries are: Nigeria, Senegal, Mali, Guinea, Ghana, DRC,
} South Africa, Tanzania, Uganda and Togo. 
of understanding and experience when it comes to racial diversity and sensitivity. Precious's experience which illustrates Chinese migrants' ignorance of racial issues. When Precious, a Zimbabwean migrant, was hired by a Chinese couple, they had just arrived in South Africa less than a month before. At first, the couple would not use the same plate or cup as Precious did, and she was not allowed to go near their space. They often stared at Precious's hair and skin and talked about her in Chinese. All of this made Precious feel really uncomfortable. "They made me feel as if I was dirty or I smelled. But they are the ones who don't keep things clean and neat. Chinese have bad hygiene, like spitting out bones on tables or throwing garbage on the ground. I'm the one who has to clean up after them. How can they think I'm dirty? Maybe because I am black, I don't know," she said.

Precious tried to tell the Chinese couple that she was uncomfortable with their reactions to her, but they did not understand much English and they denied they were talking about her. While Precious was thinking about quitting her job, these problems were mitigated and then eventually disappeared. The Chinese couple started to share the same set of tableware with her and invited her to take a nap on the lounge chair in the small room at the back of the kitchen during break time. When the wife gave birth, the couple asked her to be the nanny, and hired another Zimbabwean woman to work in the restaurant.

Precious had been working and living with that Chinese family near Chinatown for five years when I spoke with her. Aside from having a low salary, Precious said the Chinese couple treated her fairly. She was free to enter and leave the house while looking after their child. She showed me the house keys as proof that the Chinese couple trusted 
her with their home and their child. I met Precious three times near Chinatown, and twice she brought the child along.

Now, this sort of happy ending is not typical of stories of Chinese employers and Zimbabwean employees in South Africa. Like Precious, most Zimbabweans I interviewed did not have a smooth encounter with their Chinese employers in the beginning. But unlike Precious, most of them still suffered through a rough and emotional process every day. Most Zimbabwean interviewees had begun working for their Chinese employers less than two years earlier. If time is the answer to resolving racial discrimination, the question then is, does more contact and interaction with African people reduce Chinese people's racial stereotypes and discrimination? My ethnographic data show a complex answer. In the following sections, more ethnographic data are presented to examine both Chinese and Zimbabwean workplace behaviours. But first, I need to identify and discuss the issues that arise from cultural differences.

\section{"Not just about English"}

My Chinese participants often asked for my help with language. I translated menus, letters, and emails from English to Chinese, made phone calls to place orders, sorted out issues with an airline company, and taught adults and children some English. Many Zimbabwean participants also reported that their Chinese employers often asked them for help with English. Among them, Prudy's case and her own observations provide important points.

When Prudy first started working at a small Chinese restaurant owned by a

Chinese couple in Chinatown, her primary job was to provide assistance to the husband in 
the kitchen, wash dishes, and clean and reset tables. The main clientele of that restaurant was Chinese. Occasionally, when non-Chinese customers appeared in the restaurant, the wife yelled from the front counter to call her husband in the kitchen to come out because she did not speak a word of English. The husband spoke some English, but the customers did not seem to understand him. After a few frustrating experiences, the couple asked Prudy to serve non-Chinese customers. Now, when the wife sees non-Chinese customers coming in, she calls Prudy to the front.

At first, Prudy was not happy about doing extra duties while getting the same pay. But when she realized she got to keep all the tips and that her employers had hired another Zimbabwean kitchen staff member, since they were getting more non-Chinese customers, Prudy accepted the situation. She had worked there for more than four years when I met her. Prudy was fairly satisfied with the current situation, other than just wishing for a pay raise because her husband had lost his job the previous year.

I was interested in why the Chinese husband found it difficult to serve nonChinese customers, given that he spoke some English. It is not uncommon to find Chinese servers with limited English skills working at Chinese restaurants. I asked Prudy about it. She replied,

No, it was not just about English, it was the way he said it. When [non-Chinese] customers walked in, the husband would say things like, "What do you want" or "What to eat?" Customers found him rude and felt unwelcome. I told them they have to greet customers first like, "How are you?" "How can I help you?" or "Would you like to try this?" if customers were not sure about what Chinese food is. They don't get it and said it's easier with Chinese customers. 
In fact, Chinese people usually do not greet each other with questions like "How are you?" or ask people about their days. Chinese people might say "ni hao" (which means "hello" and is literally translated as "you good") when meeting someone for the first time, but in general, they are more likely to use the greeting associated with the particular time of the day, and address specific persons by their names. Moreover, a person's age, status, or job are often addressed in Chinese greetings.

For instance, during my fieldwork research at Chinese restaurants, I greeted the owners or managers by adding their last names and titles, such as "Wong jingli hao" (Hello Manager Wong) or "Lee laban zaoshang hao" (Good morning Boss Lee). For senior chefs and servers, I greeted them by addressing them with ge for men and jie for women, such as, "Wong ge hao" (Hello Wong older brother) or "Lee jie zao" (Morning Lee older sister). ${ }^{39}$ For a more informal and friendlier greeting, the most common type is related to the action taking place at that moment. For instance, Chinese co-workers usually greeted me with "Ying-Ying lai le" (Ying-Ying you are here) to acknowledge my existence or "chi le mei" (Have you eaten yet?) to show they cared. ${ }^{40}$

When I asked Faith about her impression of Chinese people, she said she had never met any in her hometown but had heard good things about them in Zimbabwe. When she came to Johannesburg and got her first job in Chinatown, she did not like them. She perceived them as very rude people, because they always told her "you give me this" or

\footnotetext{
${ }^{39}$ In Chinese, ge ge (哥哥) and jie jie (姐姐) are family titles for immediate family (older brother and older sister, respectively). But ge (哥) can also be used to address an older male and jie (姐) an older female. Likewise, black South Africans often use Mama to address older women and Baba for older men.

${ }^{40}$ Interestingly, in the Zulu language (including isiNdebele, the mother tongue of most of my Zimbabwean participants), people greet each other by saying sawubona (or sanibonani to multiple people). It is like hello in English, but sawubona literally means "I see you." Along with the Chinese greeting lai le (you are here), both Chinese and Zulu greetings share a similar sense that one does not exist until someone recognizes one's presence.
} 
"you go do that." She found the way they gave instructions to be very demanding and without manners.

This might simply be an issue with translation, leading to a misunderstanding. In English, people are more likely to use questions (“Can you pass this to me?" or "Can you go do that?") instead of directives. But in Chinese, it is not considered rude to use directives. In fact, it is generally appropriate to give direct instructions to someone with a social role that is considered "dependent," such as employees.

Faith continued to explain that the reason she disliked her Chinese employers was they had never shown any concern for her well-being. She stated, "They never asked how my family is doing. They know I am close to my mom and I have a son in Zim but they don't ask about them. I don't think they care about me. Just come to do my job and leave."

Faith's example indicates there are different ways of showing affection and different views on private and work spheres. I noticed that both my Chinese and African friends always asked how my family was doing. However, I do not recall the Chinese participants I worked with at the restaurants asking about my family. In Zambia, Di Wu (2014) also noticed that the different Chinese and Zambian ways of greeting often led to misunderstanding. Many Chinese migrant workers were overwhelmed by the number of greetings they had to do in Zambia and felt they could not keep up. I come back to this point later after more examples.

In another case, Wendy's experience suggests that the misunderstanding lay in her and her Chinese employers' different perceptions of time and expectations about work ethic. As she said, 
We [my employers and I] always fight about taking breaks or sick days off. If they see me sitting there and looking at my phone, they think I am taking breaks. But I am just bored because there is nothing else to do. During my breaks, I go outside [of the restaurant] to hang out with friends and eat lunch with them. I don't think sitting in the restaurant is taking a break.... If I am sick and I call them to say I cannot work today, they say "Fine, you just don't get paid today." I fight with them; I ask them, "How can I work when I am sick?" They said, "I am sick and I still work every day." It is true that Chinese people don't take sick days off. But they should stay home for hygiene reasons.

The comments from both Faith and Wendy reflect the majority of the Zimbabwean interviewees' responses. While low salary was the primary complaint among Zimbabwean employees, many also raised the issue that their Chinese employers or managers did not show affection and also shouted too much.

There is no denying that many Chinese employers are impatient and use loud voices as their main way of communicating with staff. When I first began working in restaurants, I was quite shocked by how much shouting I heard all the time. Many Chinese employees also complained that their Chinese employers were shouting too much. One Chinese server explained during our interview that the reason she left her last job was because of the owner's bad temper: "I worked at five or six restaurants. All employers shout. But that woman [her former employer] was too extreme. She yelled at everything, even something so small. Non-stop. Eventually no Chinese is going to work for her any more, even if the salary is not bad."

Both Chinese and Zimbabwean employees criticized Chinese employers for being short-tempered and shouting; yet, generally speaking, Chinese employers were harsher to 
Zimbabwean employees than Chinese ones. I did not ask the Chinese owners why they yelled more at the Zimbabweans than at the Chinese-it did not seem like a proper interview question. I do not, however, think it is necessarily a racial issue; rather, it is more about Chinese owners worrying about their reputation within the Chinese communities. As noted, while a large number of Chinese migrants involved in the restaurant sector might not know each other personally, they have often heard rumours about restaurant owners being cheap or difficult. Chinese owners have to be more cautious about how they treat other Chinese; otherwise, they will have a difficult time recruiting Chinese employees.

When I discussed the communication problems between Chinese and Zimbabweans with Prudy, she offered an insight: "I used to think Chinese are rude people. But when I see Chinese people shouting at each other, talking so loudly to customers, and not knowing how to greet them properly, I figured maybe Chinese don't see this as a problem. Maybe it's in their language or culture, I don't know." Prudy made a couple of valuable points. First, the Chinese who are not familiar with European or African cultures find it difficult to start conversations with strangers by asking how they are doing. They do not understand that "How are you?" is a standard greeting and does not mean that they have to engage in a personal conversation with strangers. Second, the Chinese do not necessarily see talking loudly as a rude behaviour. Sometimes, it is a more efficient way to work together. For instance, when restaurants get too busy, Chinese servers yell out orders instead of walking into the kitchen as a way to save time. In fact, I found my ethnographic data often shared similarities or overlapped with other case 
studies conducted in other parts of Africa, like Botswana (Zi 2017), Tanzania (Men 2014), and Zambia (Wu 2014).

When Yanyin Zi (2017) interviewed Batswana interviewees who worked at Chinese-owned shops, they complained that their Chinese bosses were loud and rude and often embarrassed them in front of customers. Zi noticed that Chinese employers liked to talk loudly rather than coming to stand next to the employees to give orders because it saved some time. To the Batswana employees, their Chinese bosses' loud voices sounded like shouting. As Zi writes,

Based on my observation, usually China shops are big (some even bigger than 100 $\mathrm{m})$. Since Chinese merchants are usually the ones who are in charge of the cash machine, they remain behind the machine, standing on a footstool. When they talk to their employees and give commands, they usually speak loudly so that their employees can hear them from anywhere in the shop. Some Chinese even have to speak louder than the background music they play in the shop. To their local employees their Chinese bosses' loud voices sound like shouting. What is worse is that once local employees do things wrong, most Chinese would not walk down to talk to them if they can simply direct them by talking to them from where they stand. Few Chinese choose to correct their employees later, because they usually fail to explain the situation or totally forget about it due to their limited English or hectic schedule. Therefore, they have to catch their employees when they are doing wrong and correct them immediately, regardless of the presence or absence of customers in the shop. $(2017,164)$

Tanny Men's (2014) research was based on a Chinese company in Dar es Salaam. She identifies several cultural differences that caused miscommunication between Chinese 
managers and Tanzanian workers, such as Tanzanians being more short-term goal oriented versus a more long-term orientation for the Chinese, and different perceptions of the role a boss should play. Her interviewees explained that in Tanzania "the boss is your friend"; however, in China, "the boss is the police... the CEO wants staff to be afraid... The boss is an 'untouchable' and one mistake could cancel all the good things you have done" (Men 2014, 125).

Wu's $(2014,126-35)$ ethnographic research on two Chinese farms near Lusaka examines what Chinese employers expect from their employees versus what Zambian employees expect from their employers. Wu points out that while Chinese employers expect employees to be self-disciplined and independent, Zambian workers expect the boss to take care of them, not just at work but also at home. For example, they would ask for salt, sugar, transportation arrangements, or a loan for house renovation. However, most of the Chinese bosses did not feel obligated to help Zambian workers in their private lives. The Chinese bosses found these requests demanding and were annoyed that the Zambian workers were not independent at all. But though the Chinese bosses expected their workers to be independent, that did not mean that they wanted the workers to make their own decisions at work.

$\mathrm{Wu}$ provides an example to further explain what Chinese bosses meant by “independent.” A Zambian driver was constantly fighting with his Chinese employer because he often made decisions without his boss's consent, such as making a sudden detour to get petrol. While the driver thought he was being helpful to save travel time, his Chinese employer found his decisions disrespectful. Based on this case, Wu argues:

To be independent and to avoid extra trouble for the leader does not mean that workers can make their own decisions at work. Making decisions is the 
demonstration of a leader's authority and power at work. It is also a form of control. In general, the Chinese workers are supposed to obey the manager's orders, report frequently on their work progress (huibao) to the manager and ask for instruction (qingshi) when a decision is needed. Failure to report or to ask for decisions may cause the manager's dissatisfaction and lead to the worker being criticised as 'shanzi zuozhu' (making decisions when one is not [in] the position to). It is considered as bad self-discipline and disrespectful to the leader's authority. This is the criticism that Zambian workers usually suffer. $(2014,134)$

Based on her interviews with factory owners across Africa, Irene Yuan Sun (2017) notes that factory owners complain about African workers all the time, including about laziness and low productivity. Sun argues these different cultural behaviours or role expectations are rooted in the different phases of industrialization, as she points out that factory owners, Chinese or American, have always complained about their workers during the early phases of industrialization. As Sun explains, "That's because they're accustomed to managing workers from their own country. They experience the fact that workers from the new country are less productive, and they reach for race as the explanation, when in fact the new workers simply haven't been industrialized as long as workers in their home country have" $(2017,99)$. Sun shows a story of a Mosotho women who had worked at clothing factories for ten years in Lesotho, and how she had to rethink the cultural norms and adapt to the new way of life during the transformation. Sun argues that confrontations and complaints are precisely how people reflect when they are struggling with adjustments.

In the following section I return to my data to show ethnographic examples of what Chinese employers and Zimbabwean employees experience every day at the 
workplace. The first story, based on Mrs. Luo, further demonstrates that cultural differences indeed lead to miscommunication. After the description of Mrs. Luo's account, I offer an analysis based on the argument that Chinese employers expect Zimbabwean employees to build on guanxi but, in the eyes of the Chinese, Zimbabweans' constant confrontations do damage to their guanxi.

\section{Intercultural (Mis)communication: Zimbabwean Employees}

One time I called in late because I was helping another Chinese participant with some English documents. As soon as I arrived at work, I apologized and explained this to Mrs. Luo, the owner of the restaurant. Mrs. Luo said to me, "I too want to learn English. Why don't you teach me?" I found her statement absurd because she spoke perfectly fine English. I saw her making jokes with non-Chinese customers all the time and discussing complicated business matters with non-Chinese people. Mrs. Luo spoke three Chinese dialects fluently and had learned English on her own when she relocated to South Africa ten years earlier. I told Mrs. Luo, "Your English is good. You are being too humble." She giggled and said, “Oh, well, if my English is good, why can’t I make the black employees understand me?" I asked Mrs. Luo to elaborate, and she replied:

Zimbabweans always demand more pay, but they don't move unless I tell them to.

Okay, I don't expect them to be as xingmu (醒目 smart/attentive) as Ah Ling [Mrs. Luo's favourite employee] or even like a Chinese. Before, I heard Chinese people said we [the Chinese] are the smartest and hardest working people in this world. I didn't really believe it until I ran my restaurant. It is true. You only need to tell the Chinese what to do once; they get it. Chinese are responsible and dependable. This is impossible with Zimbabweans. I have to follow and check on them every day. Forget 
it (算了算了). I am a fair person, I don't expect them to be like a Chinese. I told the Zimbabweans, if you are willing to learn, work hard, and perform well (工作表现良 好), you will get the bonus that you deserve. You have to earn it; you can't ask for it. I don't think they understood. They are getting lazier, slower, and unresponsive. Just bring troubles to me (只会给我麻烦). All Zimbabweans know English, right? If it's not them, then it's me. Aiya, I get headaches every time I deal with these black employees. Sometimes I would rather just work for another restaurant so I don't need to deal with these employee issues.

Xingmu is a Chinese term that carries different meanings in Mandarin and Cantonese. In Mandarin, xingmu means something that stands out, but Mandarin speakers do not use it as commonly as Cantonese-speaking people. The Cantonese often use this term to describe someone who is smart and likeable. It does not refer to school smarts but street smarts. Xingmuzi (醒目仔) refers to a young person who has good common sense, is easygoing, knows how to handle situations, and is capable of getting along with many people.

Mrs. Luo had, in fact, complained several times about Chinese employees. She once told me that she would not hire people from a certain village in China because she had had bad employment experiences with three employees from there. Her favourite employee, Ah Ling, was from the same village as her. Ah Ling was a xingmu employee because when she saw trash on the ground or a dirty table, she cleaned it without Mrs. Luo telling her to. When Ah Ling saw Mrs. Luo walk into the restaurant with groceries, she greeted Mrs. Luo and offered to carry the groceries to the kitchen. Moreover, Ah 
Ling did not question Mrs. Luo's commands and did not make big decision without Mrs. Luo's permission.

Ever since the above conversation I had with Mrs. Luo, I paid more attention to how she communicated with the Zimbabwean employees at work. While Mrs. Luo thought she could not communicate with her African employees effectively due to language barriers, my observation suggests otherwise. Moreover, Mrs. Luo did not like to see her employees look at their phones during working hours, although she constantly checked her phone. Chinese employees knew not to do so when Mrs. Luo was around. Perhaps Zimbabwean employees thought checking their phones was not a problem, since Mrs. Luo checked her phone all the time. They did not try to hide it. When Mrs. Luo saw Zimbabwean employees looking at their phones, instead of telling them directly that it was not proper to look at personal stuff during working hours, she assigned them other duties. Often, it was a task they had just finished, like cleaning the floor again. The Zimbabweans were puzzled because these tasks seemed unnecessary. They responded to Mrs. Luo's requests slowly and with confused expressions. Mrs. Luo would shake her head and say, “You're driving me nuts (把我气死)" in Chinese, and then "Do you understand me or not?" in English to the Zimbabweans.

It was common to hear Zimbabwean interviewees complain about unclear guidelines and expectations. However, they would rather not ask too many questions because they often got yelled at. Also, Zimbabwean employees found Chinese employers' way of speaking very indecorous, and it often made them feel embarrassed and offended. In turn, their reticence to ask questions indicated disobedience and low productivity to their employers. Instead of understanding what caused an employee's 
productivity to drop or addressing these concerns with the employee in private, Chinese employers just got more frustrated and yelled more.

As we saw in the example from Wu (2014, 126-35) above, a "good employee" is, according to Chinese standards, someone who is obedient with regards to orders, keeps the boss up to date on progress, and is responsible and dependable at the same time. Many restaurant owners I interviewed shared similar expectations, including Mrs. Luo. To her, a "good employee" was someone who was respectful to her, obeyed her commands, was attentive to the needs of operating a restaurant business, and was flexible enough to pick up various tasks without being asked and at the same time knew not to cross the line and make decisions independently of her at work. According to Mrs. Luo, the Zimbabwean employees' work ethics were the opposite of Ah Ling's. Not only did they not take up multiple tasks automatically, they often did not understand her when she gave them direct orders. This is why, according to Mrs. Luo, the Chinese were better employees than Zimbabweans. Zimbabweans often questioned her commands, constantly negotiated their job descriptions, and refused to take on more responsibilities.

One time I heard a Chinese employer yelling at a Zimbabwean employee in the kitchen. I was at the front next to the cash machine and could not hear the details. One of the Chinese chefs came to the front. I asked him what had happened. "Boss lady asked the new black woman to towel dry dishes and cups. The new black woman said they are dry, no need to do it. This stupid black woman talks too much. Just do whatever your employer asks you to do. Who cares why?" he said. This was a typical comment from Chinese employees when they saw Zimbabwean employees arguing at work. Indeed, most Chinese employees understand a hidden rule to not reject employers' orders 
directly. This is particularly true in public, because any rejection of an employer's orders is considered to damaging to the employer's mianzi (face).

As noted, the concept of mianzi involves a symbolic perception of prestige. In Mandarin shang lian (赏脸), or bi main (俾面) in Cantonese, means that mianzi can be given to people by showing respect, complimenting them, or praising them. In contrast, bu shang lian (不赏脸) in Mandarin, or ng bi main (唔俾面) in Cantonese, refers to how one can cause someone to lose mianzi by turning down something or criticizing the person. Sometimes an inappropriate facial expression, such as demonstrating irritation or not smiling, may also be interpreted as not giving mianzi. As Guo-Ming Chen and William Starosta explain, the practices of giving mianzi and earning mianzi are valued highly for Chinese:

Mientze [another spelling of mianzi] refers to the projected image of ourselves in a relationship network.... It represents our social position and prestige gained from the successful performance of our specific social roles that are well recognized by other members in the society.... In order to follow the principle of li [propriety] mentioned above one should show due respect for others' feelings and act to save their face, because any conscious act of making others lose face will damage one's own image, and saving one's face is a way to heighten one's self-esteem.... Showing no concern for face saving in social interactions often leads to emotional uneasiness or to a serious conflict. $(1997,6)$

Zimbabwean employees may not be aware that their rejection of any order could be interpreted as damaging to an employer's self-image and reputation. Even more confusing for them, the Chinese even believe to some extent that employers should not apologize when they make a mistake. 
One Zimbabwean employee, Mary, described what happened when she was accused of stealing:

One time the female owner [also a server] brought back a dish to the kitchen because she made the wrong order. She went back to the dining area while her husband [the chef] was cooking the new order. Their cousin [second chef] came into the kitchen and asked about the dish. The male owner told the cousin to eat it, and then he delivered the new dish to the customers. The cousin took the dish and went outside. When the lady boss came back to the kitchen, saw the food disappeared, she yelled at me. I told her I did not eat the food. I told her I don't like Chinese food. She said I was a liar. The husband came inside, told her the cousin ate it. She calmed down. But I was so cross. She knew what she did was wrong, and she knew I was angry. She did not apologize. She just tried to say something funny and pretend everything was okay.... I know she is not a bad person, but she has to respect me like I respect them. Mary said she just let it go because the employer had been nicer to her and bought her son something, which she perceived was some sort of apology and peace offering. What happened to Mary is not uncommon. If something went missing, accusations against Zimbabwean employees often occurred. I elaborate on the issue of employee theft in Chapter V. For now, I pay attention to how Mary handled it.

When people are falsely accused of stealing, it is understandable that they get angry and confront their employers or managers about the accusations. But arguing with Chinese employers in most cases does not solve the problem — and Mary knew it was pointless to continue to be mad. I did not ask Mary if she knew to avoid direct confrontation with her Chinese employer, but what she did prevented her employer from losing mianzi. 
During interviews, almost every Chinese employee laid out countless complaints against their employers, their co-workers, or their work environment. But I did not witness any argument between Chinese employers and employees, nor did I see any Chinese employees show any obvious resentment towards their employers, especially not in public. Nonetheless, it would be a mistake to think that the Chinese were submissive and obedient employees. They were just not as direct and straightforward as the Zimbabwean employees when it came to conflict. The following account describes what happened during one staff dinner I participated in and helps to exemplify this point.

\section{Passive-Aggressive Resistance: Chinese Employees}

One night at the end of a working day, all the Chinese employees and their employer were sitting at a table sharing dinner. The owner mentioned that he and a chef were going to cook for a wedding banquet next week, which was to take place in a small town about 200 to 300 kilometres away from Johannesburg. He was recruiting two Chinese servers to go with them. Nobody was interested - as three servers later told me when I drove them home. They felt the extra pay was not that great, plus the travel time was not included. They preferred staying home as they only got one day off a week.

Since nobody volunteered, the owner started to ask each individual if she had that day off. Nobody gave a firm "no" to him, but nobody made any promises either. Although I wanted to see a Chinese wedding banquet in a small town, I had a commitment at the University of Johannesburg on that day. I expressed my interest and told the owner that, 
unfortunately, I had to go to school. ${ }^{41}$ The other Chinese servers either apologized for having already made plans with family, or said they had to ask their family first. The next week, the owner left for the small town with one Chinese chef and three Zimbabwean kitchen helpers.

In some cases of conflict, Chinese employees ask a mediator for help. For instance, when Ah Ling told Mr. Luo that she wanted to visit her family in China for a month, Mr. Luo refused because it was a busy month. Mrs. Luo was away when Ah Ling asked, so Ah Ling told Mr. Luo that she would discuss rescheduling with her family. I do not know if Ah Ling actually talked to her family, but she did not talk to Mr. Luo again about this matter. Instead, she waited for Mrs. Luo's return and asked her for help. Since Ah Ling was Mrs. Luo's favourite employee, Mrs. Luo was willing to talk to her husband on her behalf, and she also took over some of Ah Ling's shifts. Eventually Ah Ling got the month off as she had planned, without any obvious tension with Mr. Luo.

An indirect style of communication, as Chen and Starosta suggest, can be seen as a tactic. It means that

the Chinese can pursue a smooth verbal and nonverbal interaction in the process of conflict management and resolution. In addition, the indirect communication pattern also provides the Chinese with an opportunity for not saying "no" and not showing aggressive behaviors in public, for both saying "no" and showing aggression violate the principle of li [propriety] and are detrimental to harmony. $(1997,6)$

\footnotetext{
${ }^{41}$ In fact, the thought of how not to affect the owner's mianzi had not crossed my mind. We had just served a wedding banquet of twelve tables. I was too tired to think of anything else but telling the truth. Luckily, it turned out to be a proper response.
} 
Viewed from this perspective, the examples of indirect communication from the Chinese employees can be considered to be communication tactics consisting of deliberate (e.g., being attentive to the situation) and careful acts (e.g., avoiding face-to-face confrontation).

By contrast, Zimbabwean employees often responded directly to confrontation. The following account is from a Zimbabwean interviewee when she talked about how she negotiated a longer holiday with her Chinese employer:

Last time I went to Zim I told the boss lady I need to take a month off. She refused because business is busy during Christmas. I said no, I have to go. She said fine but two weeks only, otherwise I'll lose my job. I told her, "My mother is sick. If this is your mother, what do you do?" She didn't say anything, just waved to me and said something in Chinese.... When I came back, they hired someone else. Maybe it didn't work out or I was better at the job — she called me after two weeks and asked if I want this job back. I now don't take Christmas holidays off; it's too expensive to [pay bribe to] go to Zim at that time anyway. I go home around February when it's quiet.

If we compare the two examples above, one of the main differences between Chinese and Zimbabwean employees in handling unavoidable confrontation is that Chinese employees do not react to it right away. They try to avoid obvious disagreement and face-to-face conflict. If it is unpreventable, they either reject the order in a subtle and polite way or try to find help with negotiation. They resolve the matter privately and at the right moment in order to avoid a situation where their employers might feel they have lost mianzi (face) in front of other people. 
Most Zimbabwean employees, on the other hand, do not know that by avoiding direct confrontation with their Chinese employers, problems can be dealt with much more easily. Although Zimbabweans feel that saying "no" to employers is just a natural reaction to being asked to do something they do not want to do, in the eyes of their Chinese employers, Zimbabweans show no concern for their mianzi. For instance, if the Zimbabwean chef from the opening story of this chapter could explain to his employer in private why he could not accept the promotion, instead of disobeying orders in front of other employees, his employer might be more understanding of his situation and respect his wish to remain a chef and not become a manager. That being said, I do not mean to imply that it was the Zimbabwean chef's fault, nor am I suggesting that the way Chinese employers communicate with their employees is unproblematic. My purpose is only to point out that, clearly, there is a cultural gap between how Chinese and Zimbabweans understand and interact with each other, and this gap often leads to miscommunication and tension.

Obviously, most Zimbabweans do not have knowledge of how Chinese people expect them to act, or how to treat their Chinese employers with the expected polite etiquette. For more than half of my Zimbabwean interviewees, working for the Chinese was their first employment. They were not experienced workers, which made it even more difficult to meet the expectations of their employer. More precisely, anyone who is not familiar with Chinese restaurant culture would not understand the underlying rules, including myself. For instance, I did not know that, according to the etiquette of good table manners, employees have to wait for the owner or the head chef before starting to eat. Perhaps this was because two of my field sites were smaller family- 
owned restaurants, and I worked part-time at the other two restaurants, so I did not have much chance to share staff meals.

I learned about this custom only near the end of my fieldwork when I had the first staff meal at my last field site, Golden Sun, which was a large, formal restaurant. I sat next to a senior Chinese server who was assigned to guide me. When she saw me touching my chopsticks, she told me we had to wait until the head chef picked up his. If it took mewho spoke the same language and was perceived as an "insider" (whether ethnically or nationally) — more than six months of fieldwork to find out about this rule, I wonder how long it would take for the Zimbabwean employees. Moreover, how likely are Chinese employees to teach them about these unspoken rules, to help them to gain a better working relationship with their Chinese employers?

Besides the differences in language, working culture, and expectations, another challenge is that Chinese people do not always see verbal communication as a mode of self-expression. As Chen and Starosta argue, the purpose of communication for Chinese people is not necessarily about expressing one's thoughts or feelings; it is a means of achieving and maintaining a good guanxi (harmonious relationship):

To the Chinese, conflicts are not treated as problems of communication but rather as detractors from harmony. Human communication is not a process in which we strive to direct the interaction to our own favor. Instead, it is a process in which we try to adapt and relocate ourselves in the dynamic process of interdependence and cooperation. To sincerely display a whole-hearted concern for the other is therefore a gateway to reach a harmonious relationship.... As a result, aiming to establish a conflict free interpersonal and social relationship is the ultimate goal for Chinese interactions.... $(1997,5)$ 
This point reflects their earlier argument about indirect style of communication being a tactic. This is why Chinese use indirect speech to help them test boundaries during a negotiation process before they can figure out, adjust, and adapt to the new social relationship.

In a similar vein, $\mathrm{Wu}(2014)$ argues that the indirect speech style of the Chinese is the main element of what is missing in the communication between Zambians and Chinese. As he explains,

the miscommunication between Chinese migrants and their Zambian counterparts in terms of linguistic exchanges arises as a result of the accustomed communicative style - indirect speech — that my Chinese interlocutors employ. They highly value the capacity of 'speaking appropriately' and evaluate others based on their communicative skills. 'Speaking appropriately' requires the actor to be sensitive to the context, not only the social positions and intentions of each interlocutor in the situation but also the emotional tone of the situation. (Wu 2014, 47-48)

As $\mathrm{Wu}$ has pointed out, the root cause of the communication problem between Zambian employees and Chinese employers is that Zambians do not read indirect speech or know how to "speak appropriately" according to the Chinese standard.

While I agree with Wu's argument, I would like to expand on this point. The miscommunication problem is an intersubjective phenomenon, a two-way street. It is correct to say that Zimbabweans do not understand Chinese "indirect" rules, but at the same time, it is also correct to suggest that Chinese employers often overreact when directly confronted, as they take it as an attack on their personhood. For Zimbabweans, in many cases, saying "no" only means they do not want to do a particular task. Their intention is not to insult their employers; in fact, it was not even about the Chinese 
employers at all. The Zimbabweans simply expressed their opinion in a particular context. However, their direct style of speech has often been interpreted by their Chinese employers as an inability to negotiate and a failure to reach a good guanxi together. Hence, the Chinese shut them down. Once the understanding and goal of communication are no longer mutual, what left is misinterpretation, miscommunication, and tension.

\section{Concluding Remarks}

It is important to note that the above examples and analysis should not be read as the only pattern or an essential problem in every Chinese-Zimbabwean employment relationship. As I stated in Chapter II, I do not wish to reduce everything to guanxi, as people's relationships evolve over time. Sure, people who share similar backgrounds (e.g., birthplace, language, norms) tend to bond more at first. Sure, Chinese people's guanxi gives them a foundation to build a better employer-employee relationship based on mutual understanding. However, as I also showed in that chapter, it does not mean that there are no contradictions or conflicts among Chinese im/migrants, or that guanxi always stays the same. Guanxi can be stronger or weaker depending on how people interact with each other. What matters is what people do to maintain a guanxi that flows back and forth (Yan 1996). Guanxi evolves on a case-by-case basis. I do not wish to overlook the complexity of people's relationships. This also applies to the conceptualization of intramigrant relationships between the Chinese employers and Zimbabwean employees.

This is precisely why, in the latter part of this chapter, I put the emphasis on the conflicts between Chinese employers and employees. I want to highlight the fact that there will always be conflicts in any employer-employee relationship, regardless of race, 
ethnicity, or culture. The question is, how do they deal with and resolve such conflicts? I showed how Chinese employees negotiate with their employer in an indirect way, which gives space and time for them to find a solution that satisfies everyone.

The cases of Prudy (who served non-Chinese customers) and Precious (who became a caregiver) illustrate that there are Zimbabwean employees who get along with their Chinese employers after years of negotiation and mutually gaining better understanding. In some cases, the longer Chinese and Zimbabweans work together, the better they seem to understand each other. But in most cases, misunderstandings and tensions still occur in daily interactions. Most of the Zimbabwean interviewees had worked for the Chinese for less than two years when I spoke with them, but I am still hesitant to suggest that the longer Chinese and Zimbabweans work together, the better their situation gets.

For one, my data indicate a complicated answer. Some restaurant owners certainly did change their minds about Zimbabwean people, but some owners held even more prejudice against black people after years of poor relationships with employees.

Secondly, there are Zimbabwean employees who, in fact, acknowledged knowing how to play the "Chinese" game but refused to do so as a form of resistance. A Zimbabwean woman who had worked at a Chinese restaurant for ten years told me, "Oh, I know what the boss wants me to do. I just don't want to do it. Let the Chinese do it. Why? Chinese are getting much more pay than I am. Why should I work more than the Chinese?" Her statement reminds us that when examining any employer-employee relationship, we cannot overlook power relations. In this case, as argued in the last chapter on the intramigrant economy, South Africa's racialized labour market has created the economic 
differentiation that leads Zimbabweans to earn significantly less than Chinese. The next chapter brings the social reality of income inequality into the intercultural discussion. 


\section{CHAPTER V \\ UNEQUAL INTERDEPENDENCY}

\section{Division of Labour}

Throughout my fieldwork, participants working in each restaurant position-

Chinese owners, managers, and employees and Zimbabwean kitchen managers and employees - all complained about their jobs in one way or another. What also made it difficult for them was tensions and conflicts, whether direct or indirect, like those described in the last chapter. The despair in the work environment was overwhelming at times; once I even wrote down in my fieldnotes, "This is a very depressing industry." In hindsight, I realized much of my data were collected through their complaints, and I have learned how to listen better, as my participants were releasing stress by complaining.

My last field site, Golden Sun, changed this perception. As mentioned in the previous chapter, it was a large, formal, and busy restaurant, where a senior Chinese server taught me to wait for the head chef before starting to eat. Unlike the frequent shouting I heard at other restaurants, when incidents happened at Golden Sun, everyone would stay calm and continue doing their jobs. For instance, when a Zimbabwean busser brought out the wrong dish, a Chinese server apologized to the customers and told the busser to check the kitchen. Another time, when a customer dropped a glass on the ground, the owner asked if the customers were alright, called the Zimbabwean manager, and pointed to the floor without saying anything. The manager went to the kitchen and asked a Zimbabwean employee to clean the floor. There was no yelling at the busser or cultural misunderstandings like at other restaurants. 
At first, I thought there was less tension there because the salaries were relatively high and the employers usually provided good staff meals. One time I was hanging out in the kitchen with a young Zimbabwean woman who wanted to save up money to attend a university in South Africa. Every Chinese and Zimbabwean employee in the kitchen found my presence unusual. They generally did not see people working at the front come to the kitchen. They joked about whether I was hungry and looking for food. This was when I realized the division of labour and hierarchy were more evident at Golden Sun than at other restaurants where I had conducted field research.

At Golden Sun, there was a hostess to seat customers; servers to bring out teas, take orders, and set up tables; and bussers to refill teas, deliver dishes, and clean tables. In the kitchen, there were several separated stations, such as deep-frying, steaming, boiling, cleaning, and preparing raw meats and vegetables. Each employee was given specific tasks at each station. In contrast to most Zimbabwean interviewees who complained about unclear guidelines and expectations as mentioned in the last chapter, the two Zimbabwean interviewees from Golden Sun did not share this problem. They had a clear understanding of their jobs, and they could turn to their Zimbabwean manager, who had interviewed and hired them in the first place, for instruction. During our interview, the owner of Golden Sun explained to me the importance of division of labour, which is discussed in the next section. According to his view, dividing the work process into a smaller set of tasks reduced the number of skills required of each employee, so they would be able to learn faster and become better at their jobs. At the same time, it would be easier to replace employees if, for whatever reasons, they could not come to work. 
At the other two smaller family-operated restaurants, in contrast to Golden Sun, everyone had to do whatever they could in order to keep the business going. For instance, both the female owners of the restaurants worked as cashiers and servers but helped to cook if the kitchen assistants did not show up at work. And when the female owners were busy taking orders from walk-in customers, the male owners, who were the chefs of the restaurant, had to answer the phone. The owners of these two restaurants and some others I met had all worked at other restaurants before opening their own. They all said something similar: "You need to know how to do everything before you open your own restaurant." They suggested that since the restaurant employee turnover rate was very high, they could not depend on anyone except people from their own networks such as a relative or a laoxiang (老乡 someone from the same village). Although the division of labour was less clear in the smaller restaurants, the sense of mutual dependence and bonds were stronger.

When contrasting these examples, I found the correlations between dependence and trust, and between work production and income distribution, unsettling and often in contradiction. As noted in Chapter I, most small- and medium-sized Chinese restaurant entrepreneurs in South Africa share the characteristics of petty capitalists, defined as "individuals or households who employ a small number of workers but are themselves actively involved in the labor process" (Smart and Smart 2005, 3). Smart and Smart point out that a positive aspect of this type of employment relationship can be that a "reduced separation between labor and management creates opportunities for gradual improvement of production processes through mobilization of tacit knowledge available to workers, and for flexible resolution of conflicting demands characteristic of a business 
environment" (4). Smart and Smart also suggest that an ethnographic approach is more ideal than a quantitative one to examine petty entrepreneurship, because it enables researchers to focus on the real-life experiences of "questions of loyalty, trust, exploitation, and market conditions" (12) when doing petty business.

As noted in Chapter I, there is evidence of flexibility and mobility between the positions of employee and employer for the Chinese in Johannesburg, as Smart and Smart described. Such opportunities are less available to Zimbabwean employees. But Smart and Smart have correctly pointed out that "questions of loyalty, trust, exploitation, and market conditions" (12) are challenges that petty capitalists face every day, and these perhaps can only be examined through detailed ethnographic studies. By asking similar questions - on loyalty, trust, exploitation, freedom, and market conditions - this chapter aims to integrate arguments from previous chapters in order to examine what facilitates the intra-migrant economy and why actors still participate in it even when there has been so much tension and conflict, and so many complaints.

In line with James Ferguson's recent book, Give a Man a Fish: Reflections on the New Politics of Distribution (2015), the latter discussions in this chapter revolve around the following argument: What bonds together Chinese restaurant entrepreneurship, which has been operating without legal employee contracts, is what I call "interdependency." By drawing on Ferguson's proposition for a need to redefine "freedom" as what he calls “declarations of dependence" (2013; 2015), I suggest that in Chinese guanxi and Southern African ubuntu there is a much greater emphasis on one's social relationships than individual-oriented personhood. Ubuntu can be seen as an African communitarian cultural logic, a worldview that emphasizes sharing, togetherness, and valuing human 
relationships (Thuku 2007, 94). Due to data limitations, I am unable to compare and contrast guanxi and ubuntu. But evidence suggests that in guanxi- and ubuntu-based societies, there is a sense that a person does not really exist unless this individual is in a context of relationships, duties, and roles with others. Seen from this perspective, dependency and autonomy are not two opposing ideas; rather, to be dependent on people is not an end of one's freedom but a means of building relationships with others and of participating in society.

\section{Questions of Loyalty and Trust}

As noted in Chapter I, restaurant owners often talked about how finding and keeping good employees to work at their restaurants was probably the most challenging task, especially with Chinese chefs, as the number of qualified chefs is limited in South Africa. When hiring one, restaurant owners need to calculate carefully to balance between payroll and profit because a Chinese chef's salary usually takes up a large percentage of operating costs. When I asked the owner of Golden Sun about management techniques, he emphasized that to fengonghezo (分工合作, divide the work and work in cooperation with each other) is the key as it creates cross-team dependencies, but at the same time employees can easily be trained and replaced if necessary. This is how he explained the importance of this division of labour:

We have more than thirty staff working every day [roughly ten Chinese and twenty Zimbabweans]. There is no way I can train or watch everyone. Sometimes people quit, take vacation days off, or get sick. That's why we need to fengonghezo. I train my managers, then let them handle their teams. The Zimbabwean manager [who understood some Chinese] makes sure that the Zimbabwean employees know what to 
do and how to collaborate with the Chinese teams. When everyone can distinguish their jobs, it is less complicated and easier to work together (大家把工作分清楚了就 容易上手，开工就不用搞得那麼複杂).

In his view, dividing the work process into a smaller number of tasks reduced the skills required of each employee so they were able to learn fast and become better at their jobs. At the same time, as he mentioned, he took into consideration the high turnover and low loyalty of employees; separating workers into smaller units made it easier to replace employees if they could not come to work for some reason.

On the one hand, as shown from the interview data above, a division of labour increased overall efficiency as it entailed less training, and employees quickly gained familiarity with the job because they performed the same tasks repetitively and continuously. For instance, I found working at Golden Sun was the easiest compared to the other restaurants, where I was serving, answering phones, cleaning tables, packing takeout, and even preparing food if there was a shortage in the kitchen. At Golden Sun I only needed to focus on a few specific tasks. On the other hand, the division of labour did not provide much opportunity for skill development. For instance, a Zimbabwean cook at Golden Sun could make dumpling dough and wrap the dumplings, but he did not know how to prepare fillings or how long it took to boil and fry dumplings.

Every male owner of a small-sized restaurant that I interviewed was a chef when he first started his business in order to reduce payroll costs and avoid the problem of chef shortages. If his business expanded, he preferred to hire someone from his own network, because he thought that an insider was less likely to betray him, which was the guanxi predisposition I explained earlier. Like one owner said, "I no longer teach wairen 
(outsiders). I trained a couple [from a different part of China to cook and take orders]. Once they learned everything they went and opened their own restaurant with lower prices, became my competition. I called my cousin to come to South Africa." The cousin was the restaurant's chef at the time of the interview. The interviewee planned to open a second restaurant and was training his cousin in other tasks such as taking orders and ordering supplies so the cousin could take over one of the restaurants. He stated that he had planned to do the same for the couple, but they were impatient and betrayed his trust by opening their own place.

Another interviewee, Mr. Wong, had recently expanded his restaurant by moving to a larger location, and he hired a laoxiang (老乡 someone from the same village) to be his chef. These were his reasons:

I like to hire chefs directly from my region. I don't have to train them much, and their goal is clear-come to work and save up for a few years, then return home. But it is expensive to keep a good Chinese chef. Not only do I have to pay for his accommodation, transportation, meals, but also I have to pay him in RMB (Chinese Yuan). In fact, I should have two full-time chefs, but I cannot afford two chefs' salaries now that the value of the South African rand is declining. I hired a cashier/front desk person so I can work in the kitchen.... This still costs me less than hiring a chef.

I asked Mr. Wong if he had considered training a Zimbabwean employee to become a full-time chef. He replied:

It took me a while to train each of them to do some tasks; after all, our food cultures and cooking techniques are so different. Now they know how to prepare food (e.g., breading and mixing ingredients) but only me and the chef do the final cooking. It 
might take a longer time but they are able to learn. If they really want to, I am willing to teach. But I don't think they can eat bitterness [endure hardship]. If they stand too long, they complain. If I am too loud, they say I don't respect them. This would not happen with Chinese chefs; we all have been there [shouted at by trainers and standing for long hours]. We know it is nothing; it is just how training works. And I don't know if I can trust them. I don't know how long they are going to work here or when will they leave South Africa. I would rather hire and train a Chinese. Better to rely on zijiren (自己人 insiders) than wairen (外人 outsiders).

As we can see, even though there was a shortage of chefs, and Mr. Wong saw potential in his Zimbabwean kitchen helpers, he had a hard time trusting Zimbabweans because he perceived them as outsiders. In this context, Mr. Wong defined the boundary between insider and outsider based on nationality. Later on, however, when his good friend showed up, he referred to this friend as an insider and his new front desk employee, a Chinese woman from a different region, as an outsider. It is important to note that Mr. Wong was not the only interviewee who changed the insider-outsider boundaries depending on the context, like the interviewee above who felt betrayed by the Chinese couple. More examples are shown later.

Although every restaurant owner mentioned the difficulty of employing "good" Chinese and African workers, most of them agreed that it was more difficult to trust black employees. There were a number of reasons for this attitude: 1) the problem of employee theft, 2) the absence of a contract, and 3) the discourse on illegality. In the following subsections, I discuss the employers' views on Zimbabwean employees, then I offer a different point of view, including some counter-stories to show that there is more than one perspective and things are not always as they seem. 
Employee Theft

As examples in previous chapters showed, almost every restaurant owner claimed that an African employee had stolen something, from small-scale "theft" such as eating food without authorization to stealing valuable ingredients or goods for re-sale. For instance, one time I heard two restaurant owners talking about two black men who showed up at their restaurant to sell black market prawns for half of the regular market price. I asked if they were fishermen. One owner said more likely these were stolen prawns. The other one joked, "Maybe they stole from a Chinese wholesaler" while eating the prawns and sharing them with others.

From the story above, we see that people's perception of "stealing" is much like corruption, as it is also a grey area and case specific (see Chapter II for details). If the prawns had been stolen from their restaurant or from someone they knew, most likely the restaurant owners would have called the police instead of buying and enjoying the prawns. From the perspective of Zimbabwean employees, sometimes they were unsure of their Chinese employers' "policy," and it was even more confusing when they were not allowed to do what they saw Chinese employees doing. For instance, one Zimbabwean interviewee said, "The Chinese waitress sent free drinks to customers all the time; when I brought drinks to customers, the man [her employer] shouted at me and said this is stealing." I do not know her employer, but my assumption is that the Chinese server had the employer's permission to build guanxi by offering free drinks.

In other cases, employees did not see "theft" in the same way as their employers did. An example involves Alice and her sisters, who, as described in Chapter I, worked at Silver City and ate rice and leftover food, and whose employer perceived they were 
"stealing"; to Alice, however, they were just eating something not valuable to the owner.

Later I examine this situation through the issue of reciprocal obligations, but there are three points worth mentioning here. First, not all Zimbabweans like to eat Chinese food, and some of the interviewees complained to me that their employers only provided Chinese food, so they had to bring their own lunch. Second, if anything went missing, Zimbabwean employees were often the primary suspects (e.g., see the story of Mary in Chapter IV). Third, I interpret the Zimbabweans' eating of leftovers at Silver City as a form of resistance against their tip-stealing employer. ${ }^{42}$

Furthermore, it is not unheard of for Chinese employees to have committed theft. They usually are the ones who handle the cash registers, and hence have a greater opportunity to hide tips or void out cash transactions. One Chinese server complained to me that her manager constantly stole everyone's tips, as her restaurant had a policy of "tip pooling," where servers shared their tips with the kitchen employees (bussers and cooks). That manager's job was to redistribute tips accordingly (usually $60 \%$ for the front and $40 \%$ for the kitchen), but he often put tips into his pocket. I asked the server if the owner knew. She replied, "I think he does, he must have seen something from the cameras, but it doesn't really matter to him because the manager is not stealing his money. He probably feels it will cause more trouble if he has to find a new manager." Again, I do not know this server's employer, but I did notice that although most Chinese restaurant employers were willing to share stories about how African employees stole from them, they became cautious when talking about theft by Chinese employees. I

\footnotetext{
${ }^{42}$ My inspiration for this interpretation comes from Aihwa Ong's first ethnography, Spirits of Resistance and Capitalist Discipline: Factory Women in Malaysia (1987), where she argues that Malay women workers were periodically seized by spirit possession as a way of rebelling against the exploitative working conditions without being punished by the management.
} 
asked two of my closest informants why restaurants owners were uncomfortable with this subject. One replied, “Owners don’t make any accusation unless there is strong evidence or you caught the wrongful behaviour in action. But what can you do besides firing the person? It is not like you will report it to the police. If you make too big of deal out of it, everyone is going to look bad (事情闹大了大家都难看).” She suggested that if it were not handled carefully, it could stir up unnecessary tensions and jeopardize everyone's guanxi (harmony).

The other informant added that most likely owners handled this matter privately and passively, because people might know each other or know someone who knows the accused employee. Moreover, "the [accused] employee can turn the story around or make up fake stories about your restaurant. Wairen [outsiders] don't know what is true and what is not. But when customers hear something wrong about this restaurant, how likely are they to want to go?" she said. This informant made two additional points here. First, competition is high in Johannesburg. Second, the sensitivity of this kind of accusation and bad publicity are reasons most employers would rather keep this information secret.

\section{Absence of Contract}

As noted in Chapter III, one of the job search methods used by the Zimbabweans was to walk into a Chinese restaurant and ask if it was hiring. Many of them were employed on the spot, and their Chinese employers never checked or asked about their identity documentations. Additionally, I never heard of anyone signing any contracts, including contracts between Chinese employers and Chinese employees. Alan Smart and Carolyn L. Hsu (2007) suggest that this has been a common business practice in Chinese 
communities and can be found in China and all over the world. In fact, much Chinese business has been developed through guanxi, not legal and financial institutions, especially in the case of small-business owners who had few resources. In other words, guanxi has "served to functionally replace contracts and other formal institutions. Through ever-expanding networks of 'friends,' aspiring business owners could raise capital, form partnerships, seek suppliers, gather information, and conduct relatively secure transactions" (Smart and Hsu 2007, 174). As such, guanxi has facilitated Chinese entrepreneurship in China and overseas (167).

In the context of Southern Africa, $\mathrm{Wu}$ (2014) notes that Chinese management teams usually recruited Zambians from nearby villages on a temporary task basis without contracts. He points out that the Chinese were also reluctant to draw up contracts with other Chinese people, especially between friends: "Contracts to them seem cold, fixed and formal, which is the opposite of what proper mutual affection should be: fluid and informal. Therefore, drawing contracts between friends is perceived as a gesture of 'alienation' implying mistrust and potentially damaging the interactional affection (jiaoqing)" (Wu 2014, 102). Moreover, sometimes it was the choice of workers to not have contracts, as it allowed them greater flexibility in Zambia (114).

While there is guanxi to guide Chinese employers and Chinese employees on how to negotiate terms and form obligations with each other, there is no such initial mutual understanding between Chinese employers and Zimbabwean employees. This is precisely the main argument of Chapter IV. However, there is still something binding them at a Chinese workplace, which I call "interdependency" and discuss later. For now, it is 
important to recall that the Chinese restaurant sector has been operating without legal contracts to bond employers and employees together for more than a decade. ${ }^{43}$

When asked about how to manage African employees, many employers complained that the problem of employee "no-call and no-show to work without notice" happened frequently. In order to prevent employees from not showing up, most employees were paid once per month, not weekly or bi-weekly. I do not think high rates of absenteeism by Zimbabwean workers should be a surprise given there is no contract between them and their Chinese employers. If Chinese employers can fire their Zimbabwean employees anytime, it should be expected that the Zimbabweans can quit anytime. Based on my interview data, the matter of employee no-shows happened more frequently than termination of Zimbabwean employees by employers. Only two Zimbabwean interviewees reported that they were told not to come to work the next month. In the first case, the restaurant was shutting down due to a low level of business; in the other case, the employer's cousin was coming to South Africa, and the employer had to give the Zimbabwean woman's job to her cousin.

The restaurant owners usually linked this no-show and no-call behaviour to black people's "nature," claiming that black people had a weak sense of responsibility and no concern about their future. One owner said, "After the payday no black workers showed up. It happened twice already. One man even came into the shop later and asked for his job back. Shameless!” Another owner declared, "The young woman works here, always buying new clothes. Once she got paid she spent all of it, instead of saving up."

\footnotetext{
${ }^{43}$ It is very possible that the restaurant sector has been operating this way since the beginning, as two chefs who had been in South Africa during the late 1980s told me that they were recruited and hired to work at Chinese restaurants without any contracts.
} 
When I asked what they meant by “black people's nature," one restaurant owner explained, "Black people like to enjoy life too much. Unlike us, the Chinese, who just work, work, work. I sometimes envy their 'no worrying about the future' attitude, but it is impossible not to think about my child's future." Another interviewee, who had hired South Africans before and now hired only Zimbabwean employees, explained the differences between black people from these two countries:

Black South Africans are just lazy. They don't like to work much, and will do absolutely no overtime even if you offer to pay double. Zimbabweans are better. After all, they left home for a reason. But their brain is straight (死脑筋 not being flexible). I don't mind; at least they are good and hardworking people and have been working for me for years. I treat them like zijiren (insiders). But recently everyone [Chinese] talks about black foreign workers being dangerous. I am getting concerned. This restaurant owner was referring to the increase in murders committed by foreign workers, which is discussed in the next section. I would like to return to Irene Yuan Sun's (2017) argument, discussed in Chapter IV, about why Chinese factory owners complain about African workers all the time. Sun uses the example of how American factory owners used to accuse their Chinese workers of being lazy and unproductive, and now Chinese factory owners are doing same to African workers, to argue that the problem is not in their differences of "race" or "ethnicity" but in the different phases of industrialization.

Sun's main argument in her book The Next Factory of the World: How Chinese Investment is Reshaping Africa (2017) is that Africa can be industrialized by following China's example of a manufacturing-led transformation, in order to improve African people's living standard and have Africa play a stronger role in the globalized economy. I 
hold a different view than Sun, particularly in regards to her uncritical celebration of the current global economic system. Moreover, South Africa was industrialized much earlier than China, and this argument about "different phases of industrialization" does not explain the differences between South African and Zimbabwean workers that the Chinese employers complained about. Nevertheless, Sun is correct to point out that the employers often fail to see it is not so much about "race" or "ethnicity" and that different types of jobs change people's work ethic and lifestyle, whether negatively or positively. This also explains why the older generation of Chinese usually complain about younger ones not working as hard as they do.

\section{The Discourse on Illegality}

From January to April 2015, four Chinese employers were murdered by (allegedly) undocumented migrant workers. Chinese media, Chinese social media users, and Chinese officials in South Africa called attention to the issue of the employment of undocumented foreign workers. The following excerpt (see Figure 15) from a Chinese news article titled “Illegal Workers Gradually Become 'Time Bombs' and 'Negative Assets' of Chinese Businessmen in South Africa" (Song 2015b) shows an example of how the Chinese media framed "illegal migrants." 44

\footnotetext{
${ }^{44}$ Note that I only include relevant paragraphs here. The full version of this news article can be found
} online: http://world.people.com.cn/n/2015/0506/c157278-26954005.html (Accessed July 26, 2018). 
Figure 15: Discourse on "Undocumented African Migration"

\begin{tabular}{|c|c|}
\hline 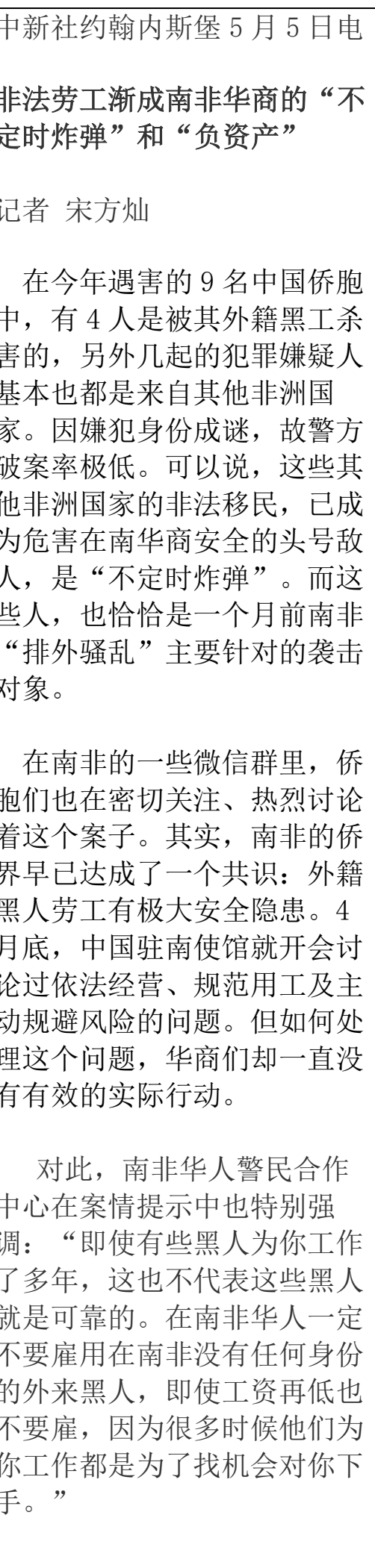 & $\begin{array}{l}\text { China News Service, Johannesburg, May } 5 \\
\text { Illegal workers gradually become "time bombs" } \\
\text { and "negative assets" of Chinese businessmen in } \\
\text { South Africa } \\
\text { Reporter: Song Fangcan } \\
\text { Of the nine Chinese migrants who were killed this } \\
\text { year, it has been confirmed that four were murdered } \\
\text { by foreign workers. Other suspects were also from } \\
\text { other African countries. Due to the suspects not } \\
\text { having documents, it was difficult for the police to } \\
\text { find them. It can be said that illegal immigrants from } \\
\text { other African countries have become the number one } \\
\text { enemy that jeopardizes the security of Chinese } \\
\text { businesspeople in South Africa and are therefore } \\
\text { "time bombs." Moreover, these people were } \\
\text { precisely the targets of South Africa's "xenophobic } \\
\text { riots" a month ago. } \\
\text { In some of South Africa's WeChat groups, overseas } \\
\text { Chinese are also paying close attention to these cases. } \\
\text { In fact, the overseas Chinese community in South } \\
\text { Africa has already reached a consensus: the risk of } \\
\text { hiring foreign black workers is high. At the end of } \\
\text { April, the Chinese Embassy in South Africa held a } \\
\text { meeting to discuss the issue of operating in } \\
\text { accordance with the law, regulating employment, and } \\
\text { taking initiative to avoid risks. But when it comes to } \\
\text { dealing with this problem in reality, Chinese } \\
\text { businesspeople have not put into practice any } \\
\text { effective actions. } \\
\text { In this regard, the South African Chinese Police and } \\
\text { Civil Cooperation Center also emphasized, "Even if } \\
\text { some black people have worked for you for many } \\
\text { years, this does not mean that these blacks are } \\
\text { reliable. In South Africa, Chinese must not employ } \\
\text { any undocumented foreigners, even if their wages are } \\
\text { really low. Because often, the reason they are willing } \\
\text { to work for you is to wait and find opportunities to } \\
\text { rob you." }\end{array}$ \\
\hline
\end{tabular}




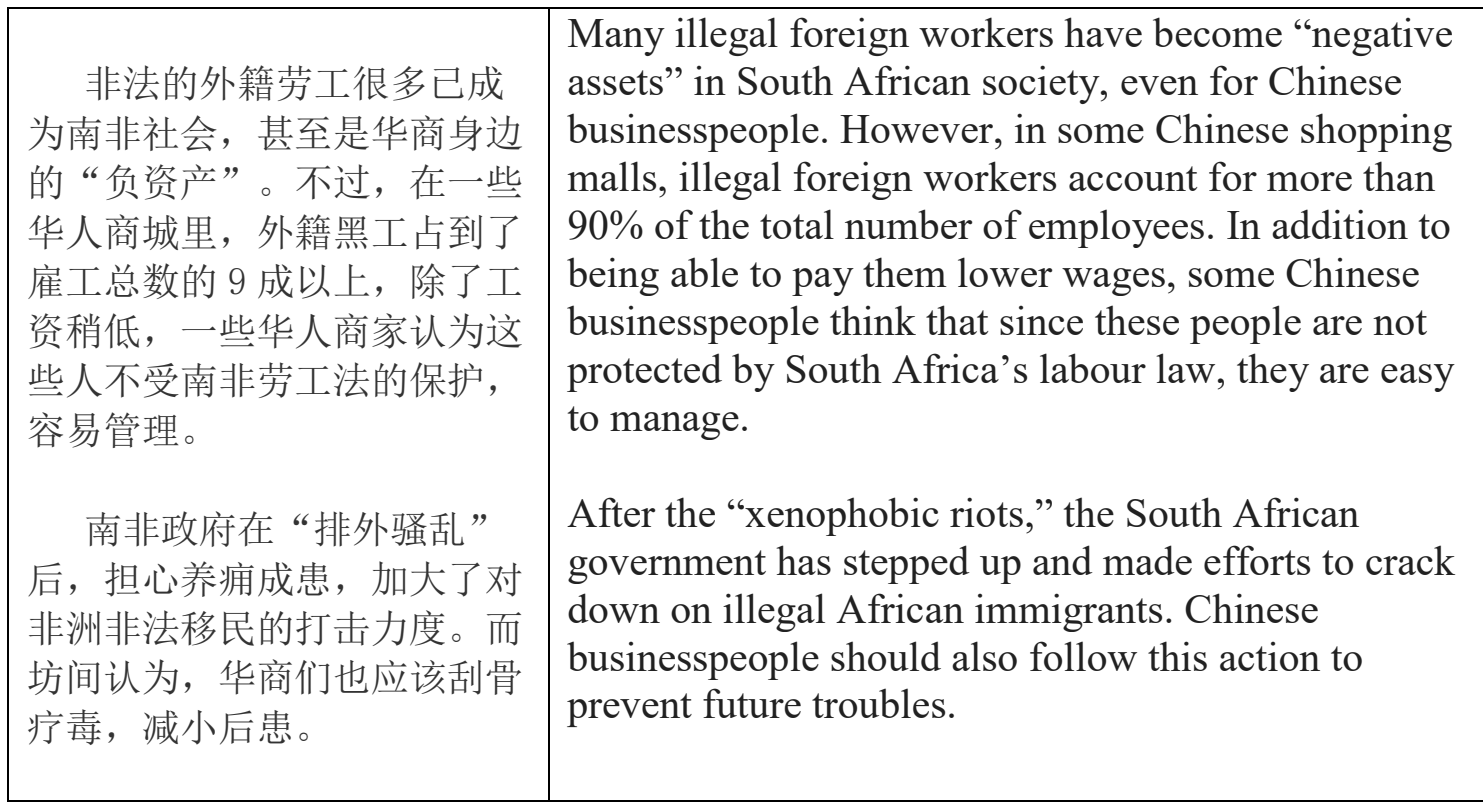

As the article indicated, the Chinese officials from the embassy in South Africa were aware of how common it was for Chinese employers to hire undocumented workers. They also made an official announcement through social media to remind Chinese migrants not to hire undocumented migrant workers. The announcement suggested that Chinese employers should go through legal channels to hire foreign employees, and make a photocopy of each employee's ID and file it with the local police department in order to protect themselves (Embassy of the People's Republic of China in Republic of South Africa 2015).

The reasons Chinese employers prefer to hire migrant workers were discussed in Chapter I. As several examples have shown in this and previous chapters, a number of Chinese employers and Zimbabwean employees are engaged in long-term working relationships. In other words, regardless of the conditions, they have reached an agreement without any regulatory guidelines or legal contracts. Somehow, they have produced a mode of working together, even in an environment that is insecure and uncertain. But when anti-black immigrant discourses were repeated in the media, many 
Chinese business owners became concerned about their African migrant employees, especially those new Chinese migrants who already felt vulnerable living with everyday racialized insecurities (see Chapter I).

First at all, let us not forget that a number of Chinese immigration and work permits are also questionable (see Chapter II). This is why I find a contradiction here: the condition of illegality is acceptable and even welcomed by the Chinese petty entrepreneurs, as it has enabled them to hire cheap labour; at the same time, the discourse of illegality tells the Chinese employers that black migrant workers are a potential threat to their safety. This growing anti-black immigrant sentiment in South Africa (detailed in Chapter III) perpetuates stereotypes and causes more prejudice against already stigmatized black migrant workers.

\section{Begging or Reciprocity?}

As I argued, it takes a long time to overcome the cross-cultural misunderstanding and miscommunication between Chinese employers and Zimbabwean employees, and this intercultural process is also complicated by the nature of their employer-employee relationship (described in Chapter IV). Though it was not the Zimbabweans' intention, Chinese employers often took Zimbabweans' directness and demands as a refusal to build a good guanxi, and Zimbabweans' confrontational style of speech as an attack on their personhood. In the last chapter I also showed why the Zimbabwean employees felt that their Chinese employers showed no affection (e.g., different ways of greeting), whereas Chinese employers often complained that the Zimbabweans did not understand renqing shigu (人情世故). Yunxiang Yan translates renqing as “moral norms and human 
feelings" $(1996,14)$. Di Wu translates shigu as "the sophistication of one's social networking skills learned in social practices" $(2014,97)$. Renqing shigu is a complicated Chinese concept but in this context, I think "being inconsiderate" can describe what my Chinese interlocutors meant, as they thought Zimbabweans often made unreasonable demands without regard to their feelings. The most common one involved direct material requests.

Several Chinese im/migrants I met mentioned that one thing they did not understand was the tendency of some Africans, even ones unfamiliar to them, to ask them if they would give away things that they were wearing or carrying. The Chinese $\mathrm{im} /$ migrants' first reaction was usually shock because it is unusual to hear a Chinese stranger or acquaintance make such a request. Many Chinese employers said it was even more common to be asked this by their employees. They saw the person who made such a request as lianpihou (脸皮厚 thick-skinned face) or buyaolian (不要脸 shameless, literally translating to "don't want face") and inconsiderate of their feelings. One Chinese employer said, "When they [Zimbabwean employees] first asked me, I was so embarrassed. I made up excuses to explain why I couldn't give it to them. Now I've developed thick skin, too. I just say no and walk away. How can they just ask openly for free things without feeling shame? In China, poor people don't do this. Only beggars do.”

To be fair, this employer was, in fact, generous. I witnessed her giving material goods (e.g., used clothes and gifts) to her Zimbabwean employees, and free food and drink to (real) beggars on the street. She was not against people getting free stuff, but it had to be on her terms. She was not without sympathy, but she did not understand their sense of entitlement. As she asked, "How can they just ask openly for free things without 
feeling shame?" I am unable to answer her question because this topic did not come up in my conversations with Zimbabwean interlocutors, and I do not wish to overinterpret their answers for them. Instead, I look at two other case studies in a similar context (Sheridan 2018; Wu 2014) and compare and contrast their findings with my own ethnographic data.

Di Wu (2014) notes that Chinese employers also made the same comment about Zambian workers lacking renqing shigu (consideration of feelings), as the Zambian workers often sought to borrow money from them. When analyzing the perception of "begging" in the Chinese and African contexts, Wu draws on the notion of different perceptions of "what a good boss should be" to argue that, to the Zambian worker, "borrowing money from the boss is unquestionable as the boss is the one that workers should go to if there is any difficulty; and boss is the one who shall take care of the workers" $(2014,101)$. However, most of the Chinese bosses did not feel obligated to help Zambian workers in their private lives and felt that they were being forced into a difficult moral dilemma:

Afraid of never being paid back, the boss is very reluctant to lend the money. Nevertheless, if s/he refuses to lend the money, the boss would consider the refusal as a potential threat to a good working relationship. Therefore, such action often leaves the Chinese bosses very annoyed and they criticise the Zambian workers who 'do not know the way to deal with human emotion (renqing shigu).' (101)

Wu states that one can easily interpret these unaligned understandings as "the exploitative nature of labour relations and argue that the cause of this vignette is the lack of legal protection for local workers at Chinese enterprises in Zambia” (138-39). Nevertheless, $\mathrm{Wu}$ argues, neither the Chinese boss nor the Zambian worker was questioning the inequality; "it is the ethics and informal work relationship that they are both concerned 
with and it is 'membership' that they desire - a form of membership which relies on mutual dependency filled with care" (139). Here, Wu refers to Ferguson's argument on dependency (2013) as a form of membership, which I elaborate on later in the chapter.

Derek Sheridan (2018) observed that Chinese employers were often surprised to hear when Tanzanian customers, strangers, and employees made frequent requests for items such as for water, cigarettes, or other gifts. On top of their experiences of petty extortion in Tanzania, Sheridan's Chinese interlocutors came to the conclusion that “'begging' was a generalized 'African' way of being” (2018, 252). In Sheridan's analysis, because "begging" is associated with losing one's face in the Chinese culture, the Chinese tended to overreact to Tanzanians' apparent directness when making material requests; as a consequence, Tanzanians liked to tease the Chinese by joking about free gifts or compensation. Sheridan suggests that the Tanzanians were intentionally making those demands in a joking way to see Chinese people's exaggerated reactions. But the Chinese did not perceive this as a joke, and what was even more confusing to the Chinese was that when they gave gifts to Tanzanians, the Tanzanians usually "thanked God" instead of them.

In Zambia, Wu (2014) also described a similar reaction from the Chinese. Out of curiosity, $\mathrm{Wu}$ asked two Zambian guards who were working for Chinese employers about why Zambians did not thank the Chinese who gave them gifts and thanked god instead. As he said to the Zambians: "But it was the Chinese giving Zambians things, right? I mean, physically" $(2014,169)$. One Zambian explained to Wu, "Yes, but if we did not pray to God for things, you won't give them to us. It is God giving us gifts through you. So we really shall thank God" (169). Wu suggests that the Zambians appreciated the gifts 
from the Chinese, but because of their different way of showing gratitude and a lack of understanding of the logic of Christianity on the part of most Chinese, the Chinese found the Zambians ungrateful.

Sheridan agrees that there are cultural differences between Chinese and Tanzanian norms of reciprocity; however, he argues that it is equally important to pay attention to the "everyday experience of economic precarity among many Tanzanians" $(2018,255)$. Sheridan also refers to Ferguson's notion of dependency to suggest that it is normal for Tanzanians to seek support from wealthier friends, as they would do the same for others who depend on them. In the views of the Tanzanians, Chinese people are rich; therefore, they should be in a position to help others with less.

Sheridan points out that the common Chinese perception of Africans is influenced by the state. As the Chinese government has been sending generous amounts of financial assistance to Africa, many Chinese see this inter-state relationship as one through which they have already given assistance to the African people, and yet the Tanzanians are still being ungrateful. Sheridan argues that this geography of inequality has shaped how the Chinese (overly) interpret their social relationships with African people.

On the one hand, Wu focuses more on the intercultural aspect, arguing that people do not always just concern themselves with their economic condition but also aim to be included in some form of membership, to feel they belong. On the other hand, Sheridan argues that it is precisely their economic inequalities that have shaped how Chinese and Africans interpret each other's behaviours. I want to put forward their arguments by suggesting that economic and cultural factors are not two opposing forces; rather, they tend to reinforce each other. This is not to suggest that culture and economy are the same 
thing. On the contrary, they are two powerful forces that always overlap and intertwine with other factors such as race and gender. Chinese and African cultural differences and economic conditions are often highlighted, yet this is only the surface of a structural problem. I now turn to my findings in South Africa.

\section{Money Borrowing and Lending}

Many Zimbabwean interviewees had tried to communicate with their employers or managers about an issue, whether it was a pay raise or a need to change attitudes. Less than $30 \%$ of them felt that these negotiations led to any improvement of the situation. Most of them wanted to leave their jobs if other options became available. But at the same time, more than $60 \%$ of interviewees stated that they would still work for the same employers if they were paid more. As one interviewee said, "Chinese people are hard people. They are hard on themselves, too. But I am always getting paid on time. This is the most important thing to me. Sometimes if I need money, they pay me in the beginning of the week." Her Chinese employer's willingness to pay her in advance when she asked contrasted with previous working experiences with non-Chinese employers.

When I was reviewing my data after the fieldwork, I found more Zimbabwean employees than Chinese employees had mentioned borrowing money from their Chinese employers. Many Chinese interviewees found this subject sensitive and did not feel comfortable getting into personal details, such as the reason for borrowing and the amount. Zimbabweans were more likely to share this information even though it was not included in my interview questions. 
This kind of conversation with Zimbabwean employees usually emerged when I asked them about what they would like to see their Chinese employers change or improve. As shown in Chapter IV, on top of common complaints about low salary, a lack of benefits, employers' rude attitudes, and poor communication, several of them talked about having a hard time repaying their Chinese employers within a short period. They wished their Chinese employers could extend the period of loan repayment.

Money borrowing and lending in Chinese and Zimbabwean communities are common practices. Many Chinese restaurant owners got financial support from family or close friends to start the business. Many Zimbabweans, too, had gotten help from their family when first settling in Johannesburg and joined ROSCAs (see Chapter III). During my fieldwork, I heard several Chinese people talking about how borrowing and lending money often created layers of tension and could jeopardize guanxi with friends and family. In fact, I was surprised to not find many Chinese ROSCAs. In Chinese, a ROSCA is called biao hui (标会 bidding association), ${ }^{45}$ and it has been widely practiced in parts of China and many overseas Chinese communities (Chen 2009; Zhang 2016).

Two points are worth noting here. First, the question of money lending from Chinese employers to Chinese and Zimbabwean employees was not addressed in my interview questions, and it is possible that it occurred more frequently than my data show. Second, there are underground Zimbabwean personal lenders, but as far as I know, the Chinese underground banking system (地下钱庄) is more developed, organized, and easily accessible, which might explain why biao hui are less popular in South Africa. One interviewee explained, when I asked her about biao hui, that she would rather deposit her

${ }^{45}$ Biao is a verb which means bidding; hui simply means group. 
money at a Chinese underground bank than a biao hui with people she does not trust well. Although participating in biao hui or underground bank is not protected by laws, people are still more likely to trust the underground bank because, according to this interviewee, it is easier for an individual to run away with the biao hui money and flee to a neighbouring country than for a whole transnational operation to collapse in both South Africa and China.

One Chinese interviewee described to me what happened when she loaned R 2000 to her close Chinese friend:

This friend promised to pay me back in two weeks. She didn't and said her son was sick and asked for a postponement. I felt bad for her, so of course I agreed. But then after a few days I caught her in a mall. She was shopping and buying luxurious clothes! I was so mad. If you have money to buy expensive stuff, why don't you repay me first? Our friendship means nothing to her? Was she lying about her son being sick? I can't trust this person anymore. She took advantage of our good guanxi and treated me like a fool. She repaid my money weeks later, but the friendship is not the same anymore.

These "money ruins friendship" kind of stories were common and familiar to many Chinese migrants in South Africa, and money is often used as a "test stone" to judge another person's character (Wu 2014). In Zambia, Wu $(2014,100)$ notes that the Chinese also try to avoid borrowing or lending money from friends.

In South Africa, one restaurant owner had loaned money to employees and friends before, and he regretted doing it, but he was still lending money to his employees, including Zimbabweans. As he said, 
I'm willing to help a good friend who is in need. But it's difficult to ask people to pay me back. I had to be careful not to make them [the borrowers] feel awkward or hurt the borrower's ego. Otherwise, they might not talk to me anymore. I was so embarrassed and don't understand why as a lender I had to beg them as if I did something wrong. Now I only lend to employees what I know I can afford to lose, and I do not expect a repayment. If they need more than I can lose, I tell them to go to underground banks.

As suggested by the interviewee above, considering the potential ruinous impact on relationships, most people try to avoid putting themselves in the situation of loaning money to friends, especially in South Africa, where underground banks are easily in reach. However, it is different between employers and employees.

In his dissertation, $\mathrm{Wu}$ (2014) did not tell how many or how frequently Chinese employers lent money to Zambian employees. My data show that at least eight Zimbabwean employees had borrowed from their Chinese employers. Given this unexpected finding came after the completion of my fieldwork, it was too late for me to trace details of money borrowing and lending between Chinese employers and Zimbabwean employees, but it is a fact that such transactions are happening. Chinese employers could, of course, deduct from an employee's salary if one of them is unable to repay; employees could also not show up at work anytime. Since there is no legal obligation involved, we have to look deeper into the interpersonal relationships at Chinese workplaces in order to understand how people construct, comprehend, and continue these informal working relationships. 


\section{Questions of Freedom and Exploitation}

In a recent book, James Ferguson (2015) points out that a large number of poor Africans do not have access to the means to sell their labour in a market for wages. Africans who lack both land and formal-sector jobs survive "through a combination of petty trade, hustling, casual labor, smuggling, prostitution, begging, theft, seeking help from relatives or lovers, and so on" (Ferguson 2015, 91). Ferguson discusses the case of South Africa to exemplify how the poor use precarious survival strategies while living in a system of what he calls "distributed livelihoods" (94). In South Africa, around 44\% of all households receive at least one social grant (6), and this is perhaps a household's only stable source of income and supports several people. As Ferguson suggests, "those who are able to access resources as dependents of the state are themselves the source of income for others we might term 'sub-dependents.' The truly destitute household, on the other hand, is the one with no children nor old people nor disabled members and therefore no eligibility for state distribution" (104, emphasis in original).

Due to this harsh reality in the Southern African region, a long-term problem rooted in the colonial era, it is almost impossible for poor people to survive on their own without any social dependence. As such, Ferguson argues that we should redefine and reexamine our understanding of "dependency," as it is often considered the opposite of autonomy, a sign of subservience or subordination. As he writes, "For while 'dependency' is obsessively decried as a problem or a trap in social policy discourse, an ethnographic view suggests that it is really only via relations of 'dependence' that most of the population survives at all. Dependence is, in this respect, not the name of the problem; it is the name of the solution" (Ferguson 2015, 97). 
This argument challenges the liberal value of "freedom" as the general understanding of being free is to be an autonomous and self-sufficient agent. That is to say, a free, autonomous person must not depend on other people. This understanding of freedom is questioned by Ferguson, who argues that to be a dependent does not mean that a person has no autonomy, and dependence "of this kind is not a passive condition—it is a carefully cultivated status that is the result of long processes of building social ties and reciprocal obligations" (2015, 107-08). He cites Saba Mahmood's (2005) ethnographic research on the women's mosque movement in Egypt, where Mahmood argues, against the common perception of Muslim women as victims of Islam, that it was the female practitioners' own desire to seek submission.

In questioning these dichotomies-freedom versus attachment, autonomy versus dependence-Ferguson argues that in the context of Southern Africa, dependence was not simply bondage or unfreedom (as the emancipatory liberal mind tends to assume). On the contrary, in a social system put together around competition for followers, it was actually the existence of possibilities for hierarchical affiliation that created the most important forms of free choice.... Such freedom as existed in such a social world (and it was not inconsiderable) came not from independence but from a plurality of opportunities for dependence. $(2015,145)$

Thus, it is only understandable, and even necessary, that poor Africans should seek to enter into hierarchical and dependent relations with well-placed others. Ferguson refers to Blair Rutherford's (2008) ethnographic research in Limpopo to point out that Zimbabwean farmworkers often deployed various livelihood strategies in exchange for job security in South Africa. Rutherford defines their trans-border condition as an "unsettled belonging" to argue that, although Zimbabwean employees have been 
mistreated by their employers, they still go to lengths to cross over the borders in order to find better livelihoods, because the reality in Southern Africa is that having an exploitative job is still better than no job. As Ferguson points out, "Their problem today is not that they are being subordinated and subjected - it is worse. The real problem is that they have become not worth subjecting, cast off from the societal snowball. For those thus abjected, subjection can only appear as a step up" (2015, 153, emphasis in original).

In a country where the unemployment rate is high, working conditions are perhaps not Zimbabwean migrant workers' first concern; the priority, rather, is to maintain their relations of dependence, even with their exploitative employers. "Such dependence, though," as Ferguson suggests, "is not the worst of outcomes" $(2015,153)$. Being subordinate and subservient should be understood as an intentional survival strategy. The real horror is when someone has no one to depend on and nowhere to belong to.

Hence, Ferguson questions why the notion of autonomy has been mainly defined as personal liberation, and why, to be free, one must be released from connections with other people. He challenges us to recognize dependency not as an end but as a means of access to social networks through building and expanding interpersonal relationships. As he suggests, "To be dependent on someone is to be able to make at least some limited claims on that person" $(2015,153)$, which is why he sees dependency as a form of "social membership" (160) where networks can at least provide a sense of belonging and inclusion.

Seeing dependency from this perspective, I found many overlaps between the Southern African ubuntu and the Chinese guanxi. Ubuntu, like guanxi, emphasizes that a society should be relationship-oriented. As Desmond Tutu explains it, 
Ubuntu is very difficult to render in the western language. It speaks to the very essence of human being. This means that they are generous, hospitable, friendly, caring and compassionate. They share what they have. It also means that my humanity is caught up, inextricably bound up, in theirs. We belong in a bundle of life. We say "a person is a person through other people.... I am human because I belong, I participate, I share." (1999 in Thuku 2007, 94)

Even though Chinese and Zimbabweans have different sets of meanings for social roles-for instance, as argued in Chapter IV, about what a good employer or employee should be like - they share certain fundamental attributes in common about personhood. For one, it is believed that personhood can only develop through human relationships. As Tutu suggests that individuals belong in a bundle of life, Chinese guanxi is a complex interdependent system among people who are in a network of social relationships, and individuals are positioned in various relations hierarchically (Yan 2009). In Chinese, to say one has good guanxi with (or is dependent on) someone is rarely perceived as a negative thing such as subservience, even though it places one in a subordinate social role. Rather, it is a claim that this person has moral obligations to one, as proper etiquette is associated with a person's social role in a particular hierarchical context, and superiors are, in a sense, indebted, holding duties to provide help and care for inferiors.

Moreover, human relationships do not only have to be about emotional support. They can be instrumental and emotional at once. In the Chinese case, as I showed in Chapter II based on the case study of Cantonese newcomers, many migrants had already been assured of employment opportunities, particularly in the restaurant and fahfee sectors, before coming to South Africa. I argued that it was the practice of guanxi that had allowed them to strengthen personal and employment relationships transnationally. 
As the story of Zhang Bao showed, a chef felt obligated to continue to work for the same employer even though he could get a higher salary somewhere else. The stronger the bond between employer and employee, the tighter people's employment relationship is. This access to other networks through guanxi, or in Ferguson's term "dependency," allows us to better understand how it can serve the function of helping people gain support through expanding networks. Guanxi and dependency, therefore, are not just about hierarchy or subjugation; rather, they are necessary for both Chinese and Zimbabwean migrants to achieve better livelihoods by finding a particular form of social membership with others who are relatively more influential.

\section{Equal but not Equal; Free but not Free}

Inevitably, there are also differences between the Southern African idea of dependency and the Chinese guanxi. Detailed descriptions of cross-cultural misunderstanding and miscommunication between Chinese employers and Zimbabwean employees were given in Chapter IV, particularly the story about Mrs. Luo who constantly used her favoured employee, Ah Ling, as the standard against which to criticize Zimbabweans as "bad" employees. These stories suggest that there is a gap between what Chinese employers expect from their employees and what black southern African employees expect from their Chinese employers. In the case of Zambia, Wu identifies what triggers their everyday disagreements: "the Zambians expect the Chinese bosses to take care of the workers (attentiveness goes down) but the Chinese bosses expect the workers to show great attentiveness towards them (attentiveness goes up)" $(2014,139)$. In other words, while the Chinese assume many rules and customs aimed at 
demonstrating respect to superiors, the Africans expect to be taken care of by superiors, at work and at home. Since there are often different interpretations of what a good employer and good employee should be, it is not surprising to see tensions and conflicts in the workplace.

Following this line of logic, I consider money borrowing as evidence of how these Chinese employers have formed some sort of social (not just working) relationship with their Zimbabwean employees. To the Zimbabwean employees, it is something the Chinese employers should do, as employers are supposed to take care of employees — which is why they complained to me about the terms of repayment. Even though the Zimbabwean employees might not show respect or proper workplace etiquette, the Chinese employers still responded to the employees' needs, like they would do for their Chinese employees.

But it is difficult for me to claim to know what exactly their social relationship is. Due to data limitations, I am unable to analyze the motivations of those Chinese employers who lent money to Zimbabwean employees. It is also difficult for me to perceive whether these petty entrepreneurs are well enough off to be depended upon. For one, these Chinese petty capitalists need to rely not only on low-paid exploitative labour but also on their own self-exploitative labour (often including their family members). If the owners are not cooking and managing at their restaurants, they are outside shopping for supplies. While their employees work at least ten hours a day, six days a week, they usually work at least twelve hours every day. This is why several owners complained to me that they would rather be employees than employers. Their profit is largely the result 
of the vulnerability and exploitation of their workers and their own self-exploitation, and it is these conflations of self- and other-exploitation that make petty capitalism possible. ${ }^{46}$ Even though, by and large, the owners do earn higher incomes than, and have an upper hand in negotiations with, their employees, it is important to understand that they do not get to control the market. Around late 2016, when South Africa's economy began to decline, and the value of the South African Rand weakened, a number of restaurants closed down, and I saw more and more posts on WeChat about the sale of restaurants. In terms of the Chinese employees, as much as I had difficulty in distinguishing between formal and informal sources of income for the Zimbabweans (see Chapter III), I also had troubles defining the Chinese employees' condition. Although they did earn higher salaries than the Zimbabweans did, their jobs were also not contract based. If one day there is no "Chinese market" for them anymore, these migrants are going to be jobless in South Africa. Even if they were to accept low-paid wages like the Zimbabwean migrant workers do, their lack of language skills would prevent them from getting work in most sectors. After all, Chinese migrant workers and their family members who depend on their remittances in China are also subject to the uncertainties of the informal economy.

Second, the Chinese employers have no legal obligation, nor do they feel a moral one, towards their Zimbabwean employees. There are, of course, a few exceptions, as shown in the advertisement examples in Chapter II where some Chinese were helping their Zimbabwean employees to look for their next job. And some restaurant owners who

\footnotetext{
${ }^{46}$ This point is based on the essay "Flexibility for Whom? Small-Scale Garment Manufacturing in Rural Mexico" by Frances Abrahamer Rothstein (2005). She argues that flexible production is linked to ambiguous class position, where family members have to work harder to be "flexible," and yet they have even less control over the process. As she writes, "flexibility and control at the local level are largely illusions that hide a reality of greater control by fewer people at the global level" $(2005,67)$.
} 
paid above-market wages also loaned money (interest free) to their Zimbabwean employees. Again, due to data limitations I am unable to confirm if the Chinese employers who assisted their Zimbabwean employees did so because they accepted them as part of their guanxi network, or, in Ferguson's terms, as a dependent relation. Harri Englund (2008) states, "what is morally right is not always morally obligatory" $(2008,35)$ to argue that "what the perspective on ethical self-formation may entail is a certain aversion to the human condition of dependence, which is all too often cast in pathological terms in the more normative ideas of "the separate person"' (45). In other words, we cannot examine one's ethical obligation to others without understanding their connection or relationship first.

That being said, I am not suggesting that exploitation does not exist or that it is not problematic as long as it is within a dependency or guanxi frame. Guanxi, as argued in Chapter II, even when perceived as a powerful aid or positive influence in Chinese people's experience, still has its limits. And Ferguson is aware that it is problematic to claim that dependency is the answer. As he writes,

Does this mean dependence is actually a good thing? Such a claim makes us uneasy. The fear is that valorizing or even acknowledging dependence may authorize or legitimate inequality. But this fear may be misplaced. Whether we approve of it or not, inequality must be confronted - it is unavoidable, as a matter of both practical politics and (as Amartya Sen [1997] has demonstrated) theoretical necessity.... Dealing with (rather than just denouncing) this reality means going beyond pious wishing for equality to ask how inequalities are socially institutionalized and whether some such modes of institutionalization are politically or ethically preferable to others. (Ferguson 2015, 155) 
In the case of Chinese im/migrants, urban and rural inequality in China was the reason a large number of the Chinese nongmin (peasants) went to work abroad and seek economic betterment (Chu 2010; Xiang 2017). The lack of work opportunities in rural areas of Zimbabwe also led im/migrants to come to South Africa. These two groups were equally vulnerable in their home countries, but through their support networks they were "free" to go abroad in search of better opportunities. Both came to feel equally "unfree" when they found that their best (or only) option in South Africa was to work in an industry with an exploitative nature. ${ }^{47}$ What constitutes this intra-migrant economy is the ability of the Chinese to avoid hiring South Africans and to maximize profit from cheap laborers, and the ability of Zimbabweans to easily obtain jobs without proper skills. In other words, inequality and insecurity were the reason an intra-migrant economy existed in the first place. As much as the Zimbabweans need the Chinese for jobs, the Chinese need Zimbabweans for labour. This is why I insist on the term "interdependency," not dependence, in order to emphasize the fact that the Chinese employers also need the Zimbabwean employees to survive. But as they enter South Africa's racialized labour market, the Chinese eventually find themselves able to climb the ladder to the middle class, while the Zimbabweans continue to struggle with being paid below minimum wage.

As noted at the beginning of this chapter, I found the correlations between dependence and trust, and between work production and income distribution, unsettling. While the separation of work into smaller tasks presumably increased productivity and interdependence among workers, owners usually only transferred their knowledge and

\footnotetext{
47 The issue of the exploitation of underpaid and overworked restaurant workers is not unique to South Africa. See Kivanc (2016) on Chinese restaurants in Toronto and Mintz (2015) for restaurants in North America in general.
} 
skills to people they trusted. Although a small number of African chefs have proven that they can cook as well as Chinese chefs if they receive proper training, still it is usually only "loyal" employees, typically a Chinese person from the same network as the owner, who receive full training and become less replaceable. African employees remain semiskilled or unskilled and hence low-paid. Consequently, they are perceived as having lower productivity and being easily replaceable by other lower paid unskilled workers.

Ferguson calls for the "labor of distribution" (2015, 51-62, 89-117), particularly in the case of Southern Africa, where he argues that the solution to the problem of unequal access is less about how to create more jobs or how to increase employee productivity because the problem is the nature of distribution. This shift from production to distribution, as I agree with Ferguson should occur, helps us to better understand that the problem is not only about Zimbabweans having less access to their employers than their Chinese co-workers due to linguistic and cultural limitations; it is also about unequal income distribution along racial lines. A full-time trained Zimbabwean chef would still earn less than any part-time or semi-trained Chinese chef because that is how South Africa's labour market works. Chinese petty capitalists seek maximum profits through this intra-migrant economy, which is embedded in South Africa's racialized inequality. 


\section{CONCLUSION}

\section{Rethinking Diaspora}

Initially, this research project was set up to examine the correlation between Chinese food and identity, with a particular interest in the theorization of diasporic identity and debates on the nature of diaspora communities, which grew out of my longterm research interest in Chinese diaspora studies. When I decided to collect data from elsewhere, outside North America and Asia, to compare and contrast diasporic experiences in different continental contexts, it led me to South Africa. The more I understood the Chinese im/migrants' lived experiences in South Africa, the more I realized I needed to step back from conceptualizing them within diaspora theory, which by and large was developed in the North American context.

As mentioned in Chapter I, almost all major earlier scholarly works on Chinese immigrants adopted the concept of the sojourner, originally developed by Paul Siu (1952) to characterize Chinese Americans and describe the historical fact that Chinese immigrants were largely excluded from most jobs in the wage economy and forced into less desirable jobs - for example, laundry and restaurant. In addition to a changing pattern of Chinese migration to the United States, more and more Americans of Chinese descent started questioning the idea of "Chineseness" and whether, in fact, they were Chinese at all, to challenge the hegemonic notion of Americanness as largely defined within a European Judeo-Christian tradition (Cho 2010).

This theoretical shift, as discussed, is not happening in South Africa. Park's studies (2008a, 2008b, 2009) show that many third- and fourth-generation Chinese South Africans retain a strong sense of attachment to China, as many of them still regard it as 
their homeland even if they do not speak Chinese and have never been to China. This long-term cross-generation clinging to an imagined homeland, Park argues, is a result of the social exclusion experienced under apartheid.

As Chen's (2013) work and my data show, only a small number of recently arrived Chinese im/migrants consider South Africa to be a permanent home, regardless of the length of their residency or legal status, and they retain a strong sense of attachment to China, which is where most of their family members live. Even though these Chinese $\mathrm{im} /$ migrants share strong "sojourner" characteristics, I decided not to place them into such a conceptual frame for a couple of reasons.

First, despite the fact that the term was developed by Paul Siu to argue that early Chinese immigrants were unable to integrate into mainstream US society because they were marginalized and isolated, this characterization was used to accuse Chinese immigrants of being "unfit" and failing to integrate or assimilate into US society. As Philip Q. Yang states,

For a long time, it was largely taken for granted that early Chinese immigrants were sojourners and that sojourning was a uniquely Chinese phenomenon, and the impact of this hypothesis extends beyond academia. Historically, opportunistic politicians and members of the anti-Chinese movement often used the sojourning orientation or the so-called unassimilability of Chinese immigrants as an argument to justify antiChinese legislation and activities. (2000, 235-36)

Second, if I were to define Chinese im/migrants as a diaspora and argue as to what constitutes them as such, I might risk reducing them to objects, contrary to how I view diaspora. 
For many years, the phenomenon of diaspora exclusively dealt with the scattering of Jewish populations. Etymologically "diaspora” comes from the Greek term diasperien; 'dia' means across, and 'sperien' refers to sow or scatter seeds (Braziel and Mannur 2003, 1). It was first used in the Septuagint when the Hebrew Bible was translated into Greek. Diaspora initially described exiled Jewish people. Later it was used as a term for the Black African diaspora, beginning in the sixteenth century when a large number of Africans were enslaved and placed in the "New World" (ibid).

As Laurence J.C. Ma (2003, 5-6) points out, the contemporary world is in "the age of migration" and the old conceptions of migration were incapable of capturing the complexities of the rapidly changing nature of global migration. New analytical frameworks are needed to understand the emerging themes. James Clifford argues there is a growing academic interest in the concept of diaspora. As he writes, "Diasporic language appears to be replacing, or at least supplementing minority discourse. Transnational connections break the binary relation of 'minority' communities with 'majority' societies - a dependency that structures projects of both assimilation and resistance" (1997, 255). Theorizations of diaspora have emerged in area studies, ethnic studies, and cultural studies; however, the concept of diaspora remains a major site of contestation (Braziel and Mannur 2003). Since it is often used as a catch-all phrase to speak of all cross-border human movement, critics have argued that the loose usage of "diaspora" does not critically reflect diverse patterns of human migration and settlement, particularly related to the experience of displacement or dispersal (Braziel and Mannur 2003).

One of the early and often-cited definitions was developed by political scientist William Safran $(1991,2005)$. He regards the Jewish diaspora as a paradigmatic "ideal 
type" to lay out six principles to define diaspora communities (1991, 83-4). Safran's definition came under criticism due to the overemphasis on the (real or imagined) linkages between the homeland and the diaspora community, which leads to an oversimplification of the entangled relationship that actually exists between a social formation and its cultural productions (Mishra 2006). In his newer article, Safran (2005, 36) recognizes that when a diaspora community adjusts to the host societies, it become a center of cultural creation. He also recognizes that to theorize the Jewish diaspora as an "ideal type" might not be the ideal. As he writes: "In my article (1991), I used the term 'ideal type' (in the Weberian sense). I now hesitate to use it, since it has been misconstrued by some as implying an 'ideal' situation" $(2005,56)$.

Generally speaking, there is a theoretical divide between two groups: scholars (e.g., Cohen 2008; Safran 1991, 2005) who use diaspora as a descriptive tool, versus scholars (e.g., Cho 2007, 2010; Clifford 1997; Gilroy 1993; Hall 1990), who suggest diaspora should be understood as a condition and a way to critique the dominant categories of solid analysis and their underlying essentialism (Kalra el al. 2005). As Lily Cho argues, "Diaspora must be understood as a condition of subjectivity and not as an object of analysis" (2007, 14, emphasis in original). In other words, while the first group is more interested in the categorization of what constitutes a diasporic community, the latter often argues that "diaspora" is not a fixed essence of the past and thus greater emphasis should be put on consciousness and experience (Kalra el al. 2005).

In my analysis, I employed Stuart Hall's concept of diaspora identity (1990) to argue that "diaspora" is a process, not a product, and is always in a process of "becoming" rather than "originating" (see Chapter I). To be more specific, diaspora is 
indeed shaped by actual and symbolic linkages to the homeland; nevertheless, the current living situation in a host society influences greatly the (re)production of diasporic identifications. Hall's concept of diaspora not only helps to explain the diversity within Chinese and Zimbabwean communities in South Africa, which are particularly divided by regional and generational differences, it also enables a better understanding of how migrants are mediated by issues of history, race, ethnicity, class, gender, and so on. If "diaspora" is a matter of "becoming" rather than "originating," not only is it still too early to see what they have "become," as most new Chinese im/migrants have been in South Africa for less than two decades, but I also think we do not yet know enough about every Chinese im/migrant community in South Africa. This research project only covers those involved in the Chinese restaurant sector (and a few in the fahfee sector). There has not been any ethnographic research with im/migrants from Taiwan and those who work for Chinese-state-owned enterprises in South Africa. Like the linkage between old Cantonese and new Cantonese diasporas, as I showed in Chapter II, which enabled the new Cantonese migrants to work in the restaurant and fahfee sectors, evidence from my study shows a strong linkage between old Taiwanese and new Chinese diasporas. Through interviews, I learned that many chefs were hired to work in South Africa by Taiwanese employers, and some of them took over the restaurants previously owned by Taiwanese migrants who left after 1998 when the South African government switched its formal diplomatic tie from Taiwan to China. These business transections not only occurred in restaurant entrepreneurship but also textile factories and commercial farms. 
As mentioned, the current conception of migration is incapable of capturing the complexities of this rapidly growing and diverse diasporic group, especially the relations and interactions between migrant groups. Thus, rather than characterizing what Chinese $\mathrm{im} /$ migrants are, I paid detailed attention to how they lived within and around restaurant life. Another reason the direction of this dissertation shifted is the encounter with Zimbabwean migrant workers in the field. Their high rate of labour force participation in Chinese restaurants and Chinese malls could not be overlooked as "only a few cases"; it had to be included in order to illustrate a fuller picture of Chinese entrepreneurship in South Africa. My fieldwork inside restaurants enabled me to gain first-hand observations of how two different migrant groups work and interact with each other, which has turned into what I call the intra-migrant economy.

\section{Ending Remarks}

In Chapter I, after giving a description of what working inside Chinese restaurants is like from both Chinese and Zimbabwean perspectives, I then used the term "everyday racialized insecurities" to elucidate that hiring Zimbabwean migrants is part of how Chinese im/migrants cope with the fear of crime and life uncertainty. The restaurant owners are petty capitalists with little capital, who themselves are dependent on other resources to make profits. They know that Zimbabwean migrant workers desperately need jobs and have fewer local resources; therefore, they think it is easier to control these migrant workers. At the same time, since there is no contract involved, they can, for whatever reason, fire migrant workers anytime without worrying about legal consequences. 
Chapters II and III analyzed how and why Chinese and Zimbabwean im/migrants ended up working in the restaurant sector without any legal contract to protect their interests. Chapter II focused on the Chinese side and the data I gathered from Chinese interviewees, recently arrived Cantonese-speaking migrants, which I turned into a case study to examine the role of guanxi in shaping Cantonese newcomers' economic activities and opportunities, as they tend to be employed in the restaurant and fahfee sectors.

In Chapter II, I also talked about another experience that the Chinese im/migrants often encounter: petty corruption. Due to linguistic and cultural barriers that prevent them from understanding lawful ways of dealing with corrupt officers, many of them tend to use a small amount of money to avoid harassment or resolve problems with South African authorities. These experiences of corruption are not limited to Chinese migrants. When South Africans were asked in a survey (Struwig et al. 2014, 34) if they had engaged in any form of corruption in the past five years, 230 respondents admitted that they had done so in various circumstances, while 362 respondents said they had never paid a bribe but would consider doing it. ${ }^{48}$ This indicates that a good portion of South Africans feel pressured to participate in corruption even when they disagree with these practices and complain about them - and my interview data suggest that Chinese migrants feel the same way about corruption and sometimes guanxi.

We should, therefore, examine guanxi by itself in order to reflect closely on Chinese im/migrants' reality. Precisely because of this reason, Chapter II was structured around rich narratives and stories, including one of my own as the opening theme, to let

${ }^{48}$ The data is based on 2,809 participants, where twenty-nine respondents refused to answer the question; 2,188 of them responded that they never paid a bribe and would never consider doing it. 
the data speak for themselves. The purpose was to show that even I, an "outsider" who had no pre-existing relationship with any of the Chinese im/migrants before my fieldwork, could not remain outside of guanxi if I wanted to be part of their everyday lives in order to conduct my participant observation-based research.

On the one hand, Chapter II showed that guanxi serves a function in this informal system and is particularly beneficial to petty capitalists for building trust when there is an absence of legal and financial institutions (Smart and Hsu 2007; Yang 1994). On the other hand, contrary to most conceptualizations of migrant networks, which assume that in transnational economic flows, social relations develop for instrumental purposes, Chinese restaurant entrepreneurship in South Africa provides a concrete example that suggests that these transnational economic flows develop and flourish through people's complex social relations.

Chapter III focused on the Zimbabwean restaurant workers and Zimbabwean $\mathrm{im} /$ migrants in general. Those who ended up working at Chinese restaurants were, by and large, Ndebele from rural areas of southwestern Zimbabwe, which is similar to the Chinese pattern of Fujanese and Cantonese migration from rural areas.

This suggests two points. First, the inequality between urban and rural areas is what brought these migrants to South Africa. Second, social networks play an important role in shaping migrants' access to accommodation and employment opportunities (Moyo 2017). I compared and contrasted Chinese and Zimbabwean migrant networks and realized that even though these two groups of migrants seem to have little in commonin terms of language, religion, and culture - they somehow find a way to work together to 
keep the restaurant industry going. There must be something that makes this informal working relationship function. This became the centre of my argument.

After all, this restaurant entrepreneurship is interconnected with larger political and economic transnational issues: China's rural emigration, South Africa's racialized labour market, and Zimbabwe's high unemployment rate. I used the term "intra-migrant economy" to suggest it is more than a migrant story of economic hardship. It also provides a helpful window into better understanding how certain groups of migrants have been positioned in the host country, and how their survival generates conflicts such as exploitation, bitterness, victimhood, and moral contestation but also creates collaborations. This led into Chapters IV and Chapter V.

Chapter IV explored issues in the uneasy working relationship between Chinese employers and Zimbabweans employees: miscommunication, misaligned attitudes and expectations, different conflict resolution styles, a lack of understanding of racial diversity, and an absence of a sense of cultural sensitivity. The main argument is that not only are there a series of intercultural miscommunications between these two groups, but their everyday interaction is also complicated by the nature of their employer-employee relationship.

As my ethnographic data shows complexity, I am hesitant to suggest that the longer Chinese and Zimbabweans work together, the better their situation will get. But I also believe it may be too early to reach a conclusion. New Chinese migration to (South) Africa is still relatively new (less than two decades); accordingly, we should understand that the current phase is only the beginning of a long-term process of intercultural interaction between Chinese and African people (Wu 2014). 
By exploring the intra-migrant economy in Chapter III, intercultural misunderstandings and miscommunication in Chapter IV, and economic dependency in Chapter V, a common theme can be seen: how people's economic practices are intertwined and embedded in history and political and cultural systems. The employment relationship between Chinese and Zimbabwean im/migrants produces hierarchy and inequality, yet the essence of the intra-migrant economy is that it needs collaboration from both migrant groups. I used the term "interdependency" to describe the economic conditions that create the intra-migrant economy, which, in turn, shapes social and cultural relationships.

The concept of interdependency allows us to look beyond on-the-surface understandings of the seemingly destructive and uneasy working relationship between two groups of migrants and get to the root of why it exists in the first place. In the case of Chinese and Zimbabwean im/migrants working in Johannesburg's Chinese restaurants, the majority of them had never worked in the restaurant sector in their home countries, and each im/migrant group was working with another they had never worked with before. What they experienced was that not only had their mode of production changed but also their lifestyles in order to accommodate their restaurant life-long working hours with coworkers from different regional and national backgrounds in an industry with an exploitative nature and in a country where racialization matters significantly. South Africa's racialized labour market led to the existence of the intra-migrant economy. The inequality is real, yet behind it is a misconception that the Chinese petty entrepreneurs control the market or their destinies. Rather than only focusing on how the Chinese petty entrepreneurs profit from the exploitation of Zimbabwean migrant workers, I suggest 
looking at the structural and systemic factors that provide the conditions for an intramigrant economy.

This interdependency also shows that there is a similar emphasis on interpersonal relations in both cultures. As mentioned, only two Zimbabwean interviewees reported that they got fired by Chinese employers (in comparison to numerous reports from Chinese interviewees about Zimbabwean no-shows). The first Zimbabwean interviewee was told not to come to work the following week because the restaurant was shutting down due to a low level of business. In the case of the second Zimbabwean interviewee, an employer's cousin was coming to South Africa from China and needed a job. Since it was a tiny takeaway restaurant that made fewer than ten items, there was no room for two employees, and the employer had to give the Zimbabwean's job to her cousin. When I asked the Zimbabwean interviewee how she felt about this, she said, "Oh, I totally understand. I'd do the same for my family."

This Zimbabwean woman could have complained about the nepotism, but she did not. The restaurant owner could have continued to employ this Zimbabwean woman to avoid paying a higher wage to the cousin, but she did not. What obligations the Chinese employers recognize differ from what Zimbabwean employees expect (in Chapter IV); yet there is a mutual understanding that there are obligations that come with one's social roles. This shift from morality to social roles enables us to see that there is no universal understanding of the moral obligation to reciprocate. Thus, I suggest, instead of examining what has been exchanged, we should first understand social relationships from the im/migrants' perspectives. 


\section{Future Research}

This last chapter leaves us with two incomplete thoughts - the first relates to understanding relations of dependence from Zimbabwean perspectives, and the second relates to a better understanding of guanxi and dependence. Ferguson (2015) points out that kinship is an important factor in making claims on others with better resources. As noted, he argues, "Dependence of this kind is not a passive condition - it is a carefully cultivated status that is the result of long processes of building social ties and reciprocal obligations" (Ferguson 2015, 107-08). Drawing from well-researched scholarly work on guanxi (e.g., Chen and Starosta 1997; Smart and Hsu 2007; Wu 2014; Yan 1996; Yang 1994) and my own ethnographic data, this dissertation demonstrated how social roles legitimize the expected obligations to provide assistance beyond kinship. But without further concrete ethnographic data from Zimbabwean im/migrants, this dissertation is unable to reflect Zimbabwean perspectives on dependence.

Due to trust issues and time restrictions, my access to Zimbabwean im/migrant circles was limited. If I had learned to speak isiNdebele beyond mere greeting phrases, perhaps it would have helped me to gain more access. But I think a collaborative fieldwork project with scholars on the Zimbabwean migration in South Africa would be more promising. Not only would it enable a deeper exploration of both differing African and Chinese perspectives, but it would also help provide a more dynamic and balanced picture.

Another important analysis that is missing in this dissertation is gender. Due to the gendered division of labour in kitchens, most of the Zimbabwean employees in Chinese restaurants were women. One male Zimbabwean interviewee expressed that he 
prefers lifting boxes all day to working in the kitchen, as it is a "woman's job." Interestingly, the position of Chinese chef is traditionally male-dominated, which stands in contrast to the Zimbabwean views on cooking as a "woman's job." But the majority of Zimbabwean chefs I met, who were trained by Chinese chefs, were men. Linking this to my argument, it would be helpful to investigate how gender shapes social roles and vice versa, and how gender shapes access to resources and the livelihood choices made. Again, I think a collaborative fieldwork project with feminist scholars who focus on African women's agency would be beneficial to shed more light on the interaction between Chinese and African im/migrants and the intersection between race and gender. Another issue is that of unequal distribution. In his book, Ferguson (2015) points out that the belief about teaching poor Africans to fish suggests there is not enough production. Such a suggestion has been commonly perceived as a solution to poverty; for instance, Irene Yuan Sun (2017) argues that moving Chinese factories to Africa would industrialize the continent and create jobs. The logic is, if people are provided with job opportunities and work hard at production, they will eventually get out of poverty. Ferguson proposes that "we need to pay attention to the idea of distribution as a necessary and valuable social activity" $(2015,90)$ pointing out that the problem is the nature of distribution. His main argument involves advocacy for a universal basic income. Although I am not an economist and I am not against job creation, I find Ferguson's argument convincing because it is evident in my findings. I showed the example of Zimbabwean chefs who would never make the same salary as the Chinese, never mind how difficult it would be to earn trust and receive training from the Chinese in the first place. Further research on the Chinese and African labour forces in Africa could certainly 
provide a critical examination of the framing of economic politics theory. Such a research project is perhaps needed more than ever as the "South-South" trade flows between China and Africa have increased rapidly in the $21^{\text {st }}$ century.

China is now Africa's largest trade partner and the largest financier of infrastructure, and Chinese entrepreneurs are flooding in all over the continent (Park 2012; Sun 2017). Current literature about China and Africa is generally focused on a larger political and economic scale—-for instance, China's aid and trade to Africa, and China's development and investment projects in Africa. ${ }^{49}$ While these are important flows to analyze, we know little about the organization of small- and medium-sized Chinese businesses in a local African context. Only recently have scholars begun to explore Chinese migrants' experiences and daily lives in Africa ethnographically—for instance, Wu's (2014) research on Chinese migrants in Zambia, research on Chinese merchants in Botswana by Zi (2017), and Sheridan's (2018) work on Chinese entrepreneurs in Tanzania.

Tanny Men (2014) notices an increasing awareness and willingness to employ more local labourers among (both state-led and private) Chinese firms across Africa. "Chinese businesses are operating more flexibly with regard to local labour" (Men 2014, 104); however, "productivity is limited by cultural divides and the inability to manage talent effectively" (104). Men argues there is a need to conduct and collect more research on cross-cultural management relations from both Chinese and African perspectives. Not only do I agree with this point, but my research would benefit from data on work relations between Chinese employers and other groups of African employees, such as

\footnotetext{
${ }^{49}$ See, for instance, Serge Debrah Brautigam (2009, 2015); Howard French (2014); Michel and Michel Beuret (2010).
} 
South Africans. The data collect from these projects will enable me to compare and contrast these data in order to provide a more complete picture of barriers between crosscultural communication, which tend to have a big impact on Chinese and African people's relations.

Perhaps the most critical subjects to future potential research is the links between diasporic entrepreneurship and economic development in both nations of origin and destination countries. As noted by Bodomo (2018), a sufficiently sized Chinese population in Africa or the African presence in China is mainly a 21 st century phenomenon. Even though it is only barely twenty years old but highly complex. What is noticeable about migration between Africa and China in both directions is that the migrants have several predominant characteristics: high cross-border mobility, little capital, limited resources, a desire to find trading opportunities and better livelihoods, and a strong entrepreneurial motivation (Bodomo 2012, 2018; Castillo 2014; Chen 2013; Huang 2018; Lan 2016; Park and Chen 2009; Park and Huynh 2010; Sheridan 2018; Wu 2014; $\mathrm{Zi} \mathrm{2017).} \mathrm{While} \mathrm{these} \mathrm{factors} \mathrm{have} \mathrm{had} \mathrm{a} \mathrm{critical} \mathrm{role} \mathrm{in} \mathrm{shaping} \mathrm{the} \mathrm{current} \mathrm{"South-}$ South" trend of migration, as argued in Chapter II, an underexamined but important social enablers of these continued migratory flows are actually the actors and their entrepreneurial actions that help migrant networks develop and employment opportunities grow in their host countries (Bodomo 2018; Krissman 2005).

This dissertation research revealed a wide range of challenges and perspectives on the factors needed to become a Chinese restaurant entrepreneur in South Africa, such as loyalty, trust, financial aid, network support, self-exploitation, and market conditions. It also revealed a high level of entrepreneurial knowledge and skill transfer from Chinese 
employers to Chinese employees, which facilitated a good number of these employees to later become entrepreneurs themselves. However, as noted in Chapter I, only a small number of the Zimbabwean employees were trained and promoted to chef or manager, and none of them had become a restaurant owner. This disparity was due to more than language barriers or racial (mis)conceptions; it also arose from cultural misunderstanding and miscommunication (Chapter IV). My current analysis in the South African context can combine with both theoretical and practical understanding of African entrepreneurship in the Chinese context in order to identify the dynamic process of individual agency in cross-border entrepreneurial relations.

Perhaps there has never been a more appropriate time for a project on migration between Africa and China and entrepreneurship for at least three reasons. First, as a result of growing trade and diplomatic ties between Africa and China, there has been a tremendous increase of scholarly interest in African entrepreneurs in China and Chinese entrepreneurs in Africa. The relationship between migration and entrepreneurship has also received political and scholarly attention globally in today's "era of migration," and evidence has shown that there are close links between migrant entrepreneurship and economic development in both nations of origin and destination countries (Naudé el al. 2017).

Second, the formal sector in many African countries is having difficulties meeting the employment demands of a young and growing African population (Ferguson 2015; Kew et al. 2015). For millions of young Africans, becoming an entrepreneur might be their only option for employment (Kew et al. 2015). Third, there are growing xenophobic attacks and tightening immigration policies. During my fieldwork in Johannesburg in 
2015, as mentioned in Chapter III, a series of xenophobic attacks on foreign migrants occurred in South Africa. Foreign-owned shops were forced to close down. At least seven people died in the violence, and hundreds of foreigners fled their homes and sought refuge at local police stations (Patel 2016). Such unsettled anti-migrant sentiment has continued, with a recent attack in August 2018 (Ngqakamba 2018).

One of the reasons behind the xenophobic attacks is that South Africans are frustrated with high rates of unemployment and blame foreigners for "stealing their jobs" (Mutanda 2017; Patel 2016). Meanwhile in China, the government has tightened its immigration policies, and there has been an emerging racial prejudice against African migrants (Bodomo 2018; Huang 2018; Lan 2016). Examining the anti-immigrant sentiment from both sides requires a better understanding of how diasporic entrepreneurship impacts the local economy. By comparing and contrasting my data with data on African entrepreneurship in China would allow me to identify intercultural experiences and challenges, and further enable me to identity commonalities or differences in environment that helped to encourage or motivate entrepreneurship. The study of diasporic entrepreneurship between Africa and China will contribute to the current theorization of diaspora studies and debates over "diaspora politics" and what provides entrepreneurial motivation and preparation.

\section{Last but not Least}

This dissertation began with Alice's story, and I want to end with another one, to return to the humanities side of anthropology. This is not my story. It is a South African story that only South Africans can write well, about a Chinese girl and a black domestic 
worker. It is from Ufrieda Ho's (2011) autobiography, Paper Sons and Daughters, A Memoir: Growing Up Chinese in South Africa. "Paper sons" or "paper daughters" refers to overseas Chinese who immigrated to North America and South Africa, especially during the Chinese Exclusion Act and apartheid, by purchasing fraudulent documentation that stated they were blood relatives of local Chinese citizens. Ho's mother ran a shop and her father was a "paper son" and a fahfee man but not by choice; in 1980s South Africa, a "yellow" man could not get jobs reserved for whites (Ho 2011). As Ho's family eventually climbed the ladder to middle class, they hired a black domestic worker, Sophie. In a chapter titled, "The Outside Toilet," this is how Ho writes about Sophie:

In our Bertrams house, Happy [family dog] shared the backyard not only with pigeons, chickens and rabbits at various times, but also with Sophie, our domestic worker. Sophie's room was in the basement beneath the kitchen. It had one small window and seemed to me always to be in pitch darkness, probably because there was no electricity in her room....

Sophie was a third parent to us in many ways, but in so many other ways she was simply a servant — never eating from our plates, living in a room separate from the house, where the pets were, where the outside toilet was. She was someone whose birth name or family name I did not even know. In Chinese culture you do not address people who are older than you, strangers included, by their first names. You show deference by tagging on an honorific. Even Yolanda and Kelvin, my own brother and sister, I call names that translate as 'my family sister' and 'my family brother': I do not use their names. But Sophie, this stand-in parent, was never afforded this respect.... 
It hurts now that I do not remember Sophie's face well and I do not even know if Sophie was her real name. Back then, I did not question this relationship in the same way that I never asked questions about the outside toilet, a feature of so many South African homes.

Now I see the outside toilet as the ceramic bowl of national shame. There it stands, apart from the rest of the house. There are no sparkling titles, no extras of a mirror to adjust a stray strand of hair, hand lotions in pump-action bottles to indulge freshly washed hands or two-ply toilet paper.

But it stands sure, apart, plain and basic; it is meant only for the maid and the gardener. And new generations have filled Sophie's shoes. They are still black women, still the women who wear overalls with matching aprons and doeks [headscarf]. They no longer have to say madam or eat from the enamel plate but they are still considered the primary suspects behind a missing brooch or the dipping sugar levels in the pantry. They are still paid a wage that is little more than the cost of some madams' pairs of shoes.

I get sad when I hear Chinese South Africans speak about their pain and humiliations at being treated like second-class citizens. Their faces burn with anger when they remember the humiliation of having to ask white people if their children could learn in their schools, or they had to carry documents like my dad had to, declaring them 'gentlemen of good standing' or they had to go from door to door with spring rolls and smiles asking to be allowed to buy or rent a house in a white suburb.

But their memories of racial injury were fuzzy when it came to their domestic workers or gardeners sometimes. Food that was past its expiry date was good enough for the 'girl'. There were still separate enamel plates and cutlery differentiated with a 
crude scrape of a sharp knife. This was for the woman who knew the exact amount of milk to pour into the madam's tea, how to coax their grumpy children to sleep and what underwear they kept in their drawers.

Sophie must have worked for our family for six or seven years and shortly after we moved to our house in Judith's Paarl, just a few kilometres away from our Bertrams home. I am not sure if she eventually had a fallout with my parents or whether she did indeed have to return to her family in that faraway ju kaa [family home], as we were told.

We never had another live-in, full-time maid and I never saw Sophie again after she said goodbye to us for the last time outside the gate. All these years later, it is a shame that in some ways I remember Happy, the sweet, loyal dog of my childhood, better than I do Sophie, this woman who was also a stand-in mom. (2011, 169-74)

As I close the book after reading it, I wonder if any of my Chinese interviewees' South African-born children will grow up to become writers and write a story about their parents' Zimbabwean employees. 


\section{REFERENCES}

Antrosio, Jason. 2016. "Sidney Mintz and Anthropology's Unfinished Revolution." Living Anthropologically website, December 26, 2016. Revised February 8, 2018. Accessed July 24, 2018. https://www.livinganthropologically.com/mintzanthropology/.

BBC News. 2013. "Somalis march in Cape Town against South Africa attacks." $B B C$ News Africa. June 7, 2013. Accessed July 26, 2018. https://www.bbc.co.uk/news/world-africa-22810926

BBC Reality Check team. 2017. "Reality Check: Are 90\% of Zimbabweans unemployed?" BBC News, December 3, 2017. Accessed July 25, 2018. http://www.bbc.com/news/business-42116932

Besley, Timoth, Stephen Coate and Glenn Loury. 1993. "The Economics of Rotating Savings and Credit Associations." The American Economic Review 83(4): 792810.

Bhoola, Fatima. 2016. "Analysis: Why the rand is falling." Mail \& Guardian. January 18, 2016. Accessed July 26, 2018. https://mg.co.za/article/2016-01-18-how-currencymarkets-work-and-why-the-rand-is-falling

Bodomo, Adams. 2012. Africans in China: A Sociocultural Study and its Implications on Africa-China Relations. Amherst, NY: Cambria Press.

. 2015. "The African Traveller and the Chinese Customs Official: Ethnic Minority Profiling at Border Check Points in Hong Kong and China?" Journal of African American Studies 19(1): 52-64.

— 2018. "The Bridge is not Burning Down: Transformation and Resilience within China's African Diaspora Communities. African Studies Quarterly 17(4): 63-83.

Brautigam, Deborah. 2009. The Dragon's Gift: The Real Story of China in Africa. New York: Oxford University Press.

. 2015. Will Africa Feed China? New York: Oxford University Press.

Breeze, Victoria and Nathan Moore. 2017. "China Tops US and UK as destination for anglophone African students." The Conversation. June 27, 2017. Accessed July 30, 2018. https://theconversation.com/china-tops-us-and-uk-as-destination-foranglophone-african-students-78967

Castillo, Roberto. 2014. "Feeling at Home in the 'Chocolate City': An Exploration of Place-Making Practices and Structures of Belonging Amongst Africans in Guangzhou." Inter-Asia Cultural Studies 15(2):235-57. 
—. 2016. "'Homing' Guangzhou: Emplacement, Belonging and Precarity among Africans in China." International Journal of Cultural Studies 19(3): 287-306.

Chen, Fung Lan 陈凤兰. 2013. Nanfei Zhongguo xinyimin yanjiu 南非中国新移民研究 (New Chinese Immigrants in South Africa). Ph.D. dissertation, Xiamen University.

Chen, Guo-Ming and William Starosta. 1997. A Review of the Concept of Intercultural Sensitivity. Human Communication 1: 1-16.

Chen, Lulu. 2009. "For Chinese Immigrants, Money Pools Offer a Risky Promise." City Beats: Columbia University Graduate School of Journalism. October 22, 2009. Accessed July 26, 2018. http://archives.jrn.columbia.edu/2009/citybeats/about/index.html

Chen, Xiao-Ping and Chao C. Chen. 2004. "On the Intricacies of the Chinese Guanxi: A Process Model of Guanxi Development." Asia Pacific Journal of Management 21: 305-324.

Chen, Yudan. 2017. "What Food Tells Us About China's Confused National Identity." Sixth Tone: Fresh Voices from Today's China. March 19, 2017. Accessed July 25, 2018. http://www.sixthtone.com/news/2075/what-food-tells-us-aboutchina $\%$ E2\%80\%99s-confused-national-identity

Chikanda, Abel and Belinda Dodson. 2013. "Bandaid transnationalism: remittance practices of emigrant Zimbabwean medical doctors." Migration and Development 2(1): 57-73.

Cho, Lily. 2007. "The Turn to Diaspora." TOPIA: Canadian Journal of Cultural Studies. 17: 11-30.

- 2010. Eating Chinese: Culture on the Menu in Small Town Canada. Toronto: University of Toronto Press.

Chu, Julie Y. 2010. Cosmologies of Credit: Transnational Mobility and the Politics of Destination in China. Durham: Duke University Press.

Clifford, James. 1997. Routes: Travel and Translation in the Late Twentieth Century. Massachusetts: Harvard University Press.

Cohen, Robin. 2008. Global Diasporas: An Introduction [Second Edition]. New York: Routledge.

Consulate-General of the People's Republic of China in Johannesburg. 2013. “提醒在约 翰内斯堡中国公民注意安全 (Reminding Chinese citizens to pay attention to 
safety in Johannesburg).” March 8, 2013. Accessed July 24, 2018.

http://johannesburg.china-consulate.org/chn/tztg/t1023276.htm

. 2014. “驻约堡总领馆提醒领区侨胞关注自身安全 (The Consulate General in Jo'burg reminds overseas Chinese to pay attention to their safety)." April 18, 2014. Accessed July 24, 2018. http://johannesburg.chinaconsulate.org/chn/tztg/t1148315.htm

一一 2015. “提高安全意识、避免遭遇抢劫切记六个 “不”一 一 中国驻约翰内斯堡 总领事馆领事提醒 (Raise Safety Awareness and Avoid Robbery, A reminder of Six "Don't"-from Consulate General of Consulate General of China in Johannesburg)." August 9, 2015. Accessed July 24, 2018. http://johannesburg.china-consulate.org/chn/tztg/t1287490.htm

. 2016. “近期抢劫案件频发, 驻约堡总领馆提醒侨胞注意安全 (Recent Robbery cases have occurred frequently, The Consulate General of Consulate General in Jo'burg reminds overseas Chinese to pay attention to safety)." September 6, 2016. Accessed July 24, 2018. http://johannesburg.chinaconsulate.org/chn/tztg/t1395220.htm

Crush, Jonathan and Daniel Tevera. 2010. "Exiting Zimbabwe" In Zimbabwe's Exodus: Crisis, Migration, Survival, edited by Jonathan Crush and Daniel Tevera. 1-49. Cape Town: Unity Press.

Crush, Jonathan, Abel Chikanda, and Godfrey Tawodzera 2015. The Third Wave: Mixed Migration from Zimbabwe to South Africa. Cape Town: Southern African Migration Programme (SAMP).

Davis, Netta. 2002. "To Serve the 'Other': Chinese-American Immigrants in the Restaurant Business" Journal for the Study of Food and Society 6(1): 70-81.

Dodson, Belinda. 2013. "Reconfiguring space, reimaging place: post-apartheid geographies of South Africa and its region." Canadian Journal of African Studies 47(1): $1-8$.

Embassy of the People's Republic of China in the Republic of South Africa. 2015. “中国 驻南非使领馆提醒旅南侨胞注意防范各地骚乱 (The Consulate General of Consulate General in South Africa reminds Overseas Chinese pay attention and to prevent riots).” April 7, 2015. Accessed July 26, 2018. http://za.chinaembassy.org/chn/lqfw/zytz/t1252626.htm

Englund, Harri. 2008. "Extreme Poverty and Existential Obligations: Beyond Morality in the Anthropology of Africa?" Social Analysis 52 (3): 33-50.

Erasmus, Yvonne and Yoon Jung Park. 2008. "Racial Classification, Redress and Citizenship: The case of the Chinese South Africans." Transformation: Critical 
Perspective on Southern Africa 68: 99-109.

Evans, Hernri-Count. 2015. "Corruption, Smuggling and Border Jumping: The Beitbridge Border Post.” Fairplanet.org, November 24, 2015. Accessed July 26, 2018. https://www.fairplanet.org/story/corruption-smuggling-and-borderjumping-the-beitbridge-border-post/

Ferguson, James. 2013. "Declarations of Dependence: Labour, Personhood, and Welfare in Southern Africa." JRAI: Journal of the Royal Anthropological Institute. 19: 223-242.

- 2015. Give a Man a Fish: Reflections on the New Politics of Distribution. Durham: Duke University Press.

Ferreira, Emsie. 2015. "Sithole murder not xenophobic: Mahlobo." IOL News. April 28, 2015. Accessed July 26, 2018. https://www.iol.co.za/news/sithole-murder-notxenophobic-mahlobo-1851253\#.VUIbM_mqqko

French, Howard. 2014. China's Second Continent: How a Million Migrants are Building a New Empire in Africa. New York: Knopf.

Godoy, Maria. 2016. "Lo Mein Loophole: How U.S. Immigration Law Fueled A Chinese Restaurant Boom." NPR - Food History \& Culture. February 22, 2016. Accessed July 26, 2018. https://www.npr.org/sections/thesalt/2016/02/22/467113401/lomein-loophole-how-u-s-immigration-law-fueled-a-chinese-restaurant-boom

Gous Nico. 2017. "The 30 Police Stations Where the Most crime was reported," The Times Live, October 24, 2017. Accessed July 25, 2018. https://www.timeslive.co.za/news/south-africa/2017-10-24-the-30-police-stationswhere-the-most-crime-was-reported/

Gilroy, Paul. 1993. The Black Atlantic: Modernity and Double Consciousness. London: Verso.

Gradin, Carlos. 2012. Race, Poverty and Deprivation in South Africa. Journal of African Economies, 22(2), 187-238.

GroundUp. 2016. "Somalis fear for their lives after Tshwane riots." Daily Maverick, June 30, 2016. Accessed July 26, 2018. https://www.dailymaverick.co.za/article/201606-30-groundup-somalis-fear-for-their-lives-after-tshwane-riots/\#.V35sOdJ96W9

Harris, Karen L. 2007. "Scattered and Silent Sources: Researching the Chinese in South Africa" In Chinese Overseas: Migration, Research and Documentation, edited by Tan Chee-Beng, Colin Storey and Julia Zimmerman, 139-165. Hong Kong: The Chinese University Press. 
Harrison, Philip, Khangelani Moyo and Yan Yang. 2012. "Strategy and Tactics: Chinese Immigrants and Diasporic Spaces in Johannesburg, South Africa." Journal of Southern African Studies 38(4): 899-925.

Hall, Stuart. 1990. "Cultural Identity and Diaspora.” In Identity: Community, Culture, and Difference, edited by Jonathan Rutherford, 222-237. London: Lawrence \& Wishart.

Huang, Guangzhi. 2018. "Policing Blacks in Guangzhou: How Public Security Constructs Africans as Sanfei." Modern China 44(6): 1-30.

Ho, Ufrieda. 2011. Paper Sons and Daughters, A Memoir: Growing up Chinese in South Africa. Johannesburg: Picador Africa.

_ 2015. "Alan Ho's Death Stirs Hope out of Tragedy." Mail \& Guardian: Africa's Best Read, April 24, 2015. Accessed July 25, 2018. http://mg.co.za/article/201504-23-allan-hos-death-stirs-hope-out-of-tragedy

IOL News. 2015. "Zimbabweans in fake South African papers ordeal." Bulawayo 24 News, October 14, 2015. Accessed July 26, 2018. https://bulawayo24.com/index-id-news-sc-africa-byo-75783-articlezimbabweans + in + fake + south + african + papers + ordeal.html

Johnstone, Frederick A. 1976. Class, Race and Gold: A study of Class Relations and Racial Discrimination in South Africa. Lanham, MD: Dalhousie University Press.

Jung, Yuson. 2012. 'Experiencing the 'West' through the 'East' in the Margins of Europe: Chinese Food Consumption Practices in Postsocialist Bulagaria" Food, Culture and Society 15(4): 579-598.

Kalipa, Siyabonga. 2015. "Home Affairs official sold us fake papers." IOL News, October 13, 2015. Accessed July 25, 2018. https://www.iol.co.za/news/homeaffairs-official-sold-us-fake-papers- 1929048

Kalra, Virinder S., Raminder Kaur and John Hutnyk. 2005. Diaspora \& Hybridity. London: SAGE Publications.

Kew, Jacqui, Rebecca Namatovu, Rilwan Aderinto, and Francis Chigunta. 2015. Africa's Young Entrepreneurs: Unlocking the Potential for a Brighter Future. Ottawa: International Development Research Centre.

King, Ambrose Yeo-chi King. 1991."Kuan-his and Network Building: A Sociological Interpretation." Daedalus 120 (2): 63-84.

Kivanc, Jake. 2016. "We Asked Toronto's Chinese Restaurant Workers About Shit Pay and Long Hours." VICE News, April 26, 2016. Accessed July 26, 2018. 
https://www.vice.com/en_ca/article/xd7eaq/we-asked-torontos-chinese-restaurantworkers-about-shit-pay-and-long-hours

Krige, Detlev. 2011. “'We are Running for a Living': Work, Leisure and Speculative Accumulation in an Underground Numbers Lottery in Johannesburg." African Studies 70(1): 3-24.

Krissman, Fred. 2005. "Sin Coyote Ni Patrón: Why the 'Migrant Network' Failed to Explain International Migration.” The International Migration Review 39(1): 444.

Kuo, Lily. 2017. "Chinese migrants have changed the face of South Africa. Now they're leaving." Quartz Africa, April 30, 2017. Accessed July 24, 2018. https://qz.com/940619/chinese-traders-changed-south-africa-now-theyre-leaving/

Lan, Shanshan. 2015. "State regulation of undocumented African migrants in China: A multi-scalar analysis." Journal of Asian and African Studies 50(3): 289-304.

—. 2016. "The Shifting Meanings of Race in China: A Case Study of the African Diaspora Communities in Guangzhou." City \& Society 28(3): 298-318.

Leung, Maggi W.H. 2002. "From four-course Peking duck to take-away Singapore rice: An inquire into the dynamics of the ethnic Chinese catering business in Germany" International Journal of Entrepreneurial Behaviour \& Research 8(1/2): 134-147.

Li, Anshan. 2016. "Chinese ignorance of race should not be confused with racism." SSCP: Social Sciences in China Press, June 6, 2016. Accessed July 26, 2018. http://www.csstoday.com/Item/3484.aspx

Li, Peter. 1993. "Chinese Investment and Business in Canada: Ethnic Entrepreneurship Reconsidered." Pacific Affairs 66(2): 219-243.

Liu, Ying-Ying Tiffany. 2017. "Exploring Guanxi in a Cross-Cultural Context: The Case of Cantonese-Speaking Chinese in Johannesburg." Journal of Chinese Overseas, 13(2): 263-286.

Ma, Laurence J. C. 2003. "Space, Place, and Transnationalism in the Chinese Diaspora" in The Chinese Diaspora: Space, Place, Mobility, and Identity, edited by Laurence J.C. Ma and Carolyn Carter, 1-50. New York: Rowman \& Littlefield Publishers.

Madia, Tshidi. 2017. "Political parties condemn xenophobic violence." News 24, February 24, 2017. Accessed July 26, 2018. https://www.news24.com/SouthAfrica/News/political-parties-condemnxenophobic-violence-20170224 
Mahmood, Saba. 2005. Politics of Piety: The Islamic Revival and the Feminist Subject. Princeton: Princeton University Press.

Makina, Daniel. 2010. "Zimbabwe in Johannesburg" in Zimbabwe's Exodus: Crisis, Migration, Survival, edited by Jonathan Crush and Daniel Tevera, 225-243. Cape Town: Unity Press.

Marsh, Jenni. 2016. "The African migrants giving up on the Chinese dream." CNN World, September 26, 2016. Accessed July 31, 2018. https://edition.cnn.com/2016/06/26/asia/africans-leaving-guangzhou-china/

Mbembe, Achille. 2015. "Achille Mbembe writes about Xenophobic South Africa." Africa is a Country website, April 16, 2015. Accessed July 26, 2018. https://africasacountry.com/2015/04/achille-mbembe-writes-about-xenophobicsouth-africa/

Mbembe, Achille and Sarah Nuttall. 2004. "Writing the World from an African Metropolis." Public Culture 16(3): 347-372.

McCool, Alice. "A walk to freedom: can Joburg's bridges heal the urban scars of apartheid?” The Guardian, December 16, 2016. Accessed July 25, 2018. https://www.theguardian.com/cities/2016/dec/16/corridors-of-freedomjohannesburg-bridges-heal-urban-scars-apartheid

McGreal, Chris. "Thousands seek sanctuary as South African turn on refuges." The Guardian, May 20, 2008. Accessed July 26, 2018. https://www.theguardian.com/world/2008/may/20/zimbabwe.southafrica

Men, Tanny. 2014. "Place-based and Place-bound Realities: A Chinese Firm's Embeddedness in Tanzania." Journal of Current Chinese Affairs 43(1): 103-138.

Michel, Serge and Michel Beuret. 2010. China Safari: On the Trail of Beijing's Expansion in Africa. New York: Nation Books.

Mintz, Sidney. 1986. Sweetness and Power: The Place of Sugar in Modern History. New York: Penguin Books.

- 2008. "Time, Sugar, and Sweetness." In Food and Culture: A Reader (2 ${ }^{\text {nd }}$ edition), edited by Carole Counihan and Penny Van Esterik, 91-103. New York Routledge.

Mintz, Corey. 2015. "A cycle of exploitation: How restaurants get cooks to work 12-hour days for minimum wage (or less)." The Globe and Mail, October 27, 2015. Accessed July 26, 2018. https://www.theglobeandmail.com/life/food-andwine/food-trends/a-cycle-of-exploitation-how-restaurants-get-cooks-to-work-12hour-days-for-minimum-wage-or-less/article26999168/ 
Mishra, Sudesh. 2006. Diaspora Criticism. Edinburgh: Edinburgh University Press Ltd.

Moyo, Khangelani. 2017. Zimbabweans in Johannesburg, South Africa: Space, Movement and Spatial Identity. PhD Dissertation (in Town and Regional Planning), University of the Witwatersrand.

Mutanda, Darlington. 2017. "Xenophobic Violence in South Africa: Mirroring Economic and Political Development Failures in Africa." African Identities 15(3): 278-294.

Naudé, Wim, Melissa Siegel and Katrin Marchand. 2017. "Migration, Entrepreneurship and Development: Critical Questions.” IZA Journal of Migration 6(5): 1-16

News 24 Online. 2008a. "Xenophobia death toll hits 62." News 24, Special Report on Xenophobia, May 31, 2008. Accessed July 26, 2018.

https://web.archive.org/web/20080602223311/http://www.news24.com:80/News2 4/South_Africa/Xenophobia/0,,2-7-2382_2332419,00.html

2008b. "Foreigners being moved to tents." News 24, Special Report on Xenophobia, June 1, 2008. Accessed July 26, 2018.

https://web.archive.org/web/20080602052131/http://www.news24.com:80/News2 4/South_Africa/Xenophobia/0,,2-7-2382_2332880,00.html

Ndenze, Babalo. 2018. "Labour Minister says National Minimum wage is here to stay," Eyewitness News, May 15, 2018. Accessed July 24, 2018.

http://ewn.co.za/2018/05/15/labour-minister-says-national-minimum-wage-ishere-to-stay

Ndou, Clive. 2015. "Foreigners must go home - King Zwelithini." The Citizen South Africa, March 23, 2015. Accessed July 25, 2018.

https://citizen.co.za/news/south-africa/349347/foreigners-must-go-home-kingzwelithini/

Ngqakamba, Sesona. 2018. "One Shot Dead, Foreign National Shops Looted in Soweto Violence.” News24. August 29, 2018. Accessed September 15, 2018. https://www.news24.com/SouthAfrica/News/one-shot-dead-foreign-nationalshops-looted-in-soweto-violence-20180829

Nicolson, Greg. 2017. "Urban Crime: Report breaks down SA's most dangerous cities." Daily Maverick, August 22, 2017. Accessed July 24, 2018. https://www.dailymaverick.co.za/article/2017-08-22-urban-crime-in-the-citiesreport-breaks-down-sas-most-dangerous-cities/\#.Wx12tkgvyUk

Ong Aihwa. 1987. Spirits of Resistance and Capitalist Discipline: Factory Women in Malaysia. New York: State University of New York Press. 
—. 1999. Flexible Citizenship: The Cultural Logics of Transnationality. Durham: Duke University.

Pampalone, Tanya. "2010a. Faces of Xenophobia: The Victims, Part 1.” Daily Maverick, July 14, 2010. Accessed July 26, 2018.

https://www.dailymaverick.co.za/article/2010-07-14-faces-of-xenophobia-2008the-victims-part-1/

. 2010b. Faces of Xenophobia: The Victims, Part 1." Daily Maverick, July 15, 2010. Accessed July 26, 2018. https://www.dailymaverick.co.za/article/2010-07-15-faces-of-xenophobia-thevictims-part-2/\#.VMEZGIqUcno

Pang, Ching Lin. 2002. "Business Opportunity or Food Pornography? Chinese Restaurant Ventures in Antwerp" International Journal of Entrepreneurial Behaviour \& Research 8(1/2): 148-161.

Park, Yoon Jung. 2008a. "State, Myths, and Agency in the Construction of Chinese South African Identities, 1948-1994." Journal of Chinese Overseas 4(1): 69-90.

- 2008b. A Matter of Honour: Being Chinese in South Africa. Auckland Park, South Africa: Jacana Media (Pty) Ltd.

- 2009. "Recent Chinese Migrations to South Africa: New Intersections of Race, Class and Ethnicity." In Representation, Expression and Identity:

Interdisciplinary Insights on Multiculturalism, Conflict and Belonging, edited by Tina Rahimy, 153-168. Oxford: Inter-Disciplinary Press.

2010. "Boundaries, Borders and Borderland Constructions: Chinese in Contemporary South Africa and the Region.” African Studies 69(3): 457-479.

. 2012 "Living In Between: The Chinese in South Africa." The Online Journal of the Migration Policy Institute, January 4, 2012. Accessed July 26, 2018. https://www.migrationpolicy.org/article/living-between-chinese-south-africa/ . 2016. "One Million Chinese in Africa." Perspectives: A Publication of the International Development Program, John Hopkins School of Advanced International Studies (SAIS) website, May 12, 2016. Accessed July 30, 2018. http://www.saisperspectives.com/2016issue/2016/5/12/n947s9csa0ik6kmkm0bzb 0hy584sfo

Park, Yoon Jung and Anna Ying Chen. 2009. "Recent Chinese Migrants in Small Towns of Post-apartheid South Africa." Revue Européenne des Migrations Internationales 25(1): 25-44.

Park, Yoon Jung and Tu T. Huynh. 2010. "Introduction: Chinese in Africa." African and 
Asian Studies 9(3): 207-212.

Patel, Khadija. 2016. "What caused the xenophobic attacks in South Africa?" Aljazeera, April 6, 2016. Accessed July 26, 2018. https://www.aljazeera.com/news/2016/04/report-blames-media-xenophobicpanic-africa-160406102827284.html

Pe, Roger. 2016. "Yes, Asia is obsessed with white skin." Philippine Daily Inquirer, October 1, 2016. Accessed July 26, 2018.

http://business.inquirer.net/215898/yes-asia-is-obsessed-with-white-skin

Pickles, John and Jeff Woods. 1989. "Taiwanese Investment in South Africa." African Affairs. October 507-528.

Raborife, Mpho "Incendiary SMS targets foreign nationals in Jo'burg." Mail \& Guardian, April 15, 2015. Accessed July 25, 2018.

https://mg.co.za/article/2015-04-15-zulus-plan-to-kill-every-foreigner-in-joburg

Rondilla, Joanne Laxamana. Colonial Faces: Beauty and Skin Color Hierarchy in the Philippines and the U.S. Ph.D. Dissertation. University of California, Berkeley.

Rothstein, France Abrahamer. 2005. "Flexibility for Whom? Small-Scale Garment Manufacturing in Rural Mexico." In Petty Capitalists and Globalization: Flexibility, Entrepreneurship, and Economic Development, edited by Alan Smart and Josephine Smart, 67-82. Albany: State University of New York Press.

Rutherford, Blair. 2008. "An Unsettled Belonging: Zimbabwean Farm Workers in Limpopo Province, South Africa." Journal of Contemporary African Studies 26(4), 401-415.

— 2010. "Zimbabweans on the Farms of Northern South Africa." In Zimbabwe's Exodus: Crisis, Migration, Survival, edited by Jonathan Crush and Daniel Tevera, 244-266. Cape Town: Unity Press.

Safran, William. 1991. Diasporas in Modern Societies: Myths of Homeland and Return. Diaspora: A Journal of Transnational Studies 1(1):83-99.

—. 2005. "The Jewish Diaspora in a Comparative and Theoretical Perspective.” Israel Studies 10(1): 36-60.

Sheridan, Derek. 2018. "'If You Greet Them, They Ignore you': Chinese Migrants, (Refused) greetings, and the Interpersonal Ethics of Global Inequality in Tanzania." Anthropological Quarterly 91(1): 237-266.

Silverman, Melinda and Tanya Zack 2008. "House Delivery, the Urban Crisis and Xenophobia" In Go Home or Die Here: Violence, Xenophobia and the 
Reinvention of Difference in South Africa, edited by Shireen Hassim, Tawana Kupe and Eric Worby, 147-160. Johannesburg: Wits University Press.

Sisulu, Elinor, Bhekinkosi Moyo and Nkosinathi Tshuma. 2007. "The Zimbabwean community in South Africa." In State of The Nation: South Africa 2007, edited by Sakhela Buhlungu, John Daniel, Roger Southall, and Jessica Lutchman, 552-573. Cape Town: HSRC Press

Siziba, Gugulethu. 2014. "Language and identity negotiations: an analysis of the experiences of Zimbabwean migrants in Johannesburg, South Africa" Journal of African Cultural Studies 26(2): 173-188

Siu, Paul C. P. 1952. The Sojourner. American Journal of Sociology. 58(1): 34-44. 1987. The Chinese Laundryman: A Study of Social Isolation. New York: New York University Press.

Smart, Alan and Carolyn L. Hsu. 2007. "Corruption or Social Capital? Tact and the Performance of Guanxi in Market Socialist China." In Corruption and the Secret of Law: A Legal Anthropological Perspective, edited by Gerhand Anders and Monique Nuijten, 167-189. Burlington, VT: Ashgate Publishing.

Smart, Alan and Josephine Smart. 2005. "Chapter 1. Introduction.” In Petty Capitalists and Globalization: Flexibility, Entrepreneurship, and Economic Development, edited by Alan Smart and Josephine Smart, 1-22. Albany: State University of New York Press.

Smart, Josephine 2003. "Ethnic Entrepreneurship, Transmigration, and Social Integration: An Ethnographic Study of Chinese Restaurant Owners in Rural Western Canada." Urban Anthropology 32(3-4): 311-342.

Smith, Daniel. 2007. A Culture of Corruption: Everyday Deception and Popular Discontent in Nigeria. Princeton: Princeton University Press.

Smith, David. 2015. David Smith, "Johannesburg's Ponte City: 'the tallest and grandest urban slum in the world," The Guardian. Published on May 11, 2015. Accessed July 23, 2018. https://www.theguardian.com/cities/2015/may/11/johannesburgsponte-city-the-tallest-and-grandest-urban-slum-in-the-world-a-history-of-cities-in50-buildings-day-33

So, Ying Lun and Anthony Walker. 2006. Explaining Guanxi: The Chinese Business Network. Abingdon, UK: Routledge.

Song, Fangcan. 2015a. “单月遇害同胞创百年纪录 南非侨界求破无解难题 (One single monthly murder rate reached 100-year high; South African Chinese seek to solve unsolved problems)." China News Service (CNS), February 9, 2015. 
Accessed July 24, 2018. http://www.chinanews.com/hr/2015/0209/7045353.shtml

. 2015b. “非法劳工渐成南非华商的 ‘不定时炸弹” 和 “负资产’ (Illegal workers gradually become 'time bombs' and 'negative assets' of Chinese businessmen in South Africa)." People's Daily Online, May 6, 2015. Accessed July 26, 2018. http://world.people.com.cn/n/2015/0506/c157278-26954005.html

— 2017. “南非连发中国旅行团被劫案 总领馆提请特别关注 (Robbers continued to rob Chinese tour groups in South Africa; Consulate General draws special attention)." China News Service (CNS), February 6, 2017. Accessed July 24, 2018. http://www.chinanews.com/gj/2017/02-06/8141405.shtml

South Africa Department of Labour Online. "Wholesale \& Retail Sector: Minimum wages for the period 01/02/2014 to 31/01/2015." Department of Labour, Republic of South Africa. Accessed July 26, 2018.

http://www.labour.gov.za/DOL/legislation/downloads/legislation/sectoraldeterminations/basic-conditions-of-employment/wholesalewages_new201415.pdf

. "Domestic Worker Minimum Wage Increases from 1 December 2015."

Department of Labour, Republic of South Africa. Accessed July 26, 2018, http://www.labour.gov.za/DOL/downloads/legislation/sectoraldeterminations/basic-conditions-of-employment/domesticwages_dec2015.pdf

South Africa History Online. 2011a. “The Homelands.” April 17, 2011. Updated on March 16, 2018. Accessed July 22, 2018.

https://www.sahistory.org.za/article/homelands

2011b. "Discovery of the Gold in 1884." October 19, 2011. Updated on April 28, 2016. Accessed July 22, 2018. http://www.sahistory.org.za/article/discoverygold-1884

Statistics South Africa. 2012. "Census 2011 in brief.” Accessed July 26, 2018.

http://www.statssa.gov.za/census/census_2011/census_products/Census_2011_Ce nsus_in_brief.pdf

. 2017a. "Living Conditions of Households in South Africa: An analysis of household expenditure and income data using the LCS 2014/2015." Accessed July 26, 2018. http://www.statssa.gov.za/publications/P0310/P03102014.pdf

_ . 2017b. "Quarterly Labour Force Survey.” Accessed July 26, 2018. https://www.statssa.gov.za/publications/P0211/P02112ndQuarter2017.pdf

Struwig Jare, Benjamin Roberts, Mercy Ngungu and Steven Gordon. 2014. "A Survey of Corruption Issues: 2013: Tabulation Report." HSRC: Human Sciences Research Council website. Report prepared for Department of Democracy, Governance and 
Service Delivery (DGSD) and Education and Skills Development (ESD). Accessed July 25, 2018. http://www.hsrc.ac.za/en/research-data/view/6888

Sun, Irene Yuan. 2017. The Next Factory of the World: How Chinese Investment is Reshaping Africa. Boston: Harvard Business Review Press.

Swails, Brent. 2015. "Xenophobic killing in South African township caught by photographer." CNN World. April 21, 2015. Accessed July 26, 2018. https://edition.cnn.com/2015/04/20/africa/south-africa-xenophobia-killing-photos/

Taiwan Today. 2011. "Taiwanese cuisine reflects nation's historical odyssey.” Taiwan Today, March 4, 2011. Accessed July 23, 2018. https://taiwantoday.tw/news.php?unit=18,23,45,18\&post=24443

The Guardian. 2017. "South African police use force to disperse anti-immigration protesters." The Guardian International edition. February 24, 2017. Accessed July 26, 2018. https://www.theguardian.com/world/2017/feb/24/south-africanpolice-use-force-anti-immigration-protest-pretoria

Thebe, Vusilizwe. 2015. "The Malayisha Industry and the Transnational Movement of Remittances to Zimbabwe." In Mean Streets: Migration, Xenophobia and Informality in South Africa, edited by Jonathan Crush, Abel Chikanda and Caroline Skinner, 194-206. Cape Town: Southern African Migration Programme (SAMP).

Thuku, Kariuki. 2007. "Chapter 5: The Silent Relevance of African Trans-Family Ethnographies: Realities and Reflections on the African Family." In The Family in the New Millennium: World Voices Supporting the "Natural" Clan, Volume 1, edited by A. Scott Loveless and Thomas B. Holman, 93-102. Westport, CT: Praeger Publishers.

van der Berg, Servaas. 2011. "Current Poverty and Income Distribution in the contact of South African History." Economic History of Developing Regions 26(1): 120-140.

van Rensburg, Kj, F Mthonti and M Erskog. 2015. "Xenophobia in Grahamstown: 'We are not leaving!"” Daily Maverick, October 29, 2015. Accessed July 26, 2018. https://www.dailymaverick.co.za/article/2015-10-29-xenophobia-ingrahamstown-we-are-not-leaving/

Yan, Yunxiang. 1996. The Flow of Gifts: Reciprocity and Social Networks in a Chinese Village. California: Stanford University Press.

- 2009. "The Good Samaritan's new trouble: A study of the changing moral landscape in contemporary China." Social Anthropology 17(1): 9-24.

Yang, Philip Q. 2000. “"The Sojourner Hypothesis’ Revisited.” Diaspora: A Journal of 
Transnational Studies 9(2): 235-258

Yang, Mayfair Mei-hui. 1994. Gifts, Favors and Banquets: The Art of Social Relationships in China. Ithaca, New York: Cornell University Press.

- 2002. "The Resilience of Guanxi and its New Deployments: A Critique of Some New Guanxi Scholarship." The China Quarterly 170: 459-476.

Yap, Melanie and Dianne Leong Man. 1996. Colour, Confusion and Concessions: The History of the Chinese in South Africa. Hong Kong: Hong Kong University Press.

Yu, Derek. "The lesser known and scarier facts about unemployment in South Africa." Mail and Guardian, September 4, 2017. Accessed July 26, 2018. https://mg.co.za/article/2017-09-04-the-lesser-known-and-scarier-facts-aboutunemployment-in-south-africa

Wilson, Francis. 2011. "Historical Roots of Inequality in South Africa." Economic History of Developing Regions 26(1): 1-15.

Wu, David Y. H. and Sidney C. H. 2004. "Introduction: The Globalization of Chinese Food and Cuisine: Markers and Breakers of Cultural Barriers." In The Globalization of Chinese Food, edited by David Y.H. Wu and Sidney C.H. Cheung, 1-20. New York: Routledge.

Wu, Di. 2014. The Everyday Life of Chinese Migrants in Zambia: Emotion, Sociality and Moral Interaction. Ph.D. Dissertation, London School of Economics and Political Science.

Xiang, Biao. 2017. “專訪人類學家項飆（上）：我們應該「認命」但不能「認輸」 Interview with anthropologist Xiang Biao (part one): We should 'accept fate' but we cannot “concede”” 端傳媒 Initium Media. April 30, 2017. Accessed July 30, 2018. https://theinitium.com/article/20170430-opinion-xiangbiao/

Xin, Katherine R. and Jone L. Pearce. 1996. "Guanxi: Connections as Substitutes for Formal Institutional Support." The Academy of Management Journal 39(6): 16411658 .

Xinhua Net. 2015. “遭抢中国商务团返程 团员讲述南非惊魂 (Chinese business delegation was robbed in South Africa; Members talked about their terrifying experience)." Xinhua Net. August 11, 2015. Accessed July 24, 2018. http://www.xinhuanet.com/world/2015-08/11/c_1116218054.htm

Zhai, Xuewei 翟学伟. 1993. Zhongguo renji guanxi de tezhi-bentu de gainian jiqi moshi 中国人际矢系的特质一本土的概念及其模式 (The Characteristics of Chinese Interpersonal Relationship-The Local Concept and Model). China Academic Journal of Sociological Studies 4: 74-83. 
Zhang, Jane. 2016. "Chinese in Brooklyn Lost $\$ 2 \mathrm{M}$ in a Loan Scam." Voices of NY, June 24, 2016. Accessed July 26, 2018. https://voicesofny.org/2016/06/chinese-inbrooklyn-lost-2m-in-a-loan-scam/

Zi, Yanyin. 2017. Iron Sharpens Iron: Social Interactions at China Shops in Botswana. Cameroon: Langaa Research \& Publishing Common Initiative Group.

ZIMSTAT (The Zimbabwe National Statistics Agency). 2014. Statistics at a GlanceUnemployment Rate. Accessed July 23, 2018. http://www.zimstat.co.zw/ 